\title{
Ciência de dados, poluição do ar e saúde
}

\author{
William Nilson de Amorim \\ TESE APRESENTADA \\ $\mathrm{AO}$ \\ Instituto de Matemática e Estatística \\ DA \\ Universidade DE SÃo PAUlo \\ PARA \\ OBTENÇÃO DO TÍTULO \\ $\mathrm{DE}$ \\ DOUTOR EM CiÊnCIAS
}

\author{
Programa: Doutorado em Estatística \\ Orientador: Prof. Dr. Antonio Carlos Pedroso de Lima
}

Durante o desenvolvimento deste trabalho o autor recebeu auxílio financeiro da CAPES e do CNPQ.

São Paulo, 23 de maio de 2019 
Ciência de dados, poluição do ar e saúde

Esta é a versão original da tese elaborada pelo candidato William Nilson de Amorim, tal como submetida à Comissão Julgadora. 


\title{
Ciência de dados, poluição do ar e saúde
}

\author{
Esta versão da tese contém as correções e alterações sugeridas \\ pela Comissão Julgadora durante a defesa da versão original do trabalho, \\ realizada em 17 de maio de 2019. Uma cópia da versão original está disponível no \\ Instituto de Matemática e Estatística da Universidade de São Paulo.
}

Comissão Julgadora:

- Prof. Dr. Antonio Carlos Pedroso de Lima (orientador) - IME-USP

- Prof. Dr. Julio da Motta Singer - IME-USP

- Prof. Dr. Paulo Eduardo Artaxo Netto - IF-USP

- Prof. Dr. Paulo Hilário Nascimento Saldiva - FM-USP

- Prof. Dr. Paulo Jorge Canas Rodrigues - UFBA 
We've been migratory animals

Living under changing weather.

- Syd Matters 


\section{Agradecimentos}

Agradeço antes de tudo aos meus orientadores, Antonio Carlos Pedroso de Lima e Julio da Motta Singer, por esses 4 anos de muito aprendizado e por me apresentarem à área de pesquisa em poluição do ar. Agradeço também à professora Maria Aparecida de Fátima, do Instituto de Astronomia e Geofísica, por todas as dúvidas esclarecidas e pelo excelente curso de meteorologia da poluição do ar. Em um mundo acadêmico cada vez mais preocupado com realizações pessoais, é um grande prazer poder trabalhar com pesquisadores que colocam a ciência em primeiro lugar.

Agradeço à minha mãe, Ivete da Conceição Cruz, e ao meu pai, Raimundo Nonato de Amorim, pelo amor, apoio e cuidado, mesmo eu sendo um filho tão distante.

Agradeço à minha irmã, Amanda Cruz de Amorim, pela amizade plena que desenvolvemos nos últimos anos. Não lembro quando resolvemos trocar de vez as briguinhas de irmãos por essa parceria, mas sem ela a minha vida seria muito mais difícil, triste e com muito menos vídeos de gatos.

Agradeço aos meus sócios/amigos da Curso-R por todo o conhecimento sobre Estatística e sobre a vida. Quando nos unimos, eu estava caminhando meio sem rumo, sem saber por onde ir nem aonde queria chegar. Foi a admiração que criei por cada um de vocês e o orgulho de fazer parte desse grupo que me mais me motivaram a repensar tudo e a traçar um novo caminho. Em particular, agradeço ao Daniel Falbel e à sua linda família pela amizade, companheirismo e risadas nesse último ano; ao Julio Trecenti por ser um líder incrível, por juntar tantas pessoas excepcionais e por me considerar uma delas; ao Athos Damiani por passar sempre tanta energia, entusiasmo e alegria e por sedear tantas e tantas rizzadas, churrascos e noites de jogos de tabuleiro; ao Caio Lente por me ensinar a ser muito mais organizado e produtivo e por me apresentar a pizza de quatro queijos com borda de chocolate branco, a minha nova comida menos favorita no mundo; e ao Fernando Correa por ser uma das pessoas mais incríveis que já conheci e por atualizar a minha percepção sobre quanto conhecimento diferente e não correlacionado uma pessoa consegue acumular.

Agradeço à minha grande amiga Larissa Vieira que, apesar de não dividirmos mais um apartamento, isso não é desculpa para eu não ganhar mais o melhor bolo de cenoura do mundo (tá certa a indignação!); e também aos meus eternos amigos Diego Mansoldo, Guilherme Biasi, Kazuyuki Tateoka, Jó Yen, Gerson Kumagaia, Matheus Nagaoka, Eduardo Carvalho, Iuri Ota, Lennon Molfetti e Tauã Gomes pelos incontáveis bons momentos.

Deixo também meus agradecimentos aos professores e funcionários do IME-USP, assim como aos colegas que tive o prazer de conviver e aprender no Instituto. Também ao CNPq e à CAPES pelas bolsas de estudo durante esses quatro anos.

Por fim, agradeço ao Starbucks do shopping Eldorado por todas as vezes que eu trabalhei lá sem consumir nada. 


\section{Resumo}

AMORIM, W. N. Ciência de dados, poluição do ar e saúde. 2019. 153 f. Tese (Doutorado) Instituto de Matemática e Estatística, Universidade de São Paulo, São Paulo, 2019.

A Estatística é uma ferramenta imprescindível para a aplicação do método científico, estando presente em todos os campos de pesquisa. As metodologias estatísticas usuais estão bem estabelecidas entre os pesquisadores das mais diversas áreas, sendo que a análise de dados em muitos trabalhos costuma ser feita pelos próprios autores. Nos últimos anos, a área conhecida como Ciência de Dados (Data Science) vem exigindo de estatísticos e não-estatísticos habilidades que vão muito além de modelagem, começando na obtenção e estruturação das bases de dados e terminando na divulgação dos resultados. Dentro dela, uma abordagem chamada de aprendizado automático ( $m a-$ chine learning) reuniu diversas técnicas e estratégias para modelagem preditiva, que, com alguns cuidados, podem ser aplicadas também para inferência. Essas novas visões da Estatística foram pouco absorvidas pela comunidade científica até então, principalmente pela ausência de estatísticos em grande parte dos estudos. Embora pesquisa de base em Probabilidade e Estatística seja importante para o desenvolvimento de novas metodologias, a criação de pontes entre essas disciplinas e suas áreas de aplicação é essencial para o avanço da ciência. O objetivo desta tese é aproximar a ciência de dados, discutindo metodologias novas e usuais, da área de pesquisa em poluição do ar, que, segundo a Organização Mundial da Saúde, é o maior risco ambiental à saúde humana. Para isso, apresentaremos diversas estratégias de análise e as aplicaremos em dados reais de poluição do ar. Os problemas utilizados como exemplo foram o estudo realizado por Salvo et al. (2017), cujo objetivo foi associar a proporção de carros rodando a gasolina com a concentração de ozônio na cidade de São Paulo, e uma extensão desse trabalho, na qual analisamos o efeito do uso de gasolina/etanol na mortalidade de idosos e crianças. Concluímos que suposições como linearidade a aditividade, feitas por alguns modelos usuais, podem ser muito restritivas para problemas essencialmente complexos, com diferentes modelos levando a diferentes conclusões, nem sempre sendo fácil identificar qual delas é a mais apropriada.

Palavras-chave: ciência de dados, aprendizado automático, regressão, inferência, poluição do ar, saúde 


\section{Abstract}

Amorim, W. N. Data science, air pollution and health. 2019. 153 f. Tese (Doutorado) - Instituto de Matemática e Estatística, Universidade de São Paulo, São Paulo, 2019.

Statistics is a fundamental part of the scientific method and it is present in all the research fields. The usual statistical techniques are well established in the scientific community, and, regardless of the area, the authors themselves perform the data analysis in most papers. In the last years, the area known as Data Science has been challenging statisticians and non-statisticians to perform tasks beyond data modeling. It starts with importing, organizing and manipulating the databases, and ends with the proper communication of the results. Another area called Machine Learning created a framework to fit predictive models, where the goal is to obtain the most precise predictions to a variable under study. These new approaches were not completely adopted by the scientific community yet, mainly due to the absence of statisticians in most of the studies. Although basic research in Probabilities and Statistics is important, the link between these disciplines and their application areas is essential for the advancement of science. The goal of this thesis was to bring together the news views of Data Science and Machine Learning and air pollution research. We presented several strategies of data analysis and apply them to reanalyze the real world air pollution problem presented by Salvo et al. (2017): explore the association between ozone concentration and the proportion of bi-fuel vehicles running on gasoline in the city of São Paulo, Brazil. We also extended this analysis to study the effect of using gasoline/ethanol in mortality (child and elderly). We concluded that assumptions such as linearity and additivity, commonly required by usual models, can be very restrictive to intrinsically complex problems, leading to different conclusions for each fitted model, with little information about which one is more appropriate.

Keywords: data science, machine learning, regresssion, inference, air pollution, health 


\section{Sumário}

Lista de Figuras $\quad$ xiii

Lista de Tabelas $\quad$ xix

1 Introdução $\quad 1$

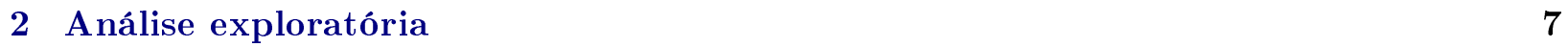

2.1 Gráficos . . . . . . . . . . . . . . . . . . . 8

$2.1 .1 \quad$ O gráfico da série . . . . . . . . . . . . . . . . 8

2.1 .2 Gráficos de dispersão . . . . . . . . . . . . . . . . . . . 11

2.1.3 Gráficos de distribuição . . . . . . . . . . . . . . . . . . . . . . . . 12

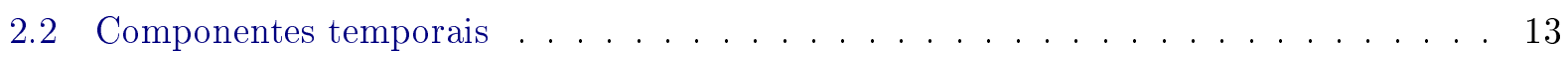

2.2 .1 Tendência . . . . . . . . . . . . . . . . . . . . . . . . . 14

2.2 .2 Sazonalidade . . . . . . . . . . . . . . . . . 15

2.2 .3 Autocorrelação . . . . . . . . . . . . . . . . . . 18

2.2 .4 Função de correlação cruzada . . . . . . . . . . . . . . . . . . . . 20

2.3 Visualizando dados de poluição durante a greve de caminhoneiros . . . . . . . . . . 21

3 Estratégias usuais de modelagem $\quad 29$

3.1 Regressão linear . . . . . . . . . . . . . . . . . . . . . . . . 31

3.1 .1 Especificação do modelo . . . . . . . . . . . . . . . . . . . . . . 31

3.1 .2 Incorporando tendência e sazonalidade . . . . . . . . . . . . . . . 32

3.1.3 Tratando erros correlacionados . . . . . . . . . . . . . . . . . . 34

3.1.4 Contornado a suposição de homoscedasticidade . . . . . . . . . . . . . . 36

3.1.5 Contornado a suposição de linearidade . . . . . . . . . . . . . . . . . 36

3.1 .6 Contornado a suposição de aditividade . . . . . . . . . . . . . . . 39

3.1.7 Avaliando a qualidade do ajuste . . . . . . . . . . . . . . . . . . . . 40

3.2 Modelos lineares generalizados . . . . . . . . . . . . . . . . . . . . 41

3.2 .1 Especificação do modelo . . . . . . . . . . . . . . . . . . . . . . 41

3.2 .2 Modelos para dados positivos assimétricos contínuos . . . . . . . . . . . . 42

3.2.3 Modelos para dados de contagem . . . . . . . . . . . . . . . . . . . 44

3.3 Modelos aditivos generalizados . . . . . . . . . . . . . . . . . 45

3.3.1 Especificação do modelo . . . . . . . . . . . . . . . . . . . . 45

3.3 .2 Splines e regressão local . . . . . . . . . . . . . . . . . 46

3.4 Modelos de séries temporais . . . . . . . . . . . . . . . . . . . . . . 48 


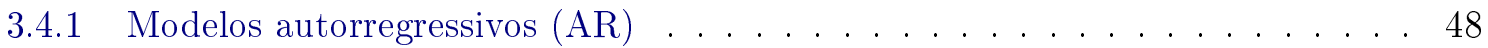

3.4.2 Modelos autorregressivos e de médias móveis (ARMA) . . . . . . . . . . . . . 49

3.4.3 Modelos autorregressivos integrados e de médias móveis (ARIMA) . . . . . . 49

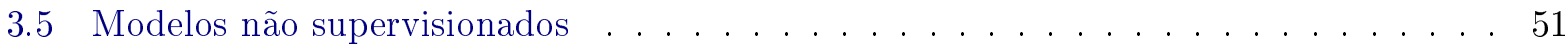

3.5.1 Análise de componentes principais . . . . . . . . . . . . . . . . 51

3.5 .2 Análise Fatorial ～. . . . . . . . . . . . . . . . . . . . . . 52

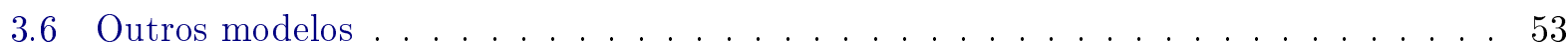

3.6 .1 Modelos mistos . . . . . . . . . . . . . . . . . . 53

3.6 .2 Modelos GARCH . . . . . . . . . . . . . . . . . . . . . 54

3.6.3 Modelos dinâmicos . . . . . . . . . . . . . . . . . . 55

4 Estratégias de aprendizado automático $\quad \mathbf{5 7}$

4.1 Sobreajuste e o balanço entre viés e variância . . . . . . . . . . . . . . . . . 58

4.2 Estimando o desempenho do modelo . . . . . . . . . . . . . . . . . . . . . . 60

4.2 .1 Validação cruzada . . . . . . . . . . . . . . . . . . . . . . . 61

4.2 .2 Bootstrapping . . . . . . . . . . . . . . . . . 63

4.3 Seleção de variáveis . . . . . . . . . . . . . . . . . . . . . . 63

4.3.1 Selecionando o melhor subconjunto de preditores . . . . . . . . . . . . . . 64

4.3 .2 Métodos passo a passo . . . . . . . . . . . . . . . . . . . . 64

4.4 Regularização . . . . . . . . . . . . . . . . . . . . . 65

4.5 Quantificando a importância dos preditores . . . . . . . . . . . . . . 67

4.6 Modelos de árvores . . . . . . . . . . . . . . . . . . . . . . . . . 67

4.6 .1 Árvores de decisão . . . . . . . . . . . . . . . . . . . . . . . 68

4.6 .2 Florestas aleatórias . . . . . . . . . . . . . . . . . . . . . . 69

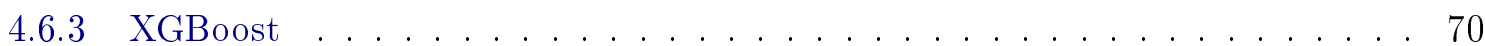

4.7 Interpretando modelos caixa-preta $\ldots \ldots \ldots \ldots \ldots \ldots$. . . . . . . . . .

4.7.1 Gráfico de dependência parcial . . . . . . . . . . . . . . . . . . . 71

4.7.2 Gráfico da esperança condicional individual . . . . . . . . . . . . . . . . . 72

4.7.3 Gráfico de efeitos locais acumulados . . . . . . . . . . . . . . . . . . 72

4.7.4 Local interpretable Model-Agnostic Explanations (LIME) . . . . . . . . . . . . 73

4.7 .5 Exemplo . . . . . . . . . . . . . . . . . . . . . . 74

5 Poluição e uso de combustíveis $\quad 79$

5.1 Etanol e ozônio . . . . . . . . . . . . . . . . . . . . . . . . . . 79

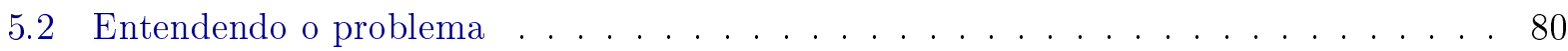

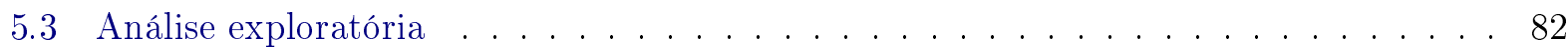

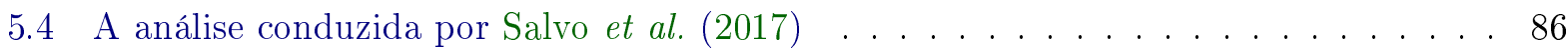

5.5 Ajustando outros modelos . . . . . . . . . . . . . . . . . . . . . . 89

5.5 .1 Modelos aditivos generalizados . . . . . . . . . . . . . . 90

5.5 .2 Modelo de regressão segmentada . . . . . . . . . . . . . . . . . . . . . . 93

5.5 .3 Floresta aleatória . . . . . . . . . . . . . . . . . . . . 94

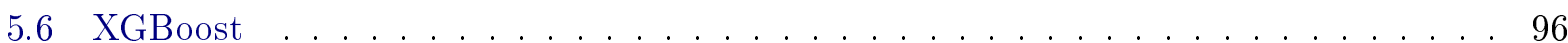

5.7 Outras estratégias de análise . . . . . . . . . . . . . . . . . . 97

5.7 .1 Seleção de variáveis . . . . . . . . . . . . . . . . . . . . . . . 97 
5.7 .2 Transformando a variável resposta . . . . . . . . . . . . . . . 98

5.7 .3 Modelo para a máxima diária . . . . . . . . . . . . . . . . . . . 99

5.7 .4 Ajustando cada estação separadamente . . . . . . . . . . . . . . . . . . . . 100

5.8 Comentários . . . . . . . . . . . . . . . . . . . . . . 101

6 Poluição e saúde pública $\quad 105$

6.1 Uso de etanol e mortalidade . . . . . . . . . . . . . . . . . . . . . . 106

6.1.1 Modelos Poisson e floresta aleatória . . . . . . . . . . . . . . . . 107

6.1.2 Floresta aleatória para a série defasada . . . . . . . . . . . . . . . . . . 110

6.2 Uso de etanol e a relação entre ozônio e $\mathrm{NO}_{\mathrm{x}} \ldots \ldots$. . . . . . . . . . . . . 111

6.3 Concentração de $\mathrm{O}_{3}$ e $\mathrm{NO}_{\mathrm{x}}$ e mortalidade . . . . . . . . . . . . . . . . . . . 113

6.4 Efeito na mortalidade por doenças cardio pulmonares . . . . . . . . . . . . . . . 114

7 Obtendo dados de poluição $\quad 119$

7.1 Raspagem de dados web . . . . . . . . . . . . . . . . . 120

7.2 Dados no Brasil . . . . . . . . . . . . . . . . . . . . . . . 122

7.3 Dados em outros países . . . . . . . . . . . . . . . . . . 123

8 Discussão $\quad 125$

$\begin{array}{lr}\text { Referências } & 127\end{array}$ 


\section{Lista de Figuras}

1.1 Esquematização do ciclo da ciência de dados. Figura adaptada do livro Wickham e Grolemund

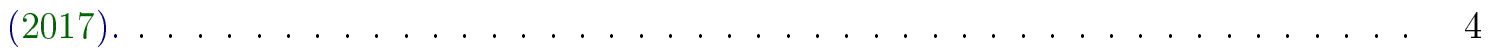

2.1 Série da concentração de ozônio para a estação Dom Pedro II, na cidade de São Paulo, no período de 2008 a 2013. Em azul, a série suavizada usando splines cúbicos. 9

2.2 Série da concentração média de ozônio ao longo do dia para a estação Dom Pedro II, na cidade de São Paulo, no período de 2008 a 2013. Não existe informação para as 6 da manhã pois é o horário em que o equipamento sofre manutenção. . . . . . . . . . 10

2.3 Série diária da concentração média de ozônio medido no começo da tarde para a estação Dom Pedro II, na cidade de São Paulo, no período de 2008 a 2013. Em azul, a série suavizada usando splines cúbicos. . . . . . . . . . . . . . . . 10

2.4 Série diária da concentração média de ozônio medido no começo da tarde para todas as estações, na cidade de São Paulo, no período de 2008 a 2013. Em azul, as séries suavizadas usando splines cúbicos. . . . . . . . . . . . . . . . . 11

2.5 Séries horárias de ozônio e de óxido de nitrogênio (NO), ambos medidos na estação Dom Pedro II, em São Paulo, no período de 2008 a 2011. Em azul, as séries suavizadas usando splines cúbicos. . . . . . . . . . . . . . . . . . 12

2.6 Gráfico de dispersão da concentração de ozônio contra a concentração de óxido de nitrogênio medidas das 12 às 16 horas na estação de monitoramento Dom Pedro II, em São Paulo, de 2008 a 2011. . . . . . . . . . . . . . . . . . . . . . . . 13

2.7 Gráfico de dispersão da concentração de ozônio contra a concentração de dióxido de nitrogênio medidas das 12 às 16 horas na estação de monitoramento Dom Pedro II, em São Paulo, de 2008 a 2011. . . . . . . . . . . . . . . . . . . . . . . 14

2.8 Gráfico de dispersão da concentração de ozônio, medida das 12 às 16 horas, contra a concentração de óxido de nitrogênio, medida das 7 às 11 horas, na estação de monitoramento Dom Pedro II, em São Paulo, de 2008 a 2011. . . . . . . . . . . . . . 15

2.9 Histograma da concentração diária média de ozônio medida das 12 às 16 horas na estação de monitoramento Dom Pedro II, na cidade de São Paulo, de 2008 a 2013. 16

2.10 Distribuição por mês da concentração diária média de ozônio medida das 12 às 16 horas na estação de monitoramento Dom Pedro II, na cidade de São Paulo, de 2008

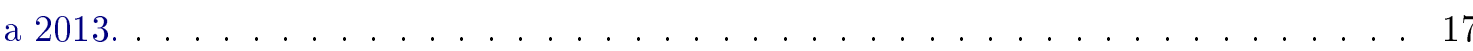

2.11 Série da concentração de ozônio diária média, medida na cidade de São Paulo (estação de monitoramento Dom Pedro II), no período de outubro de 2008 a junho de 2011, das $12 \mathrm{~h}$ às $16 \mathrm{~h} \ldots \ldots \ldots \ldots \ldots \ldots \ldots \ldots \ldots$ 
2.12 Periodogramas para a concentração horária de ozônio medida na cidade de São Paulo (estação de monitoramento Dom Pedro II), no período de outubro de 2008 a junho de 2013. Dados disponibilizados por Salvo e Geiger (2014). No painel (a), apresentamos a densidade espectral contra a frequência. No painel (b), resumimos a densidade espectral por período, apresentado em dias.

2.13 Função de autocorreção da concentração de ozônio diária média, medida na cidade de São Paulo (estação de monitoramento Dom Pedro II), no período de outubro de 2008 a junho de 2011, das $12 \mathrm{~h}$ às 16h. Dados disponibilizados por Salvo e Geiger (2014). As linhas pontilhadas representam os limites $\pm 2 / \sqrt{n}$, sendo $n$ o tamanho da amostra. Valores fora desse intervalo de confiança (95\%) podem ser considerados significantemente diferentes de zero.

2.14 Função de autocorreção parcial da concentração de ozônio diária média, medida na cidade de São Paulo (estação de monitoramento Dom Pedro II), no período de outubro de 2008 a junho de 2011, das $12 \mathrm{~h}$ às $16 \mathrm{~h}$. As linhas pontilhadas representam os limites $\pm 2 / \sqrt{n}$, sendo $n$ o tamanho da amostra. Valores fora desse intervalo de confiança (95\%) podem ser considerados significativamente diferentes de zero. . . . .

2.15 Função de correlação cruzada do ozônio em função da temperatura na estação Dom Pedro II (São Paulo) no período de outubro de 2009 a junho de 2011. As linhas pontilhadas representam os limites $\pm 2 / \sqrt{n}$, sendo $n$ o tamanho da amostra. Valores fora desse intervalo de confiança (95\%) podem ser considerados significativamente diferentes de zero. . . . . . . . . . . . . . . . . . . . . . . 21

2.16 Médias por hora e dia da semana durante todo o período observado para cada poluentes considerado na análise.

2.17 Série observada para o monóxido de carbono. O intervalo entre as retas pontilhadas corresponde ao período de paralisações.

2.18 Série observada para o ozônio. O intervalo entre as retas pontilhadas corresponde ao período de paralisações.

2.19 Série observada para o monóxido de nitrogênio. O intervalo entre as retas pontilhadas corresponde ao período de paralisações.

2.20 Série observada para o dióxido de nitrogênio. O intervalo entre as retas pontilhadas corresponde ao período de paralisações.

2.21 Série observada para o material particulado (PM10). O intervalo entre as retas pontilhadas corresponde ao período de paralisações. . . . . . . . . . . . . . . . . . . 28

3.1 Esquematização do mecanismo gerador dos dados. . . . . . . . . . . . . . . . . . . . 29

3.2 Exemplos de séries com tendência linear e quadrática, ambas positivas. . . . . . . . . 33

3.3 Exemplos de uma série com tendência não-constante. . . . . . . . . . . . . . . . . . . 34

3.4 Comparação entre os gráficos dos resíduos de um modelo linear contra o tempo para dados auto-correlacionados e dados não correlacionados.

3.5 Gráfico dos resíduos contra os valores preditos. Exemplo de nuvem de pontos em forma de funil, indicando heteroscedasticidade. . . . . . . . . . . . . . . . . . 36

3.6 A estimativa $\hat{\beta}$ representa a variação em $Y$ quando acrescemos $X$ em uma unidade,

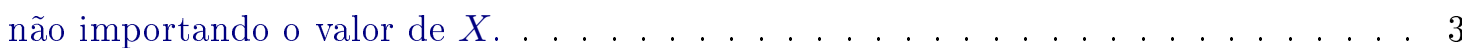


3.7 Gráfico dos resíduos contra os valores preditos, um exemplo de nuvem de pontos em forma de "U", indicando não-linearidade. . . . . . . . . . . . . . . . . 38

3.8 Exemplo de regressão segmentada. À esquerda, o gráfico de concentrações médias diárias de ozônio pela temperatura média diária. À direita, um modelo de regressão segmentada ajustada aos pontos com um ponto de corte . . . . . . . . . . . 39

3.9 Função densidade da distribuição Gama com $\mu=1$ e diversos valores de $\phi$. Conforme $\phi$ aumenta, a distribuição se torna menos assimétrica, centralizando-se ao redor da

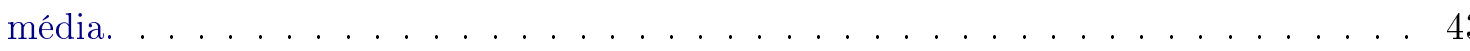

3.10 Função densidade da distribuição Normal inversa com $\mu=1$ e diversos valores de $\phi$. Conforme $\phi$ aumenta, a distribuição se torna menos assimétrica, centralizando-se ao redor da média. . . . . . . . . . . . . . . . . . . . .

3.11 Polinômios de terceiro grau ajustados em cada segmentação da variável $X$. Os nós são os pontos $x=-0.5, x=0, x=0.5$ e $x=1 \ldots \ldots \ldots \ldots$

4.1 Exemplo do balanço entre viés e variância. (a) Conjunto de 10 pontos que gostaríamos de ajustar. (b) Modelo de regressão linear simples (vermelho), modelo de regressão polinomial de grau 2 (amarelo) e modelo de regressão polinomial de grau 9 (azul), ajustados aos 10 pontos. (c) Amostra de 100 novas observações plotadas juntas dos modelos polinomiais ajustados nas 10 observações iniciais. (d) Modelos de regressão polinomial de graus 1 (vermelho), 2 (amarelo) e 9 (azul) ajustados aos 100 novos

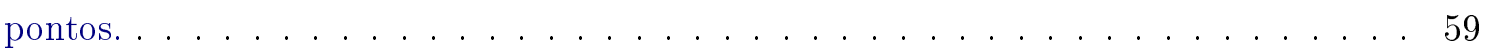

4.2 Esquematização da validação cruzada leave-one-out. . . . . . . . . . . . . 62

4.3 Esquematização da validação cruzada $k$-fold, com $k=5 \ldots \ldots \ldots$. . . . . . . 62

4.4 Exemplo de uma árvore de decisão para a concentração de ozônio explicada pela

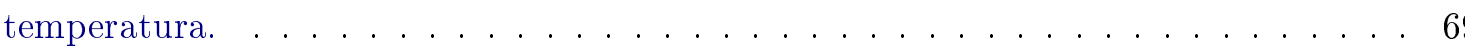

4.5 Gráficos de dispersão da média diária de $\mathrm{NO}_{x}$ contra as médias diárias de temperatura (Celsius) e umidade relativa do ar $(\%) \ldots \ldots \ldots \ldots$. . . . . . . . . . 74

4.6 Gráficos de dispersão da média diária de $\mathrm{NO}_{x}$ contra as médias diárias de temperatura (Celsius) e umidade relativa do ar $(\%) \ldots \ldots \ldots \ldots$. . . . . . . . . . 75

4.7 Valores preditos do $\mathrm{NO}_{\mathrm{x}}$ para cada modelo em função da umidade e da temperatura. 76

4.8 Gráficos de dependência parcial (PDP), esperança condicional individual (ICE) e efeitos locais acumulados (ALE) para a floresta aleatória. A curva amarela no ICE representa a média de todas as retas individuais, isto é, o PDP. . . . . . . . . 77

4.9 Gráfico de dispersão entre as médias diárias da temperatura e umidade. . . . . . . . 77

5.1 Séries da concentração de ozônio diária média e da proporção estimada de carros a gasolina rodando na cidade. As curvas azuis representam as séries suavizadas por splines cúbicos. Dados da estação Dom Pedro II, de 2008 a 2013. . . . . . . . . . . . 83

5.2 Gráfico de dispersão da concentração de ozônio contra a proporção estimada de carros rodando a gasolina na cidade. Dados da estação Dom Pedro II, de 2008 a 2013. . . . 84

5.3 Boxplot da proporção estimada de carros a gasolina para cada mês. . . . . . . . . . . 84

5.4 Gráficos ridge da temperatura diária média nos períodos da manhã (das 8 às 11 horas) e no período da tarde (12 às 17 horas). Dados da estação Dom Pedro II, de 2008 a 2013. . . . . . . . . . . . . . . . . . . . . . . 85 
5.5 Gráficos das séries da concentração de ozônio e da temperatura diária média nos períodos da manhã (das 8 às 11 horas) e no período da tarde (12 às 17 horas). Dados

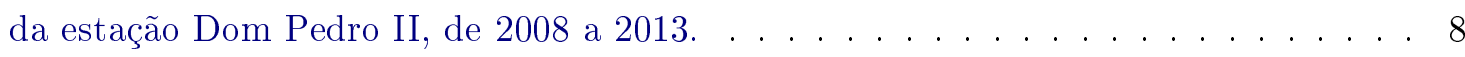

5.6 Gráficos de dispersão da concentração de ozônio pela temperatura diária média nos períodos da manhã (das 8 às 11 horas) e no período da tarde (12 às 17 horas). Dados da estação Dom Pedro II, de 2008 a 2013 . . . . . . . . . . . . . . . . . . . 86

5.7 Gráficos de dispersão da concentração de ozônio pelo congestionamento diário médio, na região da estação de monitoramento, nos períodos da manhã (das 8 às 11 horas) e no período da tarde (12 às 17 horas). Dados da estação Dom Pedro II, de 2008 a

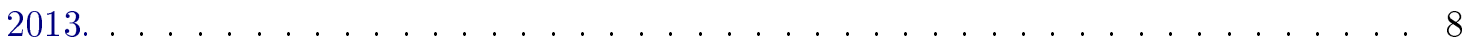

5.8 Relação entre a concentração de ozônio e o congestionamento na região da estação de monitoramento ao longo da semana. (a) Concentração de ozônio diária média ao longo da semana. (b) Congestionamento diário médio, no período da manhã e da tarde, na região da estação de monitoramento ao longo da semana. Dados da estação Dom Pedro II, de 2008 a 2013. . . . . . . . . . . . . . . . . . . . . .

5.9 Concentração de ozônio diária média ao longo da semana em dias com maior proporção de estimadas de carros abastecidos com álcool e em dias com maior proporção estimada de carros abastecidos com gasolina. Dados da estação Dom Pedro II, de 2008

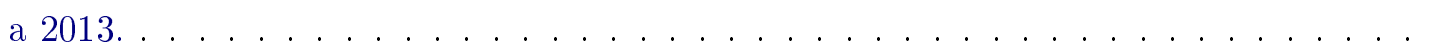

5.10 Valores da concentração de ozônio preditos pelo modelo de regressão linear ajustado por Salvo et al. (2017) contra os valores observados. . . . . . . . . . . . . . .

5.11 Função não-linear estimada pelo modelo aditivo generalizado com distribuição Normal para a proporção estimada de carros rodando a gasolina. A área cinza em volta da curva representa o intervalo de confiança com 2 erros-padrão para cima e para

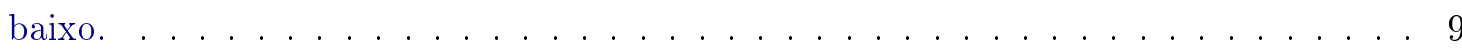

5.12 Valores da concentração de ozônio preditos pelo modelo com distribuição Normal (a) e pelo modelo com distribuição Gama (b) contra os valores observados. . . . . . . . .

5.13 Em cinza, as funções estimadas da variável referente à proporção estimada de carros a gasolina para cada uma das 200 amostras de bootstrapping. Em azul, a curva

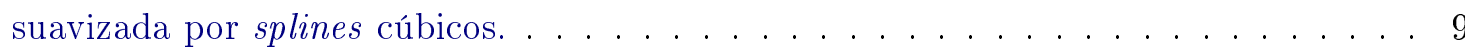

5.14 Retas de regressão segmentada para a proporção estimada de carros a gasolina. O efeito representa o valor da concentração de ozônio para cada valor da proporção estimada de carros a gasolina se todos os outros preditores tivessem valor igual a 0 . Essa medida não tem interpretação prática, mas pode ser utilizada para calcular a variação no ozônio quando variamos a proporção de carros a gasolina. . . . . . . . . 94

5.15 Valores da concentração de ozônio preditos pelo a floresta aleatória contra os valores

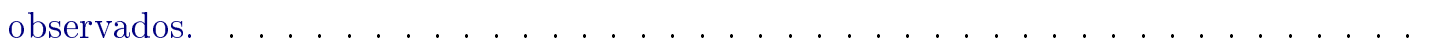

5.16 Gráficos de dependência parcial (PDP) e de efeitos locais acumulados para a floresta aleatória.

5.17 Gráficos de dependência parcial (PDP) e de efeitos locais acumulados para a proporção estimada de carros a gasolina do modelo XGBoost. . . . . . . . . . . . 96

5.18 Gráficos de efeitos locais acumulados para as variáveis climáticas do modelo XGBoost. 97 5.19 Distribuição da concentração de ozônio na amostra considerada por Salvo et al. (2017). 98 
5.20 Gráficos dos valores da concentração de ozônio preditos pelos modelos contra os valores observados. No painel da esquerda, modelo de regressão linear com transformação log. No painel do meio, modelo de regressão linear com transformação Box-Cox. No painel da direita, floresta aleatória com transformação Box-Cox. . . . . 99

5.21 Gráficos dos valores da máxima diária da concentração de ozônio preditos pelos modelos contra os valores observados. No painel da esquerda, modelo de regressão linear e, no painel da direita, a floresta aleatória. . . . . . . . . . . . . . 100

6.1 Séries da mortalidade diária para crianças e idosos. . . . . . . . . . . . . . . 107

6.2 Gráfico dos valores preditos versus os valores observados para o modelo linear generalizado com distribuição Poisson para cada um dos grupos. . . . . . . . . . . . 108

6.3 Funções estimadas para a proporção estimada de carros a gasolina pelo modelo aditivo Poisson para cada grupo. . . . . . . . . . . . . . . . . . . 109

6.4 Gráficos de dependência parcial (PDP) e de efeitos acumulados (ALE) da floresta aleatória para a variável proporção estimada de carros a gasolina. . . . . . . . . . . 109

6.5 Gráfico de correção cruzada da mortalidade diária para idosos contra a proporção estimada de carros a gasolina. . . . . . . . . . . . . . . . . . 110

6.6 Gráficos de dependência parcial (PDP) e de efeitos acumulados (ALE) da floresta aleatória para a variável proporção estimada de carros a gasolina defasada em 3 dias. 111

6.7 Séries do índice $\mathrm{NO}_{\mathrm{X}} / \mathrm{O}_{3}$ de 2008 a 2013 para as 7 estações na Região Metropolitana de São Paulo que monitoram a concentração de ambos os poluentes. . . . . . . . . . 112

6.8 Gráficos de dependência parcial (PDP) e de efeitos acumulados (ALE) da floresta aleatória para o índice $\mathrm{NO}_{\mathrm{x}} / \mathrm{O}_{3} \ldots \ldots \ldots \ldots \ldots \ldots \ldots \ldots$

6.9 Gráfico da função não linear estimada pelos modelos aditivos generalizados para as concentrações de ozônio e de óxidos de nitrogênio. . . . . . . . . . . . . . . . 114

6.10 Gráficos de dependência parcial (PDP) e de efeitos acumulados (ALE) da floresta aleatória (idosos) para as concentrações de ozônio e de óxidos de nitrogênio. . . . . . 115

6.11 Gráficos de dependência parcial (PDP) e de efeitos acumulados (ALE) da floresta aleatória (idosos) para as concentrações de ozônio e de óxidos de nitrogênio defasadas em 1 dia. . . . . . . . . . . . . . . . . . . . . . 116

6.12 Gráfico da função não linear estimada pelo modelo aditivo generalizado para as concentrações de ozônio e de óxidos de nitrogênio considerando a base de mortalidade filtrada para doenças cardio pulmonares. . . . . . . . . . . . 116

6.13 Gráficos de dependência parcial (PDP) e de efeitos acumulados (ALE) da floresta aleatória (idosos) para as concentrações de ozônio e de óxidos de nitrogênio, considerando a base de mortalidade filtrada para doenças cardio pulmonares. . . . . . . 117

6.14 Gráficos de dependência parcial (PDP) e de efeitos acumulados (ALE) da floresta aleatória (idosos) para as concentrações de ozônio e de óxidos de nitrogênio defasadas em 1 dia, considerando a base de mortalidade filtrada para doenças cardio pulmonares..118

7.1 O fluxo do web scraping. . . . . . . . . . . . . . . . . . 120

7.2 Mapa de estações de monitoramento disponíveis na Plataforma de Qualidade do Ar do Instituto de Energia e Meio Ambiente. . . . . . . . . . . . . . . . . . 122 


\section{xviii LISTA DE FIGURAS}

7.3 Exemplo de visualização do portal AirVisual para a estação Parque Dom Pedro II, em São Paulo. . . . . . . . . . . . . . . . . . . . . . . . . . 124 


\section{Lista de Tabelas}

2.1 Variação da média dos poluentes em cada estação no período de greve em relação à média nos períodos anterior e posterior à greve . . . . . . . . . . . 23

3.1 Critérios para a escolha da ordem de modelos ARIMA. . . . . . . . . . . . . 50

4.1 Raiz do erro quadrático médio (RMSE) para os modelos polinomiais de grau 1 a 9 ajustados com 10 e 100 observações no exemplo da Figura 4.1. . . . . . . . . . . . 59

4.2 Modelos de regressão linear que devem ser ajustados para selecionar o melhor subconjunto de variáveis no caso com 3 preditores, além do modelo nulo. . . . . . . . . . 64

5.1 Preditores considerados pelo modelo para a concentração de ozônio ajustado em Salvo et al. (2017). . . . . . . . . . . . . . . . . . . . 88

5.2 Resultados dos modelos aditivos generalizados em comparação com o modelo utilizado por Salvo et al. (2017). . . . . . . . . . . . . . . . . . . . 90

5.3 Resultado do modelo de regressão segmentada. . . . . . . . . . . . . . . . . 93

5.4 Resultado da floresta aleatória aplicado aos dados de Salvo et al. (2017). Os hiperparâmetros referentes ao tamanho mínimo de cada nó e o número de preditores sorteados em cada amostra foram definidos por validação cruzada. . . . . . . . . . 94

5.5 Performance do modelo XGBoost aplicado aos dados de Salvo et al. (2017) em comparação com os outros modelos ajustados. . . . . . . . . . . . . . . 96

5.6 Resultado dos modelos ajustados com a variável resposta transformada. . . . . . . . 99

5.7 Resultado dos modelos ajustados com a variável resposta transformada. . . . . . . 100

5.8 Resultados dos modelos para cada estação. A estimativa apresentada na segunda coluna se refere ao coeficiente da proporção de carros a gasolina rodando na cidade. . 102

6.1 Resultados do modelo Poisson para mortalidade geral em crianças e idosos. . . . . . 108

6.2 Resultados do modelo da floresta aleatória com proporção estimada de carros a gasolina defasada no tempo. Os valores estão ordenados do menor ao maior RMSE. . 111

6.3 Resultados dos modelos ajustados para o índice $\mathrm{NO}_{\mathrm{x}} / \mathrm{O}_{3} \ldots \ldots \ldots$. . . . . . . . 112

6.4 Resultados dos modelos ajustados para o índice $\mathrm{NO}_{\mathrm{x}} / \mathrm{O}_{3} \ldots \ldots \ldots$. . . . . . . . . 112

6.5 Resultados dos modelos ajustados para a mortalidade diária utilizando a concentração de ozônio como preditor. . . . . . . . . . . . . . . . . . . . . . . . . . 114

6.6 Resultados dos modelos ajustados para a mortalidade diária utilizando a concentração de ozônio como preditor. . . . . . . . . . . . . . . . . . . . . . 115 


\section{Capítulo 1}

\section{Introdução}

A poluição do ar, considerada pela Organização Mundial da Saúde (OMS) como o maior risco ambiental à saúde humana, é responsável por aproximadamente 7 milhões de mortes por ano, um oitavo do total global (Jasarevic et al., 2014). Poluentes como óxidos de carbono, nitrogênio e enxofre, ozônio e material particulado trazem diversos prejuízos à nossa qualidade de vida e ao meio ambiente. Eles são agentes sistemáticos em afecções como irritação dos olhos, obstrução nasal, tosse, asma e redução da função pulmonar. À exposição contínua estão associadas diversas doenças respiratórias e cardiovasculares, problemas digestivos e no sistema nervoso, câncer e aumento da mortalidade infantil (European Commission, 1999). No meio ambiente, a poluição do ar é responsável por dois grandes problemas: o efeito estufa, relacionado ao aumento da temperatura média do planeta, e a destruição da camada de ozônio, aumentando a incidência de radiação solar nociva na superfície terrestre.

As taxas elevadas de poluição do ar geralmente são produto de políticas não sustentáveis em setores como transporte, energia, saneamento e indústria. A escolha de estratégias favoráveis à saúde pública e ao meio ambiente costuma esbarrar em interesses econômicos, mesmo quando a redução a longo prazo nos gastos com tratamentos de saúde poderia gerar números positivos nesse balanço.

Como discutido em Zannetti (1990), os estudos de poluição do ar são de extrema importância pois, a partir deles, podemos

- acompanhar as concentrações dos poluentes ao longo do tempo;

- gerar evidências para a criação de leis de controle de emissão;

- avaliar os impactos de novas legislações;

- determinar e responsabilizar fontes atuais de poluição;

- selecionar regiões para futuras fontes de poluição, minimizando o impacto ambiental;

- prever e controlar episódios severos de poluição a partir de estratégias de intervenção;

- investigar o efeito da concentração de poluentes na saúde pública, principalmente em grupos de risco como crianças, gestantes e idosos;

- desenvolver soluções mais limpas (ou menos poluentes) que ainda sejam economicamente viáveis. 
A maioria dos estudos de poluição do ar utiliza modelagem, que pode envolver tanto modelos físicos quanto modelos matemáticos. Os modelos físicos correspondem a experimentos laboratoriais que tentam representar os fenômenos sob investigação. Já os modelos matemáticos são construções teóricas (analíticas ou numéricas) que visam descrever o fenômeno da forma mais precisa possível e são divididos em duas classes: determinísticos e estatísticos. Os modelos determinísticos, geralmente formulados a partir de equações de balanço químico, descrevem matematicamente os processos atmosféricos. Por sua vez, os modelos estatísticos utilizam observações coletadas sobre os agentes (supostamente) envolvidos no processo para inferir relações entre eles e produzir previsões. Nesta tese, abordaremos apenas os modelos estatísticos.

A literatura sobre modelagem em estudos de poluição do ar é vasta. Katsouyanni et al. (1996), por exemplo, utilizaram um modelo Poisson autorregressivo para investigar o efeito da poluição do ar na saúde pública a partir da concentração de diversos poluentes. Carslaw et al. (2007) usaram modelos aditivos generalizados para modelar as médias diárias de óxidos e dióxidos de nitrogênio, monóxido de carbono, benzeno e 1,3-butadieno com objetivo de avaliar a tendência das concentrações desses poluentes durante o período de 1998 a 2005 no movimentado centro de Londres. Beer et al. (2011) utilizaram funções de impacto na saúde (health impact functions) para estudar os efeitos na saúde e na economia de se utilizar etanol como aditivo na gasolina em regiões urbanas da Austrália, medindo níveis de ozônio, dióxido de nitrogênio e material particulado em câmaras de poluição. Kloog et al. (2012) utilizaram modelos mistos para prever concentrações diárias de material particulado na costa leste dos Estados Unidos a partir de medidas de profundidade óptica de aerossóis geradas por satélites.

Embora esses estudos ataquem diferentes problemas utilizando variadas técnicas estatísticas, uma característica presente em todos os estudos citados é a dificuldade inerente da modelagem de dados de poluição do ar. A formação de poluentes compreende reações químicas complexas, que envolvem diversas variáveis climáticas e, nas cidades, é altamente dependente de flutuações no trânsito de veículos causadas por horários de pico, feriados, férias escolares, eventos esportivos e culturais etc. Todos esses fatores são difíceis de serem controlados em laboratório e, por isso, as grandes cidades acabam se transformando em laboratórios naturais para estudos de poluição do ar. Comumente túneis servem como "ambientes controlados" para a coleta de dados e estações de monitoramento são instaladas próximo de grandes vias e zonas industriais. Com a disponibilidade de dados meteorológicos e de tráfego, é possível avaliar grande parte dos fatores que influenciam a formação dos poluentes.

Além do grande número de variáveis a serem consideradas nos estudos de poluição atmosférica, também é razoável imaginar que a relação entre elas não deva ser simples, o que limitaria o uso de modelos muito restritivos. Apesar disso, muitos estudos de poluição do ar utilizam algumas metodologias estatísticas usuais, que fazem suposições fortes como linearidade, aditividade ou independência ${ }^{1}$, nem sempre coerentes com a realidade. Exemplos dessas metodologias são os modelos de regressão linear, utilizados por Salvo e Geiger (2014); Salvo et al. (2017), os modelos lineares generalizados (Conceição et al., 2001b; Lin et al., 1999; Saldiva et al., 1994, 1995; Schwartz e Dockery, 1992), os modelos aditivos generalizados (Carslaw et al., 2007; Conceição et al., 2001a,b; Schwartz, 1994, 1996) e várias de suas generalizações (modelos de regressão segmentada, modelos mistos, modelos autorregressivos, entre outros).

\footnotetext{
${ }^{1}$ Esses conceitos serão tratados com detalhes no Capítulo 3.
} 
O modelo de regressão usual (Hastie et al., 2008) é muito utilizado para modelagem devido à facilidade de implementação e interpretação de seus coeficientes. Por outro lado, ele supõe que a variância das observações seja constante e que a relação entre a variável dependente e as independentes seja linear, o que pode ser muito restritivo na prática. Os modelos lineares generalizados (Nelder e Wedderburn, 1972) flexibilizam a suposição de homocedasticidade, permitindo modelar também a dispersão dos dados, mas ainda estão presos à suposição de linearidade. Já os modelos aditivos generalizados (Hastie e Tibshirani, 1990) são uma boa alternativa para modelar relações não lineares, pois permitem a inclusão de termos não paramétricos para ajustar funções suavizadas da variável resposta pelas variáveis explicativas. Contudo, assim como as outras duas classes, supõem relações aditivas, o que dificulta o ajuste de interações complexas entre os preditores. De uma forma geral, autocorrelação, heterocedasticidade, superdispersão, tendência, sazonalidade, componentes espaciais e grandes períodos sem observação (ou muitas observações omissas) são características comuns em dados de poluição do ar e precisam ser identificadas e contempladas pelo modelo escolhido.

Tomando o estudo conduzido por Salvo e Geiger (2014); Salvo et al. (2017) como exemplo, observamos que os autores utilizam um modelo de regressão linear para investigar a associação entre o uso de gasolina/etanol com a formação troposférica de ozônio, supondo que cada variável explicativa está linearmente associada com a concentração de ozônio, o que, na prática, pode não ser verdade, levando a conclusões equivocadas ou superficiais.

Nos últimos anos, a área popularmente conhecida como ciência dos dados (data science) vem expandindo as preocupações e habilidades que estatísticos e não estatísticos precisam possuir para analisar dados. O que antes era um trabalho primordialmente de visualização e modelagem, agora agrega tarefas mais gerais de importação, estruturação e manipulação de bases de dados, assim como etapas de implementação, automatização e divulgação dos resultados. Outra característica dessa área é o menor rigor matemático/probabilístico dado aos problemas, em função de uma abordagem mais prática/computacional. Isso deixa seu conteúdo mais acessível a pesquisadores e profissionais de qualquer área, já que exige um conhecimento de Estatística menos aprofundado. A Figura 1.1 representa uma esquematização do chamado ciclo da ciência de dados, cujo objetivo é ressaltar a importância dessas outras etapas da análise que antes eram colocadas em segundo plano pela Estatística. O foco desta tese será a etapa de modelagem, mas também falaremos sobre visualização e importação de dados.

Dentro da etapa de modelagem, a abordagem conhecida como aprendizado automático (machine learning) vem ganhando bastante notoriedade por resolverem problemas difíceis de modelagem preditiva $^{2}$, em especial por utilizar modelos que não estabelecem suposições sobre a forma como as variáveis estão relacionadas, permitindo ajustes muito mais precisos, e incluírem conceitos como sobreajuste, validação cruzada e regularização, essenciais no contexto de predição. Embora diversas dessas técnicas possam ser generalizadas para além da modelagem preditiva, ainda há muita confusão e resistência na sua aplicação para inferência, principalmente pela falta de interpretabilidade dos modelos mais utilizados.

Nos últimos anos, podemos encontrar alguns estudos de poluição do ar que aplicaram aprendizado automático, sobretudo em problemas de previsão, como os trabalhos de Cortina-Januchs et al. (2015); Elangasinghe et al. (2014); Feng et al. (2015). O uso contudo ainda é superficial e há

\footnotetext{
${ }^{2}$ Como transcrição de áudio, reconhecimento de textos e classificação de imagens.
} 


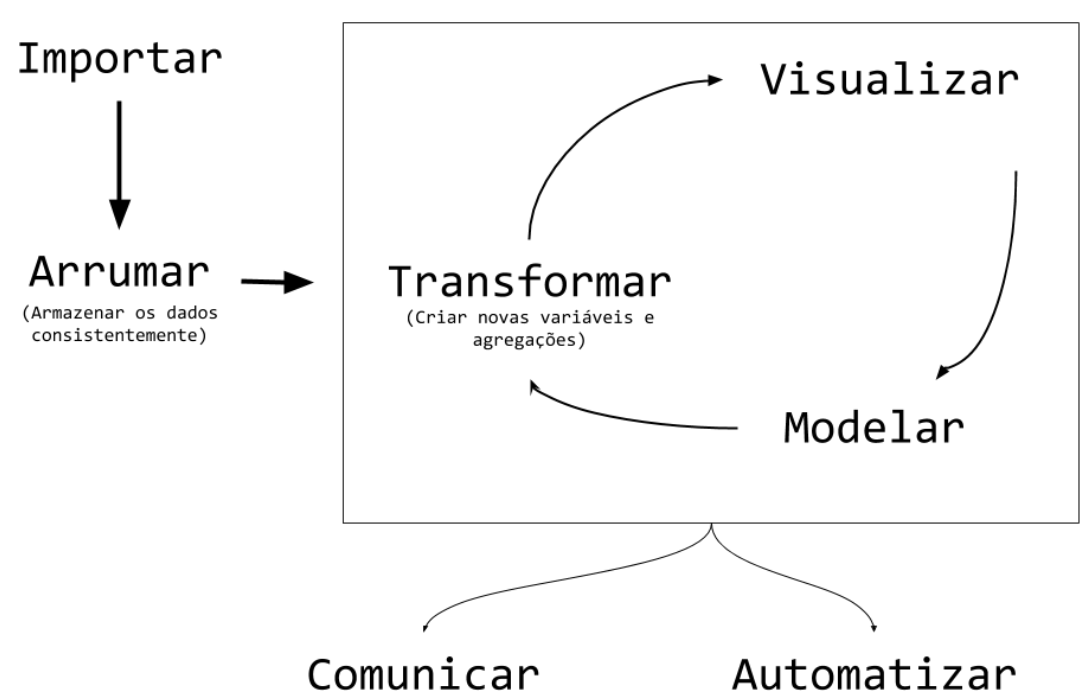

Figura 1.1: Esquematização do ciclo da ciência de dados. Figura adaptada do livro Wickham e Grolemund (2017).

bastante espaço para aprimorar a modelagem de estudos inferenciais utilizando essa abordagem. Stingone et al. (2017), por exemplo, utilizaram árvores de decisão para associar exposição à poluição do ar com habilidades cognitivas em crianças, nos Estados Unidos, que, apesar de serem altamente interpretáveis, poderiam ter sido substituídas por modelos mais precisos. Já Polezer et al. (2018) utilizam redes neurais para investigar a associação entre material particulado e doenças respiratórias, mas não utilizaram métodos de interpretação para avaliar o sentido e a intensidade dessa associação.

O objetivo desta tese é criar e discutir estratégias robustas para a análise de dados de poluição do ar usando a roupagem da ciência de dados. Vamos avaliar em quais contextos as metodologias usuais são adequadas e podem ser aplicadas e propondo abordagens com técnicas mais recentes, como o machine learning, ainda pouco utilizado em estudos de poluição do ar. Os resultados deste trabalho visam criar uma ponte entre a ciência de dados e a pesquisa em poluição do ar, auxiliando pesquisadores de outras áreas que têm pouco contato com a Estatística. Dado seu carácter multidisciplinar, é essencial que existam materiais acessíveis sobre cada uma das disciplinas que compõem esse campo de pesquisa para o adequado desenvolvimento dos trabalhos, aumentando a chance de criação de políticas públicas que promovam melhorias na saúde pública e na nossa relação com o meio ambiente.

Com essa finalidade, utilizaremos conjuntos de dados reais para apontar as vantagens e desvantagens de cada metodologia, gerando estratégias de análise que contemplem as principais dificuldades encontradas na prática. Também aplicaremos técnicas de machine learning pouco ou ainda não utilizadas no estudo de séries de poluição do ar, como validação cruzada e regularização.

No Capítulo 2, discutiremos a análise exploratória de dados de poluição, com o objetivo principal de diminuir a complexidade do problema para facilitar a busca de informações relevantes sobre o fenômeno estudado. No Capítulo 3, apresentaremos modelos usuais utilizados no ajuste de dados de poluição. No Capítulo 4, discutiremos técnicas de machine learning úteis também para modelagem inferencial. Nos Capítulos 5 e 6, aplicaremos diversas estratégias discutidas nesta tese em estudos reais de poluição do ar. No Capítulo 7, apresentaremos formas de se extrair dados públicos de poluição do ar da internet. Por fim, no Capítulo 8, concluiremos a tese discutindo e sumarizando 
as conclusões mais importantes.

Seguindo a abordagem prática da ciência de dados, o texto a seguir busca ser acessível a pesquisadores de diversas áreas, sem abandonar totalmente o formalismo matemático. Um certo grau de conhecimento estatístico será exigido em muitos pontos. Os livros Bussab e Morettin (2013) e Magalhães e Lima (2013) podem ser utilizados como referências de Estatística básica e Hastie et al. (2008); James et al. (2013) são ótimos livros para os tópicos de modelagem e machine learning. A parte computacional deste trabalho foi realizada integralmente no programa estatístico R (R Core Team, 2016), sendo Wickham e Grolemund (2017) uma excelente referência. 


\title{
Capítulo 2
}

\section{Análise exploratória}

\author{
The greatest value of a picture \\ is when it forces us to notice \\ what we never expected to see \\ — John Tukey
}

A análise exploratória corresponde à etapa "Visualizar" do ciclo da ciência de dados (Figura 1.1) e caracteriza a primeira tentativa de se extrair informação dos dados. Seu objetivo é gerar conhecimento inicial acerca do fenômeno sob estudo para guiar a etapa de modelagem. Existem diversas maneiras de conduzir uma análise exploratória, e a estratégia aplicada a cada problema depende do tipo de variável com que estamos trabalhando.

Como estudos de poluição do ar geralmente envolvem séries temporais, apresentaremos algumas técnicas para explorar variáveis dessa natureza. Uma visão mais geral sobre a análise exploratória de dados pode ser encontrada em Wickham e Grolemund (2017).

Séries temporais são variáveis observadas repetidas vezes ao longo de grandes períodos de tempo. Mesmo quando as observações são medidas em intervalos equidistantes, as séries podem apresentar "buracos" devidos a observações omissas ou delineamento do estudo. Como as técnicas abordadas nesta tese não supõem observações equidistantes, não discutiremos esse tema com detalhe durante as análises. Para a modelagem de séries com observações não igualmente espaçadas, recomendamos a leitura de Eckner (2018).

O efeito do tempo nas observações é a grande peculiaridade das séries temporais, gerando características como tendência, sazonalidade e autocorrelação, que influenciam diretamente a escolha do melhor modelo para os dados. A identificação dessas características é fundamental para a análise, o que torna a análise exploratória uma etapa de extrema importância no estudo de séries temporais. Discutiremos esse tópico na Seção 2.2.

Séries temporais são normalmente representadas pela notação $\left\{Y_{t}, t \geq 0\right\}$. Neste texto, utilizaremos a forma simplificada $Y_{t}$. Aqui, $Y$ representa o fenômeno sob estudo, denominado como variável resposta. $\mathrm{O}$ índice inteiro $t$ representa o instante em que essa variável foi avaliada $(1,2,3, \ldots)$, podendo ser medido em minutos, horas, dias, anos etc. Na maioria dos casos, estaremos interessados em associar $Y_{t} \operatorname{com} p$ outras variáveis, chamadas variáveis explicativas ou preditores. Essas variáveis serão denotadas aqui por $X_{1 t}, X_{2 t}, \ldots, X_{p t}$. Quando não houver risco de ambiguidade, omitiremos o índice $t$ tanto de $Y_{t}$ quanto de $X_{1 t}, X_{2 t}, \ldots, X_{p t}$. 
Sob o contexto de estudos de poluição do ar, apresentaremos nas próximas seções as principais técnicas para análise exploratória de séries temporais. Utilizaremos como exemplo as séries horárias de concentração de ozônio $\left(\mathrm{O}_{3}\right)$, óxido de nitrogênio $(\mathrm{NO})$, dióxido de nitrogênio $\left(\mathrm{NO}_{2}\right)$ e temperatura, todas medidas na cidade de São Paulo de 2008 a 2013, disponibilizadas por Salvo e Geiger (2014) e Salvo et al. (2017) nos respectivos endereços: http://bit.do/salvo_geiger_data e https://goo.gl/9tNzvj. Na Seção 2.3, apresentaremos uma aplicação real de análise exploratória estudando os níveis de poluição durante a greve de caminhoneiros de 2018.

\subsection{Gráficos}

\section{The simple graph has brought more information to the data analyst's mind than any other device - John Tukey}

Nós construímos gráficos para elucidar informações sobre as variáveis que estão "escondidas" na base de dados. Para cumprir esse objetivo, um gráfico precisa ser facilmente compreendido, dado que gráficos muito verbosos podem ser mal interpretados e gerar mais confusão do que esclarecimento.

Embora o conceito de gráfico estatístico seja amplamente conhecido, não há um consenso geral sobre o que realmente é um gráfico e, por consequência, quais as melhores práticas para construílo. Wilkinson (2005) atacou esse problema definindo um gráfico estatístico como o mapeamento de variáveis em atributos estéticos de formas geométricas. Essa definição, conhecida como "a gramática dos gráficos", contempla os principais modelos gráficos já conhecidos e abre caminho para a criação de estratégias bem estruturadas para a construção de gráficos.

Wickham (2010), por exemplo, utilizou a as ideias propostas por Wilkinson (2005) e definiu uma "gramática dos gráficos por camadas"1 , acrescentando que cada elemento de um gráfico representa uma camada e que o gráfico em si é a sobreposição de todas as suas camadas. O resultado dessa definição foi a origem ao pacote de $\mathrm{R}$ ggplot2, sendo uma das melhores ferramentas atuais para criação de gráficos estáticos ${ }^{2}$.

A visualização mais comum para séries temporais é o gráfico da série. Com base na definição criada por Leland, as variáveis mapeadas serão o par $\left(t, Y_{t}\right)$, as formas geométricas são retas e o atributo estético é a posição dessas retas em um eixo coordenado (com $t$, o tempo, no eixo $x$ e $Y_{t}$ no eixo y). A seguir, apresentamos alguns exemplos de como construir e interpretar esses gráficos.

\subsubsection{O gráfico da série}

O gráfico da série é um gráfico da variável $Y_{t}$ contra o tempo. A partir dele, podemos observar a existência de diversos comportamentos, como tendência, sazonalidade e heterocedasticidade ${ }^{3}$, sendo a principal técnica de visualização de séries temporais.

Apesar de ser uma ferramenta de fácil construção e interpretação, quando o volume de dados é muito grande, a simples construção do gráfico da série pode não trazer toda a informação disponível

\footnotetext{
${ }^{1}$ A layered grammar of graphics, em inglês.

${ }^{2}$ Gráficos dinâmicos, muito utilizados na internet, são normalmente construídos com ferramentas baseadas em Java Script, como o D3 e o Highcharts.

${ }^{3}$ Variância não constante ao longo do tempo.
} 
nos dados. Uma boa estratégia nesse cenário é tentar diminuir a complexidade do problema, trabalhando inicialmente com casos particulares e, em seguida, buscar os padrões encontrados nos casos mais gerais.

Como exemplo de como explorar os dados utilizando o gráfico da série, vamos analisar a concentração horária de ozônio medida na região metropolitana de São Paulo, no período de 2008 a 2013, disponibilizada por Salvo et al. (2017).

A base de dados contém medições de ozônio de 12 estações de monitoramento espalhadas pela cidade. A princípio, vamos analisar o gráfico de apenas uma delas, por exemplo, a estação Parque Dom Pedro II (Figura 2.1). Podemos observar alguns períodos sem observação e, com a ajuda da série suavizada (por splines cúbicos, ver Seção 3.3.2), uma sazonalidade anual, com picos no início de cada ano.

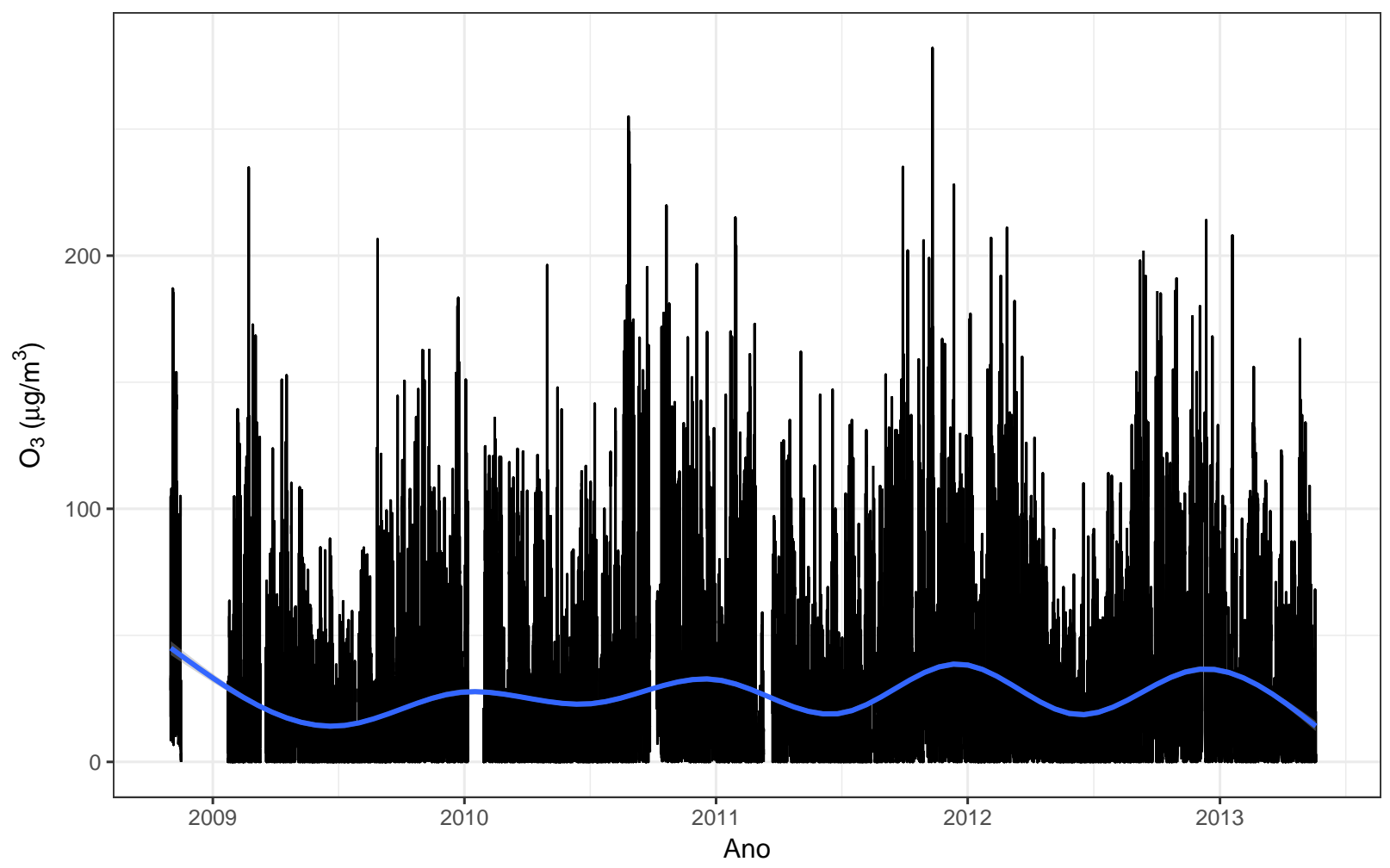

Figura 2.1: Série da concentração de ozônio para a estação Dom Pedro II, na cidade de São Paulo, no período de 2008 a 2013. Em azul, a série suavizada usando splines cúbicos.

Como a série é horária, o grande volume de observações pode ocultar alguns padrões. Para avaliar o comportamento da concentração de ozônio ao longo do dia, vamos analisar a média de cada hora dentro do período analisado (Figura 2.2). Observamos que o pico de ozônio, em geral, acontece no começo da tarde, das 12 às 16 horas.

Podemos então considerar a média diária dentro desse período para avaliar apenas o horário em que a concentração de ozônio normalmente está alta. Observe pela Figura 2.3 que fica mais fácil observar o padrão sazonal. O padrão parece não ser o mesmo em 2009, mas essa diferença provavelmente se deve à falta de informação no período. Como indicado na Figura 2.4, esse padrão se repete para todas as 12 estações.

Note que conduzir a análise exploratória na direção de casos particulares facilita a obtenção de informações importantes sobre o fenômeno. No exemplo, essa particularização poderia ainda ser 


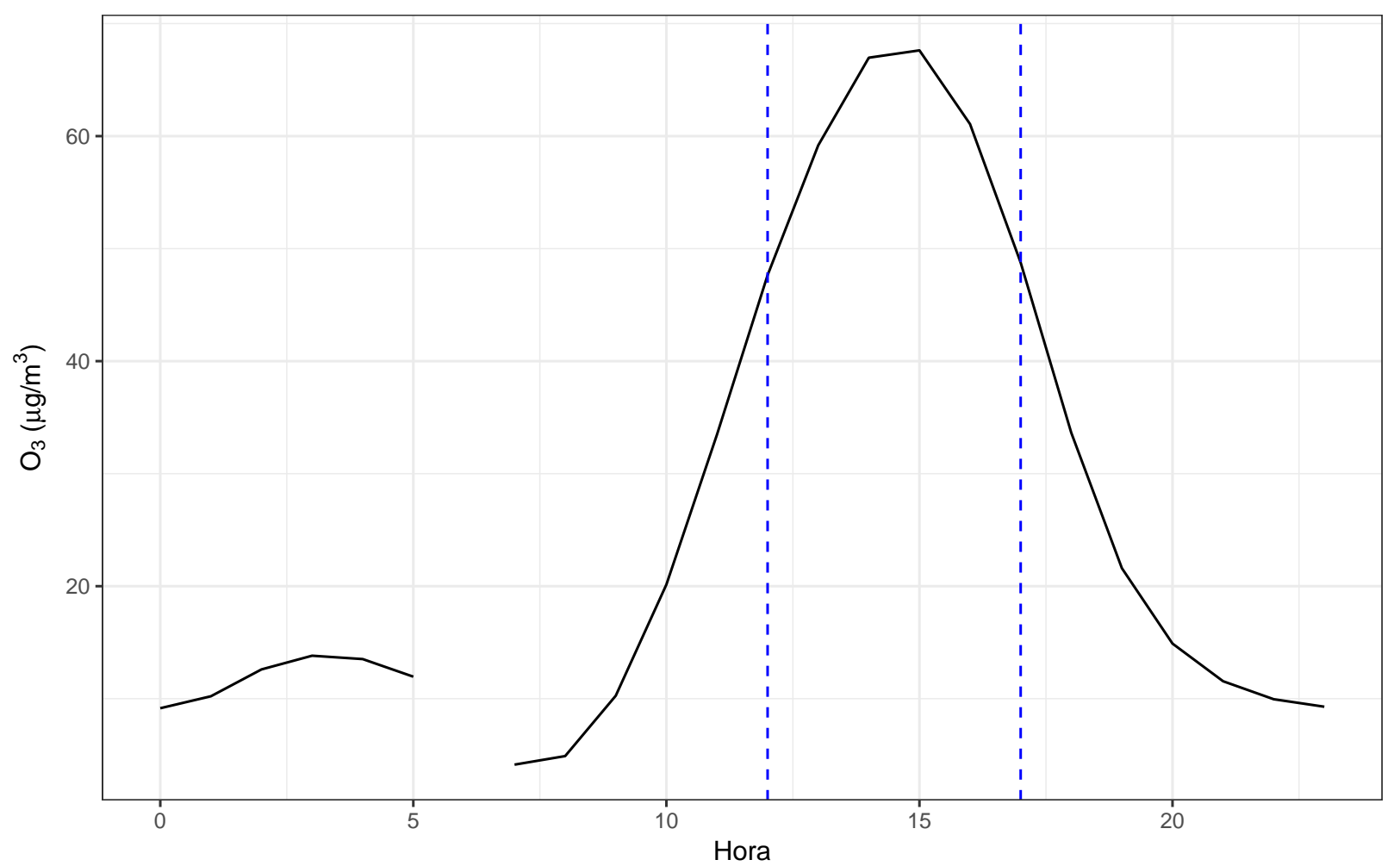

Figura 2.2: Série da concentração média de ozônio ao longo do dia para a estação Dom Pedro II, na cidade de São Paulo, no perído de 2008 a 2013. Não existe informação para as 6 da manhã pois é o horário em que o equipamento sofre manutenção.

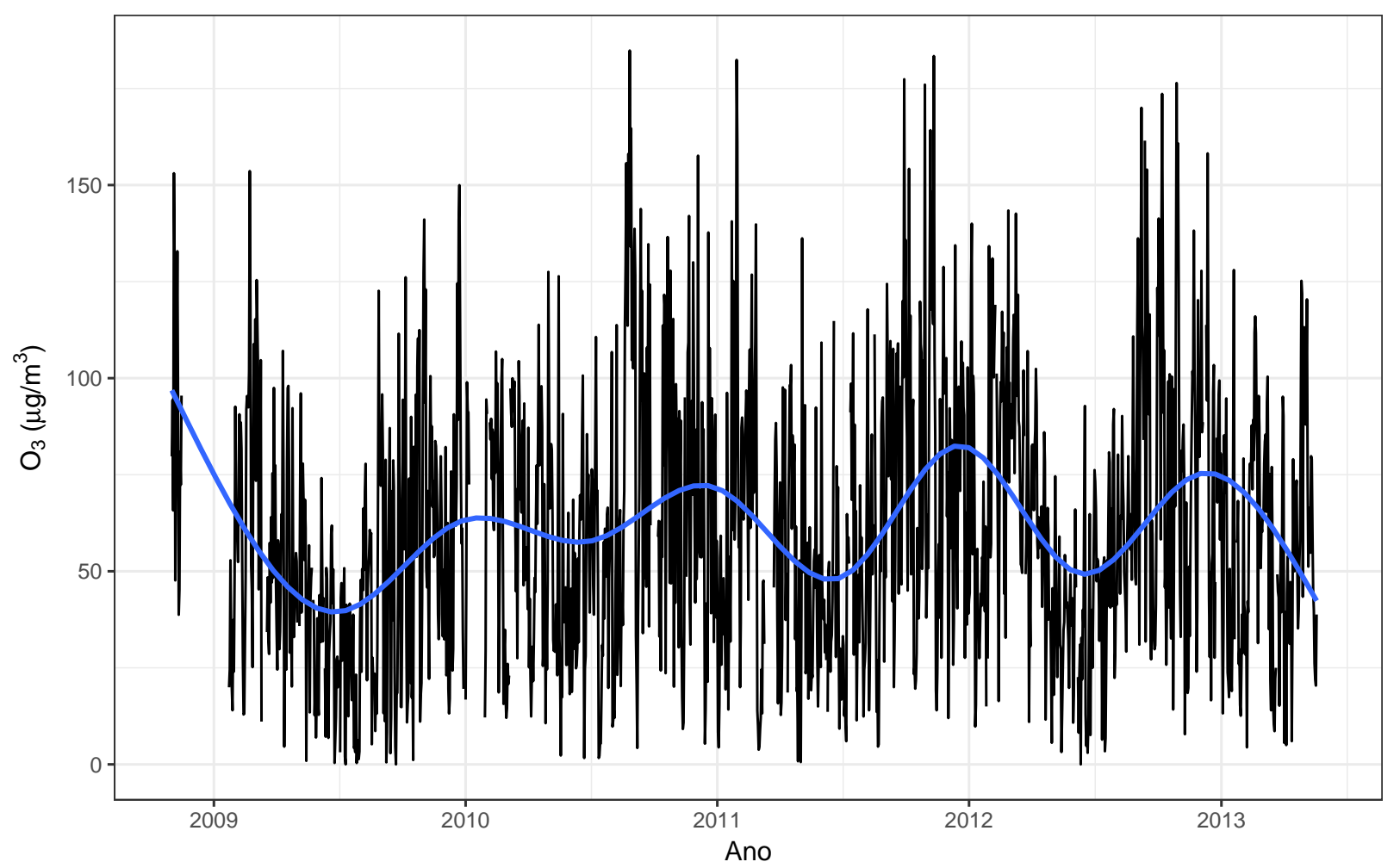

Figura 2.3: Série diária da concentração média de ozônio medido no começo da tarde para a estação Dom Pedro II, na cidade de São Paulo, no período de 2008 a 2013. Em azul, a série suavizada usando splines cúbicos. 
feita em várias direções, como avaliar as diferenças entre os dias da semana ou as estações do ano.
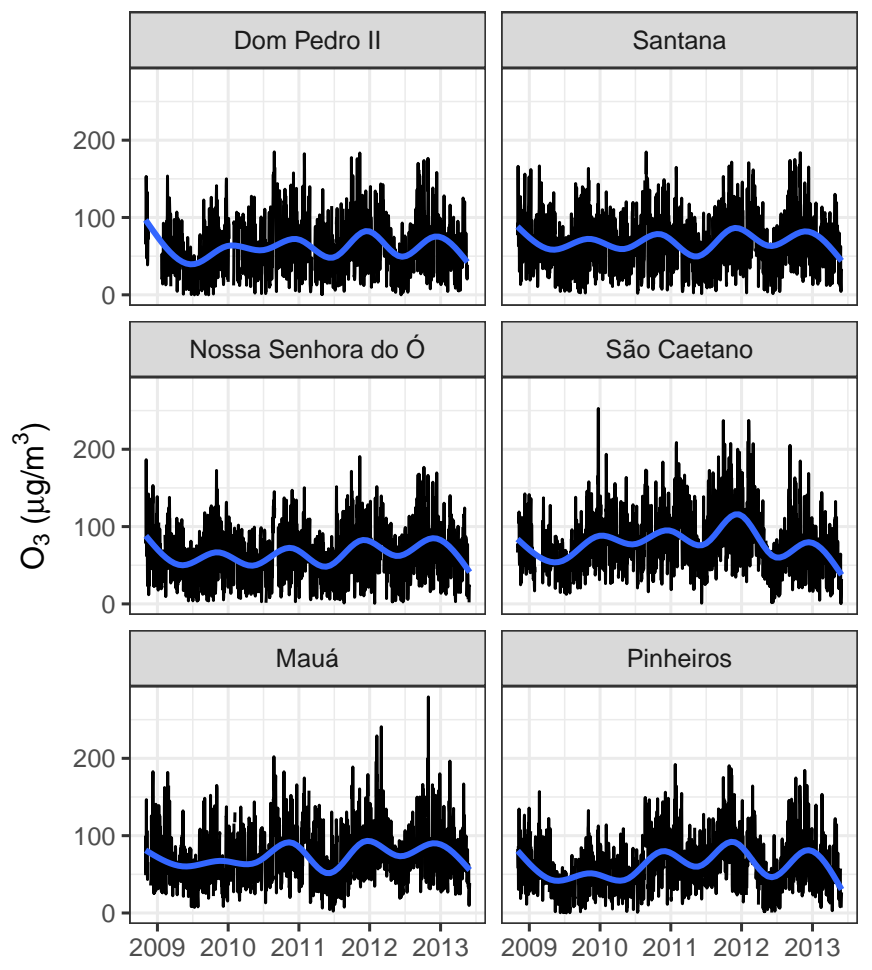
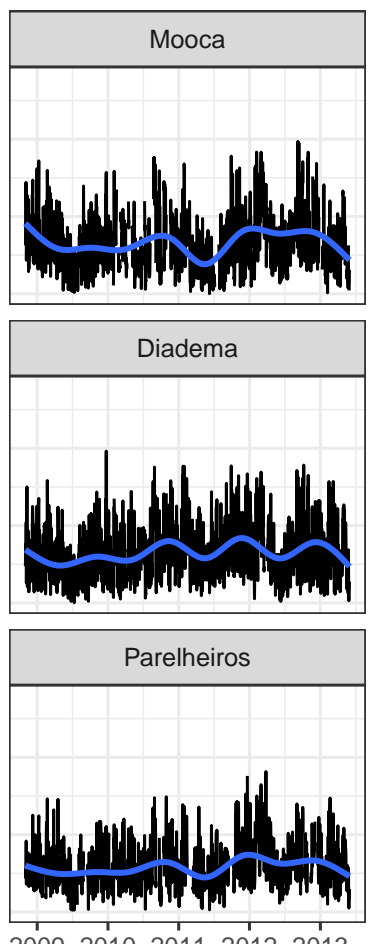

Ano

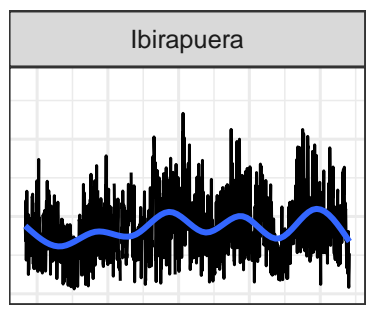

Santo André
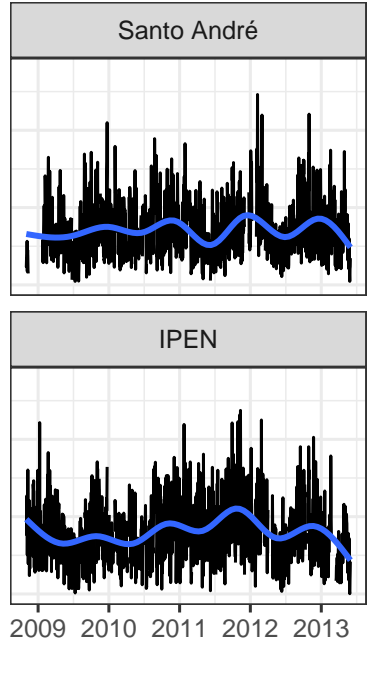

Figura 2.4: Série diária da concentração média de ozônio medido no começo da tarde para todas as estações, na cidade de São Paulo, no perído de 2008 a 2013. Em azul, as séries suavizadas usando splines cúbicos.

Muitas vezes, também temos interesse em estudar a relação entre duas séries. Os gráficos dessas séries, avaliadas em um mesmo período, podem então ser construídos na mesma figura como uma tentativa de encontrar padrões no comportamento conjunto das duas curvas. Na Figura 2.5, construímos gráficos das séries horárias de ozônio e de óxido de nitrogênio (NO), ambos medidos na estação Dom Pedro II, em São Paulo, no período de 2008 a 2011. Podemos observar que períodos de menor concentração de ozônio parecem estar associados a períodos de maior concentração de NO.

Embora construir o gráfico de duas séries na mesma figura possa trazer informações sobre como essas variáveis estão relacionadas, gráficos de dispersão são mais eficientes nessa tarefa. Na próxima seção, apresentaremos alguns exemplos de como construir e interpretar esses gráficos.

\subsubsection{Gráficos de dispersão}

Gráficos de dispersão são amplamente utilizados na Estatística. Sua principal função é estudar a associação entre duas variáveis, sendo possível encontrar indícios sobre a forma, intensidade e direção dessa relação, caso ela exista. Construímos esses gráficos posicionando pontos em um plano cartesiano, sendo a variável resposta mapeada no eixo $y$ e a variável explicativa no eixo $x$. Podemos também adicionar curvas suavizadas para facilitar a identificação da associação.

$\mathrm{Na}$ Figura 2.6, apresentamos o gráfico de dispersão da concentração média de $\mathrm{O}_{3}$ contra a concentração média de NO, ambas medidas das 12 às 16 horas, de 2008 a 2011. Observamos que a concentração de ozônio decresce de forma exponencial conforme a concentração de NO aumenta. É conhecido que o ozônio ao longo da tarde reage com o NO, portanto espera-se que dias de alta 


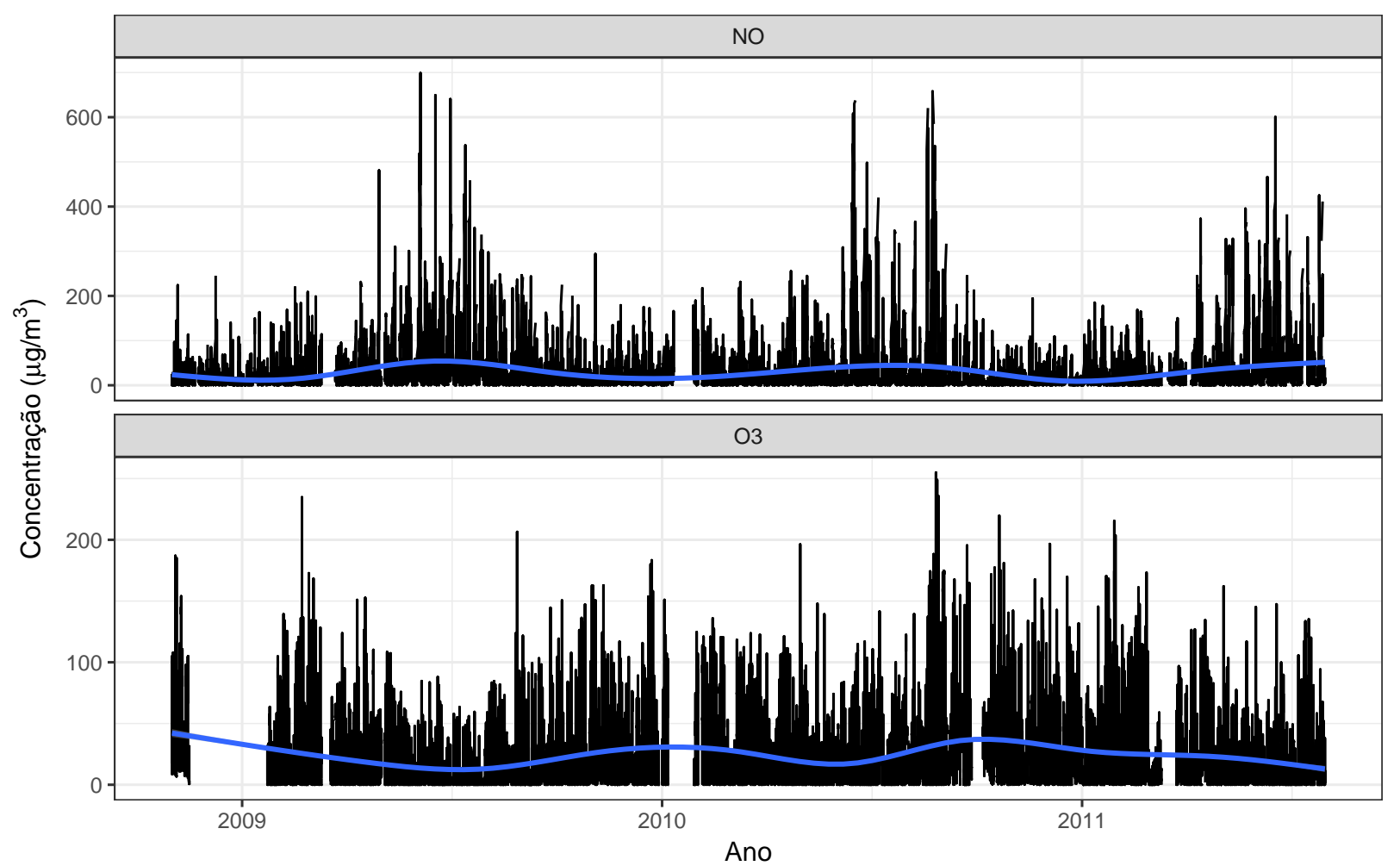

Figura 2.5: Séries horárias de ozônio e de óxido de nitrogênio (NO), ambos medidos na estação Dom Pedro II, em São Paulo, no período de 2008 a 2011. Em azul, as séries suavizadas usando splines cúbicos.

concentração de ozônio tenham baixa concentração de NO e vice-versa.

Apresentamos agora, na Figura 2.7, o gráfico de dispersão da concentração de ozônio contra a concentração de dióxido de nitrogênio, ambas também medidas das 12 às 16 horas, de 2008 a 2011. Observe que não há indícios de associação entre as duas variáveis. No entanto, sabe-se que a fotólise do $\mathrm{NO}_{2}$ pela manhã faz parte do processo gerador do ozônio ao longo da tarde. Na Figura 2.8, apresentamos o gráfico de dispersão da concentração de ozônio, medida à tarde, contra a concentração e dióxido de nitrogênio, agora medida pela manhã, das 7 às 11 horas. Observe que, neste caso, encontramos indícios de uma relação positiva entre as duas variáveis.

Uma limitação dos gráficos de dispersão é não levar em conta o efeito de outras variáveis. Muitas vezes a associação entre duas variáveis pode ser induzida ou mascarada pela ação de uma terceira. Portanto, é importante termos em mente que a interpretação desses gráficos nos dá apenas indícios sobre a associação, que devem ser estudados com mais atenção, eliminando o possível efeito de outras variáveis.

\subsubsection{Gráficos de distribuição}

Muitas vezes queremos observar a distribuição amostral de uma variável. Um gráfico muito comum nesses casos é o histograma. Na Figura 2.9, apresentamos o histograma da concentração diária média medida de ozônio das 12 às 16 horas, em São Paulo, de 2008 a 2013. Podemos observar que a distribuição amostral é levemente assimétrica à direita, sendo que mais de $70 \%$ dos dias apresenta concentração de ozônio entre 25 e $75 \mu \mathrm{g} / \mathrm{m}^{3}$.

Quando queremos, além de observar a distribuição amostral da variável resposta, compará-la entre os níveis de uma variável explicativa, podemos utilizar os boxplots. A partir dos quantis da 


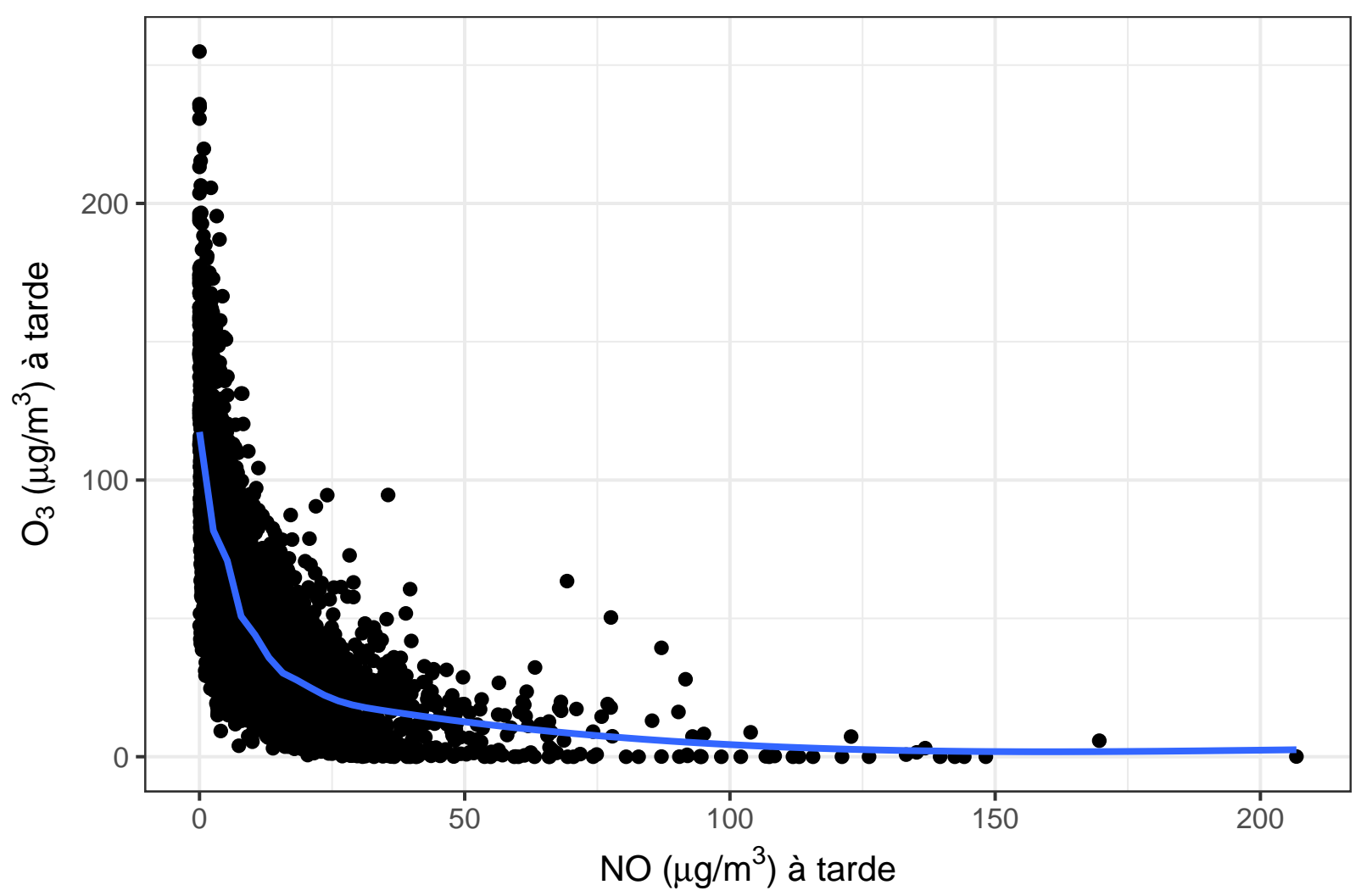

Figura 2.6: Gráfico de dispersão da concentração de ozônio contra a concentração de óxido de nitrogênio medidas das 12 às 16 horas na estação de monitoramento Dom Pedro II, em São Paulo, de 2008 a 2011.

variável resposta, esses gráficos dão uma ideia geral da sua distribuição, para cada nível da variável explicativa. Eles também nos mostram a presença de pontos atípicos, isto é, observações com valores muito abaixo ou muito acima dos valores medianos. Os chamados ridgelines plots são outra boa alternativa para comparar a distribuição amostral de uma variável para cada nível de um preditor. Eles são histogramas suavizados e trazem mais informação sobre a forma da distribuição do que os boxplots. Na Figura 2.10, apresentamos um exemplo desses gráficos. Podemos observar que as máximas de ozônio ocorrem nos meses mais quentes, sendo esses os períodos também de maior variação, provavelmente devido ao efeito conjunto da temperatura e da chuva.

Os gráficos apresentados até aqui podem gerar bastante conhecimento sobre o comportamento do fenômeno sob estudo, mas seria interessante dispormos de medidas mais objetivas. Nas próximas seções, discutiremos os conceitos de estacionariedade e autocorrelação e como identificar essas características. Além disso, apresentaremos estratégias para conduzir a análise na presença de tendência e sazonalidade.

\subsection{Componentes temporais}

Imagine, por exemplo, que estamos investigando a associação da concentração de monóxido de carbono com o número de carros rodando no horário de pico na cidade de São Paulo. Sabemos que, historicamente, os níveis de monóxido de carbono vêm diminuindo, enquanto o número de carros na cidade de São Paulo tende a aumentar. Se não utilizarmos outras variáveis como controle, nossa investigação pode concluir que o aumento do número de carros está diminuindo os níveis do 


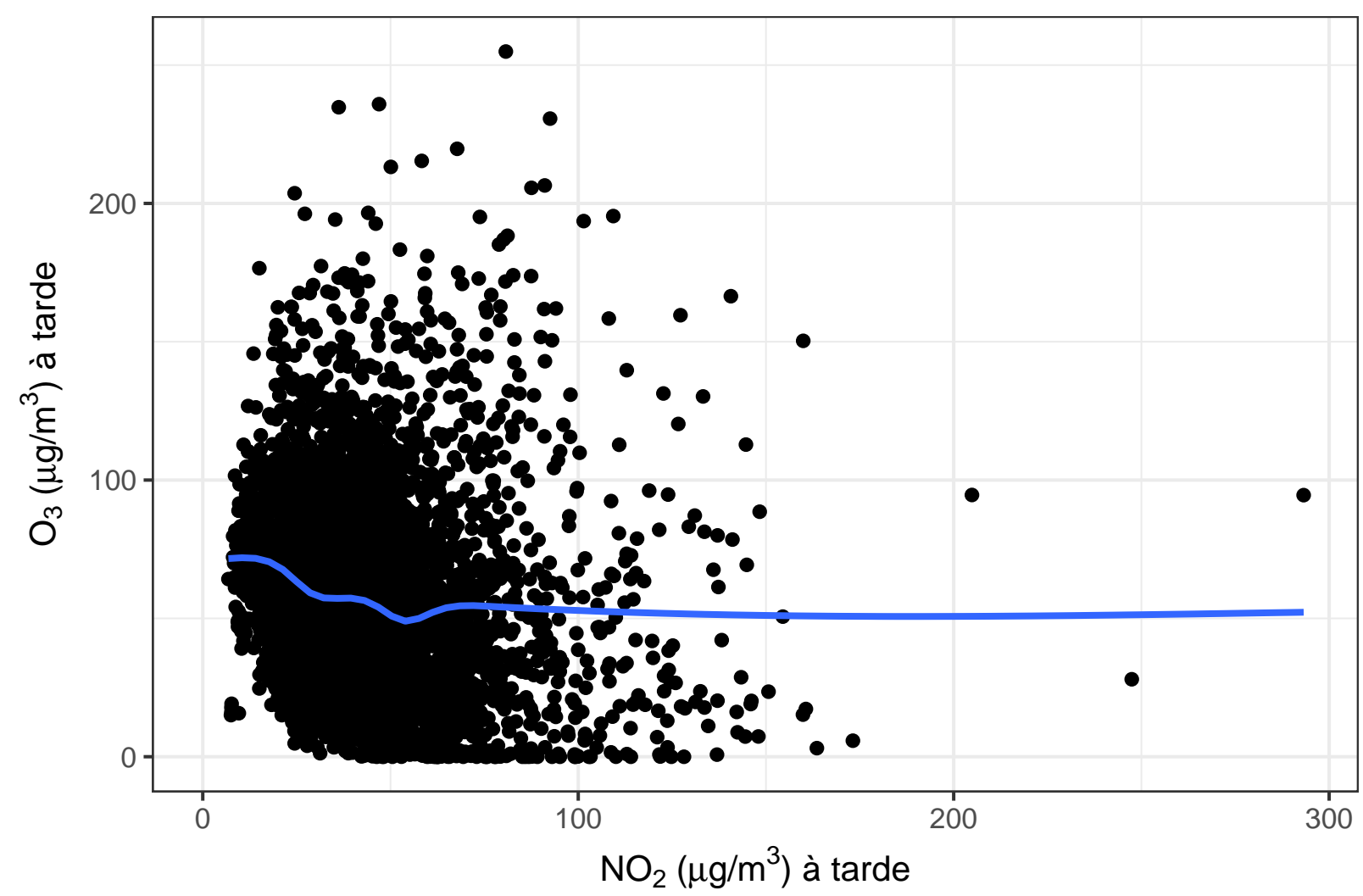

Figura 2.7: Gráfico de dispersão da concentração de ozônio contra a concentração de dióxido de nitrogênio medidas das 12 às 16 horas na estação de monitoramento Dom Pedro II, em São Paulo, de 2008 a 2011.

poluente, o que não faria sentido prático pois sabemos que existe uma associação positiva entre as variáveis. Na realidade, a diminuição histórica do monóxido de carbono se deve às regulamentações dos combustíveis e ao aumento da eficiência dos motores veiculares. Como podemos não ter dados disponíveis para incorporar essa informação no modelo, essa tendência decrescente da série precisa ser eliminada ou controlada de alguma forma. Só assim conseguiremos quantificar corretamente o efeito do número de carros na concentração de monóxido de carbono.

Tendências são os componentes temporais mais comuns em séries de tempo. Outro componente muito frequente é sazonalidade, que representa comportamento cíclicos em intervalos fixos de tempo. Em estudos de poluição, as estações do ano são a principal causa de sazonalidade.

A seguir discutiremos como identificar e eliminar esses componentes de uma série. No Capítulo 3 , discutiremos como controlá-las incorporando termos de tendência e sazonalidade ao modelo.

\subsubsection{Tendência}

A tendência de uma série pode ser eliminada pela utilização da série de diferenças. A diferença de primeira ordem é definida como

$$
\Delta Y_{t}=Y_{t}-Y_{t-1}, \quad t=1,2, \ldots
$$

Ela é utilizada para eliminar uma tendência linear de uma série. A ordem da diferença está associada ao grau da tendência. No caso de uma tendência quadrática, por exemplo, podemos utilizar a diferença de segunda ordem 


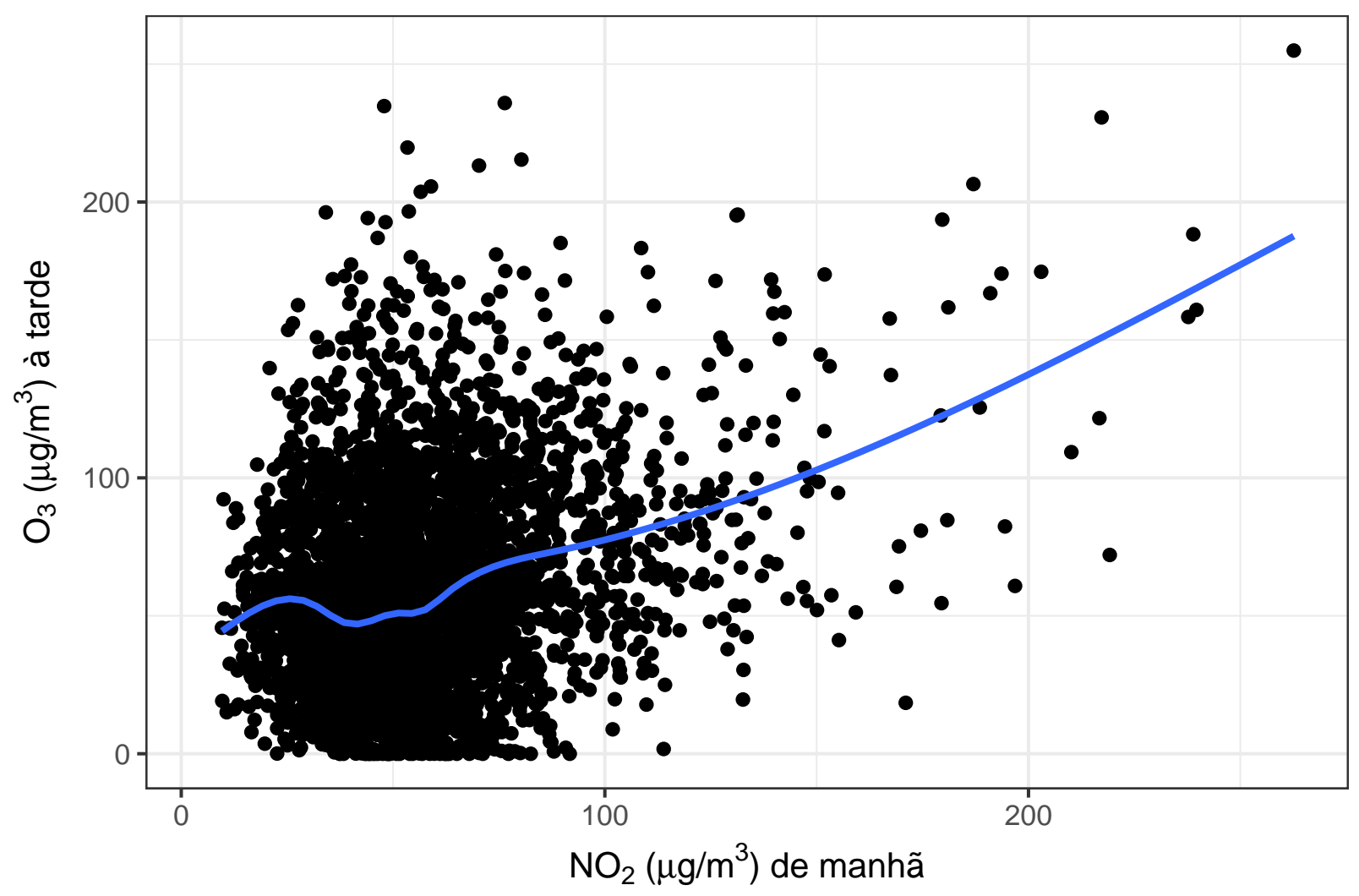

Figura 2.8: Gráfico de dispersão da concentração de ozônio, medida das 12 às 16 horas, contra a concentração de óxido de nitrogênio, medida das 7 às 11 horas, na estação de monitoramento Dom Pedro II, em São Paulo, de 2008 a 2011.

$$
\Delta^{2} Y_{t}=\Delta Y_{t}-\Delta Y_{t-1}, \quad t=1,2, \ldots
$$

No caso geral, definimos a diferença de ordem $n$ como

$$
\Delta^{n} Y_{t}=\Delta^{n-1} Y_{t}-\Delta^{n-1} Y_{t-1}, \quad t=1,2, \ldots
$$

$\mathrm{Na}$ prática, dificilmente encontramos séries com tendência de grau maior que 2, então a diferença de primeiro grau é geralmente suficiente para alcançar a estacionariedade.

Como exemplo, observe a Figura 2.11. No painel (a), temos a série da concentração diária média de ozônio, em que podemos observar uma leve tendência linear positiva, isto é, a concentração média parece crescer com o tempo. No painel (b), apresentamos o gráfico da série de diferenças (primeira ordem). Podemos observar que a série já não apresenta qualquer tendência linear.

Uma desvantagem de se utilizar a série de diferenças é a interpretação do modelo, já que a variável resposta ajustada terá sido a diferença entre duas observações consecutivas. As conclusões para essa nova variável podem não ser de interesse.

\subsubsection{Sazonalidade}

Em geral, o gráfico da série é suficiente para a identificação de sazonalidade. No entanto, em alguns casos, outras variáveis podem mascarar o efeito sazonal, sendo difícil identificar esse compo- 


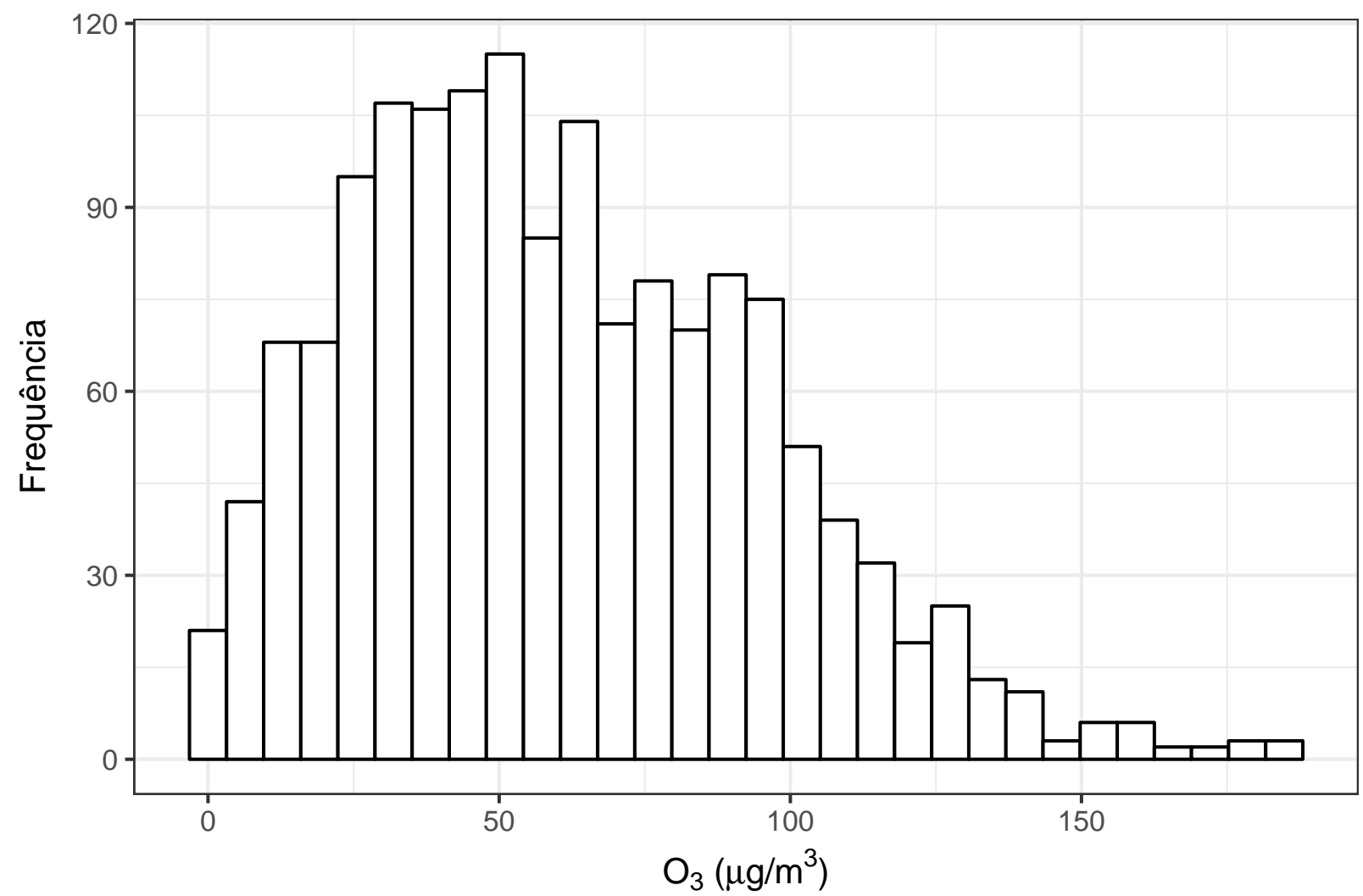

Figura 2.9: Histograma da concentração diária média de ozônio medida das 12 às 16 horas na estação de monitoramento Dom Pedro II, na cidade de São Paulo, de 2008 a 2013.

nente apenas observando o gráfico. Assim, é sempre recomendável a construção de um periodograma para auxiliar a identificação da sazonalidade.

Toda série temporal pode ser decomposta em uma soma de ondas senoidais, com frequências e amplitudes diferentes (Shumway e Stoffer, 2006). Para um conjunto de ondas de frequências diferentes e fixadas a priori, podemos calcular quais são as amplitudes de cada uma dessas ondas para que a soma delas gere a série original. Podemos então definir uma medida de associação linear entre a série original e cada uma das ondas senoidais. Essa medida, chamada de densidade espectral, é proporcional à amplitude calculada para cada onda. Assim, quanto maior a densidade espectral associada a uma determinada frequência, maior será a importância dessa frequência para explicar a periodicidade da série. O periodograma é justamente um gráfico da densidade espectral em função das frequências.

Na Figura 2.12, apresentamos o periodograma da série horária de ozônio da cidade de São Paulo de 2008 a 2013. Podemos observar que o período ${ }^{4}$ mais importante para explicar a periodicidade da série corresponde a um dia, isto é, o periodograma aponta sazonalidade diária, o que é esperado se observarmos a Figura 2.2.

Existem na literatura técnicas para remover o componente sazonal de uma série (Morettin e Toloi, 2004), mas esse tópico não será abordado aqui. Nosso foco será ajustar modelos que contemplem o componente sazonal, como veremos no Capítulo 3.

Para mais informações sobre tendência e sazonalidade, recomendamos a leitura do primeiro capítulo de Shumway e Stoffer (2006).

\footnotetext{
${ }^{4} \mathrm{O}$ período é o inverso da frequência.
} 

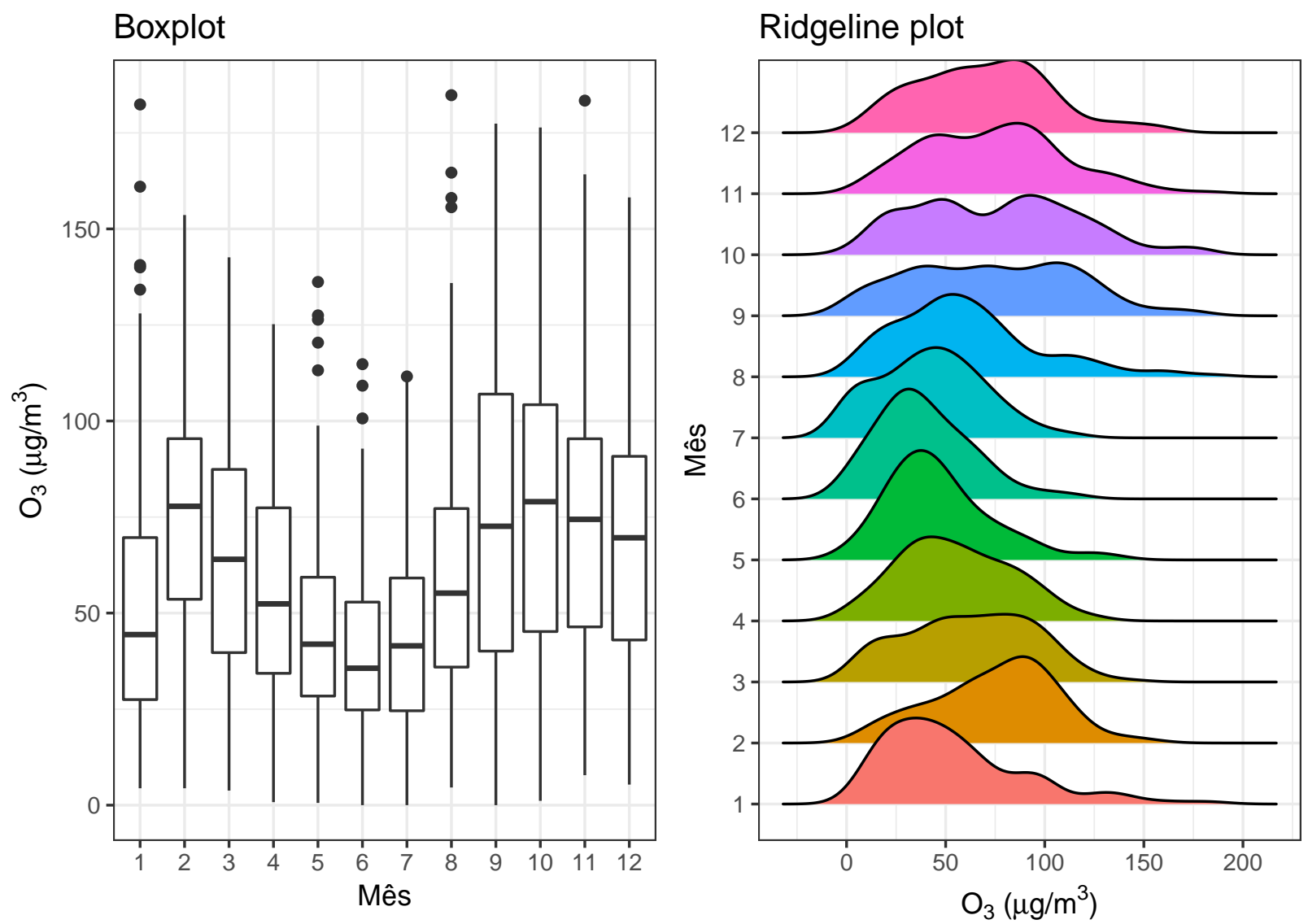

Figura 2.10: Distribuição por mês da concentração diária média de ozônio medida das 12 às 16 horas na estação de monitoramento Dom Pedro II, na cidade de São Paulo, de 2008 a 2013.

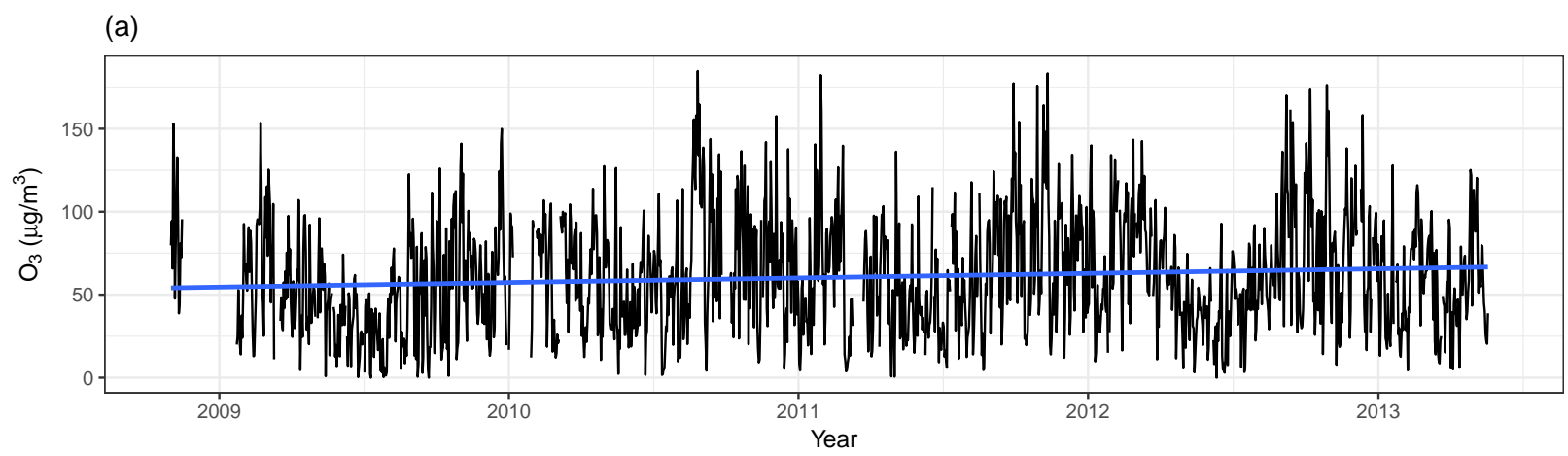

(b)

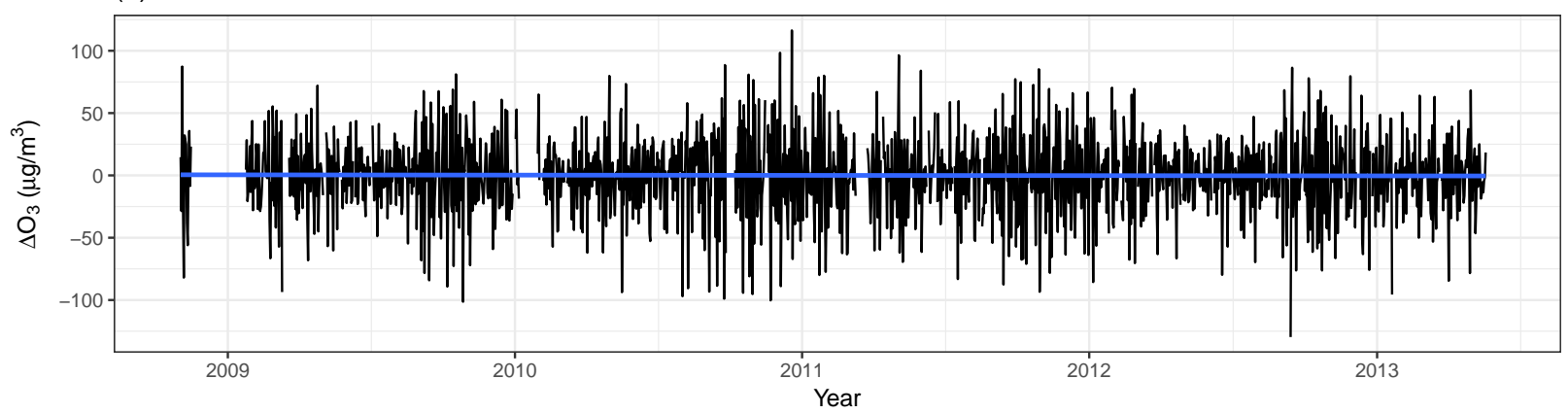

Figura 2.11: Série da concentração de ozônio diária média, medida na cidade de São Paulo (estação de monitoramento Dom Pedro II), no período de outubro de 2008 a junho de 2011, das 12h às 16h. 
(a)

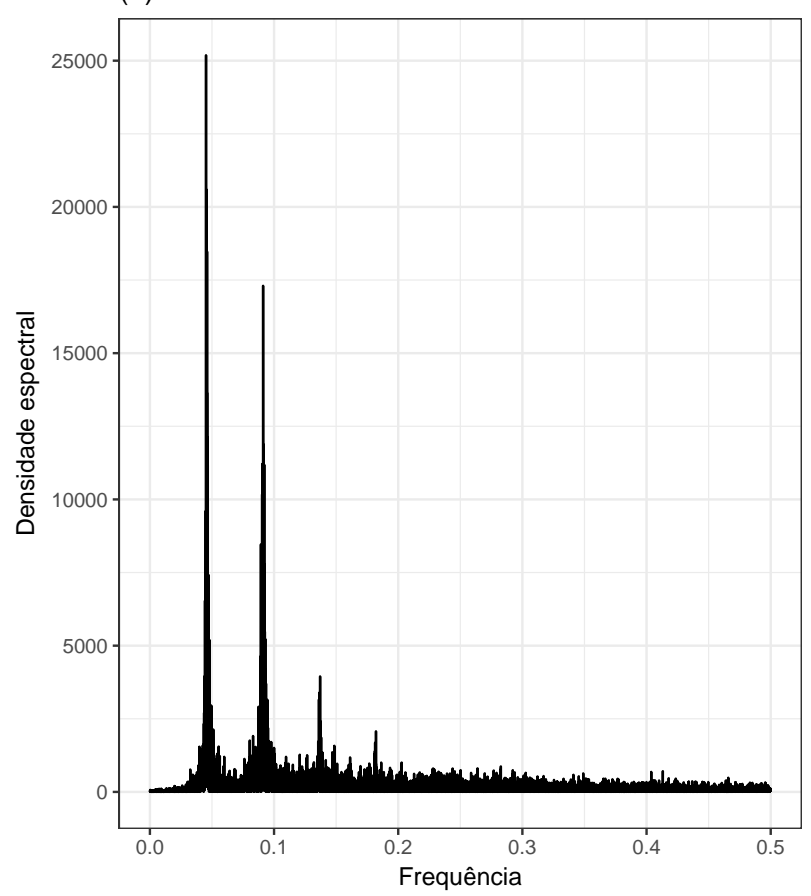

(b)

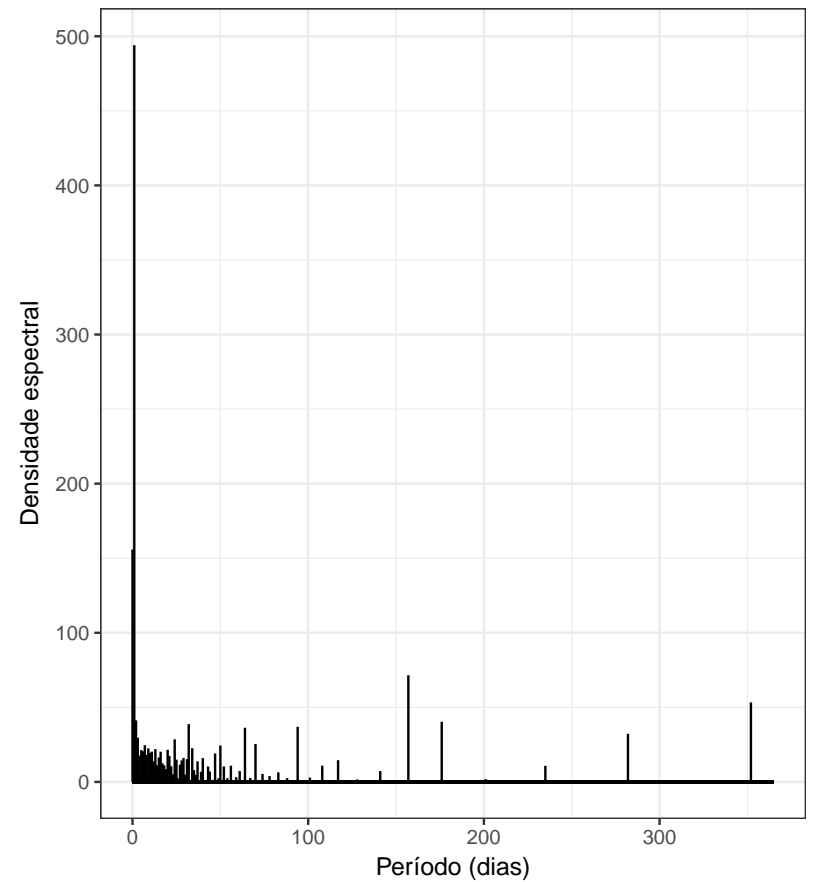

Figura 2.12: Periodogramas para a concentração horária de ozônio medida na cidade de São Paulo (estação de monitoramento Dom Pedro II), no período de outubro de 2008 a junho de 2013. Dados disponibilizados por Salvo e Geiger (2014). No painel (a), apresentamos a densidade espectral contra a frequência. No painel (b), resumimos a densidade espectral por periodo, apresentado em dias.

\subsubsection{Autocorrelação}

É natural supormos a existência de algum grau de associação entre as observações de uma série temporal coletadas em instantes próximos. Por exemplo, considere a concentração de um poluente medida às nove da manhã em uma certa localidade. Se o valor observado foi alto, as concentrações às oito e às dez da manhã provavelmente também foram altas. Essa informação extraída de $Y_{t}$ sobre o valor das observações anteriores, $Y_{t-1}, Y_{t-2}, \ldots$, ou das seguintes, $Y_{t+1}, Y_{t+2}, \ldots$, é chamada de autocorrelação ou, neste contexto, correlação temporal.

Dependendo da forma como as observações estão associadas, podemos definir diferentes tipos de correlação. Uma das medidas mais simples e mais utilizadas na prática se chama correlação linear. Ela supõe que a relação entre as observações pode ser descrita por uma função linear, ou seja, invariante com o valor das observações ${ }^{5}$. Quando outro tipo de relação não for especificada, essa será a definição utilizada neste trabalho para descrevermos a correlação temporal entre as observações.

A autocorrelação de uma série pode ser representada pela função de autocorrelação, digamos $\rho(s, t)$, que mede a previsibilidade da série no instante $t$, a partir apenas do valor da variável no instante $s$. Essa medida varia no intervalo $[-1,1]$, com os extremos representando uma correlação perfeita entre as observações $Y_{t}$ e $Y_{s}$. Se $Y_{t}$ pode ser perfeitamente predita por $Y_{s}$ por meio de uma função linear, então a autocorrelação será 1, se a associação for positiva, ou -1, se a associação for negativa.

Fazendo $h=t-s$, a função de autocorrelação pode ser estimada por

\footnotetext{
${ }^{5}$ Para mais detalhes sobre a interpretação de linearidade, consulte a Seção 3.1.5.
} 


$$
\rho(0, h)=\rho(h)=\frac{\gamma(h)}{\gamma(0)}
$$

sendo

$$
\gamma(h)=\frac{1}{n} \sum_{t=1}^{n-h}\left(y_{t+h}-\bar{y}\right)\left(y_{t}-\bar{y}\right)
$$

a função de autocovariância amostral, $y_{t}$ o valor observado no instante $t$ e $\bar{y}=\frac{1}{n} \sum_{t=1}^{n} y_{t}$ a média amostral.

Na Figura 2.13, apresentamos a função de autocorreção da concentração de ozônio medida na estação Parque Dom Pedro II. Podemos observar que a autocorrelação é sempre positiva e não decai para o zero, indicando que a série apresenta tendência. Em caso contrário, esperaríamos que apenas observações próximas fossem correlacionadas, e então a função de autocorrelação convergiria rapidamente para zero conforme aumentássemos o valor de $h$.

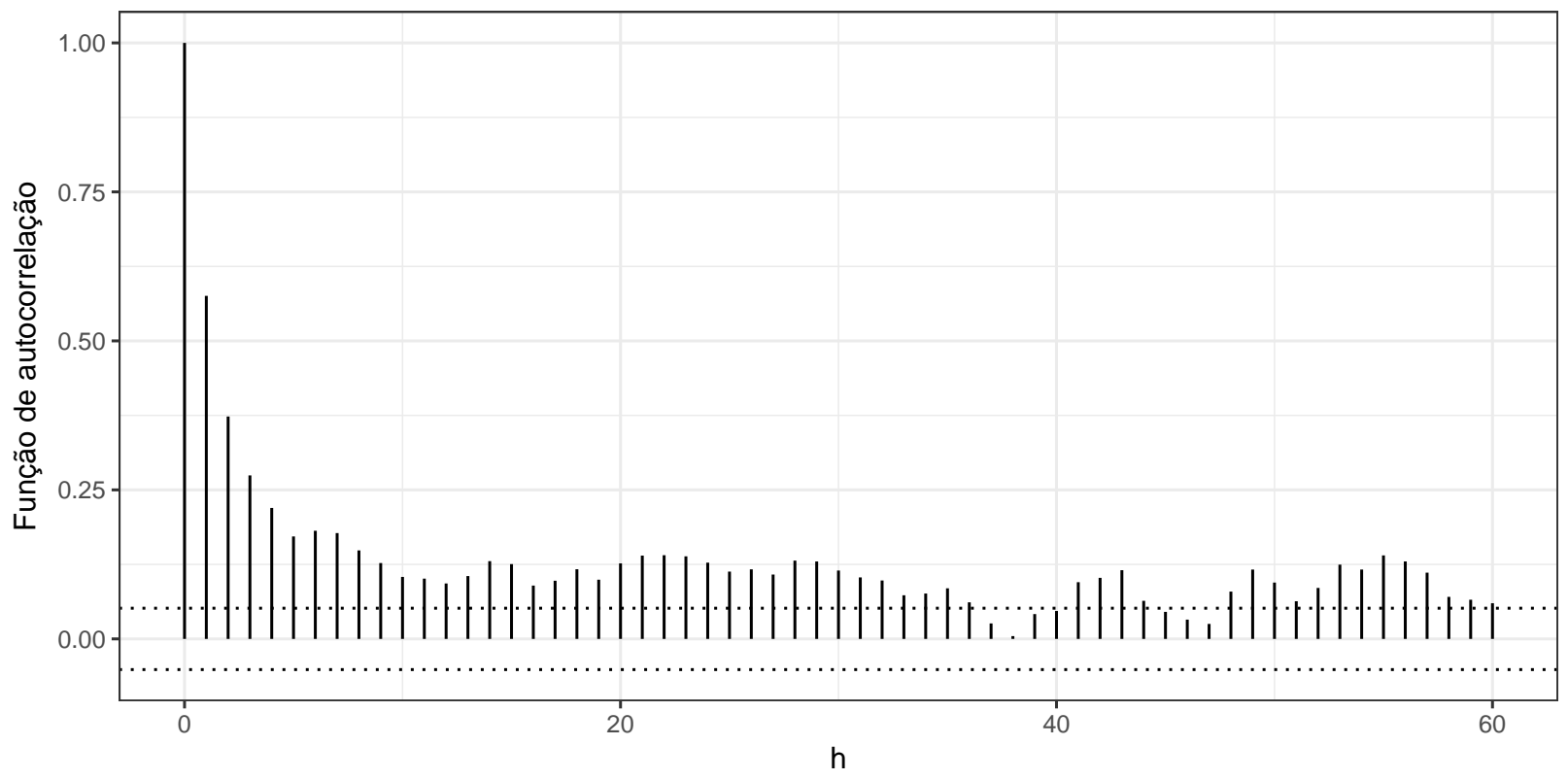

Figura 2.13: Função de autocorreção da concentração de ozônio diária média, medida na cidade de São Paulo (estação de monitoramento Dom Pedro II), no período de outubro de 2008 a junho de 2011, das 12h às 16h. Dados disponibilizados por Salvo e Geiger (2014). As linhas pontilhadas representam os limites $\pm 2 / \sqrt{n}$, sendo $n$ o tamanho da amostra. Valores fora desse intervalo de confiança (95\%) podem ser considerados significantemente diferentes de zero.

Note que se as observações $Y_{t}$ e $Y_{t-1}$ são correlacionadas, e da mesma forma as observações $Y_{t-1}$ e $Y_{t-2}$, parte da correlação entre $Y_{t}$ e $Y_{t-2}$ pode ser explicada por $Y_{t-1}$. Como a função de autocorrelação nos dá a correlação total entre $Y_{t}$ e $Y_{t-2}$, independentemente do fato de parte dela poder ser explicada por $Y_{t-1}$, se quisermos encontrar apenas a variabilidade explicada por $Y_{t-2}$ precisamos utilizar a função de autocorrelação parcial. No caso geral, essa função mede a correlação entre as observações $Y_{t}$ e $Y_{t-m}$, controlando pelas observações intermediárias $Y_{t-1}, Y_{t-2}, \ldots, Y_{t-m+1}$.

Na Figura 2.14, apresentamos a função de autocorreção parcial da concentração de ozônio, como no exemplo anterior. Podemos observar agora que a maioria das defasagens são não significativas. Mesmo assim, ainda encontramos algumas defasagens altas significativas, indicando que a série 
realmente apresenta alguma tendência.

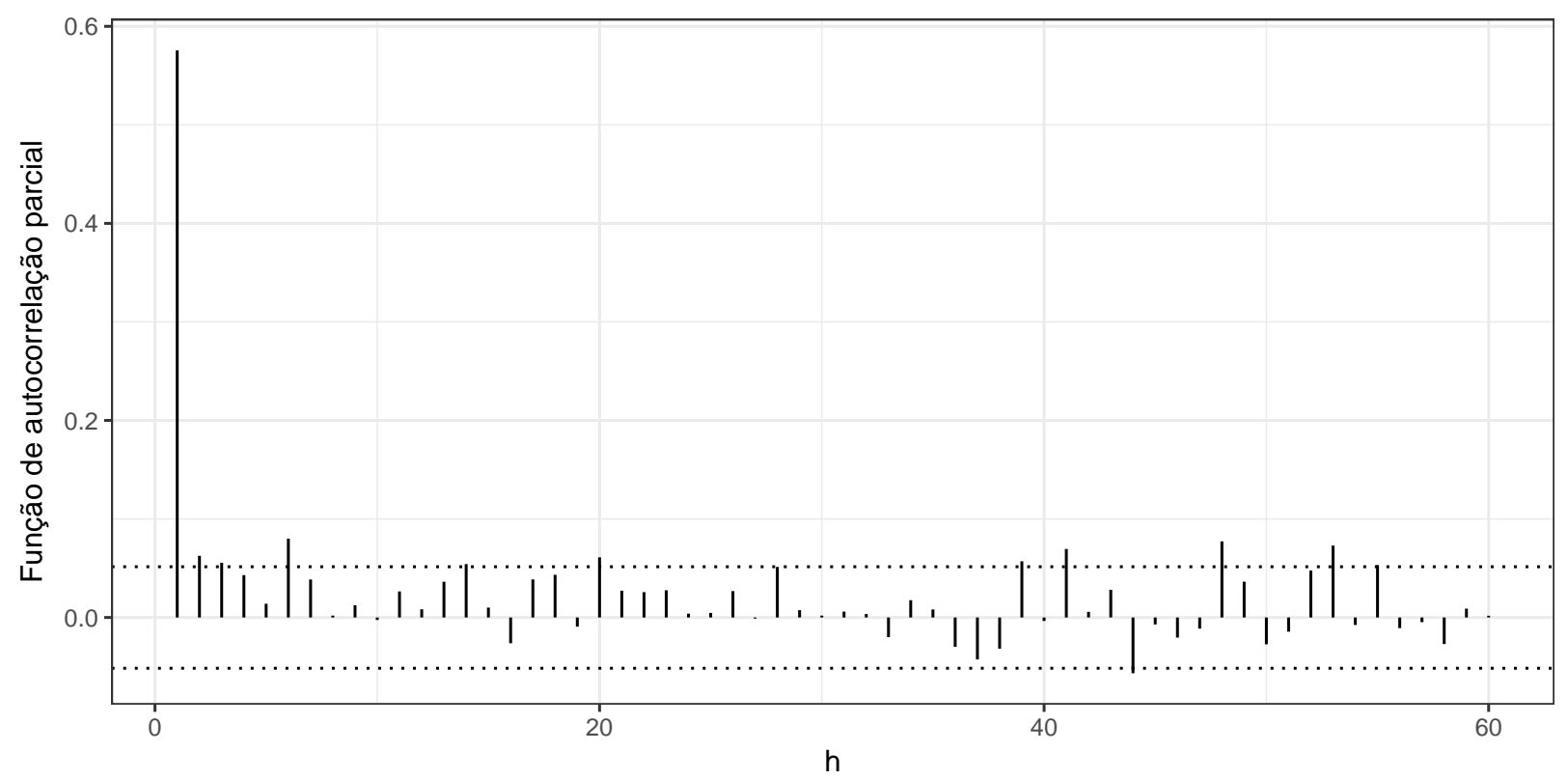

Figura 2.14: Função de autocorreção parcial da concentração de ozônio diária média, medida na cidade de São Paulo (estação de monitoramento Dom Pedro II), no periodo de outubro de 2008 a junho de 2011, das $12 \mathrm{~h}$ às $16 \mathrm{~h}$. As linhas pontilhadas representam os limites $\pm 2 / \sqrt{n}$, sendo $n$ o tamanho da amostra. Valores fora desse intervalo de confiança (95\%) podem ser considerados significativamente diferentes de zero.

Até agora discutimos como avaliar a correlação entre observações defasadas de uma mesma série. A seguir, vamos discutir como avaliar a associação entre observações de duas ou mais séries.

\subsubsection{Função de correlação cruzada}

Muitas vezes, queremos avaliar a previsibilidade de uma determinada série $Y_{t}$ a partir de outra série, digamos $X_{s}$. Nesse caso, utilizamo a função de correlação cruzada, que pode ser estimada por

$$
\rho_{x y}(h)=\frac{\gamma_{x y}(h)}{\sqrt{\gamma_{x}(0) \gamma_{y}(0)}}
$$

com $\gamma .(h)$ como definido em (2.2) e

$$
\gamma_{x y}(h)=\frac{1}{n} \sum_{t=1}^{n-h}\left(x_{t+h}-\bar{x}\right)\left(y_{t}-\bar{y}\right)
$$

a função de covariância cruzada amostral. Essa expressão nos dá a relação entre $Y_{t}$ e $X_{t+h}$, para todo $t \geq 0$. Assim, valores positivos de $h$ revelam o quanto $Y_{t}$ antecipa $X_{t+h}$ e valores negativos de $h$ o quanto $X_{t+h}$ antecipa $Y_{t}$. Repare que $\rho_{X Y}(h)=\rho_{Y X}(-h)$.

Em estudos de poluição do ar, é muito comum a inclusão de variáveis defasadas na análise. Essas variáveis representam fenômenos que antecipam a formação de um poluente ou a ocorrência de doenças. Uma chuva no período da manhã, por exemplo, além de alterar o trânsito, pode diminuir a concentração de poluentes no começo da tarde. Altos níveis de poluentes em um determinado dia, podem aumentar o número de internações por problemas respiratórios dias ou até semanas depois.

A identificação de quais variáveis defasadas devem entrar na análise pode ser uma tarefa difícil, 
principalmente quando existe muita incerteza sobre o processo de geração do fenômeno sob estudo. A função de correlação cruzada é uma boa alternativa neste caso. Com ela, podemos avaliar quais são os valores da defasagem $h$ que geram maior correlação entre as séries e utilizá-los para definir as variáveis defasadas.

A Figura 2.15 apresenta a função de correlação cruzada do ozônio contra a temperatura na estação Parque Dom Pedro II. Ambas as medidas são horárias. Observamos que a maior correlação (após a defasagem zero) é na defasagem -1, isto é, a concentração de ozônio parece ser altamente associada com a temperatura medida uma hora antes. Assim, a temperatura no instante $t-1$ é uma boa candidata para ser incluída no modelo.

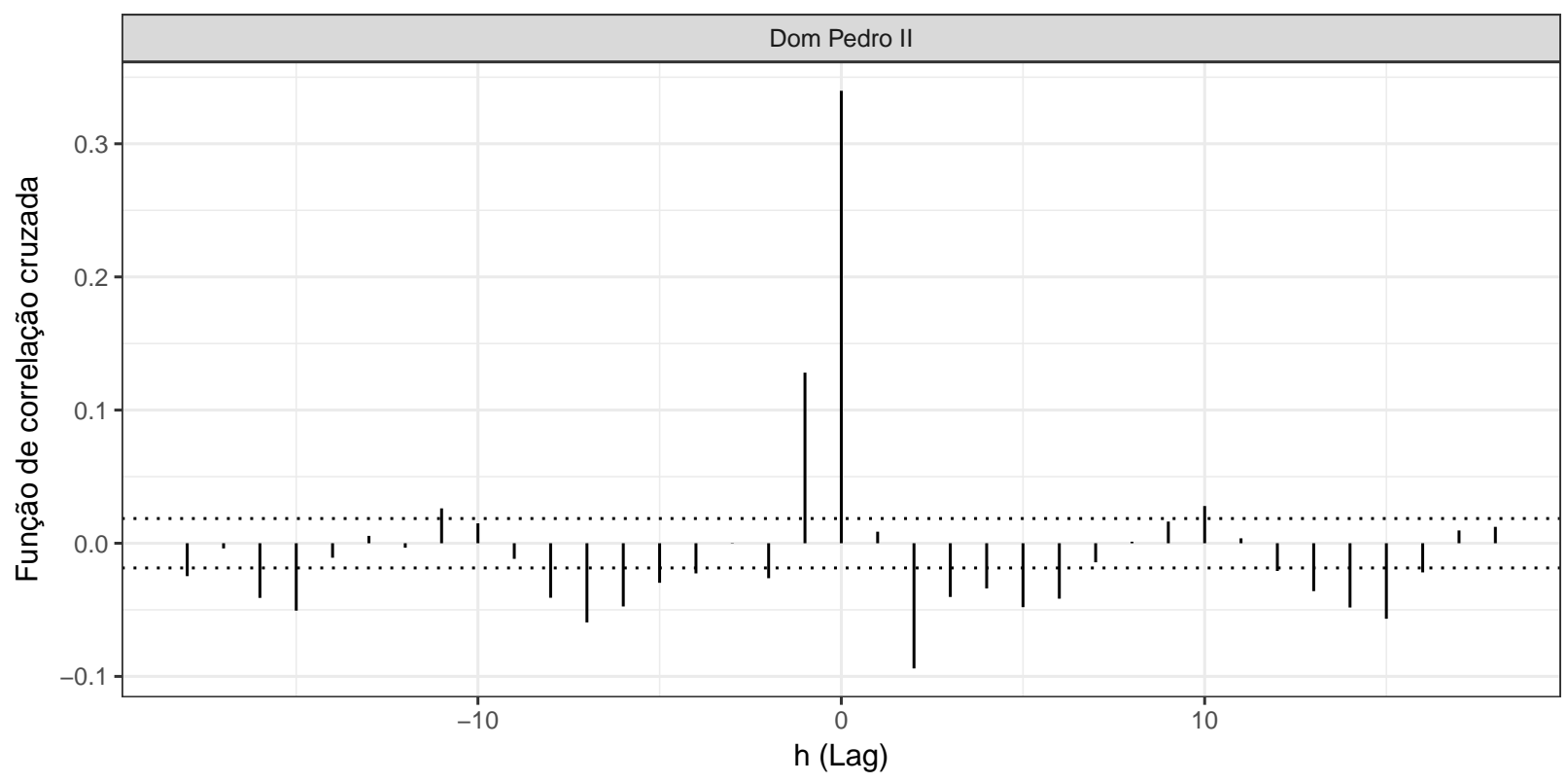

Figura 2.15: Função de correlação cruzada do ozônio em função da temperatura na estação Dom Pedro II (São Paulo) no período de outubro de 2009 a junho de 2011. As linhas pontilhadas representam os limites $\pm 2 / \sqrt{n}$, sendo $n$ o tamanho da amostra. Valores fora desse intervalo de confiança (95\%) podem ser considerados significativamente diferentes de zero.

Em alguns casos, quando o fenômeno associado não varia muito no tempo, podemos considerar a média de um certo intervalo como variável defasada. Pela Figura 2.15, observamos uma certa correlação entre o ozônio e a temperatura nas defasagens de -5 a -8. Assim, a média da temperatura medida entre $t-8$ e $t-5$ também poderia ser incluída no modelo.

As técnicas abordadas até aqui podem ser utilizadas para obter um conhecimento inicial sobre o fenômeno estudado, auxiliando-nos a escolher a melhor estratégia de modelagem. No próximo capítulo, apresentaremos os principais modelos utilizados em análises envolvendo poluição do ar.

\subsection{Visualizando dados de poluição durante a greve de caminhoneiros}

A greve dos caminhoneiros foi como ficou conhecida a paralisação de caminhoneiros autônomos em todo o território brasileiro em maio de 2018. As manifestações começaram no dia 21 de maio e duraram até o início de junho. Nesse período, muitas cidades sofreram com desabastecimento, principalmente de combustível, diminuindo não apenas o tráfego de veículos pesados, mas também de automóveis. Como as emissões veiculares são a principal fonte de diversos poluentes em centros 
urbanos, seria interessante analisarmos o impacto dessas paralisações nos níveis de poluição.

Utilizando os dados disponibilizados pela Companhia de Ambiental do Estado de São Paulo (CETESB), analisamos a concentração de alguns poluentes entre os dias 23 e 30 de maio ${ }^{6}$ na região metropolitana de São Paulo. Os poluentes considerados foram: monóxido de carbono (CO), ozônio $\left(\mathrm{O}_{3}\right)$, monóxido e dióxido de nitrogênio $\left(\mathrm{NO}\right.$ e $\left.\mathrm{NO}_{2}\right)$ e material particulado 10 (MP10). Também consideramos períodos anteriores e posteriores à greve, para avaliar a mudança causada pelas paralisações, e os mesmos dias em anos anteriores, em que não houve greve. O período total analisado foi de $1^{0}$ de maio a 14 de junho, dos anos de 2016, 2017 e 2018.

As concentrações de cada poluente foram medidas em estações de monitoramento da CETESB: Osasco, Pinheiros, Parque Dom Pedro II e Ibirapuera. O critério para a escolha foi a disponibilidade de dados para os poluentes escolhidos e o perfil do tráfego de veículos na região das estações. As estações Parque Dom Pedro II e Pinheiros ficam em regiões de tráfego intenso, a primeira no centro da cidade e a segunda próxima à marginal Pinheiros, via expressa que liga as zonas sul, oeste e norte. A estação de Osasco também fica numa região de tráfego intenso e relativamente próxima a duas rodovias. A estação Ibirapuera não é muito afetada pelo tráfego pois fica dentro do Parque Ibirapuera e será utilizada como comparação.

Para construir os gráficos das séries, utilizamos a Figura 2.16 para avaliar a média horária de cada poluente em cada dia da semana. Assim, em vez de utilizarmos as séries horárias, que apresentam sazonalidade diária, construímos as séries da média diária nos horários de pico. Esse gráfico mostra, por exemplo, que os picos de CO acontecem de manhã e no começo da noite e que os níveis desse poluente são bem menores nos fins de semana.

Na Tabela 2.1, apresentamos a variação da média dos poluentes em cada estação no período de greve em relação à média nos períodos anterior e posterior à greve. Nas Figuras 2.17, 2.18, 2.19, 2.20 e 2.21 apresentamos, respectivamente, as séries para o monóxido de carbono, o ozônio, o monóxido e dióxido de nitrogênio e para o material particulado. Observamos que, com exceção do ozônio, a concentração média dos poluentes durante o período de paralisação diminuiu. A maior redução foi a de NO, que é diretamente produzido pela queima de combustíveis, principalmente gasolina e diesel.

O ozônio é produto de um complexo processo químico que ocorre ao longo do dia, envolvendo diversos compostos e a radiação solar, sendo que uma explicação para o aumento de sua concentração durante a greve pode ser dada pela diminuição dos níveis de NO. O NO faz parte do balanço diário do ozônio, consumindo-o ao longo da tarde e diminuindo suas concentrações. Como o NO diminuiu devido a redução do tráfego de veículos, menos ozônio era consumido e por isso o aumento na concentração.

Esta análise considera apenas as séries durante o período de greve para explicar a variação da concentração dos poluentes. Uma análise mais completa deveria considerar também os efeitos climáticos (temperatura, precipitação, vento, radiação, entre outros). As conclusões aqui supõem que esses fatores se mantiveram homogêneos durante o período analisado, o que pode não ser razoável. Mais resultados podem ser encontrados em https://www.rpollution.com/blog/greve-caminhoneiros/.

\footnotetext{
${ }^{6}$ Período em que as consequências das paralisações foram mais intensas.
} 


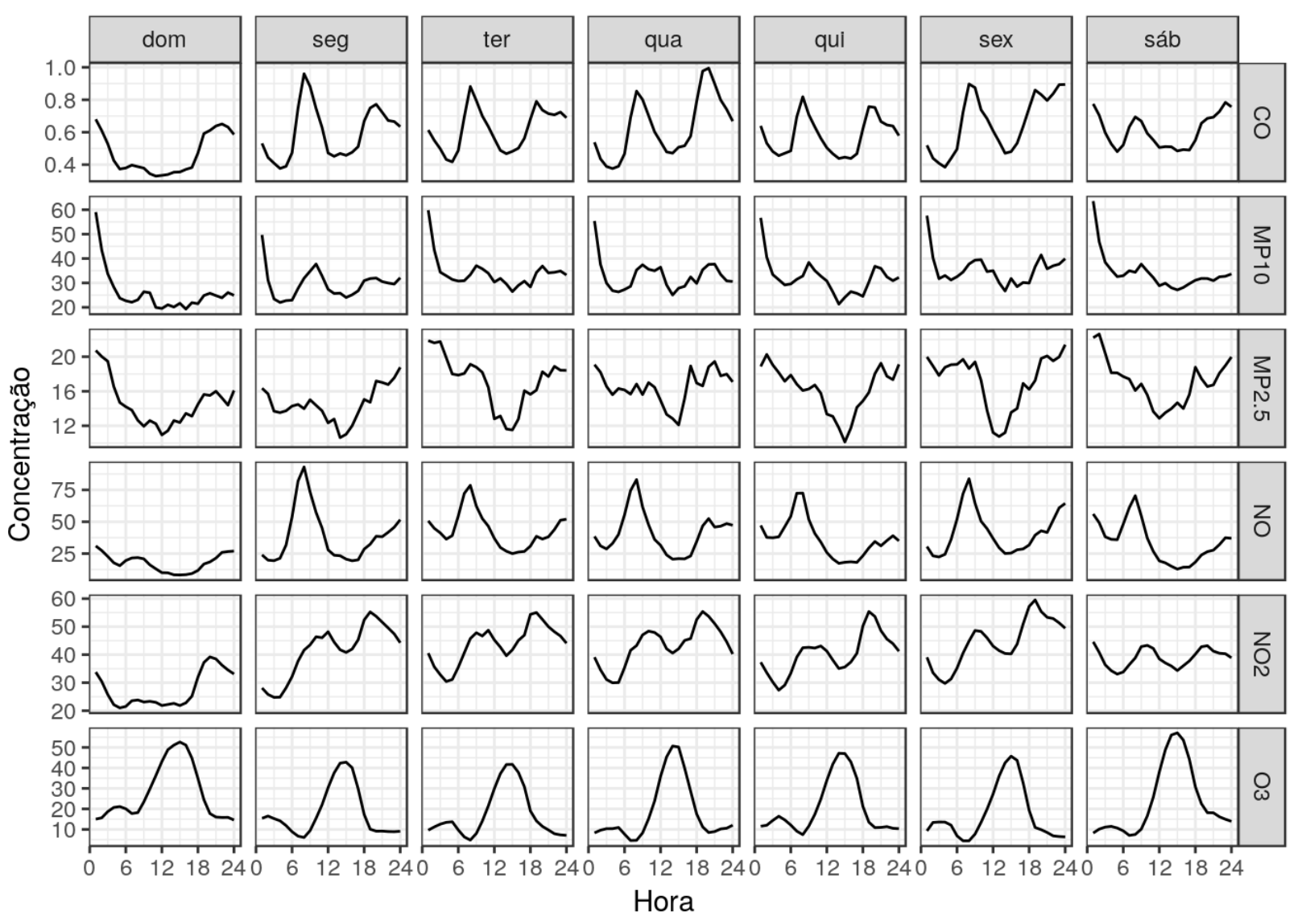

Figura 2.16: Médias por hora e dia da semana durante todo o período observado para cada poluentes considerado na análise.

Tabela 2.1: Variação da média dos poluentes em cada estação no período de greve em relação à média nos periodos anterior e posterior à greve

\begin{tabular}{c|c|c|c|c}
\hline Poluente & Ibirapuera & Osasco & $\begin{array}{c}\text { Parque D. } \\
\text { Pedro II }\end{array}$ & Pinheiros \\
\hline $\mathrm{CO}$ & $-48.02 \%$ & $-32.78 \%$ & $-51.16 \%$ & $-65.9 \%$ \\
$\mathrm{O}_{3}$ & $53.7 \%$ & N/A & $68.43 \%$ & $126 \%$ \\
$\mathrm{NO}$ & $-89.66 \%$ & $-50.9 \%$ & $-75.38 \%$ & $-83.09 \%$ \\
$\mathrm{NO}_{2}$ & $-42.49 \%$ & $-13.24 \%$ & $-38.73 \%$ & $-39.45 \%$ \\
$\mathrm{MP} 10$ & $\mathrm{~N} / \mathrm{A}$ & $-19.1 \%$ & $-19.06 \%$ & $-20.06 \%$ \\
\hline
\end{tabular}



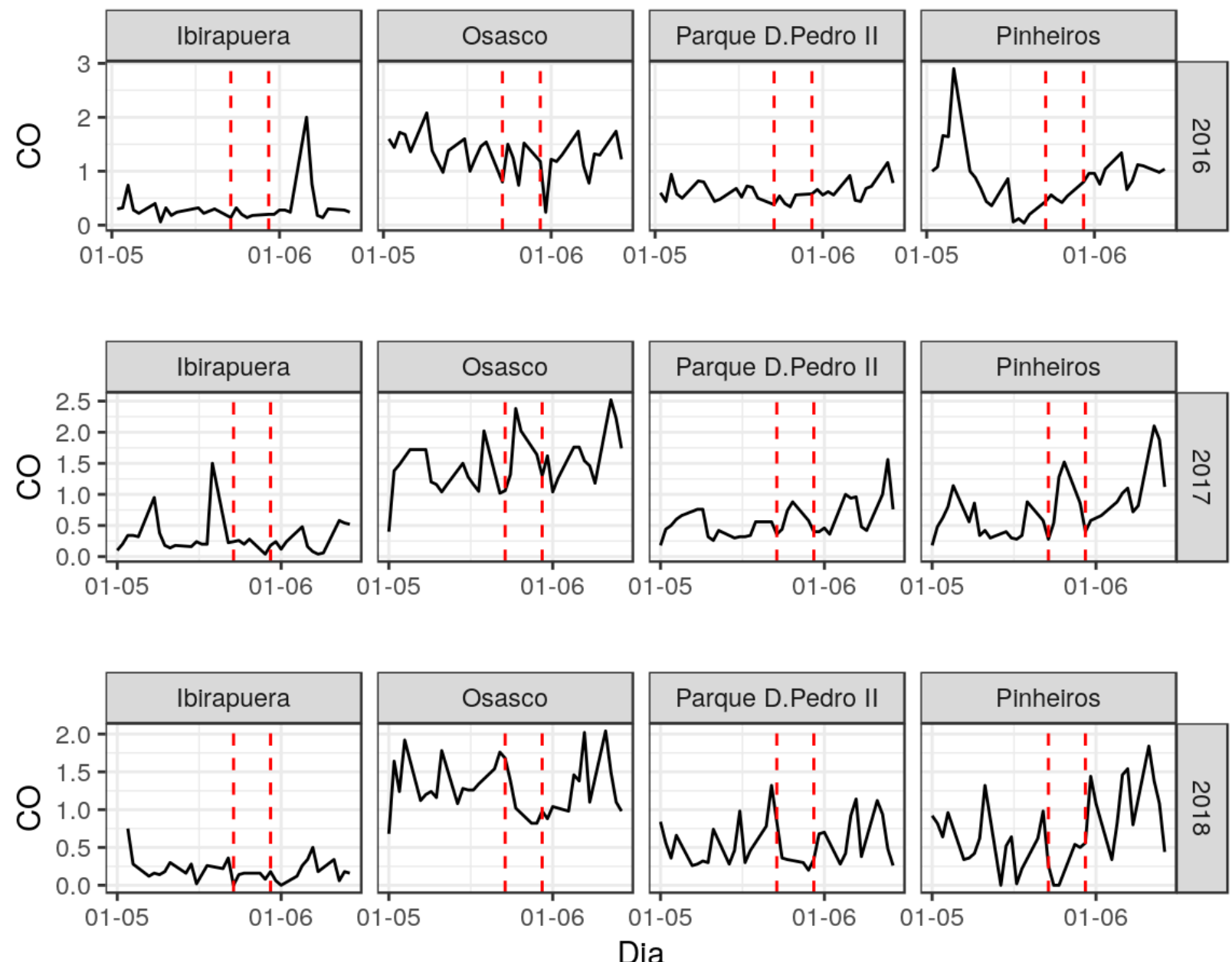

Figura 2.17: Série observada para o monóxido de carbono. O intervalo entre as retas pontilhadas corresponde ao período de paralisações. 

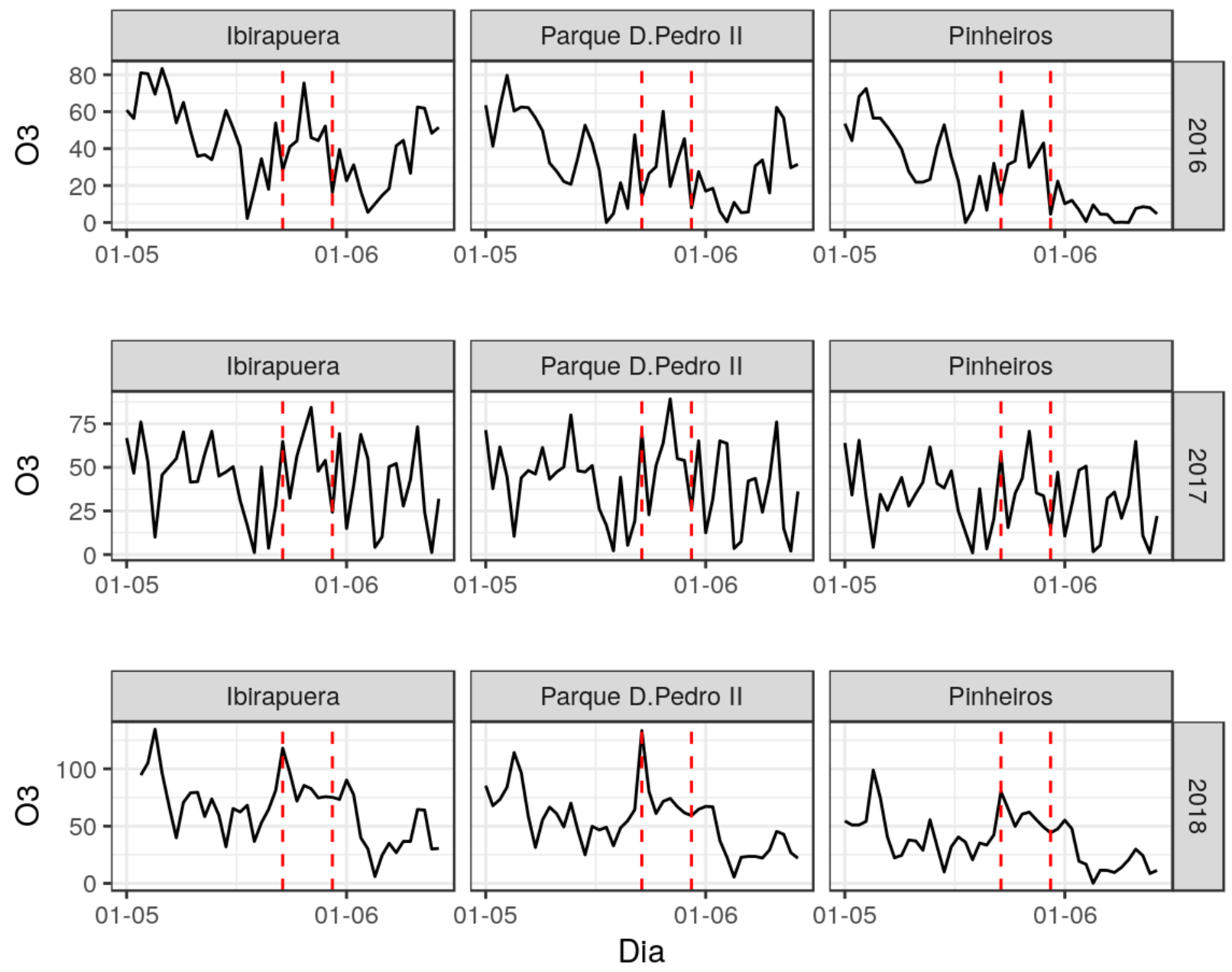

Figura 2.18: Série observada para o ozônio. O intervalo entre as retas pontilhadas corresponde ao período de paralisações. 

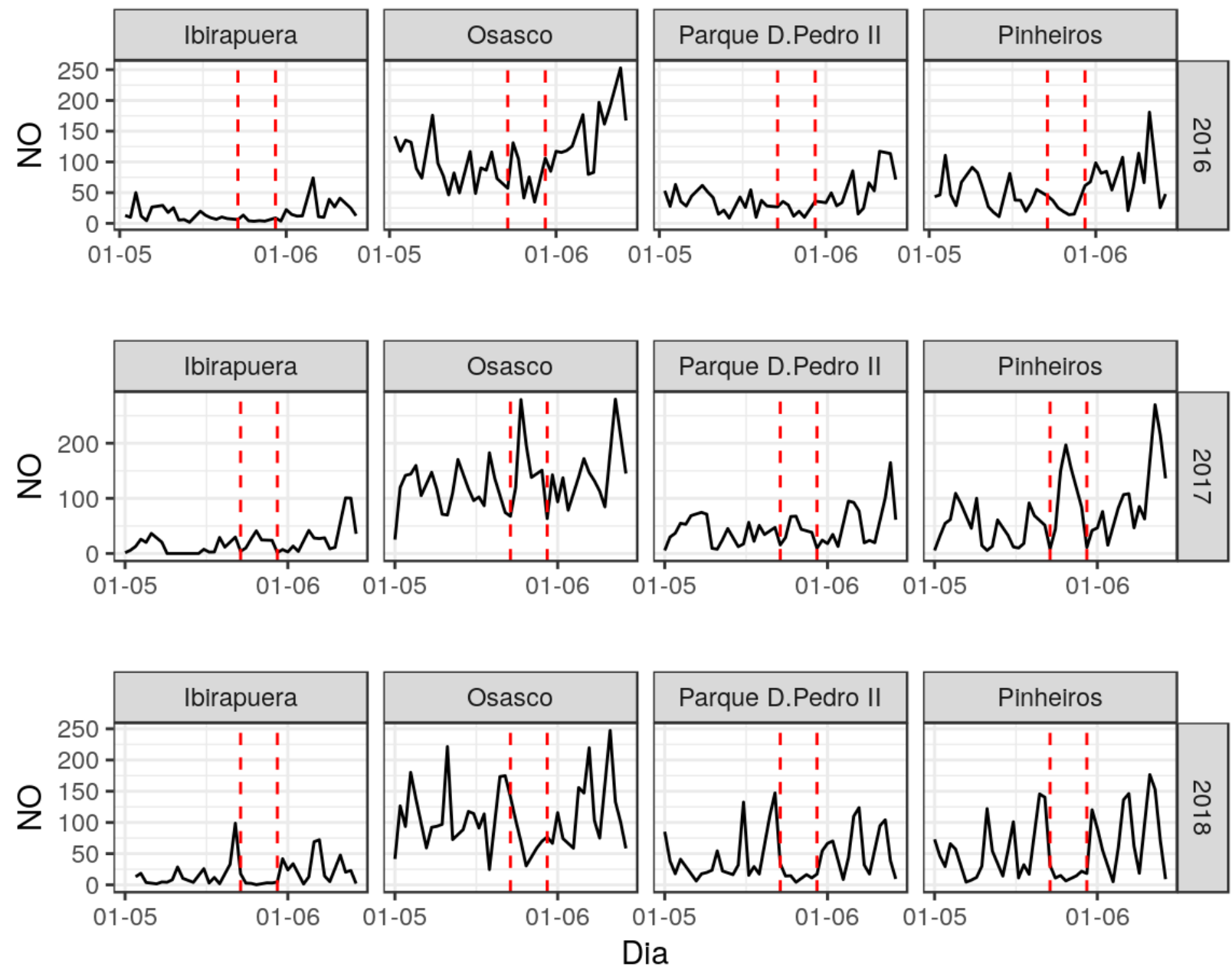

Figura 2.19: Série observada para o monóxido de nitrogênio. O intervalo entre as retas pontilhadas corresponde ao período de paralisações. 

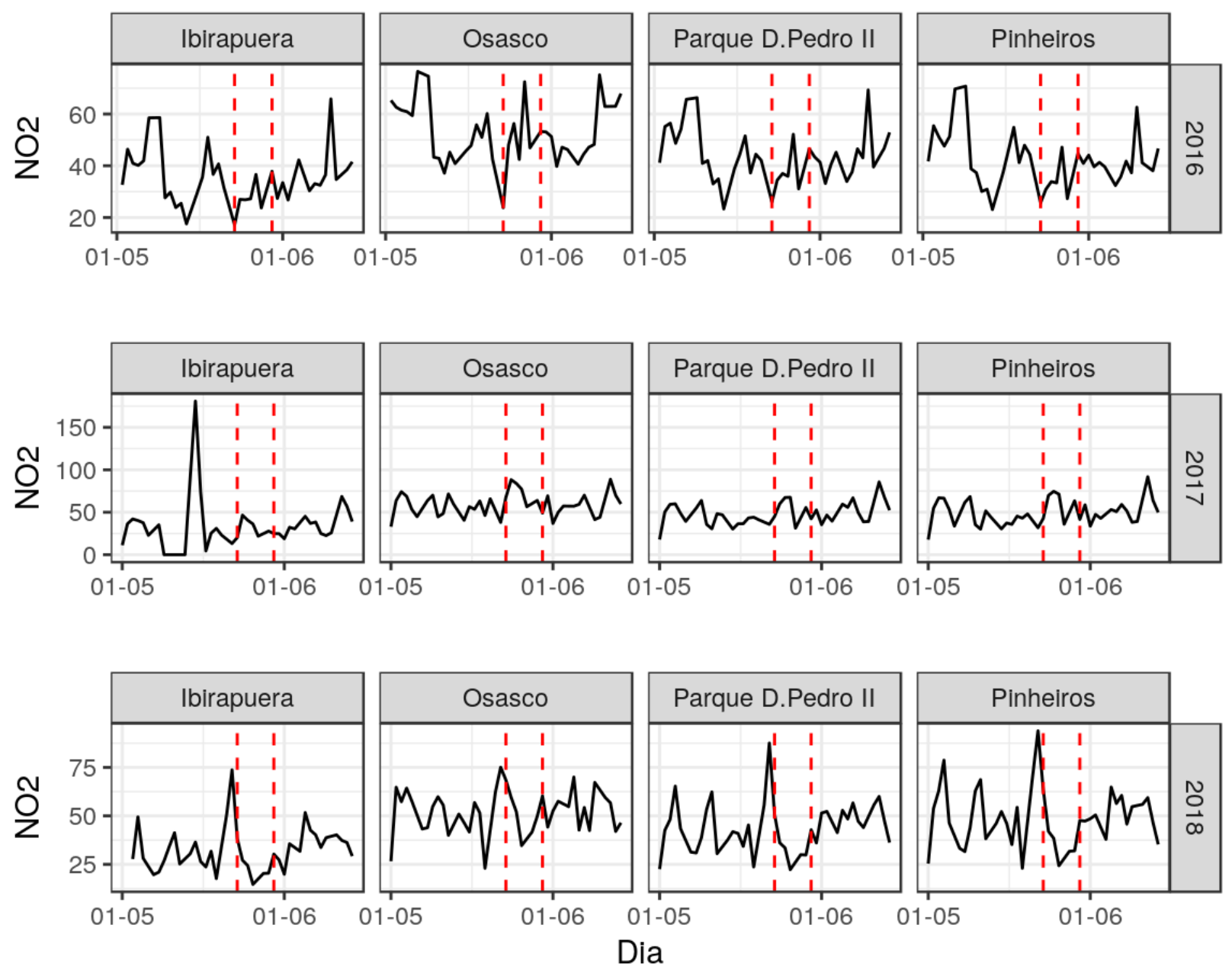

Figura 2.20: Série observada para o dióxido de nitrogênio. O intervalo entre as retas pontilhadas corresponde ao período de paralisações. 

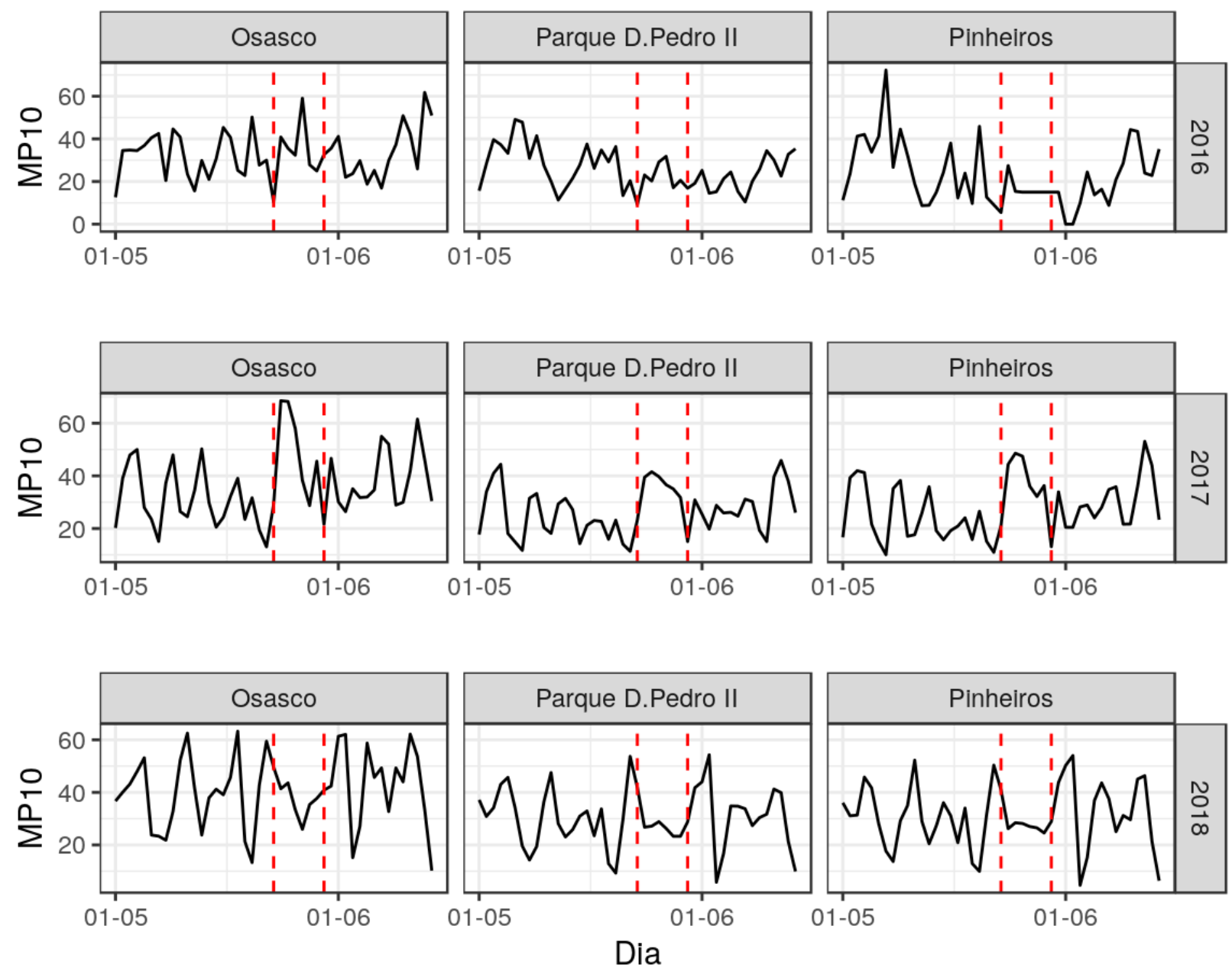

Figura 2.21: Série observada para o material particulado (PM10). O intervalo entre as retas pontilhadas corresponde ao periodo de paralisações. 


\title{
Capítulo 3
}

\section{Estratégias usuais de modelagem}

\author{
Data will often point with almost \\ equal emphasis on several possible \\ models, and it is important that the \\ statistician recognize and accept this. \\ - McCullah and Nelder (1989)
}

O grande objetivo de uma análise estatística é usar um conjunto de dados para gerar conhecimento sobre um fenômeno de interesse. Podemos pensar nesse fenômeno como um mecanismo da natureza, desconhecido e complexo, no qual um conjunto de variáveis explicativas $\mathbf{X}=\left(X_{1}, \ldots, X_{p}\right)$ são transformadas em uma variável resposta $Y^{1}$ (Figura 3.1). Os dados são o resultado desse processo (Breiman, 2001).

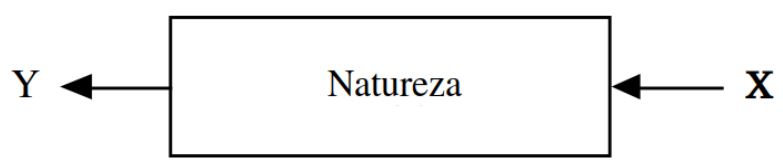

Figura 3.1: Esquematização do mecanismo gerador dos dados.

No contexto da modelagem estatística supervisionada² (Hastie et al., 2008), dada a variável resposta $Y$ e o vetor de variáveis explicativas $\mathbf{X}=\left(X_{1}, \ldots, X_{p}\right)$, queremos encontrar funções $f$ 's tais que

$$
Y \approx f(\mathbf{X})
$$

isto é, queremos uma função $f(\cdot)$ que descreva o mecanismo gerador dos dados da forma mais precisa possível. A partir dessa função, poderíamos tanto fazer predições - descobrir qual é o novo valor de $Y$ para novas observações $\mathbf{X}$ - quanto inferência - investigar como as variáveis $\mathbf{X}$ e $Y$ estão relacionadas.

A expressão (3.1) representa qualquer classe de modelo supervisionado, a depender da escolha de $f(\cdot)$. De uma forma geral, modelos estatísticos são simplificações da realidade e, por isso, estão

\footnotetext{
${ }^{1}$ Também podemos ter o caso multivariado, em que são geradas um conjunto de variáveis respostas $\mathbf{Y}$.

${ }^{2}$ No qual uma variável resposta conduz ou supervisiona a estimação dos parâmetros do modelo. Na prática, são os casos em que temos acesso a uma amostra da variável resposta.
} 
sujeitos a erros. Quando modelamos a série de um poluente, por exemplo, estamos supondo que a sua concentração pode ser aproximada por uma função matemática de variáveis explicativas ao longo do tempo. Neste caso, o erro total do modelo quantifica o quanto a nossa função se afasta do verdadeiro mecanismo gerador do poluente. Parte desse erro é irredutível e se deve a impedimentos práticos, como erros de medida, variáveis que não podem ser observadas e desconhecimento de outros fatores que influenciam o fenômeno. A parte redutível do erro é minimizada pela escolha adequada do modelo utilizado, o que torna essencial o desenvolvimento de estratégias de modelagem que contemplem as particularidades de cada estudo. Nesse sentido, podemos reescrever (3.1) como

$$
Y=f(\mathbf{X})+\epsilon
$$

sendo $\epsilon$ o erro irredutível, que representa toda a informação de $Y$ que não pode ser explicada pelos preditores $\mathbf{X}$. O nosso objetivo na modelagem estatística é encontrar a função $f(\cdot)$ que melhor se aproxime de $Y$, minimizando assim o erro redutível. Esse processo de encontrar a melhor $f(\cdot)$ é chamado de estimação.

Na prática, há duas abordagens bastante utilizadas na especificação da função $f(\cdot)$. A primeira consiste em especificar a forma como as variáveis $Y$ e $\mathbf{X}$ se relacionam a partir de parâmetros, que estrutura a função $f(\cdot)$ e reduz o problema de estimação a encontrar os parâmetros que reduzam o erro do modelo. Essa abordagem é conhecida como modelagem paramétrica e pode ser probabilística, quando o processo de estimação dos parâmetros faz suposições sobre a distribuição da variável resposta, ou não probabilística, quando nenhuma suposição sobre a distribuição de $Y$ é feita. Como exemplo de modelos paramétricos probabilísticos, podemos citar os modelos de regressão (ver próximas seções), e de modelos não probabilísticos, podemos citar a máquina de vetores de suporte (support vector machine ou SVM) (Hastie et al., 2008).

A segunda abordagem é mais flexível e permite que os próprios dados definam uma estrutura para $f(\cdot)$. Neste caso, os próprios dados definem a forma da função, usualmente a partir de divisões no espaço formado pelas variáveis $\mathbf{X}$. Essa abordagem é chamada de modelagem não paramétrica, tendo os modelos de árvores como principais representantes (discutiremos esses modelos no Capítulo $4)$.

Uma outra forma de se pensar a modelagem estatística foi introduzida por Breiman (2001), que dividiu os modelos em duas classes: modelos de dados (data models) e modelos algorítmicos (algorithmic models). A primeira classe representa os modelos cuja a forma de $f(\cdot)$ é conhecida e definida a priori. Esses modelos geralmente fazem suposições fortes sobre a relação entre $Y$ e $\mathbf{X}$ e são utilizados em especial para inferência, pois produzem resultados interpretáveis. O maior exemplo dentre dessa classe são os modelos paramétricos probabilísticos. A segunda classe não está preocupada com a forma de $f(\cdot)$, mas apenas em encontrar um algoritmo que encontre a melhor estimativa de $Y$ para novos valores de $\mathbf{X}$. Esses modelos são quase sempre não interpretáveis, conhecidos como modelos caixa-preta, e muito utilizados para predição. Os exemplos mais famosos de algorithmic models são os modelos de árvores e as redes neurais (Goodfellow et al., 2016).

Por estarem mais bem estabelecidos dentro da comunidade científica e pela facilidade de interpretação, os modelos historicamente mais utilizados em trabalhos científicos são os data models ou, mais especificamente, os paramétricos probabilísticos. Neste capítulo, introduziremos os principais modelos paramétricos probabilísticos utilizados na literatura para análise de dados de poluição do ar, como o modelo de regressão linear, os modelos aditivos e os modelos de séries temporais. No 
Capítulo 4, apresentaremos alguns modelos caixa-preta e como utilizá-los no contexto de inferência.

\subsection{Regressão linear}

O modelo de regressão linear corresponde à aproximação (3.1) mais simples e bem estabelecida dentro da Estatística. Mesmo com a disponibilidade de modelos menos restritivos, essa classe de modelos ainda é bastante utilizada, principalmente por se ajustar bem a diversos problemas reais, facilidade de interpretação dos resultados e estar disponível nos principais programas computacionais estatísticos.

Em estudos de poluição do ar, modelos de regressão linear podem ser ajustados para investigar a relação entre variáveis explicativas e uma variável resposta, seja a concentração de poluentes ou dados epidemiológicos. Saldiva et al. (1995), por exemplo, utilizaram esses modelos para estudar o efeito de alguns poluentes nas taxas de mortalidade de idosos, controlando por condições climáticas e sazonais. Já Salvo et al. (2017) aplicaram o modelo de regressão linear para associar os níveis de partículas finas e ozônio com a proporção de carros a gasolina na cidade de São Paulo.

Apesar da sua popularidade, a complexidade presente nos estudos de poluição atmosférica, como relações não lineares entre as variáveis, pode desqualificar o modelo de regressão linear como a opção mais adequada para o ajuste dos dados. No entanto, pela sua facilidade de implementação e interpretação, ele é uma boa ferramenta para uma análise preliminar.

Nas próximas seções, especificaremos o modelo de regressão linear, discutiremos as suas restrições e apresentaremos as maneiras mais utilizadas para tratar séries com tendência, sazonalidade e autocorrelação.

\subsubsection{Especificação do modelo}

Seja $Y_{t}$ a variável resposta, $\mathbf{X}_{t}=\left(X_{1 t}, \ldots, X_{p t}\right)$ um vetor de variáveis explicativas cuja associação com $Y_{t}$ estamos interessados em avaliar e $t=1, \ldots, n$ o instante no tempo no qual essas variáveis foram medidas. Aqui, não faremos suposições sobre a natureza dos preditores $\mathbf{X}_{t}$, isto é, essas variáveis podem ser fixas ou aleatórias, qualitativas ou quantitativas. Dados os vetores de parâmetros desconhecidos $\boldsymbol{\beta}=\left(\beta_{0}, \beta_{1}, \ldots, \beta_{p}\right)$, o modelo de regressão linear pode ser definido por

$$
Y_{t}=\beta_{0}+\beta_{1} X_{1 t}+\ldots+\beta_{p} X_{p t}+\epsilon_{t}, \quad t=1, \ldots, n
$$

Em geral, supomos que os erros $\left(\epsilon_{1}, \ldots, \epsilon_{n}\right)$ sejam não-correlacionados, tenham média zero e variância constante (homocedasticidade) ${ }^{3}$. Além disso, a especificação (3.3) impõe que a relação entre a resposta $Y_{t}$ e os preditores $\mathbf{X}_{t}$ seja linear e aditiva.

A suposição de linearidade estabelece que a variação esperada em $Y_{t}$ induzida pelo acréscimo de uma unidade em $X_{i t}$, mantidos fixados os outros preditores, é constante e não depende do valor de $X_{i t}$. A interpretação dos coeficientes será discutida com mais detalhes na Seção 3.1.5 e nas aplicações dos Capítulos 5 e 6. Conceitos mais gerais podem ser encontrados em Hastie et al. (2008) e James et al. (2013).

\footnotetext{
${ }^{3}$ A suposição de distribuição Normal também é feita em alguns casos. Essa suposição é relevante na construção de intervalos de confiança e testes de hipóteses para os coeficientes do modelo. No entanto, para amostras grandes, característica comum em estudos de poluição do ar, existem resultados assintóticos (Sen et al., 2009) que garantem a validade desses procedimentos.
} 
A suposição de aditividade estabelece que a variação esperada em $Y_{t}$ causada por uma mudança no preditor $X_{i t}$ independe do valor (fixado) dos outros preditores. Essa suposição pode ser relaxada com a introdução de termos de interação (ver Seção 3.3 de James et al. (2013)), que abordaremos na Seção 3.1.6.

$\mathrm{Na}$ prática, os coeficientes $\beta_{1}, \ldots, \beta_{p}$ são desconhecidos e precisam ser estimados. O procedimento de estimação mais utilizado é o método de mínimos quadrados (Hastie et al., 2008). Outro método bastante utilizado é a estimação por máxima verossimilhança (Casella e Berger, 2001). Sob a suposição de que $Y$ segue uma distribuição Normal, as duas abordagens são equivalentes.

Como o modelo de regressão linear não exige que as observações sejam equidistantes no tempo, podemos utilizá-lo para avaliar a associação de séries com "buracos" ou grandes períodos sem informação, apesar de a identificação da estrutura de tendência e sazonalidade ser mais difícil neste caso.

A adequação do modelo é avaliada a partir de medidas de qualidade de ajuste, como o $R^{2}$ e o erro quadrático médio, e da análise de resíduos. A partir da expressão (3.3), para $t=1, \ldots, n$, podemos definir os resíduos como

$$
r_{t}=Y_{t}-\widehat{Y}_{t}
$$

em que $\hat{Y}_{t}$ representa o valor predito de $Y_{t}$ com base nas estimativas dos coeficientes do modelo. Os resíduos medem o quanto os valores preditos se afastam dos valores observados, sendo muito úteis para avaliar a qualidade do ajuste e a violação das suposições do modelo. Esse tópico será discutido com mais detalhes na Seção 3.1.7.

No R, os modelos de regressão linear podem ser ajustados via mínimos quadrados com a função $\operatorname{lm}($ ) do pacote stats ou utilizando a função train do pacote caret com method $=$ "lm". O pacote caret traz uma abordagem padronizada para o ajuste de modelos estatísticos no contexto de predição.

A seguir, abordaremos como modelar tendência e sazonalidade utilizando o modelo de regressão linear.

\subsubsection{Incorporando tendência e sazonalidade}

Como vimos nos exemplos do Capítulo 2, séries de poluição do ar podem apresentar tendência (positiva ou negativa) e diversos tipos de sazonalidade (diária, semanal, anual etc). Fatores como crescimento populacional, industrialização, aumento da frota de automóveis, leis de regulamentação de combustíveis, estações do ano, entre outros, podem gerar mudanças a longo prazo na concentração de poluentes, alterando o comportamento da série, e muitas vezes não temos informação disponível para incorporá-los no modelo.

Para controlar esses componentes, podemos modelar a tendência e a sazonalidade da série incluindo preditores no modelo de regressão linear ${ }^{4}$. A inclusão desses termos é interessante principalmente nos casos em que não estamos interessados em estudar a evolução da série, mas sim o efeito de preditores na variável resposta, independentemente desses componentes.

\footnotetext{
${ }^{4}$ As vantagens de se incluir um termo de tendência ao modelo, em vez de transformar a série original, como discutido na Seção 2.2, são: (1) poder interpretar os coeficientes do modelo em função da variável original e (2) estimar a tendência da série.
} 
Para acrescentar um termo de tendência linear ao modelo (3.3), podemos especificar $X_{1 t}=t$, $t=1, \ldots, n$. Assim, um coeficiente $\beta_{1}$ positivo em (3.3) indica que $Y$ cresce linearmente com o tempo, enquanto um coeficiente negativo indica que $Y$ decresce linearmente com o tempo. Podemos definir outras formas para a tendência, como quadrática, $X_{1 t}=t^{2}$, ou logarítmica, $X_{1 t}=\log (t)$. A Figura 3.2 mostra um exemplo de séries com tendências linear e quadrática.

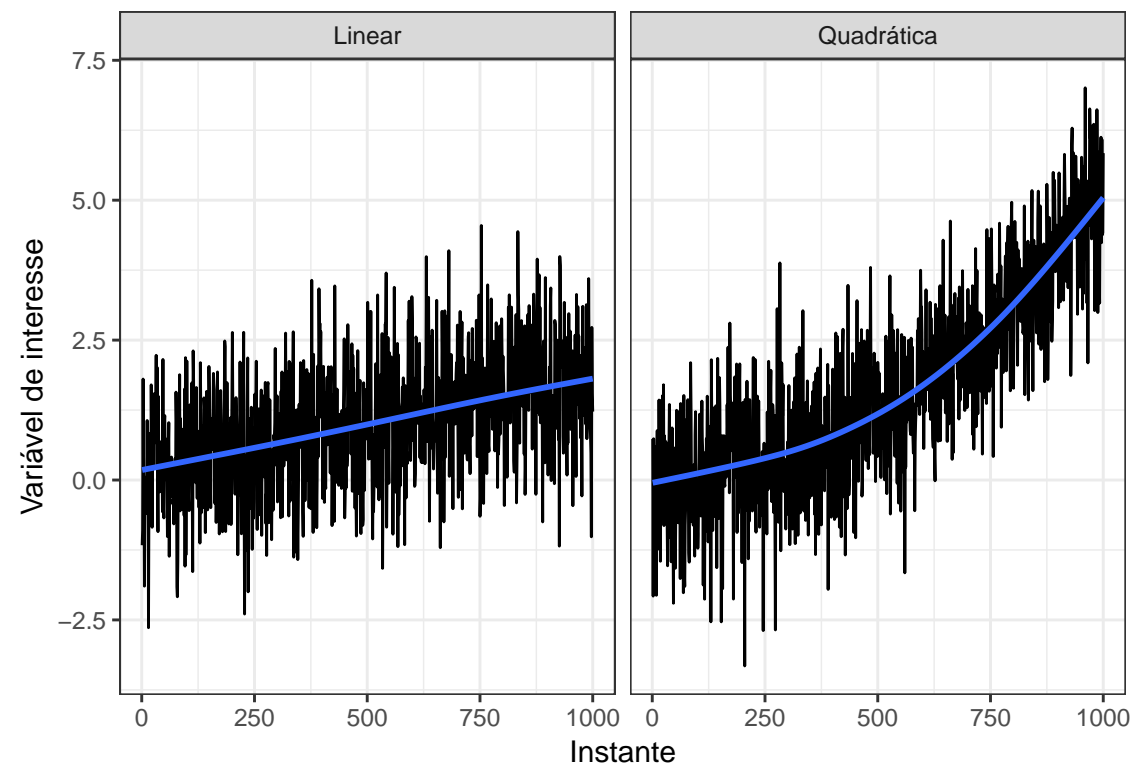

Figura 3.2: Exemplos de séries com tendência linear e quadrática, ambas positivas.

Note que, se modelarmos a tendência dessa maneira, estamos impondo a mesma função ao longo de todo período observado. Em alguns casos, a tendência pode ser diferente em certos intervalos de tempo (Figura 3.3). Uma alternativa seria definir um termo de tendência para cada intervalo, por exemplo:

$$
X_{1 t}= \begin{cases}t, & \text { se } t \text { pertence ao conjunto }\{1,2, \ldots, m\} ; \text { e } \\ 0, & \text { em caso contrário. }\end{cases}
$$

e

$$
X_{2 t}= \begin{cases}t-m, & \text { se } t \text { pertence ao conjunto }\{m+1, m+2, \ldots, m+n\} ; \mathrm{e} \\ 0, & \text { em caso contrário. }\end{cases}
$$

A presença de sazonalidade indica que a média da variável resposta está associada a efeitos periódicos, ligados a intervalos de tempo, como dias, semanas, meses, estações do ano, temporadas de chuva etc. Os níveis de ozônio, por exemplo, crescem no verão e diminuem no inverno; o número de problemas respiratórios tende a aumentar nos meses mais secos; e a concentração de diversos poluentes varia nos fins de semana, devido à menor intensidade de tráfego. Quando não conseguimos controlar esses fatores diretamente, precisamos incluir no modelo termos que expliquem a sazonalidade.

De uma maneira geral, podemos classificar a sazonalidade como determinística - o padrão é constante ao longo do tempo - ou estocástica - o padrão muda ao longo do tempo. É possível controlar a sazonalidade determinística no modelo (3.3) a partir de variáveis indicadoras. Se, por exemplo, acreditamos que há um efeito sazonal de mês, podemos adicionar ao modelo 11 variáveis indicadoras $X_{i t}, i=1, \ldots, 11$ tais que 


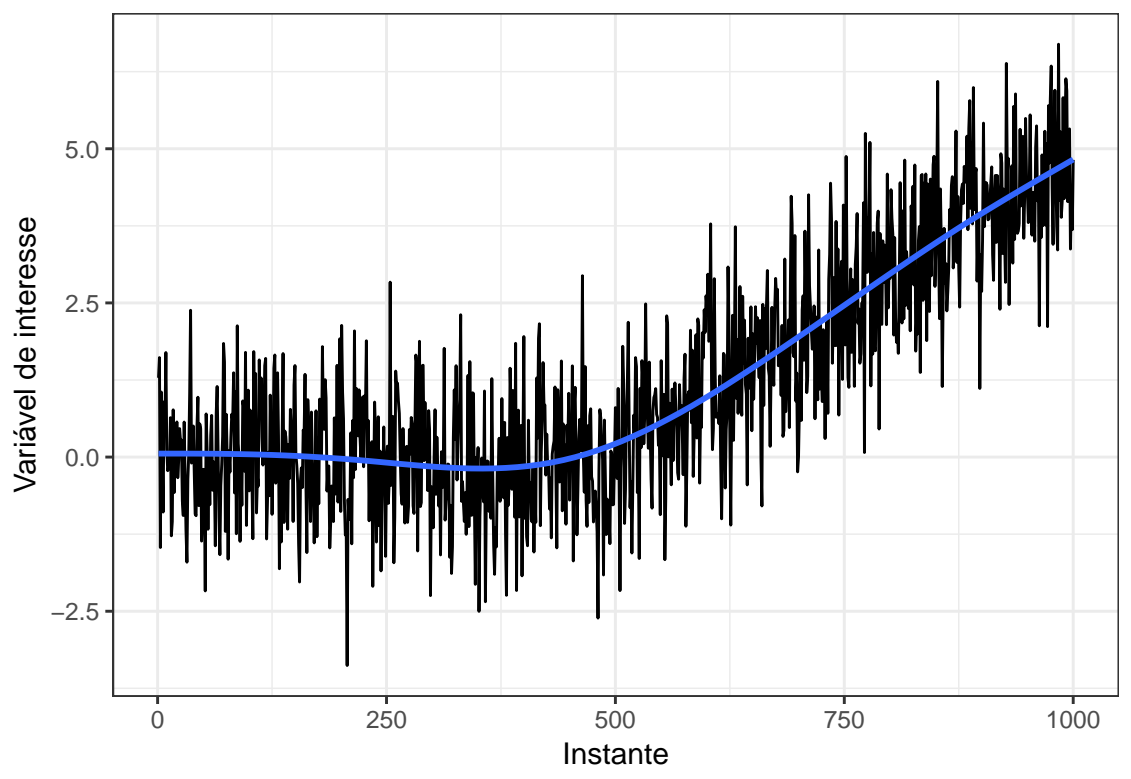

Figura 3.3: Exemplos de uma série com tendência não-constante.

$$
X_{i t}= \begin{cases}1, & \text { se a observação } t \text { pertence ao } i \text {-ésimo mês do ano; e } \\ 0, & \text { caso contrário. }\end{cases}
$$

Com essa formulação, o mês de dezembro será tomado como referência, isto é, a interpretação dos coeficientes correspondentes aos meses será feita sempre em relação ao mês de dezembro.

A inclusão de variáveis indicadoras também pode ser feita para controlar o efeito de variáveis que não estão disponíveis na amostra. Belusic et al. (2015), por exemplo, utilizaram variáveis indicadoras para a hora do dia com o objetivo de controlar o efeito do trânsito no monitoramento de diversos poluentes na cidade de Zagreb, na Croácia. Dessa forma, cada coeficiente explicará as condições específicas da hora do dia a que ele se refere. Uma desvantagem dessa estratégia é não podermos avaliar se o coeficiente de fato está capturando o efeito do trânsito ou qualquer outra variável associada com a concentração dos poluentes que também varia a cada hora. Para mais informações sobre a utilização de variáveis indicadoras em modelos de regressão, consultar a Seção 3.3.1 de James et al. (2013).

Se a sazonalidade for estocástica, procedimentos um pouco mais sofisticados serão necessários para controlá-la. Não trataremos desse tópico neste trabalho. Mais informações podem ser encontradas em Shumway e Stoffer (2006).

A seguir, discutiremos como contornar as suposições de erros não correlacionados, homocedasticidade, linearidade e aditividade utilizando o modelo de regressão linear.

\subsubsection{Tratando erros correlacionados}

O processo de estimação do modelo de regressão linear supõe que os erros $\left(\epsilon_{1}, \ldots, \epsilon_{n}\right)$ sejam não correlacionados. Isso significa que, dados os preditores, as variáveis $Y_{1}, \ldots, Y_{n}$ devem ser independentes. Uma forma de avaliar a violação dessa suposição é construir o gráfico dos resíduos do modelo em função do tempo. A presença de padrões na sequência de pontos, isto é, resíduos adjacentes com valores próximos, é um indício de correlação. Na Figura 3.4, apresentamos os resíduos de um modelo de regressão linear ajustado com dados autocorrelacionados e com dados não correlacionados. Para 
o primeiro caso, observe que os pontos adjacentes tendem a permanecer em um mesmo lado da reta $y=0$. Na ausência de correlação, temos uma sequência aleatória de valores positivos e negativos.

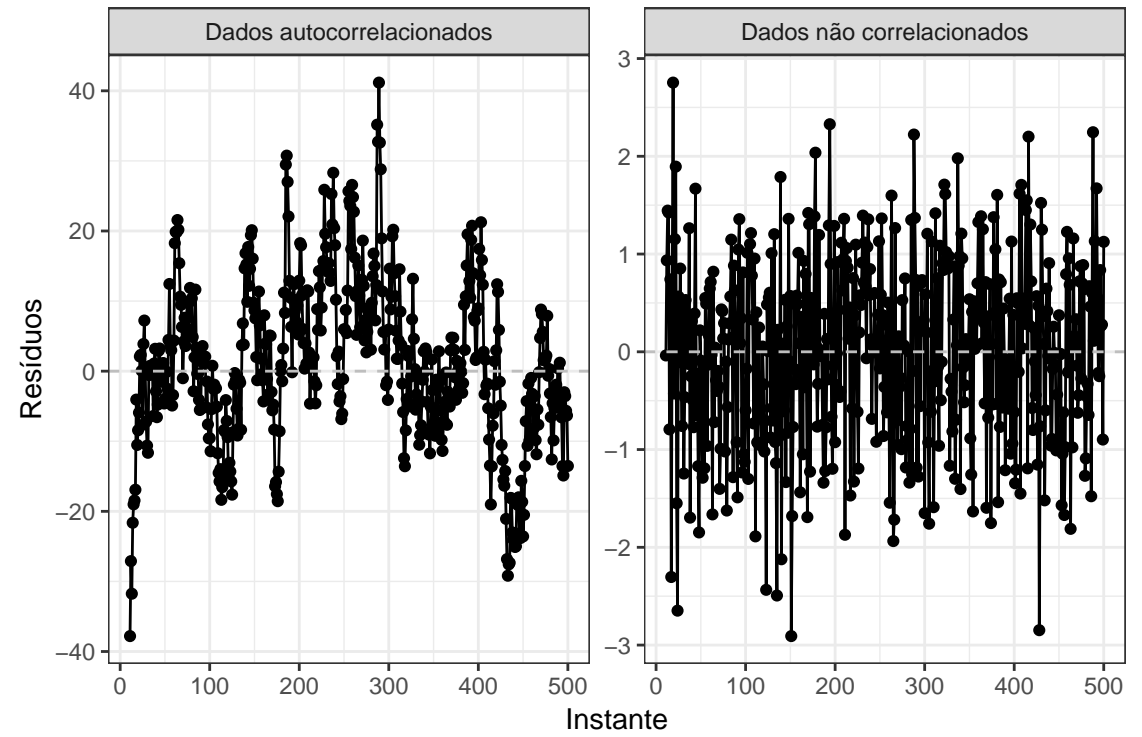

Figura 3.4: Comparação entre os gráficos dos resíduos de um modelo linear contra o tempo para dados auto-correlacionados e dados não correlacionados.

Se as observações são muito correlacionadas, os erros-padrão estimados pelo modelo de regressão linear poderão ser muito diferentes dos verdadeiros erros, o que comprometeria a inferência, já que testes de hipóteses acerca dos parâmetros dependem diretamente dessas estimativas. Nesses casos, outras estratégias de modelagem devem ser adotadas.

Outro tipo de correlação muito comum é a causada por observações que pertencem a um mesmo grupo. Indivíduos de uma mesma família, por exemplo, compartilham a mesma genética e tendem apresentar respostas correlacionadas em estudos epidemiológicos. A localidade também configura formação de grupos, já que pessoas que moram numa mesma região geralmente estão expostas às mesmas condições ambientais. Observações realizadas em diferentes localizações, mas no mesmo instante também podem apresentar correlação.

Em estudos de poluição do ar, observações correlacionadas não costumam ser um grande empecilho. Mesmo quando estamos trabalhando com séries horárias, geralmente conseguimos controlar a maioria dos fatores que induzem correlação, como condições climáticas ou trânsito. Quando não temos informação de algum preditor importante ou a correlação dos erros aleatórios ainda é alta, podemos adicionar uma variável indicadora para a hora do dia, por exemplo, para capturar a parte da variabilidade de $Y$ não explicada por $\mathbf{X}$ que está variando por hora e induzindo a correlação. Dependendo dos objetivos do estudo, também podemos agregar os dados para reduzir o efeito da autocorrelação. Se estamos trabalhando com uma série horária e não temos o objetivo de investir a relação entre as variáveis ao longo do dia, podemos simplificar o problema utilizando a série de médias diárias (veja o exemplo discutido na Seção 5.2), pois esperamos que autocorrelação entre as concentrações médias de dois dias consecutivos seja consideravelmente menor. Essa foi a estratégia adotada por Salvo e Geiger (2014) para controlar a autocorrelação nas concentrações horárias de ozônio. Já Salvo et al. (2017), para reduzir o efeito da correlação entre medidas de uma mesma estação de monitoramento na estimação da variabilidade dos coeficientes, utilizaram métodos robustos para o cálculo do erro-padrão. Os chamados clustered standard errors (Cameron e Miller, 
2015) são obtidos a partir de uma especificação da matriz de variâncias e covariâncias que contempla a correlação entre indivíduos de um mesmo grupo.

Outra alternativa consiste na utilização de modelos que contemplam observações correlacionadas, como os modelos mistos (Demidenko, 2013; McCulloch e Searle, 2001). Falaremos brevemente destes modelos na Seção 3.6.1

\subsubsection{Contornado a suposição de homoscedasticidade}

Assim como a média, a variância de $Y$ também pode mudar segundo algum preditor ou o próprio tempo, violando a suposição de homocedasticidade do modelo de regressão linear. Nesses casos, precisamos escolher entre utilizar modelos mais flexíveis, que contemplem variância não constante, ou aplicar transformações que estabilizem a variância das informações.

O gráfico dos resíduos em função dos valores preditos é uma boa ferramenta para identificar heterocedasticidade. Como podemos observar na Figura 3.5, nuvens de pontos em forma de funil são indícios de observações heteroscedásticas: a variância é maior para valores preditos menores.

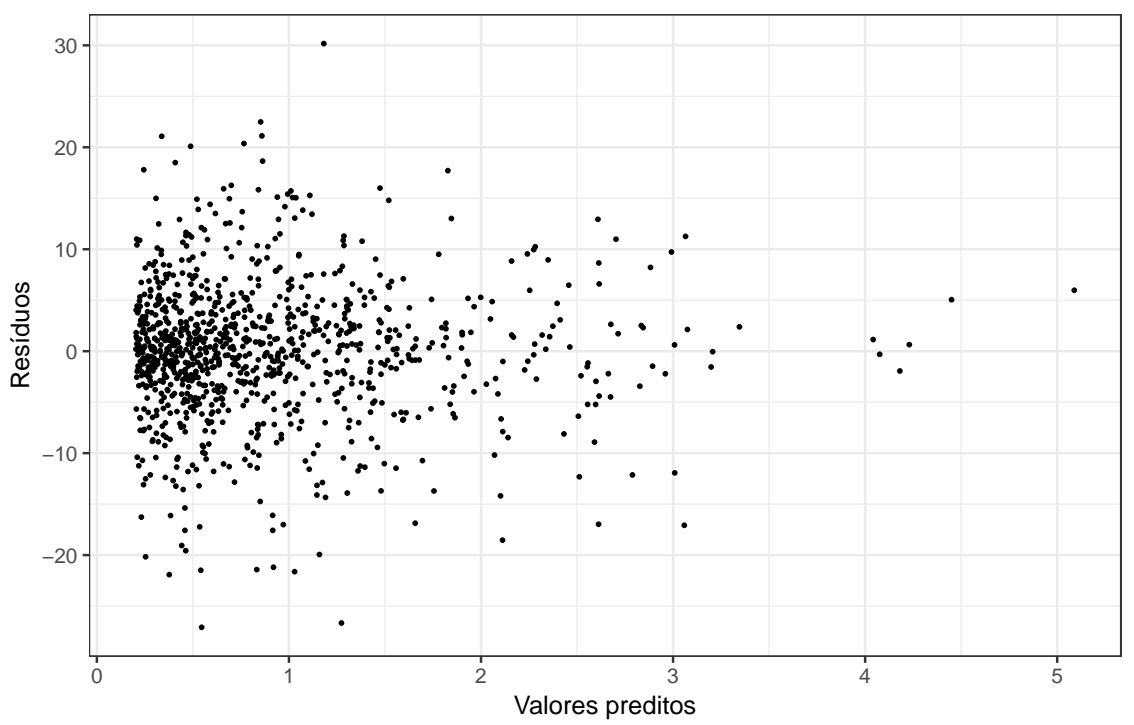

Figura 3.5: Gráfico dos resíduos contra os valores preditos. Exemplo de nuvem de pontos em forma de funil, indicando heteroscedasticidade.

Uma maneira de estabilizar a variância das observações é transformar a variável $Y$ usando funções côncavas, como $\log Y$ e $\sqrt{Y}$. Uma outra alternativa consiste em ponderar as observações com pesos proporcionais ao inverso de sua variância, mas essa técnica se limita aos casos em que a variabilidade pode ser estimada com precisão.

Os modelos lineares generalizados duplos (Paula, 2013) e os modelos mistos (Demidenko, 2013; McCulloch e Searle, 2001) são alternativas aos modelos de regressão linear que modelam também a variância das observações.

\subsubsection{Contornado a suposição de linearidade}

Para entendermos melhor a suposição de linearidade, vamos considerar o modelo de regressão linear mais simples, com apenas um preditor: 


$$
Y_{t}=\beta_{0}+\beta_{1} X_{t}+\epsilon_{t}, \quad t=1, \ldots, n .
$$

Ao estimarmos os parâmetros $\beta_{0}$ e $\beta_{1}$ (pelo método de mínimos quadrados, por exemplo), obtemos a seguinte reta de regressão

$$
\widehat{Y}_{t}=\hat{\beta}_{0}+\hat{\beta}_{1} X_{t}, \quad t=1, \ldots, n,
$$

sendo $\widehat{Y}_{t}$ o valor de $Y_{t}$ predito pelo modelo e $\hat{\beta}_{0}$ e $\hat{\beta}_{1}$ estimativas de $\beta_{0}$ e $\beta_{1}$ respectivamente. Note que (3.7) representa a equação de uma reta com intercepto $\hat{\beta}_{0}$ e coeficiente angular $\hat{\beta}_{1}$. Isso significa que essa reta cruza o eixo $y$ no ponto $\hat{\beta}_{0}$ e, se variamos o valor de $X_{t}$ em uma unidade, $\widehat{Y}_{t}$ vai variar $\hat{\beta}_{1}$ unidades, não importa qual seja o valor de $X_{t}$ ( $\hat{\beta}_{1}$ determina a inclinação da reta). Essa associação entre $\widehat{Y}_{t}$ e $X_{t}$ (ou $Y_{t}$ e $X_{t}$ ) é dita linear com respeito aos parâmetros e está ilustrada na Figura 3.6, para $\hat{\beta}_{0}$ igual a 0 e $\hat{\beta}_{1}$ igual a 10 . Quando temos mais de um preditor, como no modelo (3.3), a interpretação é análoga para cada par $\left(\widehat{Y}_{t}, X_{i t}\right)$ se mantivermos as as outras variáveis fixadas.

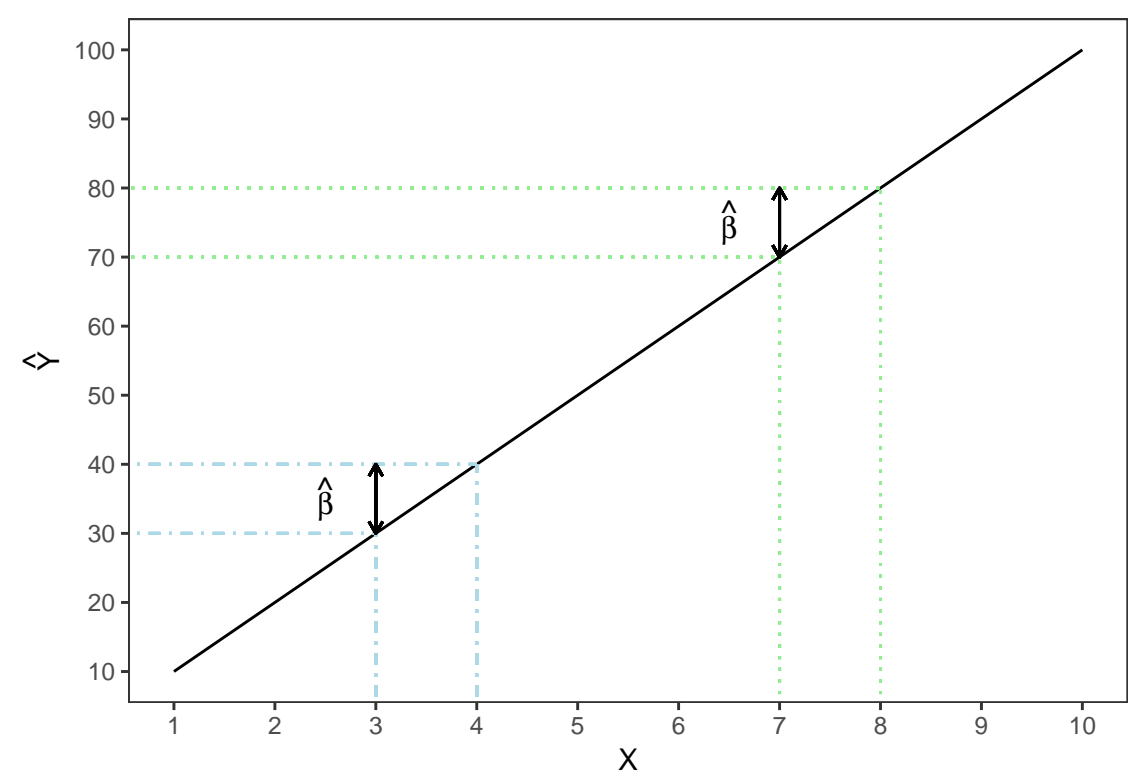

Figura 3.6: A estimativa $\hat{\beta}$ representa a variação em $Y$ quando acrescemos $X$ em uma unidade, não importando o valor de $X$.

Repare que a suposição de linearidade é mais forte do que apenas monotonicidade. Enquanto a monotonicidade restringe que a associação entre as variáveis seja sempre crescente ou decrescente, a linearidade também restringe o quanto a variável resposta varia quando o preditor aumenta ou diminui em uma unidade. Essa diferença é importante pois muitas vezes utilizamos modelos lineares na tentativa de explicar relações que são apenas monotônicas, o que pode gerar estimativas pouco confiáveis e conclusões equivocadas. Uma discussão mais detalhada sobre esse problema pode ser encontrada em Achen (2005).

Os resíduos, definidos pela expressão (3.4), podem ser utilizados para avaliar se a suposição de linearidade é razoável. A ideia consiste em construir o gráfico dos resíduos contra os valores preditos e verificar se a nuvem de pontos apresenta algum padrão. Nuvens em forma de "U", por exemplo, mostram que o modelo não está bem ajustado para valores extremos de $Y$, indicando não linearidade (veja Figura 3.7). 


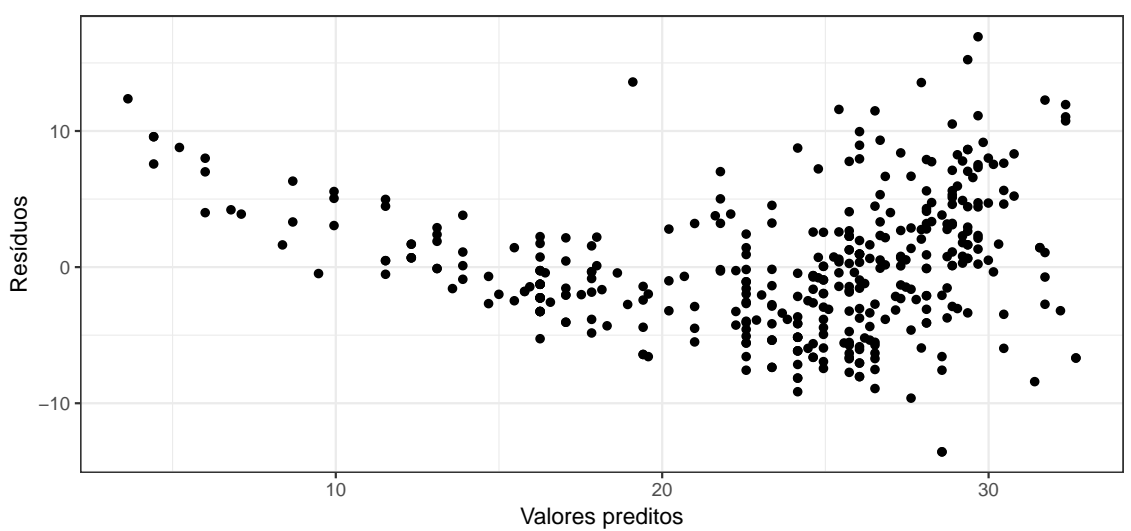

Figura 3.7: Gráfico dos resíduos contra os valores preditos, um exemplo de nuvem de pontos em forma de " $U$ ", indicando não-linearidade.

Uma maneira simples de contornar esse problema é ajustar modelos da forma

$$
Y_{t}=\beta_{0}+\beta_{1} T\left(X_{t}\right)+\epsilon_{t}, \quad t=1, \ldots, n,
$$

em que $T(\cdot)$ representa uma função "linearizadora". As escolhas mais comuns para $T(X)$ são $\log X$ e $\sqrt{X}$. Observe que, embora a relação entre $Y$ e $X$ em (3.8) não seja mais linear, o modelo continua sendo linear nos parâmetros. Um ponto negativo nessa abordagem é a perda de interpretabilidade do modelo, já que os parâmetros estarão associados agora à $T(X)$ e não mais a $X$.

Modelos polinomiais (James et al., 2013) também podem ser utilizados para contornar a nãolinearidade. Dado um único preditor $X$, um modelo polinomial pode ser especificado como

$$
Y_{t}=\beta_{0}+\beta_{1} X_{t}+\beta_{2} X_{t}^{2}+\cdots+\beta_{p} X_{t}^{p}+\epsilon_{t}, \quad t=1, \ldots, n
$$

Essa classe de modelos é bem flexível e permite ajustar associações complexas entre as variáveis $X$ e $Y$, sendo uma boa alternativa para predição, mas pouco utilizados para inferência devido a maior dificuldade de interpretação.

Modelos de regressão segmentada (Muggeo, 2003) são outra alternativa para ajustar relações não-lineares. Vamos supor que, para um determinado local, as médias diárias da concentração de ozônio e da temperatura sejam relacionadas como na gráfico da esquerda da Figura 3.8. O ajuste de um modelo de regressão segmentada a exemplo consiste em estimar um ou mais pontos de corte para a temperatura e, em cada região formada, ajustar uma reta de regressão com inclinação possivelmente diferente. O gráfico da direita apresenta as retas de regressão segmentada para um ponto de corte na temperatura.

A especificação do modelo, além de permitir que a inclinação das retas ajustadas mude em cada ponto de corte, possui parâmetros interpretáveis, ao contrário do modelo polinomial e dos modelos aditivos (ver Seção 3.3). A ideia por trás do algoritmo de estimação consiste em achar os pontos de corte no preditor que melhor representem mudanças na relação preditor/resposta. Isso é feito utilizando uma técnica de linearização do modelo utilizando a expansão de Taylor de primeira ordem (ver Muggeo (2003) para mais detalhes). Dessa forma, o ponto de corte passa a ser um parâmetro do modelo e a dificuldade computacional é a mesma de um ajuste de um modelo de regressão linear. 

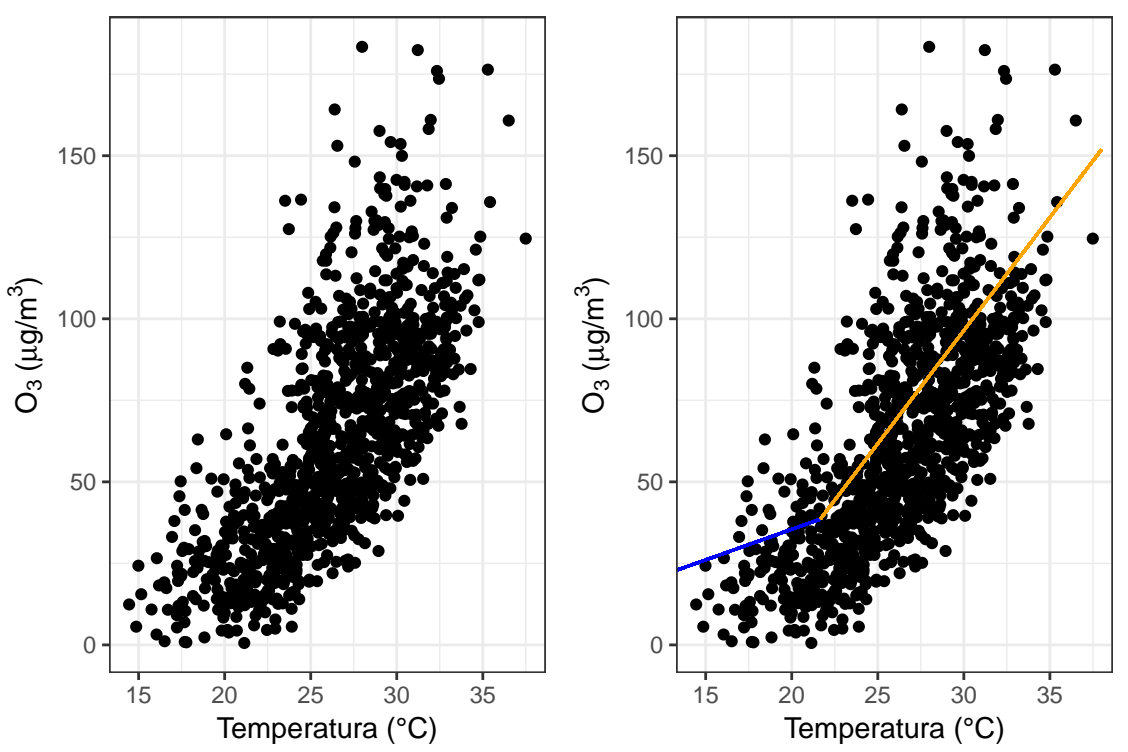

Figura 3.8: Exemplo de regressão segmentada. $\grave{A}$ esquerda, o gráfico de concentrações médias diárias de ozônio pela temperatura média diária. À direita, um modelo de regressão segmentada ajustada aos pontos com um ponto de corte.

Mais detalhes sobre linearidade e outras alternativas para contornar essa suposição podem ser encontradas em Hastie et al. (2008) e James et al. (2013).

\subsubsection{Contornado a suposição de aditividade}

Pela suposição de aditividade, os termos do modelo (3.3) são sempre somados, permitindo que cada coeficiente possa ser interpretado independentemente dos demais se os mantivermos fixados.

Na prática, o efeito de uma variável explicativa $X_{1}$ em $Y$ pode depender do nível de um outro preditor $X_{2}$. O efeito da poluição do ar $\left(X_{1}\right)$ em crises respiratórias $(Y)$, por exemplo, é muito mais acentuado em certas condições climáticas, como dias de baixa umidade $\left(X_{2}\right)$. Essa relação entre $X_{1}$ e $X_{2}$ na variabilidade de $Y$ é chamada de interação.

Gráficos de perfis (Singer et al., 2018) podem ser utilizados para identificar interação entre variáveis. Esses gráficos exigem que pelo menos um dos preditores seja categórico. Se ambas variáveis forem quantitativas, uma delas pode ser categorizada para a construção dos gráficos de perfis.

A interação de duas variáveis pode ser contemplada pelo modelo de regressão linear acrescentandose termos da forma $X_{1} \times X_{2}$. Interações de três ou mais variáveis também podem ser incluídas, mas são de difícil interpretação.

Termos de interação bastante utilizados em estudos de poluição do ar são aqueles entre as variáveis meteorológicas. Em geral, além de controlarmos o efeito marginal da temperatura, umidade, precipitação, radiação, vento etc., precisamos também incluir o efeito conjunto dessas variáveis.

Alguns modelos, como os de árvore (ver Capítulo 4), lidam com interações de forma mais natural, pois fazem divisões no hiperespaço gerado pelas variáveis explicativas. Isso permite que a função estimada capture relações muito mais complexas entre as variáveis sem precisarmos especificá-las. 


\subsubsection{Avaliando a qualidade do ajuste}

Como discutido anteriormente, modelos sempre estarão sujeitos a erros. Mesmo quando os dados não violam as suposições estabelecidas, precisamos verificar se o modelo escolhido está bem ajustado aos dados. Para modelos de regressão linear, isso pode ser feito a partir da raiz do erro quadrático médio $\left(\mathrm{RMSE}^{5}\right)$ e do coeficiente de determinação $\left(R^{2}\right)$.

A raiz do erro quadrático médio é uma estimativa do desvio-padrão de $\epsilon$, uma medida do quanto, em média, a resposta $Y$ se desvia da reta de regressão. Valores baixos de RMSE significam que $\hat{Y}_{t} \approx Y_{t}$, para $t=1, \ldots, n$, sugerindo que o modelo está bem ajustado aos dados. Como essa medida depende da magnitude da variável resposta, não podemos definir qual valor configura o que é um RMSE pequeno.

O coeficiente de determinação é uma medida da proporção da variância de $Y$ explicada pelos preditores incluídos no modelo. Esse coeficiente varia entre 0 e 1 e, ao contrário do RMSE, não depende da escala de $Y$. Valores próximos de 1 apontam que uma porção considerável da variabilidade está sendo explicada, indicando que o modelo se ajusta bem aos dados.

Valores altos de RMSE ou baixos de $R^{2}$ sugerem problemas com o modelo. Não linearidade e omissão de preditores importantes são os mais comuns. No primeiro caso, a principal estratégia é transformar os preditores cuja associação com $Y$ suspeitamos ser não linear, assim como discutido na Seção 3.1.5. A solução para o segundo caso é obter mais informação sobre o fenômeno sob análise e incluir novos preditores ao modelo. Essa é uma tarefa complicada, pois dificilmente temos acesso a novas variáveis explicativas, geralmente demonstrando uma falha no delineamento do estudo.

Acrescentar mais preditores ao modelo sempre irá diminuir o RMSE e aumentar o $R^{2}$, o que torna a estratégia de escolher o modelo com menor RMSE ou menor $R^{2}$ problemática. O excesso de parâmetros pode gerar sobreajuste (overfitting), que acontece quando o modelo passa a explicar padrões que não são generalizáveis para a população. Um modelo sobreajustado captura a variação gerada pelos erros aleatórios, que, por construção, não pode ser explicada pelos preditores. Sendo assim, o modelo será ótimo para representar a amostra, mas, em geral, péssimo para ser estendido para um contexto mais amplo.

Para avaliar se um preditor está ou não melhorando o ajuste o suficiente para mantermos no modelo, podemos utilizar versões do RMSE e do $R^{2}$ penalizadas pelo número de parâmetros, conhecidas como RMSE ajustado e $R^{2}$ ajustado. Os valores dessas medidas diminuem quando acrescentamos variáveis que não colaboram muito para explicar a variabilidade de $Y$, o que nos permite controlar o balanço (trade off) existente entre um modelo mal ajustado e um modelo sobreajustado. No entanto, repare que ainda estamos calculando o erro de ajuste, que geralmente é uma estimativa ruim do erro que vamos cometer ao generalizar o modelo para a população. No Capítulo 4, discutiremos os conceitos de erro de treino, erro de teste e validação cruzada, essenciais para evitar o sobreajuste.

Em estudos inferenciais, o coeficiente $R^{2}$ costuma ser mais utilizado que o RMSE para a avaliação do ajuste de modelos de regressão linear. Com objetivo de explicar a variabilidade da concentração de ozônio na cidade de São Paulo, Salvo e Geiger (2014), por exemplo, ajustaram sete modelos lineares com diferentes preditores para controlar os efeitos meteorológicos e de tráfego e escolheram aquele com maior $R^{2}$ como o modelo final. O RMSE é bastante utilizado na avaliação de modelos

\footnotetext{
${ }^{5}$ Sigla para o termo em inglês root mean square error. Utilizaremos aqui a sigla em inglês porque ela é bastante comum na literatura e nos programas estatísticos.
} 
preditivos.

Em alguns casos, a complexidade do fenômeno sob estudo demandará modelos mais flexíveis que o modelo de regressão linear. A seguir, discutiremos os modelos lineares generalizados, uma ampla classe de modelos que permite a utilização de distribuições interessantes para o ajuste de diversos casos práticos, e os modelos aditivos generalizados, que flexibiliza a suposição de linearidade entre a variável resposta e os preditores.

\subsection{Modelos lineares generalizados}

Ao atribuirmos um modelo probabilístico para os dados, estamos supondo que as observações no mundo real se comportam conforme uma distribuição de probabilidades, cujos parâmetros podem ser relacionados com os coeficientes do modelo e estimados, por exemplo, por máxima verossimilhança (Casella e Berger, 2001).

Para o modelo de regressão linear discutido na última seção, podemos utilizar o método de mínimos quadrados para estimação e, para grandes amostras, existem resultados assintóticos que garantem as propriedades necessárias para a construção de intervalos de confiança e testes de hipóteses. Quando trabalhamos com amostras pequenas, não podemos garantir a validade dos resultados assintóticos, e então supomos que a variável resposta é normalmente distribuída para a construção dos intervalos e testes. Embora muito utilizada, a distribuição Normal pode ser restritiva na prática, pois ela assume que as observações variam na reta real (valores positivos e negativos) e são simetricamente distribuídas em torno da média.

A concentração de poluentes é uma medida positiva, em geral assimétrica e heteroscedástica. Quando estamos trabalhando com dados epidemiológicos, o número de casos de doenças ou mortalidade é uma contagem, isto é, assume apenas valores não negativos inteiros. Se queremos aplicar modelos que estabelecem suposições sobre a distribuição de probabilidade das observações, é importante que possamos escolher distribuições compatíveis com a natureza dos dados. Nesses casos, as distribuições Gama e Poisson seriam, respectivamente, boas alternativas para a modelagem de concentração de poluentes e dados epidemiológicos de contagem.

Os modelos lineares generalizados, introduzidos por Nelder e Wedderburn (1972), são uma generalização do modelo de regressão linear que permitem a utilização de distribuições para dados assimétricos (Gama, Normal inversa, Log-normal), dados de contagem (Poisson, Binomial negativa), dados binários (Binomial), entre outros. Nas próximas seções, discutiremos como utilizar essa classe de modelos para o ajuste de dados de poluição do ar.

\subsubsection{Especificação do modelo}

Sejam $Y_{t}$ e $\mathbf{X}_{t}$ definidos como na Seção 3.1.1. O modelo linear generalizado pode ser definido como

$$
\begin{gathered}
Y_{t} \mid \mathbf{X}_{t} \stackrel{i n d}{\sim} \mathcal{D}\left(\mu_{t}, \phi\right) \\
g\left(\mu_{t}\right)=\beta_{0}+\beta_{1} X_{1 t}+\ldots+\beta_{p} X_{p t}, \quad t=1, \ldots, n,
\end{gathered}
$$


sendo $^{6} \mathcal{D}$ uma distribuição pertencente à família exponencial ${ }^{7}, g(\cdot)$ uma função de ligação, $\mu_{t}$ um parâmetro de posição e $\phi$ um parâmetro de precisão ${ }^{8}$.

Os parâmetros deste modelo podem ser estimados por máxima verossimilhança. Os cálculos envolvem o uso de procedimentos iterativos, como Newton-Raphson e escore de Fisher (Dobson, 1990). Distribuições que têm um parâmetro de precisão permitem a modelagem conjunta de $\mu$ e $\phi$, flexibilizando a suposição de homocedasticidade estabelecida em (3.9). Mais informações sobre esses modelos podem ser encontradas em Paula (2013).

A especificação dos termos de tendência e sazonalidade para modelos lineares generalizados pode ser feita como apresentado na Seção 3.1.2 para os modelos de regressão linear. A utilização de resíduos para avaliar a qualidade do ajuste também pode ser conduzida de forma análoga à apresentada nas seções anteriores. Os resíduos mais utilizados em modelos lineares generalizados são definidos a partir da função desvio (deviance). Uma técnica muito utilizada é a construção de gráficos envelope para investigar a adequação da distribuição escolhida para os dados. Para mais informações sobre a análise de resíduos de modelos lineares generalizados, consulte Paula (2013).

Os modelos com distribuição Gama, Normal inversa e Log normal são boas alternativas para ajustar dados positivos assimétricos, sendo, em geral, mais adequados para concentrações de poluentes do que a distribuição Normal. Discutiremos os dois primeiros na Seção 3.2.2.

Dados de contagem, como o número de casos de uma doença ou mortalidade, são usualmente ajustados pelo modelo Poisson. Conceição et al. (2001b), por exemplo, utilizaram esse modelo para avaliar a associação entre poluição atmosférica e marcadores de mobi-mortalidade em idosos na cidade de São Paulo. No entanto, a distribuição Poisson impõe que a média e a variância das observações são iguais e pode não se ajustar bem quando os dados apresentam sobredispersão (variância maior que a média). O modelo com resposta binomial negativa é uma alternativa nesses casos, já que permite a modelagem conjunta dos parâmetros de posição e dispersão. Discutiremos esses modelos com mais detalhes na Seção 3.2.3.

\subsubsection{Modelos para dados positivos assimétricos contínuos}

A distribuição Gama costuma ser a principal alternativa para o ajuste de dados positivos assimétricos. Se $Y \sim \operatorname{Gama}(\mu, \phi)$, sendo $\mu>0$ a média de $Y, \phi>0$ um parâmetro de precisão, a sua função densidade de probabilidade está representada na Figura 3.9 para $\mu=1$ e diversos valores de $\phi$. Podemos observar que, à medida que $\phi$ aumenta, a distribuição Gama se torna mais simétrica em torno da média. Conforme $\phi$ tende para infinito, $Y$ se aproxima da distribuição Normal de média $\mu$ e variância $\mu^{2} \phi^{-1}$, o que torna a distribuição Gama atrativa para a modelagem tanto de observações assimétricas quanto de observações simétricas cuja dispersão varia em função da média ao quadrado.

Uma alternativa para a distribuição Gama é a Normal inversa. Considere agora $Y \sim \operatorname{NI}(\mu, \phi)$, novamente sendo $\mu>0$ a média de $Y$ e $\phi>0$ um parâmetro de precisão. Podemos ver pela

\footnotetext{
${ }^{6} \mathrm{~A}$ notação $Y_{t} \mid \mathbf{X}_{t} \stackrel{i n d}{\sim} \mathcal{D}\left(\mu_{t}, \phi\right)$ significa que, conhecido os valores dos preditores $\mathbf{X}_{\mathbf{t}}$, as variáveis $Y_{1}, \ldots, Y_{n}$ são independentes e seguem a distribuição $\mathcal{D}$, governada pelos parâmetros $\mu_{t}$ e $\phi$.

${ }^{7}$ A família exponencial corresponde a uma classe de distribuições de probabilidade que, sob certas condições de regularidade, apresentam certas características em comum. Essas características permitem que a mesma estratégia de estimação possa ser utilizada para qualquer uma das distribuições dentro dessa família. Para mais informações, consulte Paula (2013).

${ }^{8} \mathrm{Se} \phi$ e um parâmetro de precisão, $\phi^{-1}$ é um parâmetro de dispersão. Algumas distribuições não têm um parâmetro de precisão. Nas distribuições Binomial e Poisson, por exemplo, $\phi=1$ e a precisão é uma função da média $\mu$.
} 


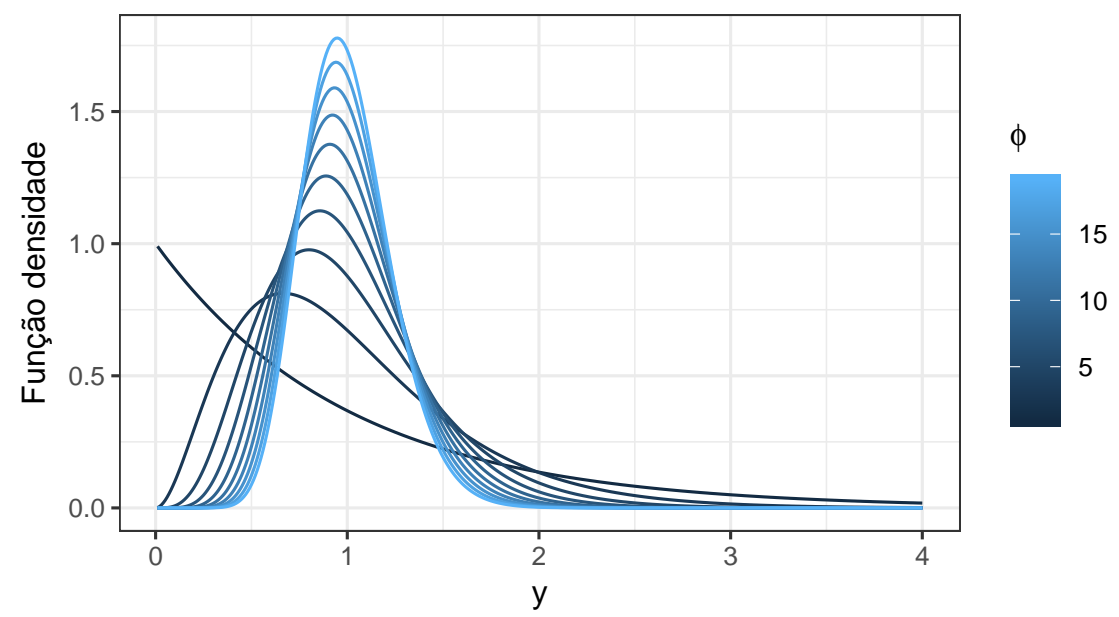

Figura 3.9: Função densidade da distribuição Gama com $\mu=1$ e diversos valores de $\phi$. Conforme $\phi$ aumenta, a distribuição se torna menos assimétrica, centralizando-se ao redor da média.

Figura 3.10 que, para $\mu=1$, a assimetria da distribuição diminui conforme $\phi$ aumenta. Mais precisamente, $Y$ se aproxima de uma distribuição Normal com média $\mu$ e variância $\mu^{3} \phi^{-1}$. A Normal inversa é apropriada para modelar tanto observações assimétricas quanto observações simétricas cuja dispersão varia em função da média ao cubo.

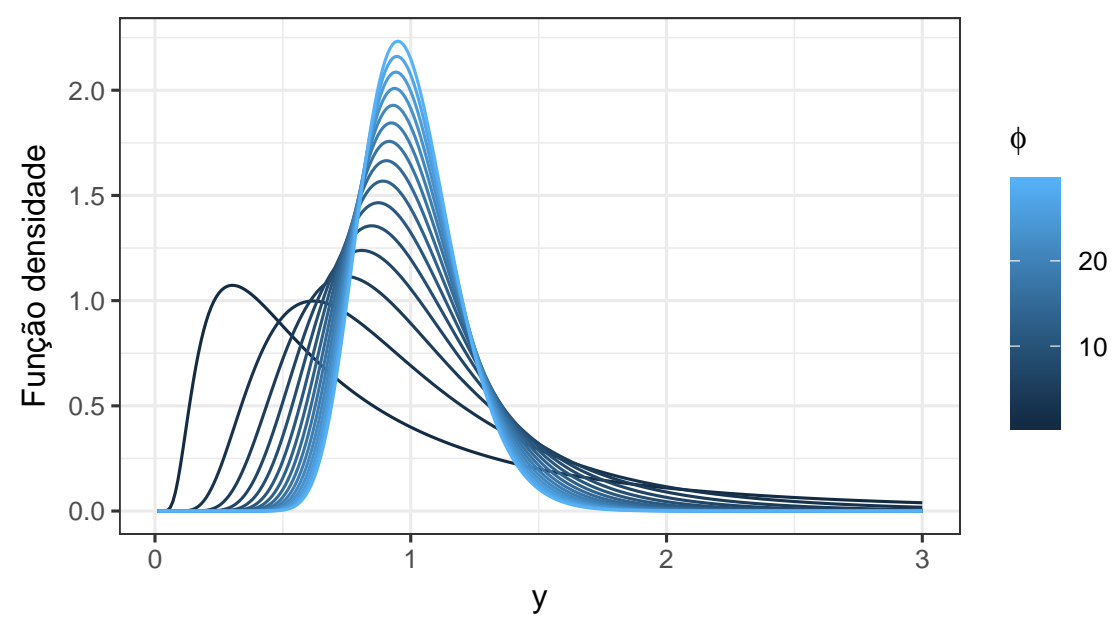

Figura 3.10: Função densidade da distribuição Normal inversa com $\mu=1$ e diversos valores de $\phi$. Conforme $\phi$ aumenta, a distribuição se torna menos assimétrica, centralizando-se ao redor da média.

As funções de ligação mais utilizadas em ambos os modelos são a identidade $(g(\mu)=\mu)$, a logarítmica $(g(\mu)=\log (\mu))$ e a recíproca $(g(\mu)=1 / \mu)$. Gráficos de resíduos podem ser construídos para avaliar a adequabilidade da distribuição e da função de ligação escolhidas. Para mais informações sobre análise de diagnóstico para modelos lineares generalizados, consultar Williams (1987) e Paula (2013) .

No R, os modelos Gama e Normal inversa podem ser ajustados com a função glm () do pacote stats, utilizando os argumentos family = Gamma e family = inverse.gaussian, respectivamente. No pacote caret, modelos lineares generalizados podem ser ajustados utilizando a função train () com method="glm".

Outras distribuições da família exponencial também podem ser utilizadas para a análise de dados positivos assimétricos, como a Weibull, a Pareto e a Log-Normal (Wood, 2006). Fora do con- 
texto de modelos lineares generalizados, a distribuição de Birnbaum-Saunders generalizada (GBS) é outra alternativa para o ajuste de dados positivos assimétricos. Leiva et al. (2008), por exemplo, utilizaram o modelo GBS para ajustar concentrações horárias de dióxido de enxofre em Santiago, no Chile, mostrando que essa distribuição se ajustava melhor aos dados do que a Log-Normal. Para mais informações sobre a distribuição de Birnbaum-Saunders, consulte Barros et al. (2009) e Leiva (2015).

\subsubsection{Modelos para dados de contagem}

Em algumas situações, o objetivo do estudo de poluição do ar não está em descrever as séries de poluentes, mas sim utilizá-las para explicar eventos epidemiológicos, como, por exemplo, a morbidade ou mortalidade causada por doenças respiratórias. A variável resposta nesses estudos é, em geral, uma contagem, isto é, assume valores inteiros positivos que representam o número de casos da doença ou de mortes em cada instante observado.

Schwartz e Dockery (1992), por exemplo, utilizaram o modelo Poisson para avaliar a relação entre a concentração de material particulado e o número de mortes no dia seguinte, sugerindo uma associação positiva entre as variáveis. Conceição et al. (2001b) também utilizando o modelo Poisson, estudaram a relação entre a concentração de alguns poluentes e marcadores de mortalidade em idosos na cidade de São Paulo, controlando por variáveis meteorológicas. Os autores observaram uma associação positiva entre mortalidade e níveis de $\mathrm{CO}, \mathrm{SO}_{2}$ e, em menor escala, PM10. Já Saldiva et al. (1995) discutiram a utilização de um modelo Poisson para modelar a associação entre concentração de diversos poluentes e a mortalidade em idosos, mas optaram pelo ajuste de um modelo gaussiano, justificando que a aproximação pela distribuição Normal era válida pois a média diária de mortes era suficiente alta (62 eventos por dia).

Se a variável resposta $Y$, segue uma distribuição Poisson com parâmetro $\lambda$, simbolicamente $Y \sim$ Poisson $(\lambda)$, o modelo assume que o evento sob estudo ocorre com taxa $\lambda$ dentro de um intervalo de tempo fixado ${ }^{9}$. Essa taxa representa o valor médio ${ }^{10}$ de casos observados no intervalo e, na prática, queremos explicá-la a partir de séries de poluentes, controlando por variáveis climáticas. Dessa forma, para o modelo Poisson, temos $\mu_{t}=\lambda_{t}$ em (3.9). A função de ligação mais utilizada nesse contexto é a logarítmica.

Na distribuição Poisson, a média é igual à variância, isto é, $E(Y)=V A R(Y)=\lambda$. Isso o restringe o modelo Poisson apenas para dados em que essa igualdade é verdadeira ${ }^{11}$. Se $Y \sim$ $\operatorname{BN}(\mu, \phi)$, temos que $E(Y)=\mu$ e $V A R(Y)=\mu+\mu^{2} / \phi$, com $\mu \geq 0$ e $\phi>0$, o que faz a distribuição Binomial Negativa adequada para dados com variância maior do que a média.

Modelos de contagem geralmente são utilizados para obter uma estimativa do risco de mortalidade associado a cada poluente, isto é, qual a variação esperada na taxa de mortalidade se aumentássemos (ou diminuíssemos) a concentração de um poluente em $m$ unidades. Essa quantidade, conhecida como dose-resposta, concentração-resposta ou exposição-resposta, é muito importante para a implementação de medidas para a redução da poluição do ar pois quantifica de forma objetiva o efeito dos poluentes na saúde pública.

\footnotetext{
${ }^{9}$ Esse intervalo de tempo se refere à frequência com que os dados são coletados, isto é, se as séries são diárias, semanais, mensais, anuais etc.

${ }^{10} \mathrm{~A}$ distribuição de Poisson atribui maiores probabilidades aos valores próximos à média $\lambda$.

${ }^{11}$ Para o modelo Poisson, $\phi=1$.
} 
No R, o modelo Poisson pode ser ajustado com a função $g \operatorname{lm}()$ do pacote stats, utilizando o argumento family = poisson, enquanto o modelo com resposta Binomial Negativa utilizando a função $\mathrm{glm} . \mathrm{nb}$ () do pacote MASS. Utilizando o pacote caret, esses modelos podem ser ajustados utilizando a função train( ) com method="glm".

\subsection{Modelos aditivos generalizados}

Os modelos lineares têm um papel muito importante na análise de dados, provendo técnicas de inferência e predição computacionalmente simples e de fácil interpretação. Contudo, em problemas reais, a relação entre a variável resposta e os preditores pode não ser linear, tornando os modelos lineares muito restritivos. No estudo de poluentes atmosféricos, por exemplo, o aspecto temporal dos dados gera efeitos sazonais cuja relação com a variável reposta é mais bem representada por curvas senoidais do que por retas.

Os modelos aditivos generalizados (Hastie et al., 2008) são um método integrado, automático e flexível para identificar e caracterizar relações não lineares entre as variáveis. Ao contrário das estratégias discutidas na Seção 3.1.5, como transformação da variável e regressão polinomial, os modelos aditivos generalizados não são lineares nos parâmetros, permitindo a estimação de funções não lineares entre os preditores e a resposta. Belusic et al. (2015), por exemplo, utilizaram essa classe de modelos para avaliar quais as variáveis mais importantes para descrever a série de diversos poluentes em Zagreb, Croácia. O modelo ajustado apontou que as variáveis meteorológicas explicavam a maior proporção da variabilidade dos poluentes.

Nesta seção, vamos discutir o ajuste e interpretação dos modelos aditivos generalizados no contexto de estudos de poluição do ar.

\subsubsection{Especificação do modelo}

O modelo aditivo generalizado é uma extensão do modelo linear generalizado que permite associar cada um dos preditores à variável resposta a partir de funções não lineares, mantendo a suposição de aditividade (Seção 3.1.6). Como nas seções anteriores, sejam $Y_{t}$ e $\mathbf{X}_{t}$ séries temporais que representam, respectivamente, a variável resposta e as variáveis preditoras, com $t=1, \ldots, n$. O modelo aditivo generalizado pode ser escrito como

$$
\begin{gathered}
Y_{t} \mid \mathbf{X}_{t} \stackrel{i n d}{\sim} \mathcal{D}\left(\mu_{t}, \phi\right) \\
g\left(\mu_{t}\right)=\beta_{0}+f_{1}\left(X_{1 t}\right)+\cdots+f_{p}\left(X_{p t}\right),
\end{gathered}
$$

sendo $\mathcal{D}$ uma distribuição pertencente à família exponencial e $f_{i}, i=1, \ldots, p$, funções possivelmente não lineares. No caso mais simples, assim como nos modelos lineares generalizados, supõe-se que as variáveis $Y_{t}$ são homocedásticas, independentes e normalmente distribuídas.

Existem diversas propostas sobre como as funções $f_{1}, \ldots, f_{p}$ devem ser representadas, incluindo o uso de splines naturais, splines suavizados e regressão local (Hastie e Tibshirani, 1990). Outro ponto importante diz respeito à suavidade dessas funções, controlada por parâmetros de alisamento, que devem ser determinados a priori ${ }^{12}$. Curvas muito suaves podem ser muito restritivas, enquanto

\footnotetext{
${ }^{12}$ Uma maneira de determinar valores para esses parâmetros é utilizar validação cruzada, que será discutida no Capítulo 4.
} 
curvas muito rugosas podem sobreajustar os dados (overfitting). Discutiremos esse tema com mais detalhes na Seção 3.3.2.

O procedimento de estimação no contexto de modelos aditivos generalizados depende da forma escolhida para as funções $f_{1}, \ldots, f_{p}$. A utilização de splines naturais, por exemplo, permite a aplicação direta de mínimos quadrados, graças à sua construção a partir de funçôes base (ver Seção 3.3.2). Já para splines penalizados, o processo de estimação envolve algoritmos um pouco mais complexos, como retroajustamento (backfitting) (Breiman e Friedman, 1985). Para mais informações sobre a estimação dos parâmetros dos modelos aditivos generalizados, consulte Hastie e Tibshirani (1990) e Hastie et al. (2008).

A seguir, introduziremos os conceitos de splines e regressão local.

\subsubsection{Splines e regressão local}

Considere novamente o modelo mais simples, com apenas uma variável explicativa

$$
Y_{t}=\beta_{0}+\beta_{1} X_{t}+\epsilon_{t}, \quad t=1, \ldots, t .
$$

Uma das principais ideias por trás dos modelos aditivos generalizados está na utilização de funções base. Essa abordagem considera uma família de transformações $b_{1}(X), b_{2}(X), \ldots, b_{k}(X)$, fixadas e conhecidas, no lugar de $X$ em (3.11). Assim, o modelo (3.11) passa a ser

$$
Y_{t}=\beta_{0}+\beta_{1} b_{1}\left(X_{t}\right)+\beta_{2} b_{2}\left(X_{t}\right)+\cdots+\beta_{k} b_{k}\left(X_{t}\right)+\epsilon_{t}, \quad t=1, \ldots, t,
$$

que pode assumir diversas classes de associações não lineares entre $X$ e $Y$. Note que o modelo polinomial apresentado na Seção 3.1.5 é um caso particular de (3.12), com $b_{j}\left(X_{t}\right)=X_{t}^{j}, j=1, \ldots, k$.

Como uma tentativa para aumentar a flexibilidade da curva ajustada, podemos segmentar $X$ e ajustar diferentes polinômios de grau $d$ em cada um dos intervalos ${ }^{13}$. Cada ponto de segmentação é chamado de nó, e uma segmentação com $k$ nós gera $k+1$ polinômios. Na Figura 3.11 apresentamos um exemplo com polinômios de terceiro grau e 4 nós. Nesse exemplo, a expressão (3.12) tem a forma

$$
Y_{t}= \begin{cases}\beta_{01}+\beta_{11} X_{t}+\beta_{21} X_{t}^{2}+\beta_{31} X_{t}^{3}+\epsilon_{t}, & \text { se } X_{t} \leq-0.5, \\ \beta_{02}+\beta_{12} X_{t}+\beta_{22} X_{t}^{2}+\beta_{32} X_{t}^{3}+\epsilon_{t}, & \text { se }-0.5<X_{t} \leq 0, \\ \beta_{02}+\beta_{13} X_{t}+\beta_{23} X_{t}^{2}+\beta_{33} X_{t}^{3}+\epsilon_{t}, & \text { se } 0<X_{t} \leq 0.5, \\ \beta_{02}+\beta_{14} X_{t}+\beta_{24} X_{t}^{2}+\beta_{34} X_{t}^{3}+\epsilon_{t}, & \text { se } 0.5<X_{t} \leq 1, \\ \beta_{05}+\beta_{15} X_{t}+\beta_{25} X_{t}^{2}+\beta_{35} X_{t}^{3}+\epsilon_{t}, & \text { se } X_{t}>1,\end{cases}
$$

sendo que as funções base $b_{1}(X), b_{2}(X), \ldots, b_{k}(X)$ nesse caso são construídas com a ajuda de funções indicadoras. Esse modelo é conhecido como modelo polinomial cúbico segmentado.

Repare que a curva formada pela junção de cada um dos polinômios na Figura 3.11 não é contínua, isto é, apresenta saltos nos nós. Essa característica não é desejável para um modelo ajustado, já que essas descontinuidades não são interpretáveis. Para contornar esse problema, vamos definir um spline de grau $d$ como um polinômio segmentado de grau $d$ com as $d-1$ primeiras derivadas contínuas em cada nó. Essa restrição garante a continuidade e suavidade (ausência de vértices)

\footnotetext{
$X$.

${ }^{13}$ Em contrapartida ao modelo polinomial, que ajusta um único polinômio sobre todo o intervalo de variação de
} 


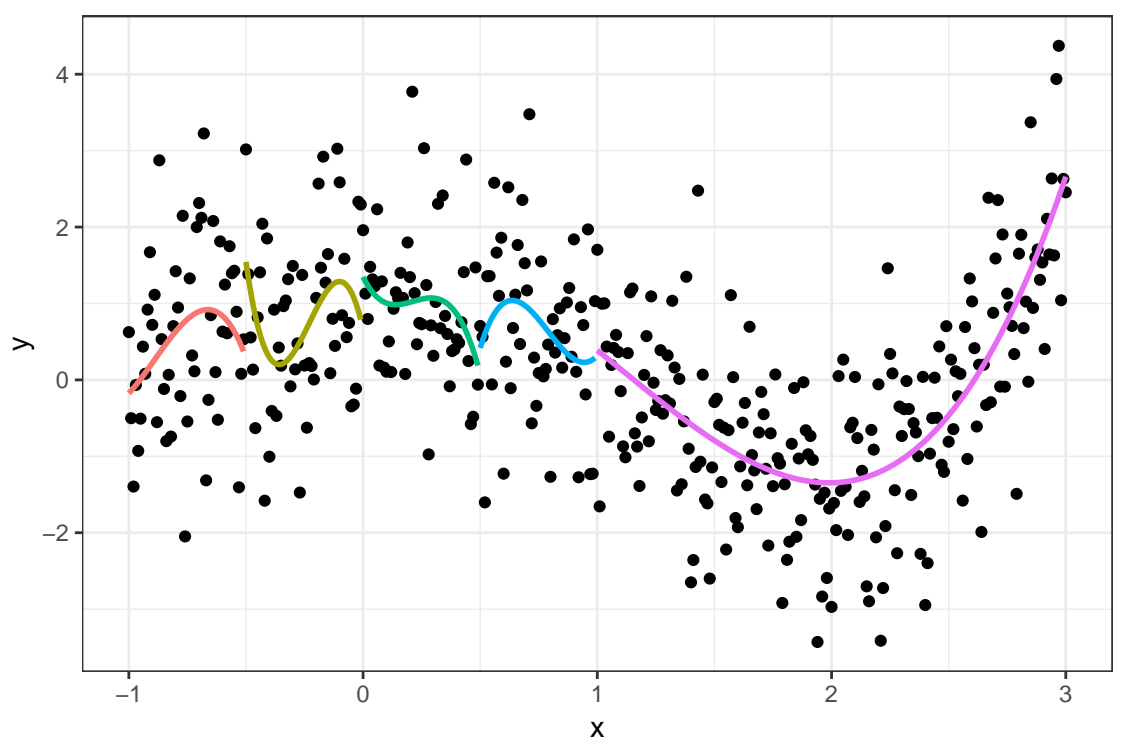

Figura 3.11: Polinômios de terceiro grau ajustados em cada segmentação da variável X. Os nós são os pontos $x=-0.5, x=0, x=0.5$ e $x=1$.

da curva obtida. Mais detalhes sobre a construção dos splines cúbicos podem ser encontrados em Hastie et al. (2008) e James et al. (2013).

Além das restrições sobre as derivadas, podemos adicionar restrições de fronteira, exigindo que a função seja linear na região de $X$ abaixo do menor nó e acima do maior nó. Essas restrições diminuem a variância nos extremos do preditor, produzindo estimativas mais estáveis. Um spline cúbico com restrições de fronteira é chamado de spline natural.

No ajuste de splines cúbicos ou naturais, o número de nós determina o grau de suavidade da curva, e a sua escolha pode ser feita por validação cruzada (James et al., 2013). De uma forma geral, a maior parte dos nós é posicionada nas regiões do preditor com mais informação, isto é, mais observações. Por pragmatismo, para modelos com mais de uma variável explicativa, costuma-se adotar o mesmo número de nós para todos os preditores.

Os splines suavizados constituem uma classe de funções suavizadoras que não utilizam a abordagem por funções bases. De maneira resumida, um spline suavizado é uma função $f$ que minimiza a seguinte expressão

$$
\sum_{i=1}^{n}\left(Y_{i}-f\left(X_{i}\right)\right)^{2}+\lambda \int f^{\prime \prime}(u)^{2} d u
$$

O primeiro termo dessa expressão garante que $f$ se ajustará bem aos dados, enquanto o segundo penaliza a sua variabilidade, isto é, controla o quanto $f$ será suave. A suavidade é regulada pelo parâmetro $\lambda$, sendo que $f$ se torna mais suave conforme $\lambda$ cresce. A escolha desse parâmetro é geralmente feita por validação cruzada.

Uma outra forma para ajustar funções não lineares entre $X$ e $Y$ é conhecida como regressão local. Essencialmente, essa técnica consiste em ajustar modelos de regressão simples em regiões de pontos ao redor de cada observação $x_{0}$ do preditor $X$. Essas regiões são formadas pelos $k$ pontos mais próximos de $x_{0}$, sendo que o parâmetro $s=k / n$, determina o quão suave ou rugosa será a curva ajustada. O ajuste é feito por mínimos quadrados ponderados, com pesos inversamente proporcionais à distância do ponto em relação a $x_{0}$. Assim, os pontos na vizinhança de $x_{0}$ mais 
afastados recebem peso menor.

$\mathrm{Na}$ linguagem $\mathrm{R}$, modelos aditivos generalizados podem ser ajustados utilizando-se a função gam () do pacote mgcv. Essa função permite a utilização de splines como função suavizadora. Para a utilização de regressão local, é necessário usar a função gam () do pacote gam. Também é possível utilizar o pacote caret, a partir da função train() e method = "gam".

Para mais informações sobre splines, regressão local e modelos lineares aditivos em geral, consultar Hastie et al. (2008) e James et al. (2013).

\subsection{Modelos de séries temporais}

Às vezes, queremos explicar a série $Y$ apenas por seus valores defasados no tempo (autocorrelação) ou pelos valores defasados dos preditores $X_{1}, \ldots, X_{p}$ (correlação cruzada). Isso é feito principalmente em estudos de previsão, nos quais não temos o valor de preditores no instante futuro para alimentar o modelo. Imagine, por exemplo, que temos as concentrações médias de ozônio para os dias $1,2, \ldots, t$ e queremos construir um modelo para prever a concentração média no dia $t+1$. Se incluirmos como preditor nesse modelo a temperatura média contemporânea, vamos precisar da temperatura média do dia $t+1$ para prever a concentração de ozônio, sendo que não teremos essa informação no dia $t$.

O maior objetivo dos modelos de séries temporais é ajustar os componentes temporais de uma série (autocorrelação, tendência e sazonalidade), gerando um bom modelo para previsão. Nesta seção, vamos introduzir a classe de modelos ARIMA (Box e Jenkins, 1970), que contemplam a correlação gerada por relações lineares entre observações defasadas no tempo da própria variável. A associação entre a variável resposta covariáveis defasadas no tempo não será tratada aqui, mas são contemplados por modelos de regressão defasada (lagged regression), discutidos nas seções 4.10 e 5.6 de Shumway e Stoffer (2006).

\subsubsection{Modelos autorregressivos (AR)}

Modelos autorregressivos se baseiam na ideia de que $Y_{t}$ pode ser explicada como uma função de $p$ valores passados $Y_{t-1}, \ldots, Y_{t-p}$, sendo $p$ o número de passos no passado necessários para prever o valor no instante $t$. Se $Y_{t}$ é uma série estacionária, o modelo autorregressivo de ordem $P$, abreviado como $\operatorname{AR}(p)$, é definido como

$$
Y_{t}=\phi_{1} Y_{t-1}+\cdots+\phi_{p} Y_{t-p}+w_{t}
$$

sendo $\phi_{1}, \ldots, \phi_{p}$ constantes com $\phi_{p} \neq 0$ e $w_{t} \sim N\left(0, \sigma_{w}^{2}\right), t \geq 0$. Sem perda de generalidade, supomos que a média de $Y_{t}$ é zero ${ }^{14}$.

Os modelos $\operatorname{AR}(p)$ são muito utilizados em Economia, onde é natural pensar o valor de alguma variável no instante $t$ como função de seus valores defasados, e em algumas áreas da Física e Geofísica, onde os estimadores autorregressivos são utilizados para estimar o espectro de certos processos.

\footnotetext{
${ }^{14}$ Se a média de $Y_{t}$ é $\mu \neq 0$, então o modelo é definido para $Y_{t}-\mu$, o que equivale a acrescentar um intercepto $\alpha=\mu\left(1-\phi_{1}-\ldots \phi_{p}\right)$ ao modelo (3.14).
} 


\subsubsection{Modelos autorregressivos e de médias móveis (ARMA)}

Uma alternativa para o modelo $\operatorname{AR}(p)$ é o modelo de médias móveis de ordem $q$. Esse modelo assume que $Y_{t}$ é gerado a partir de uma combinação linear dos erros $w_{t}, w_{t-1}, \ldots, w_{t-q}$. Formalmente, o modelo de médias móveis de ordem $q, \mathrm{MA}(q)$, é definido como

$$
Y_{t}=w_{t}+\theta_{1} w_{t-1}+\cdots+\theta_{q} w_{t-q}
$$

sendo $\theta_{1}, \ldots, \theta_{q}$ constantes com $\theta_{q} \neq 0$ e $w_{t} \sim N\left(0, \sigma_{w}^{2}\right), t \geq 0$.

Ao contrário dos modelos autorregressivos, representar um processo por um modelo de médias móveis puro parece não ser intuitivo.

A utilização de modelos com termos autorregressivos e de médias móveis pode ser uma boa alternativa para muitas séries encontradas na prática, pois eles normalmente requerem um menor número de parâmetros para explicar a autocorrelação da série (Morettin e Toloi, 2004). Nesse sentido, dizemos que uma série temporal $Y_{t}$ é $\operatorname{ARMA}(p, q)$ se ela é estacionária e se

$$
Y_{t}=\phi_{1} Y_{t-1}+\cdots+\phi_{p} Y_{t-p}+w_{t}+\theta_{1} w_{t-1}+\cdots+\theta_{q} w_{t-q}
$$

$\operatorname{com} \phi_{p} \neq 0, \theta_{q} \neq 0$ e $\sigma_{w}^{2}>0$.

Repare que os modelos $\operatorname{AR}(p)$ e $\operatorname{MA}(q)$ são casos particulares do $\operatorname{ARMA}(p, q)$, com $q=0$ e $p=0$ respectivamente.

A estimação dos parâmetros $\left(\phi_{1}, \ldots, \phi_{p}\right)$ e $\left(\theta_{1}, \ldots, \theta_{q}\right)$ pode ser feita por máxima verossimilhança ou pelo método de mínimos quadrados. Para mais informações, consulte a Seção 3.6 de Shumway e Stoffer (2006).

As três classes de modelos apresentadas até aqui consideram que a série $Y_{t}$ é estacionária, o que normalmente não acontece na prática. Para flexibilizar essa restrição, apresentaremos a seguir os modelos $\operatorname{ARIMA}(p, d, q)$, uma extensão da classe ARMA que considera a diferenciação de grau $d$ da série para eliminar a não estacionariedade.

\subsubsection{Modelos autorregressivos integrados e de médias móveis (ARIMA)}

Vimos na Seção 3.1.2 que séries não estacionárias podem ser diferenciadas para se alcançar a estacionariedade. De maneira geral, essa estratégia é válida para séries que não apresentam "comportamento explosivo" ou, em outros termos, que apresentam alguma homogeneidade em seu comportamento não-estacionário. Morettin e Toloi (2004) enquadram séries dessa natureza, chamadas de séries não estacionárias homogêneas, em dois grupos:

- séries que oscilam ao redor de um nível médio durante algum tempo e depois saltam para outro nível temporário;

- e séries que oscilam em uma direção por algum tempo e depois mudam para outra direção temporária.

O primeiro tipo requer apenas uma diferença para torná-las estacionárias, enquanto o segundo requer duas. Dessa forma, a série não estacionária homogênea $Y_{t}$ é dita $\operatorname{ARIMA}(p, d, q)$ se $\Delta^{d} Y_{t}$, como definido em (2.1), é $\operatorname{ARMA}(p, q)$. 
Como discutido na Seção 3.8 de Shumway e Stoffer (2006) e no Capítulo 6 de Morettin e Toloi (2004), precisamos seguir alguns passos essenciais no ajuste de modelos ARIMA:

1. Construir o gráfico da série.

2. Transformar a série, se necessário.

3. Identificar a ordem de dependência do modelo.

4. Estimar os parâmetros.

5. Calcular medidas de diagnóstico.

6. Selecionar o melhor modelo.

No primeiro passo, podemos encontrar anomalias, como heterocedasticidade, a partir do gráfico da série contra o tempo. No passo 2, corrigimos essas anomalias utilizando alguma transformação.

No passo 3, precisamos identificar as ordens $p, d$ e $q$ do modelo. O próprio gráfico da série irá sugerir se alguma diferenciação será necessária. Se alguma diferenciação for realizada, calculamos $\Delta Y_{t}, t=2, \ldots, n$, e avaliamos no gráfico da série $\Delta Y_{t}$ contra o tempo $t$ se outra diferença é necessária. Continuamos esse processo, sempre verificando os gráficos da série diferenciada contra o tempo ${ }^{15}$.

Com o valor de $d$ selecionado, observamos o gráfico da função de autocorrelação amostral e da função de autocorrelação parcial amostral de $\Delta^{d} Y_{t}$. Sugestões para os valores de $p$ e $q$ podem ser encontrados segundo os critérios apresentados na Tabela 3.1.

Tabela 3.1: Critérios para a escolha da ordem de modelos ARIMA.

\begin{tabular}{c|c|c|c}
\hline & $\operatorname{AR}(p)$ & $\operatorname{MA}(q)$ & $\operatorname{ARMA}(p, q)$ \\
\hline ACF & Cauda longa & Desaparece após o lag $q$ & Cauda longa \\
PACF & Desaparece após o lag $p$ & Cauda longa & Cauda longa \\
\hline
\end{tabular}

A ideia nesse passo é utilizar os gráficos das funções de autocorrelação e autocorrelação parcial para escolher alguns valores para $p, d$ e $q$ e, no passo 4 , ajustar os respectivos modelos. Assim, a partir da análise de diagnóstico realizada no passo 5 , selecionar, no passo 6 , o modelo que melhor se ajustou aos dados.

A classe ARIMA pode ser generalizada para incluir o ajuste da sazonalidade. Essa nova classe, conhecida como SARIMA, inclui termos autorregressivos e de médias móveis para termos separados por lags de tamanho $s$. Para mais informações, recomendamos a leitura do Capítulo 10 de Morettin e Toloi (2004) e da Seção 3.9 de Shumway e Stoffer (2006).

$\mathrm{Na}$ linguagem $\mathrm{R}$, uma maneira conveniente para ajustar um modelo ARIMA é utilizar a função auto.arima () do pacote forecast. O algoritmo dessa função retorna o melhor modelo ARIMA com base em alguma métrica de qualidade de ajuste do modelo ${ }^{16}$, ajustando todas as combinações de valores para $p, d$ e $q$ segundo alguma restrição (combinação de todas as ordens menores que 5, por exemplo).

\footnotetext{
${ }^{15}$ Cuidado para não introduzir dependência onde não existe. Por exemplo, $Y_{t}=w_{t}$ é serialmente não-correlacionada, mas $\Delta Y_{t}=w_{t}-w_{t-1}$ é MA(1).

${ }^{16}$ As opções disponíveis são AIC, AICc ou BIC.
} 


\subsection{Modelos não supervisionados}

Nas seções anteriores, apresentamos alguns modelos supervisionados, nos quais uma variável resposta supervisiona o aprendizado sobre fenômeno de interesse. Em alguns problemas, nós não temos acesso à variável resposta, nos restando buscar informação sobre o fenômeno de interesse apenas a partir da correlação entre os preditores. Essa estratégia é chamada de análise não supervisionada e é geralmente utilizada para realizar agrupamentos e redução de dimensionalidade.

Em estudos de poluição do ar, modelos não supervisionados são utilizados principalmente para a deteç̧ão de fontes de poluentes, isto é, dadas as medidas de concentração de diversos poluentes ao longo de um período, formamos grupos com as emissões mais correlacionadas e, a partir de inventários de poluição e conhecimento teórico, identificamos as fontes representadas por cada grupo (Buhr et al., 1992; Chavent et al., 2009; Thurston e Spengler, 1985). Em estudos epidemiológicos, essas técnicas também podem ser utilizadas para determinar as principais doenças responsáveis por internação em hospitais (Tecer, 2009).

A seguir, apresentaremos a análise de componentes principais (Jolliffe, 2002) e a análise fatorial (Child, 2006), dois modelos não supervisionados bastante utilizados em estudos de poluição do ar.

\subsubsection{Análise de componentes principais}

Suponha que queiramos investigar a concentração de dois poluentes, digamos $X_{1}$ e $X_{2}$. Dada uma amostra de tamanho $n$ dessas variáveis, para explorar esses dados descritivamente, poderíamos construir um gráfico de dispersão de $X_{1}$ contra $X_{2}$ e, a partir dele, observar tanto a variabilidade desses poluentes quanto como sua correlação. Se eles apresentarem correlação positiva, teríamos indícios de que eles são gerados pela mesma fonte ou sob as mesmas condições atmosféricas.

Suponha agora que, em vez de 2 poluentes, tivéssemos 10. Para construir gráficos de dispersão para todas as combinações dois a dois, precisaríamos analisar 45 gráficos, sendo que cada um deles só traria uma pequena parte da informação contida nos dados, pois estaríamos ignorando possíveis interações entre as variáveis.

Em geral, para $p$ poluentes, gostaríamos de uma maneira de visualizar o máximo possível da informação contida no espaço $p$-dimensional gerado pelos preditores $X_{1}, \ldots, X_{p}$ em uma representação (gráfica) com poucas (duas) dimensões. Esse é o objetivo da análise de componentes principais.

Dado um conjunto de preditores $X_{1}, X_{2}, \ldots, X_{p}$, a análise de componentes principais visa encontrar uma projeção ortogonal $Z_{1}, Z_{2}, \ldots, Z_{p}$, tal que

$$
\operatorname{VAR}\left(Z_{1}\right) \geq \operatorname{VAR}\left(Z_{2}\right) \geq \cdots, \operatorname{VAR}\left(Z_{p}\right)
$$

Isso implica que, em geral, com apenas as primeiras variáveis $Z_{1}, Z_{2}, \ldots, Z_{p}$, digamos $Z_{1}$ e $Z_{2}$, podemos explicar a maior parte da variabilidade dos preditores $X_{1}, X_{2}, \ldots, X_{p}$. Assim, $Z_{1}$ e $Z_{2}$ representariam em apenas 2 dimensões a maior parte da informação contida nos dados originais.

Cada variável $Z_{i}$, chamada de $i$-ésima componente principal, é uma combinação linear dos preditores $X_{1}, X_{2}, \ldots, X_{p}$, isto é,

$$
Z_{i}=\phi_{1 i} X_{1}+\phi_{2 i} X_{2}+\cdots \phi_{p i} X_{p}
$$

sendo que os elementos $\phi_{1 i}, \ldots, \phi_{p i}$ são os pesos do $i$-ésimo componente principal. Como esses 
pesos são normalizados, $\sum_{j=1}^{p} \phi_{j i}^{2}=1$, temos que $\phi_{j i}<1$, para todo $j=1, \ldots, p$. Assim, os $\phi_{1 i}, \ldots, \phi_{p i}$ próximos de 1 indicam preditores positivamente associados e cuja variabilidade está sendo representada por $Z_{i}$.

Como $Z_{1}, Z_{2}, \ldots, Z_{p}$ representa uma projeção ortogonal, cada par de componentes $\left(Z_{i}, Z_{j}\right)$ é não correlacionado. Dessa forma, o componente $Z_{2}$, por exemplo, é a combinação linear de $X_{1}, X_{2}, \ldots, X_{p}$ de maior variância entre todas as combinações lineares que são não correlacionadas $\operatorname{com} Z_{1}$. Isso quer dizer que as fontes de variação representadas por $Z_{2}$ são não correlacionadas com as encontradas em $Z_{1}$.

Voltando ao nosso exemplo com os poluentes, se a análise de componentes principais indicasse os poluentes $X_{1}, X_{3}$ e $X_{5}$ como aqueles com maiores pesos para o componente $Z_{1}$, então saberíamos que esses são os poluentes que mais contribuem com a variação total dos dados e poderíamos estudar o que causa essa variação. Da mesma forma, se os poluentes $X_{2}, X_{3}$ e $X_{4}$ são aqueles com maior peso para o componente $Z_{2}$, então sabemos que a causa da variabilidade desses poluentes é não correlacionada com a anterior.

Os cálculos por trás da análise de componentes principais envolvem decomposição espectral (Nicholson, 2001), uma técnica de álgebra linear para decompor matrizes em função de seus autovetores e autovalores.

$\mathrm{Na}$ linguagem $\mathrm{R}$, podemos realizar uma análise de componentes principais utilizando a função prcomp () do pacote stats.

\subsubsection{Análise Fatorial}

Assim como a análise de componentes principais, a análise fatorial também pode ser utilizada para redução de dimensionalidade. A segunda técnica difere da primeira em dois pontos principais. Primeiro, a análise fatorial supõe que a variância e covariância contida em um conjunto de variáveis $X_{1}, X_{2}, \ldots, X_{p}$ podem ser explicadas por um conjunto menor de fatores latentes ${ }^{17}$. Se esses fatores são definidos a priori, o modelo pode ser utilizado para testar teorias sobre a relação entre os fatores e as variáveis observadas. O segundo ponto diz respeito à inclusão de erros aleatórios. Enquanto a análise de componentes principais calcula um novo conjunto de variáveis que explica $100 \%$ da variabilidade das variáveis originais, a análise fatorial considera que parte da variabilidade das variáveis originais pode ser explicada pelos fatores latentes, mas uma outra parte é devida a ruído aleatório.

A análise fatorial é geralmente utilizada para avaliarmos fontes de poluição, sendo que cada fator representa uma fonte diferente. Podemos pensar em cada fonte como uma variável latente, que pode ser representada por uma combinação linear das concentrações observadas. A inclusão de erros aleatórios seria justificada, por exemplo, pela variação nas concentrações causadas por condições atmosféricas.

Dada uma amostra de tamanho $n$ dos preditores $X_{1}, X_{2}, \ldots, X_{p}$, a análise fatorial procura estimar os pesos $l_{i j}, i=1, \ldots, p$ e $j=1, \ldots, m$, tais que

$$
Z_{i k}=l_{i 1} F_{1 k}+\cdots l_{i m} F_{m k}+\epsilon_{i k},
$$

sendo que, para a $k$-ésima observação da amostra, $Z_{i k}=\frac{X_{i k}-\bar{X}_{i}}{\sigma_{i}}$ é o $i$-ésimo preditor normalizado,

\footnotetext{
${ }^{17}$ Variáveis aleatórias que não podem ser observadas diretamente, como inteligência ou intensidade de dor
} 
$F_{j k}$ é o $j$-ésimo fator e $\epsilon_{i k}$ é o erro associado ao $i$-ésimo preditor.

O número de fatores $m$ deve ser escolhido antes do ajuste, sendo que a interpretação de cada fator é externa ao modelo. Mesmo quando cada fator é construído teoricamente a priori, o modelo não indica qual dos termos $F_{j k}$ representa cada fator. A identificação dos fatores é feita então a partir de conhecimento teórico sobre o fenômeno estudado.

Mais informações sobre análise fatorial, como o processo de estimação e interpretação geométrica, podem ser encontradas em Everitt e Hothorn (2011). Na linguagem R, esse modelo pode ser ajustado utilizando a função factanal () do pacote stats.

\subsection{Outros modelos}

\subsubsection{Modelos mistos}

Os modelos mistos (ou modelos de coeficientes aleatórios) foram introduzidos por Fisher (1918) para estudar a correlação de traços hereditários em pais, mães e filhos. Eles são particularmente úteis em estudos clínicos, ensaios biológicos e estudos sociais, nos quais variáveis medidas em uma mesma unidade amostral (medidas repetidas) ou unidades amostrais com agrupamentos naturais ${ }^{18}$ (dados hierárquicos) geram observações correlacionadas.

Essa classe de modelos utiliza coeficientes aleatórios para controlar os efeitos individuais e de grupo que não podem ser observados ${ }^{19}$. Ao contrário dos coeficientes fixos dos modelos de regressão vistos até aqui, que modelam a média da variável resposta, os efeitos aleatórios introduzem uma estrutura para a variância de $Y$, contemplando a correlação entre observações de um mesmo grupo e as diferentes variâncias de observações de diferentes grupos.

Em estudos de poluição do ar, modelos mistos são usados principalmente para controlar variações individuais em estudos epidemiológicos longitudinais. Liao et al. (1999), por exemplo, avaliaram a resposta autonômica cardiovascular associadas a variações diárias de material particulado 2.5 em 26 idosos durante 3 semanas consecutivas, mostrando que o aumento dos níveis de MP2.5 estão associados a um menor controle autonômico cardíaco. Coull et al. (2001) utilizaram um modelo aditivo misto para associar mudanças na concentração de poluentes atmosféricos com a função pulmonar de crianças ao longo de 109 dias. Eles mostraram que o modelo misto era o mais adequado para contemplar a heterogeneidade populacional da suscetibilidade à poluição. Chuang et al. (2011) avaliaram o uso de um componente aleatório para os graus de liberdade de um modelo aditivo Poisson em estudos epidemiológicos de poluição do ar. Os autores observaram que esse modelo gerava erros-padrão maiores do que o modelo aditivo usual e concluíram que um alisamento variável da função não linear em conjunto com essa maior variabilidade poderia refletir melhor a realidade. Já Kloog et al. (2012) utilizaram modelos mistos para prever concentrações diárias de material particulado (MP2.5) na costa leste dos Estados Unidos a partir de medidas de profundidade óptica de aerossóis feitas por satélites de 2000 a 2008, encontrando um bom modelo para prever exposições humanas a esse poluente tanto a curto quanto a longo prazo.

Mais informações sobre modelos mistos, como especificação do modelo, estimação e outros exemplos, podem ser encontradas em Singer et al. (2018) e Galecki e Burzykowski (2013).

\footnotetext{
${ }^{18}$ Como membros de uma mesma família, pacientes de um mesmo hospital, animais de uma mesma ninhada ou moradores de uma mesma região.

${ }^{19}$ Como carga genética, criação, o efeito do atendimento por um mesmo médico, níveis de poluição do ar de uma mesma região etc.
} 
Na linguagem R, modelos mistos podem ser ajustados pelas funções dos pacotes nlme e lme 4 .

\subsubsection{Modelos GARCH}

Os modelos para séries temporais apresentados até aqui são utilizados para modelar a média condicional de um processo quando a variância condicional (volatilidade) é constante. Em muitos problemas, contudo, a suposição de homoscedasticidade pode não ser verdadeira.

Os modelos autoregressivos com heteroscedasticidade condicional (ARCH), propostos por Engle (1982), foram desenvolvidos para contemplar mudanças da volatilidade da série. Se $\epsilon_{t} \sim N(0,1)$, para $t=1, \ldots, n$, o modelo $\operatorname{ARCH}(q)$ é definido por

$$
\begin{gathered}
Y_{t}=f(\mathbf{X}, \mathbf{Y})+\sigma_{t} \epsilon_{t} \\
\sigma_{t}^{2}=\alpha_{0}+\alpha_{1} \epsilon_{t-1}^{2}+\ldots \epsilon_{q} \epsilon_{t-q}^{2},
\end{gathered}
$$

com $\alpha_{0}>0$ e $\alpha_{i} \geq 0, i>0$, sendo $f(\mathbf{X}, \mathbf{Y})$ uma função dos preditores $\left\{\left(X_{1 i}, \ldots, X_{p i}\right), i \leq t\right\}$ e das variáveis defasadas $\left(Y_{1}, \ldots, Y_{t-1}\right)$. Repare que a primeira expressão de (3.18) permite o ajuste de diversas classes de modelo para a média condicional de $Y_{t}$, como modelos de regressão linear, modelos ARIMA e modelos de função de transferência, enquanto a segunda impõe um modelo autorregressivo de ordem $p$ para a volatilidade do processo.

Bollerslev (1986) estendeu a classe ARCH, propondo os GARCH (generalized ARCH). Essa nova classe permite o ajuste de um modelo ARMA para a variância do erro $\left(\sigma^{2}\right)$, modelando a volatilidade da série com menos parâmetros que um modelo ARCH (Morettin e Toloi, 2004). Esse modelo pode ser expresso por

$$
\begin{gathered}
Y_{t}=f(\mathbf{X}, \mathbf{Y})+\sigma_{t} \epsilon_{t} \\
\sigma_{t}^{2}=\alpha_{0}+\alpha_{1} \epsilon_{t-1}^{2}+\ldots \alpha_{q} \epsilon_{t-q}^{2}+\beta_{1} \sigma_{t-1}^{2}+\ldots+\beta_{p} \sigma_{t-p}^{2},
\end{gathered}
$$

sendo $f(\mathbf{X}, \mathbf{Y})$ definida como antes.

Por ser um modelo com muitos parâmetros, a especificação do modelo $\operatorname{GARCH}(p, q)$, geralmente é dividida em três passos:

1. Estimar o melhor modelo $\operatorname{AR}(q)$ :

$$
Y_{t}=a_{0}+a_{1} Y_{t-1}+\cdots a_{q} Y_{t-q}+\epsilon_{t}
$$

2. Calcular e construir o gráfico das autocorrelações de $\epsilon^{2}$, dadas por

$$
\rho_{i}=\frac{\sum_{t=i+1}^{T}\left(\hat{\epsilon}_{t}^{2}-\hat{\sigma}_{t}^{2}\right)\left(\hat{\epsilon}_{t-1}^{2}-\hat{\sigma}_{t-1}^{2}\right)}{\sum_{t=1}^{T}\left(\hat{\epsilon}_{t}^{2}-\hat{\sigma}_{t}^{2}\right)^{2}},
$$

sendo $T$ o tamanho amostral.

3. Avaliar valores de $\rho_{i}$ maiores que $1 / \sqrt{T}$.

A estimação desses modelos pode ser conduzida da mesma forma que para os modelos ARMA, discutida na Seção 3.6 de Shumway e Stoffer (2006). Na linguagem R, esse modelo pode ser ajustado 
usando a função garch () do pacote tseries.

Em estudos de poluição do ar, modelos GARCH são utilizados principalmente para aprimorar modelos de previsão, como feito por Kumar e Ridder (2010) para dados de ozônio em Bruxelas e Londres.

\subsubsection{Modelos dinâmicos}

Estudos de poluição atmosférica envolvem dados cuja coleta é naturalmente suscetível à omissão. A medição de poluentes e de variáveis meteorológicas, por exemplo, envolve equipamentos que estão sujeitos a imprecisões, falhas e precisam ser constantemente regulados. Esses dados geralmente são mantidos pela administração pública, cuja redução de verbas pode descontinuar ou reduzir os planos de coleta.

Às vezes, o próprio delineamento do estudo gera dados faltantes. Na análise feita por Salvo e Geiger (2014), os autores descartaram da amostra os meses frios (julho à setembro), devido à menor formação de ozônio nesse período. Por causa da influência do tráfego no estudo, os feriados e fins de semanas também não foram considerados. Essas exclusões geraram uma série com "buracos", inviabilizando a aplicação de modelos que fazem a suposição de observações equidistantes, como os modelos ARIMA apresentados anteriormente.

Os modelos6 lineares dinâmicos (ou espaço-estado ou filtros de Kalman), introduzidos por Kalman (1960) e Kalman e Bucy (1961), são uma alternativa nesses casos. Eles são caracterizados por duas suposições principais. A primeira afirma que a verdadeira variável sob estudo, $U_{t}$, é um fenômeno não observável. Neste caso, o que realmente observamos é uma transformação linear desse fenômeno, $A_{t} U_{t}$, acrescida de um ruído, $v_{t}$. A segunda suposição diz respeito ao processo de geração de $U_{t}$. Mais precisamente, na sua forma mais básica, $U_{t}$ é gerado por um processo autorregressivo de primeira ordem.

Dadas essas duas suposições, podemos escrever o modelo de espaço-estado da seguinte maneira:

$$
\begin{gathered}
Y_{t}=a_{t} U_{t}+v_{t} \\
U_{t}=\phi U_{t-1}+w_{t},
\end{gathered}
$$

com $a_{t}$ e $\phi$ os parâmetros do modelo e $w_{t} \sim N\left(0, \sigma_{w}\right)$. A primeira equação em (3.20) é chamada de equação de estado, enquanto a segunda é chamada de equação de observação.

A aplicação desses modelos nos permite ajustar a série a partir de suas observações passadas, como nos modelos ARIMA, mas, a cada passo (instante), incorporamos informação de um processo externo, que pode ser tanto a informação de variáveis explicativas quanto de outros processos autorregressivos. Assim, valores omissos no instante $t$ são estimados a partir da informação contida em $1, \ldots, t-1$, sendo uma maneira natural e integrada para lidar com os buracos da série.

Dordonnat et al. (2008) apresentam um reconhecida aplicação de modelos dinâmicos para previsão de consumo de energia elétrica na França. Mais informações sobre o modelo, no contexto de poluição do ar, podem ser encontradas no capítulo 12.3 de Zannetti (1990). 


\title{
Capítulo 4
}

\section{Estratégias de aprendizado automático}

\author{
There are no routine statistical questions, \\ only questionable statistical routines. \\ - Sir David Cox
}

Nos últimos anos, a abordagem conhecida como machine learning ${ }^{1}$ se tornou muito popular, principalmente pela sua eficiência na resolução de problemas de predição, como detecção de imagens, transcrição de áudio e sistemas de recomendação de compras. Por trás de todo o marketing em volta desse termo, existe um conjunto de práticas e técnicas que visam gerar a predição mais precisa possível para um fenômeno.

No capítulo anterior, apresentamos diversas classes de modelos úteis para fazer inferência em estudos de poluição do ar. A utilização desses modelos depende de suposições sobre a forma com que as variáveis explicativas e a variável resposta estão relacionadas. De maneira geral, essas suposições são partes de um modelo probabilístico para a variável resposta $Y$, cuja parametrização dependerá de alguma função dos preditores ${ }^{2} \mathbf{X}$. O modelo de regressão linear (3.3), por exemplo,supõe que:

- a média de $Y$ depende das variáveis em $\mathbf{X}$ a partir da relação $\beta_{0}+\beta_{1} X_{1}+\cdots \beta_{p} X_{p}$ (linearidade e aditividade);

- a variância de $Y, \sigma^{2}$, é constante para todas as observações na população.

Essas suposições, potencialmente restritivas, permitem que o modelo seja interpretável, isto é, ao estimarmos os coeficientes $\beta_{0}, \beta_{1}, \ldots, \beta_{p}$, entendemos como a variável $Y$ é influenciada por cada preditor $X_{1}, \ldots, X_{p}$.

As técnicas e modelos utilizados para machine learning colocam a interpretabilidade em segundo plano e priorizam a produção de predições o mais precisas possível para a resposta de interesse. As estratégias dentro dessa abordagem enfrentam a dualidade entre flexibilidade e sobreajuste, isto é, buscam entre modelos complexos (normalmente não interpretáveis) aquele que melhor se ajuste aos dados, mas que ainda possa ser generalizado para além da amostra. Embora essa visão não seja

\footnotetext{
${ }^{1}$ Também conhecida como modelagem preditiva, aprendizado estatístico, aprendizagem automática ou aprendizado de máquina.

${ }^{2}$ Muita da literatura sobre machine learning vem da área da Ciência da Computação. Os computólogos, de uma maneira geral, denominam as variáveis respostas como variáveis de saída ou outputs e os preditores como variáveis de entrada ou inputs.
} 
adequada para inferência, muitas das práticas podem ser incorporadas em estudos inferenciais na tentativa de encontrar modelos mais bem ajustados.

Neste capítulo, discutiremos com mais detalhes o conceito de sobreajuste, apresentando métodos de reamostragem, seleção de variáveis e regularização. Em seguida, introduziremos alguns modelos de árvores, bastante utilizados para modelagem preditiva devido à sua alta precisão. Por fim, apresentaremos alguns métodos gráficos para interpretar modelos "caixa-preta".

\subsection{Sobreajuste e o balanço entre viés e variância}

Como discutido na introdução do Capítulo 3, dificilmente vamos encontrar uma função $f(\cdot)$ que relacione perfeitamente a variável resposta $Y$ e os preditores $\mathbf{X}$, pois estamos sempre sujeitos a dois tipos de erros: um erro redutível e outro irredutível. O erro redutível indica o quanto o modelo escolhido não se adéqua bem ao fenômeno estudado e tem esse nome porque podemos sempre encontrar uma candidata de $f(\cdot)$ que se aproxime mais do processo gerador de $Y$. Reduzir ao máximo esse erro é o grande objetivo da modelagem.

No entanto, mesmo que conseguíssemos eliminar o erro redutível, nossas predições não seriam perfeitas devido ao erro irredutível. Esse erro representa a parte da variabilidade de $Y$ que não pode ser explicada pelos preditores em $\mathbf{X}$, comumente chamado de erro aleatório ou ruído. Assim, por construção, todo modelo estatístico tem um erro associado.

O sobreajuste ou overfitting acontece quando, na tentativa de eliminar o erro redutível, acabamos eliminando também o erro irredutível. Conforme aumentamos a complexidade do modelo, podemos passar a explicar variações aleatórias, que não estão associadas aos preditores considerados. Assim, um modelo sobreajustado gera conclusões que os dados disponíveis não são capazes de sustentar em um contexto mais amplo.

Essa dualidade entre qualidade do ajuste e capacidade de generalização é o maior paradigma da modelagem preditiva, e deveria ter atenção especial em qualquer contexto de modelagem, pois queremos sempre generalizar os resultados do modelo para a população de interesse. Na prática, gostaríamos de encontrar o melhor ajuste que generalize bem os resultados para a população, e essa tarefa pode ser resumida na minimização de duas quantidades: o viés e a variância. Para entender melhor o que essas quantidades representam, imagine que precisamos ajustar um modelo para os dez pontos apresentados na Figura 4.1 (a). Podemos começar ajustando um modelo de regressão linear simples,

$$
Y_{i}=\beta_{0}+\beta_{1} X_{i}+\epsilon_{i}, \quad i=1, \ldots, 10
$$

e calcular a raiz do erro quadrático médio (RMSE), definido na Seção 3.1.7, para avaliar o quanto a reta ajustada se afasta dos pontos. Uma forma de tentar melhorar o ajuste seria acrescentar um termo quadrático e verificar se a RMSE diminui. Podemos repetir esse procedimento acrescentando termos de graus cada vez maiores ${ }^{3}$, até encontrarmos o menor RMSE.

Na Tabela 4.1, apresentamos a RMSE obtida para os modelos de regressão polinomial até o nono grau. Observe que, conforme aumentamos a complexidade do modelo (grau do polinômio), a RMSE diminui, até chegar em 0 para o polinômio de grau 9. Se utilizarmos apenas a RMSE como

\footnotetext{
${ }^{3}$ Esses são os modelos polinomiais apresentados na Seção 3.1.5. O modelo de regressão linear simples é um modelo polinomial de grau 1.
} 
medida da performance do modelo, escolheríamos justamente esse polinômio como modelo final. No entanto, pela Figura 4.1 (b), observamos que esse modelo claramente não representa bem o comportamento dos pontos.

(a)

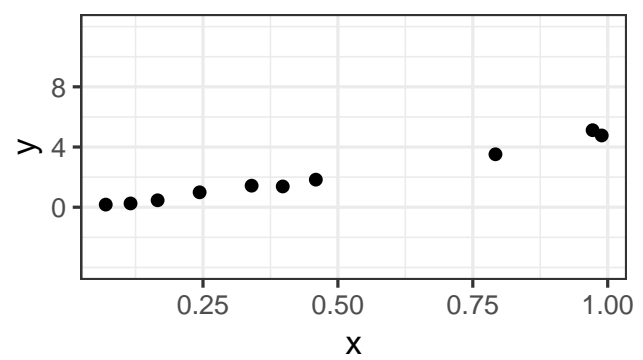

(c)

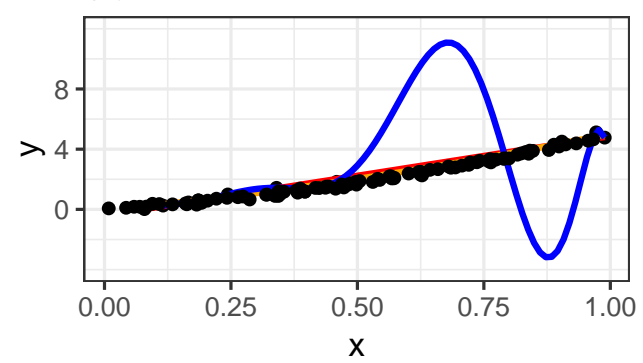

(b)

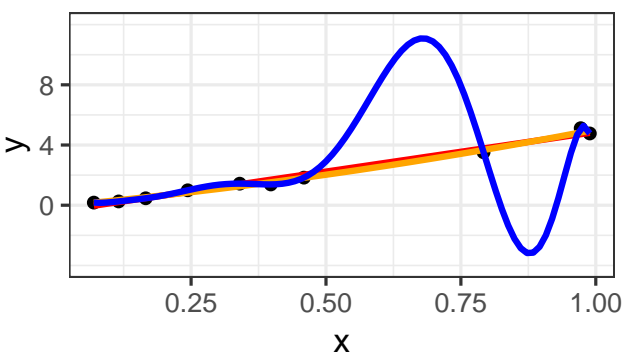

(d)

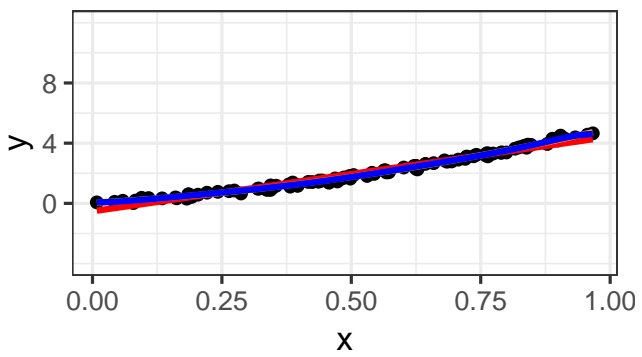

Figura 4.1: Exemplo do balanço entre viés e variância. (a) Conjunto de 10 pontos que gostaríamos de ajustar. (b) Modelo de regressão linear simples (vermelho), modelo de regressão polinomial de grau 2 (amarelo) e modelo de regressão polinomial de grau 9 (azul), ajustados aos 10 pontos. (c) Amostra de 100 novas observações plotadas juntas dos modelos polinomiais ajustados nas 10 observações iniciais. (d) Modelos de regressão polinomial de graus 1 (vermelho), 2 (amarelo) e 9 (azul) ajustados aos 100 novos pontos.

Tabela 4.1: Raiz do erro quadrático médio (RMSE) para os modelos polinomiais de grau 1 a 9 ajustados com 10 e 100 observações no exemplo da Figura 4.1.

\begin{tabular}{c|c|c}
\hline $\begin{array}{c}\text { Grau do } \\
\text { polinômio }\end{array}$ & RMSE (10 obs.) & RMSE (100 obs.) \\
\hline 1 & 0.204 & 0.360 \\
\hline 2 & 0.149 & 0.226 \\
\hline 3 & 0.140 & 0.199 \\
\hline 4 & 0.140 & 0.198 \\
\hline 5 & 0.102 & 0.289 \\
\hline 6 & 0.086 & 0.360 \\
\hline 7 & 0.063 & 0.320 \\
\hline 8 & 0.031 & 1.152 \\
\hline 9 & 0.000 & 3.904 \\
\hline
\end{tabular}

Considere agora, nesse mesmo exemplo, que conseguimos uma nova amostra com mais 100 observações geradas pelo mesmo fenômeno que gerou as 10 primeiras. A Figura 4.1 (c) confirma o 
quanto o modelo polinomial de grau 9 se ajustou mal aos dados, enquanto os modelos de grau 1 e 2 parecem escolhas mais razoáveis. Podemos observar ainda na Tabela 4.1 que a RMSE do modelo polinomial de grau 9 calculada nas 100 novas observações ${ }^{4}$ é o maior entre todos os candidatos. Por fim, observe na Figura 4.1 (d) como a curva desse modelo muda quando o ajustamos agora usando também as 100 novas observações.

Como enfatizado anteriormente, estamos sempre em busca de modelos que se ajustem bem à amostra, mas que também possam ser generalizados para a população. Assim, chamaremos de viés o quanto o modelo ajustado está distante das observações da amostra e de variância o quanto o modelo mudaria se o ajustássemos em uma nova amostra. $\mathrm{O}$ viés representa o erro induzido por aproximar um fenômeno real, que pode pode ser extremamente complicado, por um modelo muito mais simples. Já a variância indica o quanto erraríamos se usássemos o modelo para predizer novas observações. Dizemos então que modelos mal ajustados apresentam alto viés e modelos com baixo poder de generalização apresentam alta variância.

É muito comum utilizarmos estratégias que se preocupam apenas com a minimização do viés. Essas estratégias elegem como boas escolhas modelos complexos, visando um ajuste cada vez melhor aos dados, sem levar em conta o quanto isso será representativo na população. No exemplo anterior, isso fica claro com o ajuste de polinômios de grau cada vez maior aos dados. O polinômio de grau 9 ilustra o conceito de sobreajuste: baixo viés, mas alta variância, não sendo apropriado para representar o fenômeno de interesse. Controlar o balanço entre viés e variância é um dos maiores desafios da modelagem preditiva.

Na presença de muitos preditores, não é possível visualizar graficamente o sobreajuste, como mostrado no exemplo. Por isso, na prática, pode não ser trivial identificar um modelo sobreajustado. Para contornar esse problema, apresentaremos na próxima seção medidas utilizadas para quantificar o viés e a variância de um modelo.

\subsection{Estimando o desempenho do modelo}

Na Seção 3.1.7, vimos que o $R^{2}$ e a RMSE podem ser utilizados para avaliar a qualidade do ajuste de um modelo. Em alguns casos, podemos querer utilizar o erro absoluto médio (MAE, mean absolute error), que, ao contrário da RMSE, não dá mais peso para erros em valores muito altos da variável resposta.

A escolha da métrica de performance vai depender sempre do objetivo do estudo. Independentemente da medida escolhida, ao calculá-la para as próprias observações utilizadas no ajuste, temos uma estimativa do viés do modelo, isto é, quanto o modelo escolhido se ajusta bem à amostra. Essa quantidade é chamada de erro de treino. Para obtermos uma estimativa da variância, precisamos calculá-la para observações não utilizadas no ajuste, representando uma nova amostra do fenômeno sob estudo. Essa quantidade é chamada de erro de teste.

$\mathrm{Na}$ prática, nem sempre teremos à disposição uma nova base de dados para a estimação do erro de teste. Uma alternativa nesses casos é utilizar métodos de reamostragem, que consistem em separar a base disponível em observações utilizadas para treinar o modelo e observações para estimar sua variância. Na próxima seção, apresentaremos dois métodos de reamostragem bastante

\footnotetext{
${ }^{4}$ Aqui, os modelos não foram reajustados. Foram considerados os modelos ajustados apenas com as 10 primeiras observações
} 
utilizados: a validação cruzada e o bootstrapping.

\subsubsection{Validação cruzada}

Como na maioria dos estudos não é possível obter facilmente novas observações, podemos calcular o erro de teste, estimativa da variância do modelo, dividindo a amostra original em duas partes: uma utilizada para o ajuste do modelo (amostra de treino) e a outra para o cálculo do erro (amostra de teste), essa última agindo como se fosse um conjunto de novas observações. Essa técnica é conhecida como validação cruzada (James et al., 2013). Há diversos tipos de validação cruzada, que dependem da forma utilizada para dividir a amostra. Nesta seção, apresentaremos os principais tipos de validação cruzada e discutiremos as vantagens e desvantagens de cada um.

\section{Amostra de validação}

A utilização de uma amostra de validação é a forma mais simples de validação cruzada. A estratégia consiste em dividir aleatoriamente as observações em um conjunto de treino, usado para ajustar o modelo, e outro de teste, utilizado exclusivamente para estimar o erro de teste. A proporção de observações em cada uma depende do tamanho amostral. Costuma-se utilizar $30 \%$ da amostra original no conjunto de teste, mas esse número pode ser menor para amostras muito grandes (mais de 100 mil observações, por exemplo).

As maiores vantagens dessa técnica são a sua simplicidade e a necessidade de se ajustar o modelo uma única vez. No entanto, conforme discutido em James et al. (2013), a amostra de validação apresenta duas potenciais desvantagens:

- a estimativa do erro de teste pode apresentar alta variabilidade, dependendo de quais observações ficaram na amostra de treino e quais ficaram na amostra de validação;

- como a acurácia de modelos estatísticos é menor quando ajustados com menos observações, e apenas parte das observações são utilizadas para treinar o modelo, o erro de teste pode estar sendo superestimado.

A seguir, apresentaremos a validação cruzada leave-one-out (LOOCV), uma técnica de reamostragem que não possui essas limitações.

\section{Validação cruzada leave-one-out (LOOCV)}

Considere uma amostra com $n$ observações. A LOOCV consiste em rodar o modelo escolhido $n$ vezes, sendo que, em cada ajuste, deixamos de fora a $i$-ésima observação, $i=1, \ldots, n$, e a utilizamos para calcular o erro de teste. A estimativa final do erro de teste será então a média das $n$ medidas parciais. Uma esquematização dessa técnica está representada na Figura 4.2.

Repare que, neste caso, todas as observações são utilizadas no ajuste do modelo e na estimativa do erro de teste, o que elimina as limitações incorridas ao utilizarmos a amostra de validação. No entanto, uma desvantagem aqui é a necessidade de ajustar o modelo $n$ vezes. Quando $n$ é muito grande, a LOOCV pode exigir muito esforço computacional, inviabilizando a sua utilização.

Vale ressaltar que esse procedimento é utilizado para estimar as métricas de performance do modelo, sendo que o ajuste do modelo final da análise contempla todas as observações da amostra. 


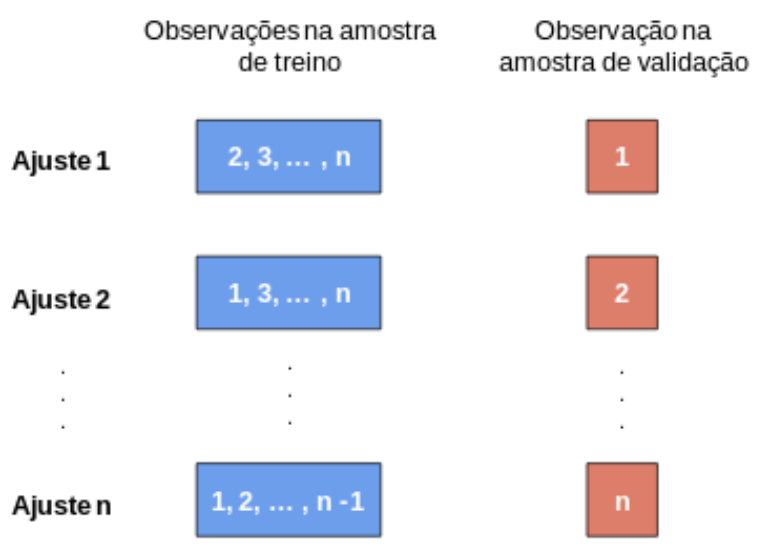

Figura 4.2: Esquematização da validação cruzada leave-one-out.

Dessa forma, ao fim desse procedimento, $n+1$ modelos são ajustados: as $n$ iterações da LOOCV, para a estimação do erro preditivo, e o ajuste final do modelo, com todas as observações.

A seguir, apresentamos validação cruzada $k$-fold, uma generalização da LOOCV que não apresenta a contrapartida computacional.

\section{Validação cruzada k-fold}

Podemos generalizar a LOOCV criando $k$ amostras de teste, com aproximadamente a mesma quantidade de observações e sem intersecção. Então ajustamos o modelo $k$ vezes, sendo que em cada ajuste selecionamos um conjunto diferente como amostra de teste e as observações restantes como a de treino. Essa abordagem é chamada de $k$-fold. Note que a LOOCV é o caso especial em que $k=n$. Na prática, escolhemos valores de $k$ entre 3 e 10 , sendo que $k=5$ é bastante utilizado (Figura 4.3).

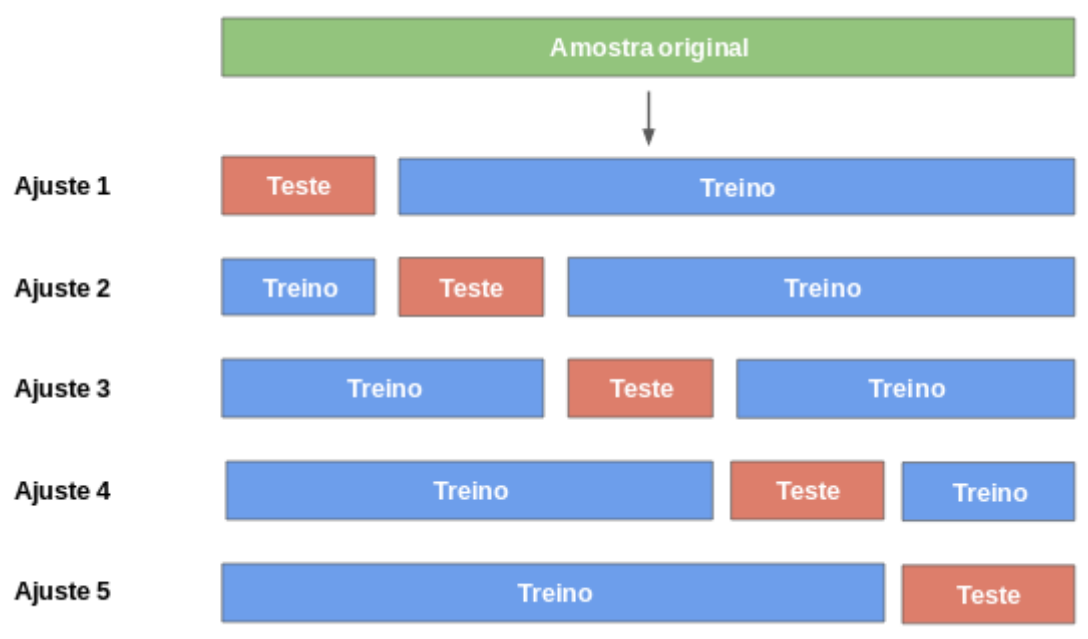

Figura 4.3: Esquematização da validação cruzada $k$-fold, com $k=5$.

A maior vantagem da validação cruzada $k$-fold sobre a LOOCV é computacional. Em vez de ajustarmos o modelo $n$ vezes, ajustamos apenas $k$, sendo que $k<<n$. E como utilizamos todas as observações para treinar o modelo, não temos as limitações de se utilizar uma única amostra de 
validação.

Assim como na LOOCV, o objetivo desse procedimento é estimar o erro de predição. Ao fim, ajustamos o modelo utilizando todas as observações na amostra, que será considerado o modelo final. Assim, o modelo é ajustado $k+1$ vezes: as $k$ iterações da validação $k$-fold e o ajuste com todas as observações.

A validação cruzada é geralmente utilizada para avaliar a performance do modelo. A seguir, apresentaremos uma técnica de reamostragem muito utilizada também para o cálculo do erropadrão das estimativas do modelo.

\subsubsection{Bootstrapping}

O bootstrapping é uma poderosa ferramenta utilizada para quantificar incertezas associadas a estimadores e modelos estatísticos. Ela consiste em gerar $m$ novas amostras a partir de sorteios com reposição da amostra original. Para cada uma das amostras geradas, ajustamos o modelo escolhido e guardamos as estimativas dos parâmetros. Ao repetirmos esse processo para as $m$ amostras, teremos $m$ estimativas diferentes para cada parâmetro do modelo. Assim, para cada parâmetro, podemos, por exemplo, calcular o desvio-padrão dessas $m$ estimativas e utilizar essa medida como o erro-padrão associado ao coeficiente. Repare que os parâmetros do modelo devem ser estimados utilizando a amostra original. Nesse exemplo, o bootstrapping seria usado apenas para estimar a variabilidade dos coeficientes.

Essa técnica é utilizada principalmente quando não conhecemos a distribuição dos estimadores do modelo ou quando precisamos controlar outras fontes de variabilidade. Salvo e Geiger (2014) e Salvo et al. (2017), por exemplo, utilizaram o bootstrapping para estimar o erro-padrão dos coeficientes do modelo de regressão linear ajustado para associar a concentração de ozônio na cidade de São Paulo com a proporção estimada de veículos bicombustíveis abastecidos com gasolina. Segundo os autores, essa estratégia foi utilizada para contemplar a variação causada pelo erro de medida presente na estimação da proporção de carros a gasolina e na medição das condições climáticas.

O bootstrapping também pode ser utilizado para a estimação da performance do modelo. Neste caso, cada uma das $m$ amostras é utilizada como conjunto de treino e as observações que foram sorteadas em cada amostra são utilizada com conjunto de teste. Em geral, o tamanho de cada amostra de bootstrapping tem o mesmo tamanho da base original.

Mais informações sobre o bootstrapping podem ser encontradas em James et al. (2013).

\subsection{Seleção de variáveis}

$\mathrm{Na}$ especificação do modelo, muitas vezes incluímos variáveis que não são associadas com o fenômeno sob estudo. Isso acontece principalmente quando temos pouco conhecimento sobre o mecanismo gerador do fenômeno ou quando estamos justamente investigando quais fatores estão associados a ele.

Como variáveis irrelevantes geram uma complexidade desnecessária no modelo, podemos pensar em estratégias para retirá-las da análise, aumentando a interpretabilidade dos resultados. Nesta seção, apresentaremos algumas técnicas de seleção de variáveis que podem ser utilizadas em qualquer classe de modelos estatísticos. 


\subsubsection{Selecionando o melhor subconjunto de preditores}

A maneira mais simples para selecionarmos variáveis em um modelo é ajustar todas as possíveis combinações dos $p$ preditores e avaliar qual produz o melhor ajuste segundo alguma métrica de performance. Essa estratégia é chamada de seleção do melhor subconjunto de preditores (best subset selection, em inglês) e seu procedimento de seleção pode ser resumido pelos passo abaixo:

1. Ajustar o modelo nulo, sem nenhum preditor $(k=0)$.

2. Para cada $k=1, \ldots, p$, ajustar todos os modelos possíveis com $k$ preditores e escolher o melhor entre eles, isto é, aquele com menor RSME ou maior $R^{2}$ por exemplo.

3. Dentre os $p+1$ modelos selecionados em (1) e (2), selecionar o melhor usando o $R^{2}$ ajustado, RMSE calculada por validação cruzada (erro de teste), AIC ou BIC 5 .

Observe que a métrica utilizada para selecionar o modelo final deve ser penalizada pelo número de parâmetros, pois, caso contrário, escolheríamos sempre o modelo com mais preditores.

Para um número relativamente pequeno de variáveis, selecionar o melhor subconjunto de preditores é uma estratégia conceitualmente simples e de fácil execução. No entanto, conforme $p$ cresce, essa técnica pode se tornar computacionalmente inviável. Na Tabela 4.2 apresentamos os 7 modelos que precisaríamos ajustar se tivéssemos 3 preditores, $X_{1}, X_{2}$ e $X_{3}$, considerando um modelo de regressão linear (Seção 3.1). Para $p=20$, por exemplo, precisaríamos rodar mais de um milhão de modelos, o que poderia inviabilizar a execução dessa estratégia.

Tabela 4.2: Modelos de regressão linear que devem ser ajustados para selecionar o melhor subconjunto de variáveis no caso com 3 preditores, além do modelo nulo.

\begin{tabular}{c|c|c}
\hline Uma variável & Duas variáveis & Três variáveis \\
\hline$Y=\beta_{0}+\beta_{1} X_{1}+\epsilon$ & $Y=\beta_{0}+\beta_{1} X_{1}+\beta_{2} X_{2}+\epsilon$ & \\
$Y=\beta_{0}+\beta_{1} X_{2}+\epsilon$ & $Y=\beta_{0}+\beta_{1} X_{1}+\beta_{2} X_{3}+\epsilon$ & $Y=\beta_{0}+\beta_{1} X_{1}+\beta_{2} X_{2}+\beta_{3} X_{3}+\epsilon$ \\
$Y=\beta_{0}+\beta_{1} X_{3}+\epsilon$ & $Y=\beta_{0}+\beta_{1} X_{2}+\beta_{2} X_{3}+\epsilon$ & \\
\hline
\end{tabular}

A seguir, apresentamos algumas estratégias computacionalmente eficientes para aplicarmos em problemas com muitos preditores.

\subsubsection{Métodos passo a passo}

Os métodos passo a passo (stepwise) são algoritmos de seleção de variáveis que visam encontrar o melhor sub-conjunto de preditores dentro de um conjunto restrito de combinações em vez de ajustar todos os $2^{p}$ modelos possíveis.

A diferença entre cada método stepwise está em como as variáveis são adicionas ou retiradas do modelo em cada passo. Os mais utilizados são o foward stepwise e o backward stepwise.

O foward stepwise consiste na execução dos seguintes passos:

1. Ajuste o modelo nulo $\left(M_{0}\right)$, sem preditores.

2. Ajuste todos os $p$ modelos com 1 preditor e escolha o melhor ${ }^{6}\left(M_{1}\right)$.

\footnotetext{
${ }^{5} \mathrm{O}$ AIC e o BIC são medidas da qualidade do ajuste penalizadas pelo número de parâmetros do modelo. Mais informações, consultar James et al. (2013)

${ }^{6}$ Maior $R^{2}$, por exemplo.
} 
3. Ajuste todos os $p-1$ modelos com 2 preditores que contenham o preditor selecionado no passo anterior e escolha o melhor $\left(M_{2}\right)$.

4. De forma análoga, ajuste os modelos com $3,4, \ldots, p$ preditores, mantendo sempre como base o modelo obtido anteriormente, e em cada passo escolha o melhor $\left(M_{3}, M_{4}, \ldots, M_{p}\right)$.

5. Escolha o melhor modelo entre $M_{0}, M_{1}, \ldots, M_{p}$ utilizando erro preditivo, AIC, BIC ou $R^{2}$ ajustado.

Repare que o foward stepwise diminui o número de modelos ajustados de $2^{p}$ para $1+p(p+1) / 2$. Para $p=20$, o número de modelos diminui de 1.048.576 para 211 .

A ideia do método backward stepwise é parecida com a do foward. A diferença é que começamos no passo 1 com o modelo completo $\left(M_{p}\right)$, com todos os preditores, e nos passos seguintes retiramos cada um dos preditores e ajustamos os modelos correspondentes, selecionando sempre aquele com maior $R^{2}\left(M_{p-1}, M_{p-2}, \ldots, M_{0}\right)$. Ao fim, escolhemos o melhor entre os modelos $M_{0}, M_{1}, \ldots, M_{p}$ utilizando erro preditivo, AIC, BIC ou $R^{2}$ ajustado. O número de modelos ajustados nesse caso é igual ao do foward stepwise.

Ainda existem métodos stepwise híbridos, nos quais os preditores são adicionados sequencialmente, assim como no foward stepwise, mas em cada etapa avalia-se se um dos preditores já incluídos deve ou não sair do modelo. Essa estratégia tenta considerar mais modelos, chegando mais perto da seleção do melhor subconjunto discutida na seção anterior. Para mais informações, consultar Nelder e Wedderburn (1972).

\subsection{Regularização}

Os métodos de seleção de subconjuntos de preditores apresentados na seção anterior diminuem a complexidade do modelo eliminando variáveis que não contribuem significativamente com a diminuição do viés, potencialmente diminuindo a variância. As técnicas de regularização apresentam uma ideia similar: diminuir a variância do modelo a partir de suavizações que introduzem um pouco de viés. Essas técnicas envolvem o ajuste de um único modelo e introduzem penalizações no processo de estimação que limitam as estimativas dos coeficientes, encolhendo seus valores em direção a zero.

A utilização da regularização pode levar a uma redução substancial da variância do modelo, sendo uma boa estratégia para evitar o sobreajuste. Apresentaremos nesta seção as formas mais utilizadas de regularização: a regressão ridge e o LASSO (least absolute shrinkage and selection operator).

\section{Regressão Ridge}

De uma forma geral, o processo de estimação dos parâmetros de um modelo consiste na minimização de uma função de perda $L(y, f(x))$ que depende dos dados observados $(x, y)$ e do modelo escolhido $(f(\cdot))$. As técnicas de regularização consistem em adicionar uma penalidade nessa função de perda, de tal forma que os coeficientes dos preditores pouco associados à variável resposta sejam encolhidos em direção a zero.

No caso da regressão ridge (James et al., 2013), a função de perda penalizada é dada por 


$$
L(y, f(x))+\lambda \sum_{j=1}^{p} \beta_{j}^{2},
$$

sendo $\beta_{1}, \ldots, \beta_{p}$ os parâmetros do modelo $f(\cdot)$ e $\lambda$ um hiperparâmetro ${ }^{7}$ que controla o impacto da penalização nas estimativas dos coeficientes. Quando $\lambda=0$, o termo é anulado e as estimativas são calculadas sem penalização. Conforme $\lambda \longrightarrow \infty$, os coeficientes $\beta_{j}$ passam a ser penalizados, encolhendo seus valores em direção a zero. A vantagem disso está na potencial redução da variância do modelo, em troca de um pequeno aumento do viés, já que os coeficientes menos importantes recebem cada vez menos peso. Assim, a regularização é uma alternativa para lidarmos com o balanço entre viés e variância discutido na Seção 4.1.

No caso da regressão ridge, é possível mostrar que, para qualquer $i=1, \ldots, p, \beta_{i}=0$ apenas se $\lambda=\infty$. Isso significa que não estamos fazendo seleção de variáveis, isto é, o modelo ajustado sempre terá todos os preditores. Apesar de estarmos melhorando a performance do modelo diminuindo o peso dos preditores menos importantes, isso pode não ser o ideal quando quisermos de fato eliminar variáveis do modelo. Nesses casos, uma boa alternativa é utilizar o LASSO.

\section{Least absolute shrinkage and selection operator (LASSO)}

O LASSO (least absolute shrinkage and selection operator) é uma técnica análoga à regressão ridge, mas com função de perda penalização dada por

$$
L(y, f(x))+\lambda \sum_{j=1}^{p}\left|\beta_{j}\right| .
$$

Para $\lambda$ suficientemente grande, essa penalização força alguns dos coeficientes sejam estimados exatamente como 0 e os correspondentes preditores associados serão eliminados do ajuste. Assim, ao utilizarmos o LASSO, estamos ao mesmo tempo reduzindo a variância do modelo e executando seleção de variáveis.

Um ponto importante sobre a aplicação das técnicas de regularização é a escala dos preditores. A maioria dos processos de estimação usuais é invariante à escala em que os preditores foram medidos, isto é, ajustar o modelo usando o preditor $X_{1}$ ou $c X_{1}, c$ um número real, não mudará a interpretação dos resultados. No caso da regressão ridge e do LASSO, a escala dos preditores influencia não só a estimativa dos próprios coeficientes, mas também a estimativa dos outros parâmetros do modelo. Dessa forma, um passo importante anterior à aplicação dessas técnicas é a padronização dos preditores, de tal forma que todos fiquem com a mesma média e variância. Essa padronização pode ser feita a partir da expressão

$$
\tilde{X}_{i j}=\frac{X_{i j}-\bar{X}_{j}}{\sqrt{\frac{1}{n} \sum_{i=1}^{n}\left(X_{i j}-\bar{X}_{j}\right)^{2}}},
$$

sendo o denominador dessa expressão a estimativa do desvio-padrão do $j$-ésimo preditor. Consequentemente, todos os preditores terão média 0 desvio-padrão igual a 1.

Embora haja muita discussão sobre a validade de testes de hipóteses do tipo $\beta=0$ para

\footnotetext{
${ }^{7}$ Hiperparâmetros são parâmetros que não são estimados diretamente pelos dados.
} 
o LASSO, já que o algoritmo zera automaticamente os coeficientes menos importantes, alguns trabalhos vêm surgindo nos últimos anos sobre o cálculo do erro-padrão e sobre o desenvolvimento de testes paras as estimativas (Javanmard e Montanari, 2014; Lockhart et al., 2014). Uma boa alternativa para avaliar a variabilidade das estimativas dos coeficientes é utilizar o bootstrapping.

Para uma discussão mais aprofundada sobre a interpretação da regressão ridge e do LASSO, consulte o Capítulo 6 de James et al. (2013). Para o desenvolvimento matemático dessas técnicas, o Capítulo 5 de Hastie et al. (2008) é uma ótima referência.

\subsection{Quantificando a importância dos preditores}

Nas últimas seções, discutimos técnicas para removermos do modelo as variáveis que não ajudam a explicar a variabilidade da variável resposta. Em alguns casos, também gostaríamos de saber, entre os preditores que permaneceram no modelo, quais são os mais importantes.

Os valores $p$ são amplamente utilizados para definir as variáveis estatisticamente significativas para explicar a variável resposta. Dada a estimativa de um coeficiente $\beta$, o valor $p$ associado representa uma medida de evidência a favor da hipótese $\beta=0$ e pode ser utilizado tanto para seleção de variáveis quanto para quantificar a magnitude de uma associação. Mais precisamente, se o valor $p$ for muito baixo (próximo de zero), o cenário $\beta=0$ se torna improvável e então rejeitamos a hipótese de que o coeficiente é nulo. Caso contrário, se o valor $p$ for alto, a estimativa obtida não é inverossímil dentro do cenário $\beta=0$ e então não rejeitamos essa hipótese.

Ao cálculo do valor $p$ está associado uma estatística de teste, que também pode ser usada para quantificar a importância dos preditores. No modelo de regressão linear, por exemplo, a estatística do teste $t$ pode ser utilizada, de tal forma que, quanto maior o valor absoluto da estatística, maior será a importância do preditor para explicar a variável resposta.

Em alguns casos, a variação no erro preditivo quando um preditor é eliminado do modelo é utilizada como medida de importância. Essa métrica mais geral é bastante utilizada em modelos de regressão que envolvem funções suavizadoras, como os modelos aditivos generalizados.

Já para para a regressão ridge ou o LASSO, em que padronizamos as variáveis explicativas, uma medida de importância pode ser o próprio valor do coeficiente.

As métricas de importância dependem do modelo utilizado. De uma forma geral, os programas estatísticos já possuem métricas de importância implementadas. No R, a função var Imp () do pacote caret calcula uma medida de importância para a maioria dos modelos disponíveis.

\subsection{Modelos de árvores}

Modelos baseados em árvores (Hastie e Tibshirani, 1990; James et al., 2013) são bastante utilizados tanto para regressão quanto para classificação. Eles envolvem a segmentação do espaço gerado pelas variáveis explicativas em algumas regiões mais simples, onde a média ou a moda da variável resposta são utilizadas como predição.

As chamadas árvores de decisão são modelos conceitualmente e computacionalmente simples, bastante populares pela sua interpretabilidade, apesar da precisão inferior quando comparados com modelos mais complexos. Generalizações desse modelos, como as florestas aleatórias (random forests), costumam apresentar alta precisão, mesmo quando comparadas a modelos lineares, porém 
são pouco interpretáveis.

Nesta seção, introduziremos os principais conceitos por trás das árvores de decisão e da floresta aleatória.

\subsection{1 Árvores de decisão}

As árvores de decisão se baseiam no particionamento do espaço gerado pelas variáveis explicativas. As predições são dadas pela média das observações dentro de cada subespaço obtido ${ }^{8}$, e a construção desses subespaços visa minimizar alguma medida de erro (como o RMSE).

Na Figura 4.4, apresentamos uma árvore de decisão para explicar a variabilidade da concentração de ozônio pela temperatura (tp). Nesse exemplo, a temperatura foi particionada em 2 pontos: 26 e 29 graus Celsius. Assim, a média da concentração de ozônio dentro de cada uma das três regiões obtidas pela partição serão as predições dadas pela árvore. No caso, a estimativa da concentração de ozônio será $38 \mu \mathrm{g} / \mathrm{m}^{3}$ para dias com temperatura menor que $26^{\circ} \mathrm{C}, 69 \mu \mathrm{g} / \mathrm{m}^{3}$ para dias com temperatura entre 26 e $29^{\circ} \mathrm{C}$ e $92 \mu \mathrm{g} / \mathrm{m}^{3}$ para dias com temperatura maior ou igual a $29^{\circ} \mathrm{C}$.

No caso geral, para $p$ variáveis explicativas $X_{1}, \ldots, X_{p}$ e uma amostra de tamanho $n$, a construção da árvore pode ser resumida a partir do seguinte algoritmo:

1. Todas as observações começam na mesma partição.

2. Para cada variável explicativa $X_{j}$ e seus valores observados $x_{j i}, j=1, \ldots, p$ e $i=1, \ldots, n$, são testadas todas as partições $X_{j}<x_{j i}$ e escolhida aquela que minimize alguma medida de erro (em geral, RMSE).

3. O passo 2 é repetido, agora dentro de cada subespaço obtido, até que um dos subespaços tenha menos de um número mínimo de observações pré-definido.

Na Figura 4.4, cada partição, chamada de nó, é representada pelos módulos verdes. Os nós na base da árvore são chamados de nós terminais e representam os subespaços obtidos pelo particionamento. A interpretação do diagrama começa pelo primeiro nó (no topo da figura) e, para cada nova observação, seguimos as regras de decisão até alcançar um nó terminal, que apresentam a predição para dessa observação e o número de observações da amostra dentro desse subespaço (absoluto e proporcional ao tamanho da amostra). Quando temos mais de um preditor, cada nó poderá indicar uma partição em um preditor diferente.

Observe que no exemplo temos 3 nós finais, mas, teoricamente, poderíamos continuar particionando o intervalo de valores da temperatura até cada possível valor ter o seu próprio nó. Esse seria um caso de árvore de decisão sobreajustada, apresentando pouco poder de generalização. A escolha do número de nós finais é feita a partir de uma técnica conhecida como "poda", que consiste em usar validação cruzada para definir a melhor altura para a árvore.

Na linguagem R, árvores de decisão podem ser ajustadas a partir da função rpart ( ) do pacote rpart.

As árvores de decisão imitam bem o processo de tomada de decisão do cérebro humano, e por isso são mais simples de interpretar até mesmo que o modelo de regressão linear. No entanto, elas apresentam baixo poder preditivo e raramente são utilizadas para descrever processos muito

\footnotetext{
${ }^{8}$ No caso de uma variável resposta quantitativa. No caso de classificação, variáveis respostas categóricas, a predição será a classe mais frequente dentro do subespaço.
} 


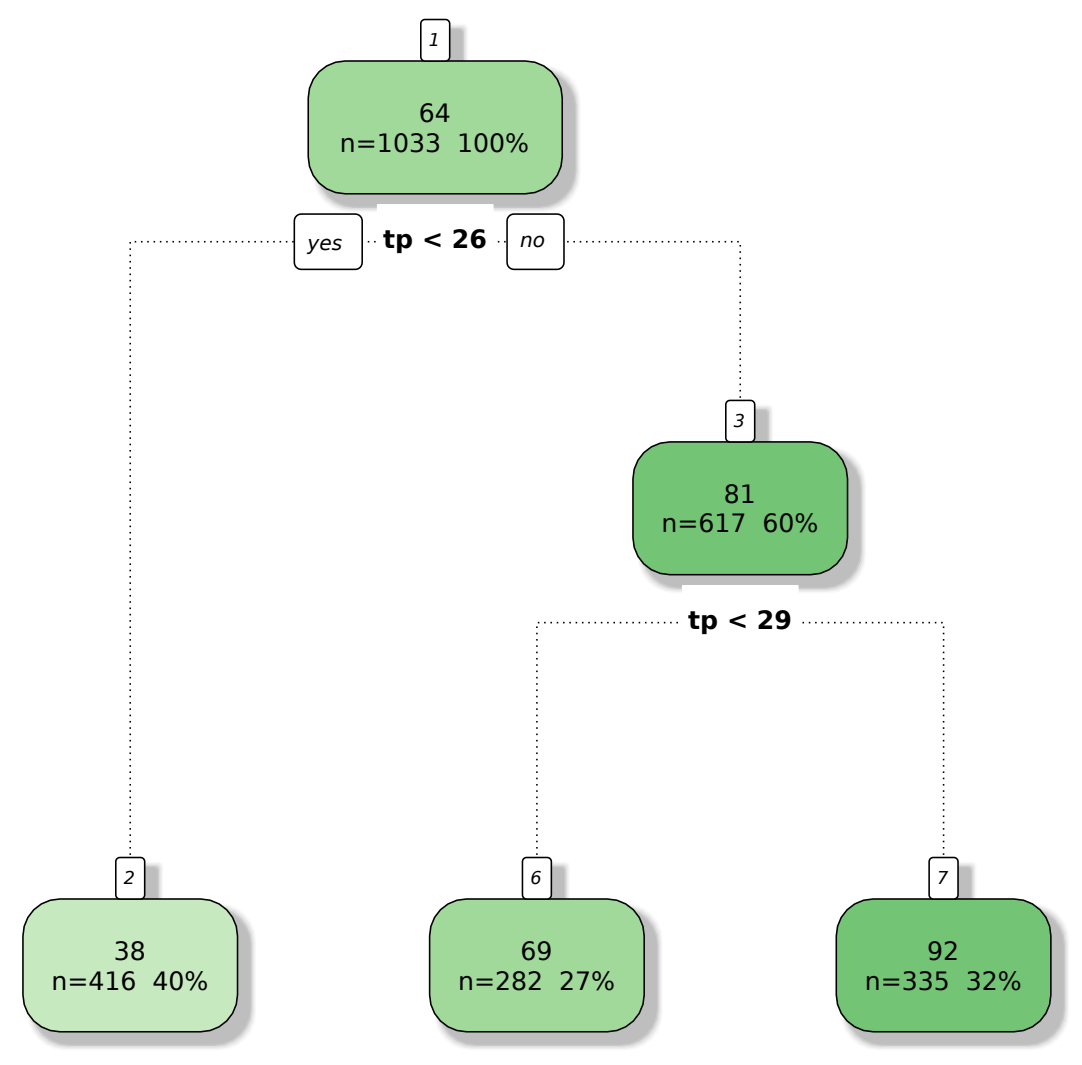

Figura 4.4: Exemplo de uma árvore de decisão para a concentração de ozônio explicada pela temperatura.

complexos. A seguir, apresentaremos as florestas aleatórias, que abrem mão da interpretabilidade em troca de um alto grau de precisão.

\subsubsection{Florestas aleatórias}

As predições obtidas a partir de árvores de decisão tendem a ter alta variância, isto é, se dividirmos nossa amostra em duas e aplicarmos o mesmo modelo de árvores de decisão em cada uma, há uma grande chance de obtermos divisões diferentes no espaço amostral e, consequentemente, diferentes predições.

Uma maneira de lidar com esse problema é gerar diferentes amostras de bootstrapping, ajustar o mesmo modelo em cada uma delas e utilizar predições médias como estimativas finais do modelo. Em um contexto geral, essa técnica é chamada de bootstrapping aggregation ou bagging. Ela pode ser utilizada para qualquer modelo e seu objetivo geral é diminuir a variância das estimativas.

As chamadas florestas aleatórias (random forests) (Hastie et al., 2008) são uma aplicação do bagging para árvores de decisão. Neste modelo, além de utilizarmos uma amostra de boostraping diferente para cada árvore ajustada, também fazemos uma seleção dos preditores para cada ajuste. Isso impede que as árvores ajustadas sejam muito correlacionadas e permite que preditores que seriam preteridos por serem "menos importantes" também ajudem a explicar a variação da variável resposta.

Em cada iteração do algoritmo,

1. sorteamos $m$ dos $p$ preditores, $m \leq p$; 
2. geramos uma amostra de boostrapping a partir da base completa;

3. ajustamos uma árvore de decisão utilizando os $m$ preditores escolhidos em (1) e a amostra em (2).

Repetindo esse procedimento $M$ vezes, teremos $M$ estimativas, e predição final será a média dessas $M$ estimativas (no caso de regressão) ou a classe mais frequente (no caso de classificação). Geralmente, $m$ é escolhido como $\sqrt{p}$, mas esse hiperparâmetro pode ser definido utilizando validação cruzada. $M$ por volta de 200 costuma ser suficiente para gerar bons resultados ${ }^{9}$.

Florestas aleatórias podem ser ajustadas utilizando a função train () do pacote caret com method = "ranger". Os principais hiperparâmetros que devem ser escolhidos são o número de sorteados em cada ajuste $(m)$ e o número mínimo de observações nos nós finais de cada árvore.

\subsubsection{XGBoost}

Assim como o bagging, apresentado na seção anterior, o algoritmo boosting é uma abordagem geral aplicada a diversos modelos para aumentar seu poder preditivo. No contexto de árvores de decisão, a ideia aqui é construir árvores sequencialmente, sendo que cada árvore utiliza informações obtidas da árvore anterior. Ao contrário do bagging, o algoritmo boosting não envolve amostras de bootstraping, sendo que cada passo do algoritmo utiliza uma versão modificada dos dados originais.

A ideia por trás do algoritmo boosting é "aprender devagar". Em vez de tentarmos ajustar uma grande árvore com toda a base de dados, ajustamos árvores com poucos nós $\hat{f}^{1}(x), \hat{f}^{2}(x), \ldots, \hat{f}^{B}(x)$ sequencialmente, de tal forma que a árvore $\hat{f}^{i}(x)$ é ajustada utilizando os resíduos da árvore $\hat{f}^{i-1}(x)$. Considere $\hat{f}(x)$ a função estimada do modelo e que, inicialmente, $\hat{f}(x)=0$. Em cada passo do algoritmo, a nova árvore $\hat{f}^{i}(x)$ é somada à função estimada $\hat{f}(x)$ utilizando-se um parâmetro de encolhimento $\lambda>0$, isto é, no passo $i, \hat{f}(x)$ passa a ser $\hat{f}(x)+\lambda \hat{f}^{i}(x)$. Assim, os resíduos são atualizados em cada passo e $\hat{f}(x)$ se torna mais precisa ${ }^{10}$ lentamente em regiões onde sua performance era ruim. O parâmetro de encolhimento $\lambda$, o número de árvores $B$ e o tamanho de cada árvore (controlado pelo número de nós terminais) são os principais hiperparâmetros do modelo e podem ser escolhidos por validação cruzada.

O gradient boosting generaliza o boosting substituindo o ajuste dos resíduos pela minimização de uma função de custo $L(y, f(x))$. Em cada etapa, ajustamos uma árvore não mais aos resíduos, mas sim às quantidades

$$
g_{i}=-\left[\frac{\delta L\left(y_{i}-f\left(x_{i}\right)\right)}{\delta f\left(x_{i}\right)}\right]_{f=f^{i-1}}, \quad i=1, \ldots, n
$$

As quantidades $g_{1}, \ldots, g_{n}$ representam o gradiente da função de custo em relação a cada árvore $f^{i}(x)$. Portanto, em cada etapa, minimizamos lentamente a função de custo a partir da nova árvore ajustada. Esse é um algoritmo de minimização chamado de gradient descent (Kiefer e Wolfowitz, 1952).

Por fim, o XGBoost (ou extreme gradient boosting) é uma implementação eficiente do gradient boosting que utiliza alguns "truques" para otimizar o processo de estimação, como penalização das

\footnotetext{
${ }^{9}$ Para valores de $M$ muito altos (maior que 200), a amostragem dos preditores passa a criar árvores mais parecidas com as já existentes, o que não gera maiores ganhos de precisão.

${ }^{10}$ Obtém melhores predições, segundo alguma métrica de erro.
} 
árvores para controlar a velocidade de aprendizado, aleatorização dos parâmetros para diminuir a correlação entre as árvores e encolhimento dos nós terminais para diminuir o sobreajuste. Esse algoritmo é um dos mais utilizados em problemas preditivos complexos hoje em dia, estando entre os modelos que mais ganharam competições de modelagem preditiva.

Na linguagem $\mathrm{R}$, podemos ajustar o XGBoost utilizando a função train() do pacote caret com o argumento method = "xgbTree" ou diretamente as funções do pacote xgboost.

Assim como a floresta aleatória, esses modelos são não interpretáveis e demandam o uso de técnicas gráficas para a avaliação da associação entre as variáveis. Discutiremos esse tópico na próxima seção.

\subsection{Interpretando modelos caixa-preta}

Ao contrário dos modelos apresentados no capítulo anterior, modelos como a floresta aleatória ou o XGboost não são interpretáveis. Isso implica que não conseguimos avaliar diretamente como cada preditor está associado com a variável resposta, impossibilitando que esses modelos sejam usados para inferência ou criando muita desconfiança a respeito do que esses modelos estão fazendo por trás das cortinas.

Nesta seção, vamos apresentar algumas técnicas que, sob algumas suposições ou restrições, visam elucidar a relação entre os preditores e os valores preditos, abrindo um pouco a caixa-preta dos modelos de aprendizado automático.

\subsubsection{Gráfico de dependência parcial}

O objetivo do gráfico de dependência parcial é mostrar o efeito marginal de um preditor no valor predito pelo modelo. A partir dele, podemos investigar qual é a forma e o sentido da relação entre cada preditor e a variável resposta.

Dado um modelo não interpretável $f(X, Z)$, um preditor sob investigação $X$ e um vetor $Z$ representando os outros preditores do modelo, a ideia por trás da construção do gráfico de dependência parcial consiste em:

1. fixar alguns valores para $X$, digamos $x=\left(x_{1}, \ldots, x_{M}\right)$;

2. para cada $x_{i}, i=1, \ldots, M$, repetir:

a) para cada uma das $n$ observações na amostra, substituir o valor observado de $X$ por $x_{i}$ e calcular o valor predito do modelo, $\hat{f}\left(x_{i}, z\right.$.);

b) calcular a média das $n$ predições, $\bar{f}_{i}\left(x_{i}\right)=\frac{1}{n} \sum_{j=1}^{n} \hat{f}\left(x_{i}, z_{j}\right)$;

3. construir o gráfico dos valores $x$ contra as médias das predições $\bar{f}(x)$.

A função $\bar{f}(x)$ podem ser interpretada como uma estimativa da distribuição marginal das predições que depende apenas do preditor X, obtida calculando-se a média das predições sobre os outros preditores. Essa estratégia é razoável apenas se os preditores $X$ e $Z$ são não correlacionados. Caso contrário, o uso dessa média como estimativa da distribuição marginal $\bar{f}(x)$ pode colocar peso em regiões inverossímeis ou de probabilidade zero. 


\subsubsection{Gráfico da esperança condicional individual}

O gráfico da esperança condicional individual é equivalente ao gráfico de dependência parcial, com a diferença que aqui traçamos uma curva para cada observação da amostra, sendo que o gráfico de dependência parcial é a média das curvas do gráfico da esperança condicional individual.

O algoritmo para construção desse gráfico consiste nos passos (1) e (2a) da seção anterior, sendo que plotamos as $n$ curvas formadas pelos pontos $\left(x_{1}, \hat{f}\left(x_{1}, z_{j}\right)\right), \ldots,\left(x_{M}, \hat{f}\left(x_{M}, z_{j}\right)\right), j=1, \ldots, n$. Além de ser ainda mais intuitivo que o gráfico de dependência parcial, a grande vantagem do gráfico da esperança condicional individual é mostrar relações heterogêneas geradas por interações entre os preditores.

\subsubsection{Gráfico de efeitos locais acumulados}

O gráfico de efeitos locais acumulados é uma alternativa ao gráfico de dependência parcial no caso de preditores correlacionados. A estratégia aqui é, para cada valor $x$ do preditor sob investigação $X$, estimar a distribuição marginal das predições $\hat{f}(x)$ utilizando apenas as observações da amostra similares a $x$. Esse gráfico mostra qual é a predição do modelo em uma pequena região ao redor de $x$ para observações da base dentro dessa região.

Dado o preditor $X$ de interesse, o algoritmo para construção desse gráfico é dado por:

1. particionar $X$ em $M$ intervalos (usualmente os quantis de $X$ são utilizados);

2. para cada uma das $m_{i}$ observações dentro do $i$-ésimo intervalo, calcular

$$
\hat{f}_{i j}^{d}=\hat{f}\left(x_{i}^{+}, z_{j}\right)-\hat{f}\left(x_{i}^{-}, z_{j}\right), \quad j=1, \ldots, m_{i},
$$

sendo $x_{i}^{+}$e $x_{i}^{-}$, respectivamente, os limites superior e inferior do intervalo $i$.

3. Para cada valor $x$ de $X$, calcular a média acumulada

$$
\bar{f}_{a}(x)=\sum_{i=1}^{k(x)} \frac{1}{m_{i}} \sum_{j=1}^{m_{i}} \hat{f}_{i j}^{d},
$$

sendo $k(x)$ o índice do intervalo ao qual o valor $x$ pertence.

4. Calcular $\bar{f}_{a c}(x)$, o valor centralizado de $\bar{f}_{a}(x)$ considerando todas as $n$ observações da amostra:

$$
\bar{f}_{a c}(x)=\bar{f}_{a}(x)-\frac{1}{n} \sum_{i=1}^{n} \bar{f}_{a}\left(x_{i}\right)
$$

5. Para cada valor observado de $X$, plotar $\bar{f}_{a c}\left(x^{c}\right) \times x^{c}$, sendo $x_{1}^{c}, \ldots, x_{M-1}^{c}$ os pontos de corte utilizados para construir os $M$ intervalos em (1).

A partir desse algoritmo, podemos fazer algumas considerações sobre o gráfico de efeitos locais acumulados:

- As diferenças calculadas no passo (2) explicam o termo efeitos locais. Para cada valor $x$ do preditor $X$, essas diferenças estimam o quanto a predição é alterada por pequenas mudanças no valor de $x$. 
- Calcular a média das diferenças das predições em cada intervalo (em vez de apenas a média das predições) também garante que o efeito estimado para o preditor $X$ não seja influenciado pelo efeito de algum outro preditor correlacionado com $X$.

- Como cada $\frac{1}{m_{i}} \sum_{1}^{m_{i}} \hat{f}_{i}^{d}$ representa a diferença média nas predições quando $X$ varia localmente, dentro do intervalo $i$, a soma acumulada no passo (3) é realizada para que $\bar{f}_{a}(x)$ represente o efeito do preditor $X$ nas predições.

- Ao contrário do gráfico de dependência parcial e do gráfico de esperança condicional individual, que apresentam no eixo $y$ o valor predito, o gráfico de efeitos locais acumulados consideram nesse eixo a diferença em relação ao valor predito médio.

\subsubsection{Local interpretable Model-Agnostic Explanations (LIME)}

Uma outra técnica utilizada para interpretar modelos caixa-preta é o Local Interpretable ModelAgnostic Explanations (LIME) (Ribeiro et al., 2016). Ela vem sendo muito utilizada para detectar, explicar e corrigir problemas com modelos preditivos, pois permite avaliar, para cada observação da amostra, quais preditores mais influenciaram a sua própria predição.

O LIME assume que todo modelo complexo prevê valores parecidos para duas observações muito próximas, sendo possível encontrar um modelo simples que seja uma boa aproximação do modelo complexo na vizinhança da observação que queremos explicar. Assim, a partir de um modelo interpretável podemos obter para cada observação uma explicação sobre a predição feita pelo modelo não-interpretável.

O algoritmo consiste em:

1. Para cada predição a ser explicada, permutar as observações da amostra $n$ vezes.

2. Predizer cada uma das observações permutadas usando o modelo complexo.

3. Calcular uma medida de distância e similaridade entre as permutações e a observação original. Geralmente a distância de Gower é utilizada (Gower, 1971).

4. Selecionar as $m$ variáveis mais importantes utilizadas pelo modelo complexo para explicar os dados permutados.

5. Ajustar um modelo interpretável aos dados permutados, utilizando as predições do modelo complexo como variável resposta e as $m$ variáveis selecionadas no passo anterior como preditores, ponderando pela medida de similaridade com a observação original.

6. Usar as estimativas desse modelo simples como as explicações para o comportamento local do modelo complexo.

Embora o LIME possa ser utilizado para explicar o modelo globalmente, utilizando uma grande quantidade de pontos da base de treino, essa abordagem funciona bem para problemas bem comportados, como classificação de imagens, em que cada preditor representa um pixel, e textos, em que cada preditor representa uma palavra. Em problemas muito complexos, principalmente de regressão (variável resposta numérica) com muitos preditores, pode ser difícil encontrar modelos simples que expliquem bem as predições localmente. 
A implementação do LIME exige definir como as observações serão permutadas, qual medida de similaridade será usada, qual o valor de $m$ e qual modelo interpretável será utilizado. Uma boa discussão sobre esses pontos pode ser encontrada na documentação do pacote lime, no qual a técnica foi implementada na linguagem $\mathrm{R}$.

\subsubsection{Exemplo}

Para ilustrar a utilização desses métodos gráficos de interpretação, vamos considerar um problema simples no qual queremos associar médias diária de $\mathrm{NO}_{\mathrm{X}}$ com médias diárias de temperatura e umidade. Vamos então ajustar uma floresta aleatória para esses dados e tentar interpretar os resultados do modelo.

Na Figura 4.5 apresentamos o gráfico de dispersão do $\mathrm{NO}_{\mathrm{X}}$ contra cada uma das variáveis explicativas. Embora os gráficos de dispersão não evidencie essa relação, podemos observar pela série temporal do $\mathrm{NO}_{\mathrm{x}}$ (Figura 4.6) que as maiores concentrações desse poluente tendem a acontecer no inverno, onde o clima ${ }^{11}$ é mais frio e seco.

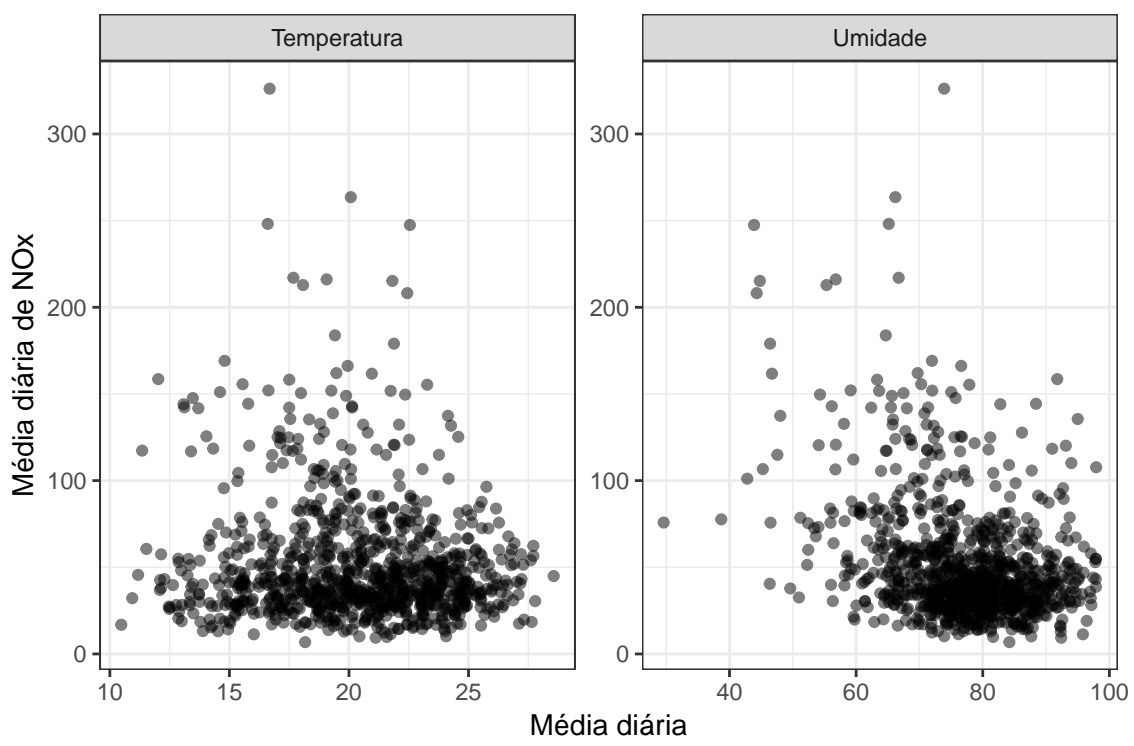

Figura 4.5: Gráficos de dispersão da média diária de $\mathrm{NO}_{x}$ contra as médias diárias de temperatura (Celsius) e umidade relativa do ar (\%).

Inicialmente, ajustamos modelos de regressão linear para esses dados, pois eles são interpretáveis e podemos comparar seus resultados com os da floresta aleatória. Focando o exemplo apenas na interpretação da umidade, ajustamos modelos considerando (1) apenas a umidade como preditor, (2) umidade e temperatura como preditores e (3) umidade, temperatura e a interação entre as duas variáveis como preditores. Na Figura 4.7, apresentamos os gráficos do valor predito contra a umidade para cada um dos modelos. Repare que, para os modelos (2) e (3), avaliamos o efeito de umidade para diferentes temperaturas, que é constante no modelo sem interação e diminui conforme a temperatura aumenta no modelo com interação.

Ajustamos então uma floresta aleatória para os mesmos dados e construímos os gráficos de dependência parcial (PDP), esperança condicional individual (ICE) e efeitos locais acumulados (ALE) para interpretar os resultados (Figura 4.8). Pelo PDP e ICE, observamos um efeito estranho

\footnotetext{
${ }^{11}$ Dados para a cidade de São Paulo, de 2008 a 2011.
} 

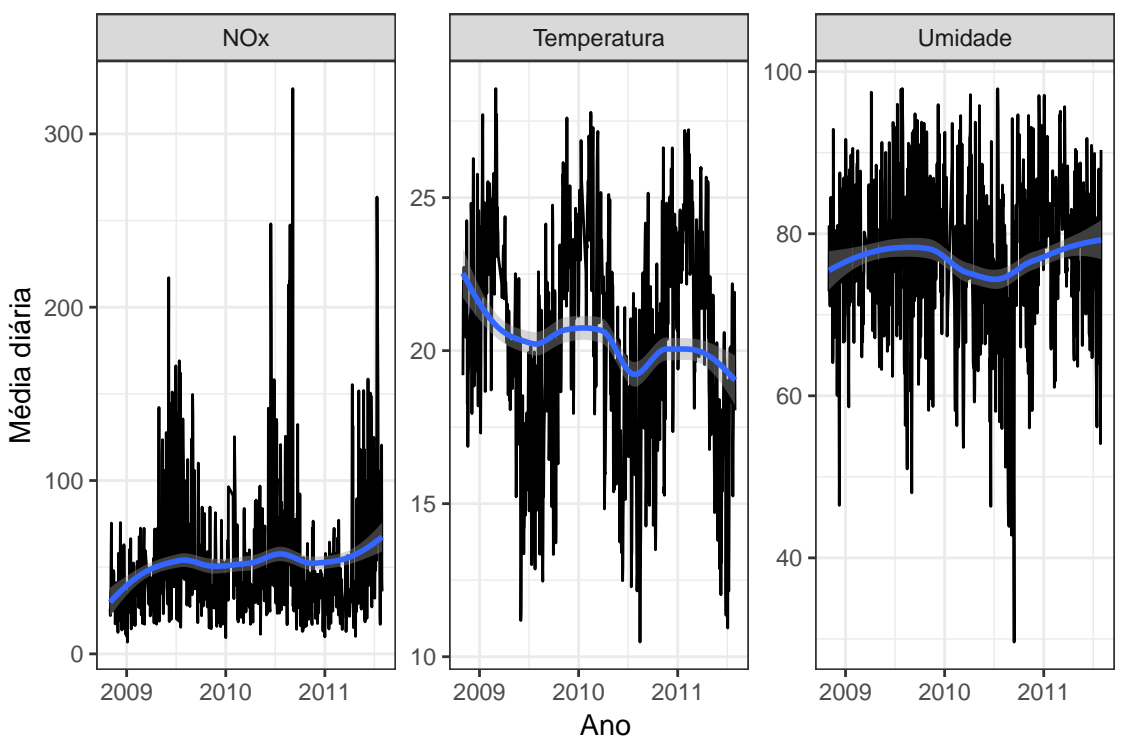

Figura 4.6: Gráficos de dispersão da média diária de $N O_{x}$ contra as médias diárias de temperatura (Celsius) e umidade relativa do ar (\%).

nos preditores para valores baixos de umidade. Isso acontece porque a temperatura e a umidade são correlacionadas, como podemos observar pelo gráfico de dispersão na Figura 4.9. Como há poucos dias com baixa umidade, esses gráficos acabam capturando o efeito da temperatura na concentração de $\mathrm{NO}_{\mathrm{x}}$. Nessa situação, o gráfico adequado para analisar o efeito da umidade seria o ALE, pois ele avalia localmente o efeito de cada valor da umidade na predição, desconsiderando regiões com poucas observações e eliminando a influência dos outros preditores.

O ALE também nos mostra que a relação entre umidade e concentração de $\mathrm{NO}_{\mathrm{x}}$ pode ser nãolinear, dado o aumento na predição quando aumentamos a umidade de $85 \%$ para $100 \%$. Embora essa relação possa estar apenas sendo induzida pela ausência de outros preditores importantes para explicar a variabilidade do $\mathrm{NO}_{\mathrm{x}}$, é interessante notar que não conseguimos identificá-la a partir do modelo de regressão linear considerado. 

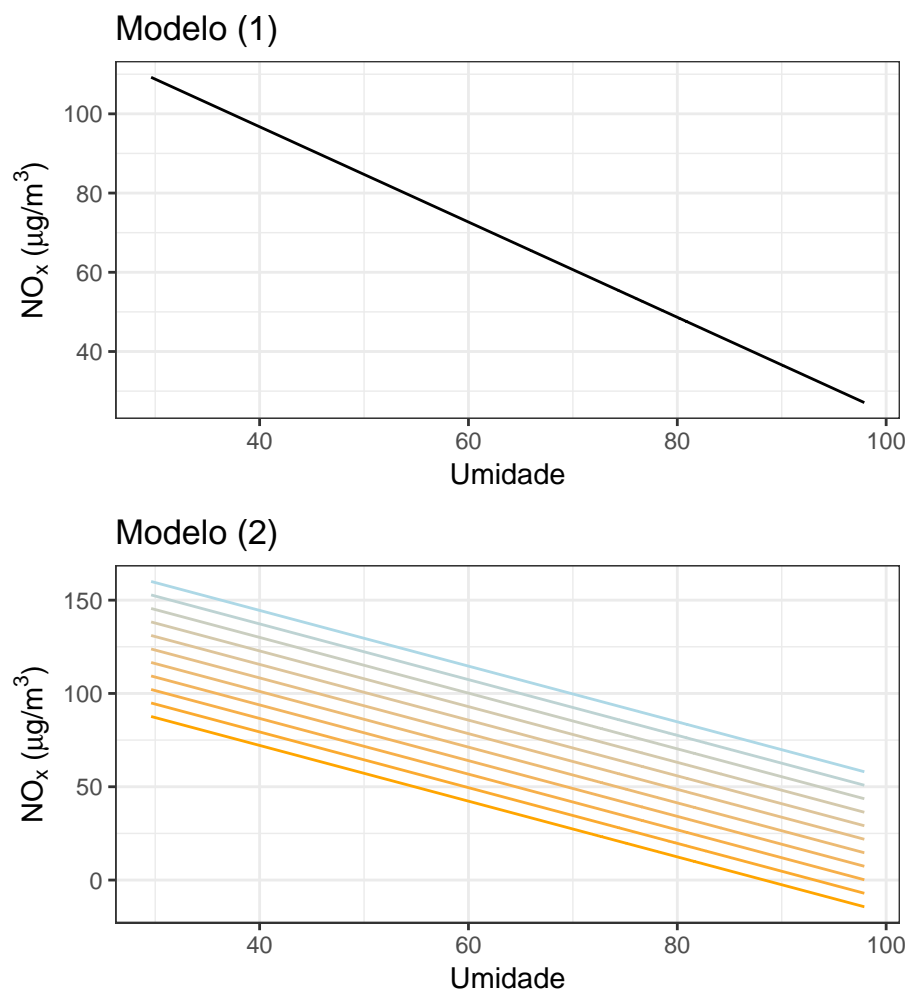

\section{Temperatura}

35

$-30$

25

20

15

10

\section{Modelo (3)}

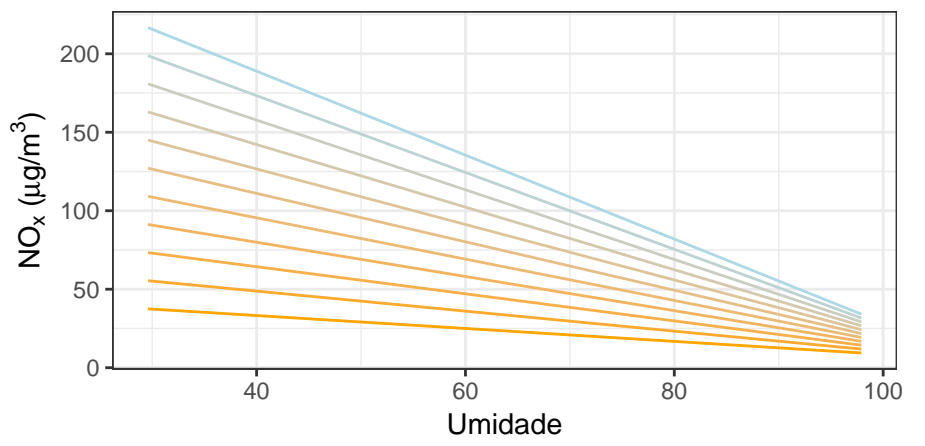

Temperatura

35

30

25

20

15

10

Umidade

Figura 4.7: Valores preditos do NOx para cada modelo em função da umidade e da temperatura. 

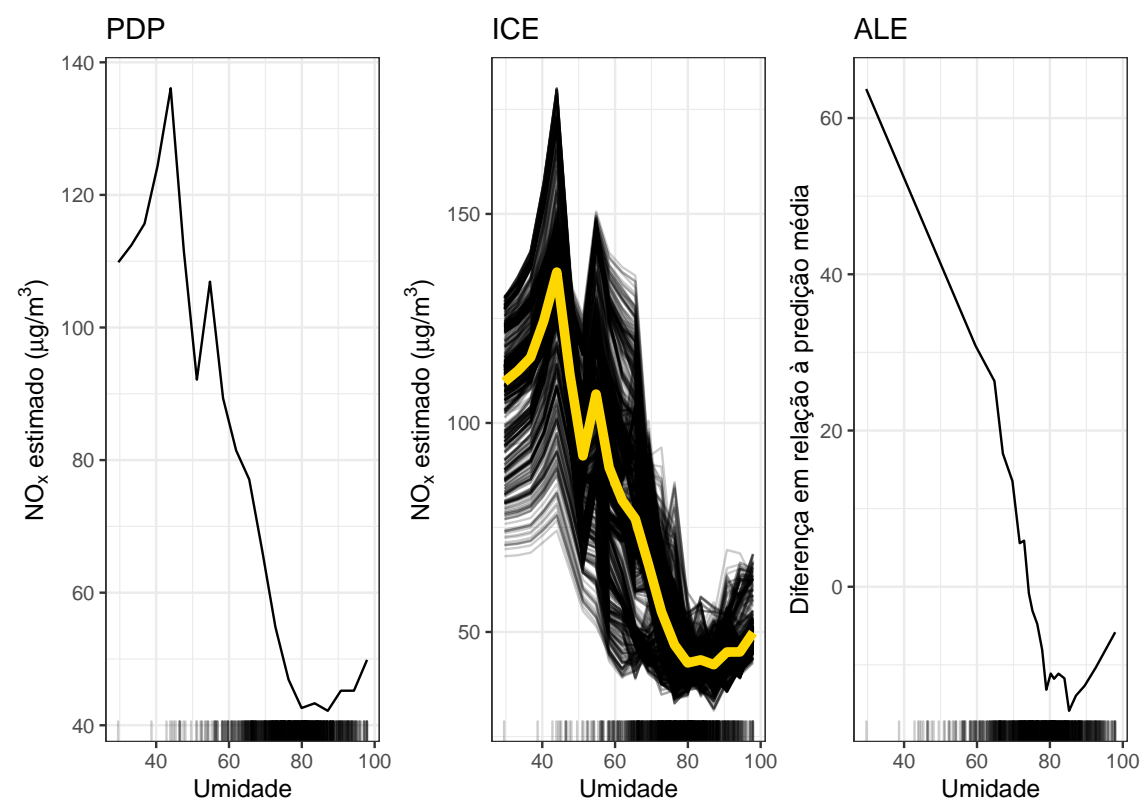

Figura 4.8: Gráficos de dependência parcial (PDP), esperança condicional individual (ICE) e efeitos locais acumulados (ALE) para a floresta aleatória. A curva amarela no ICE representa a média de todas as retas individuais, isto é, o PDP.

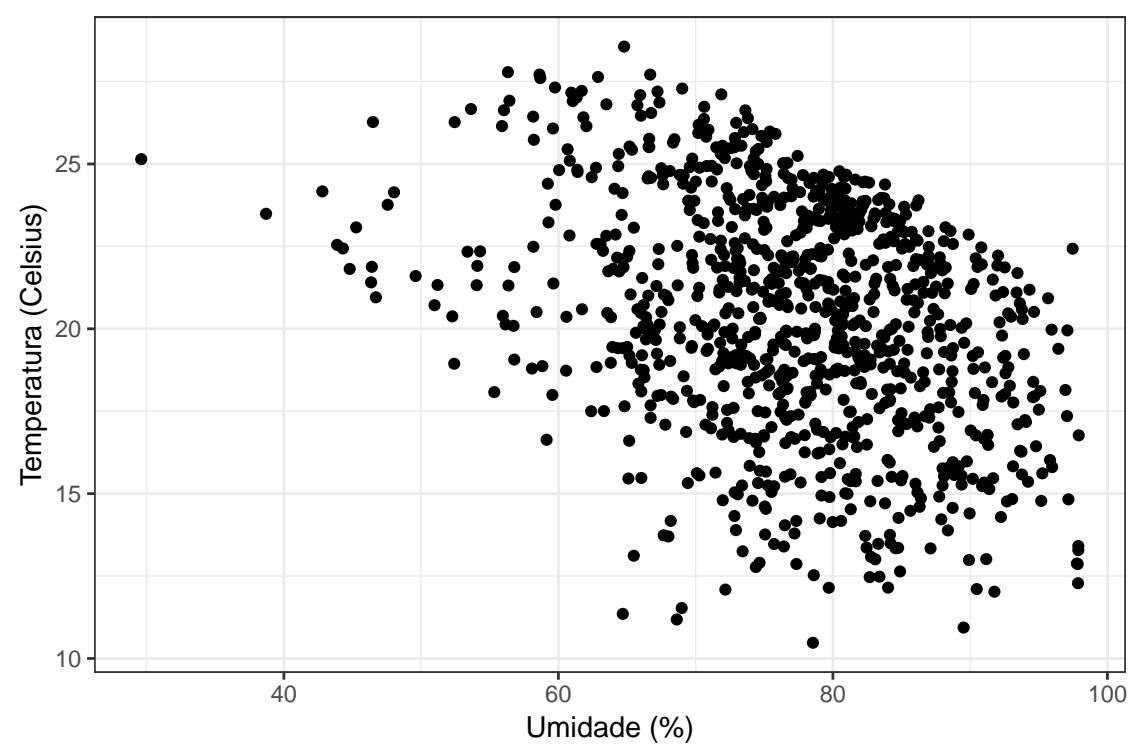

Figura 4.9: Gráfico de dispersão entre as médias diárias da temperatura e umidade. 


\section{Capítulo 5}

\section{Poluição e uso de combustíveis}

Investigar a relação entre o uso de combustíveis e a concentração de poluentes é um problema muito comum em estudos de poluição do ar devido à grande contribuição da fonte veicular nos níveis de diversos gases e partículas. Neste capítulo, vamos analisar a associação entre uso de etanol e a concentração de ozônio na cidade de São Paulo.

\subsection{Etanol e ozônio}

Devido à forte dependência de combustíveis fósseis, o setor de transportes é considerado pela União Europeia o mais resiliente aos esforços para a redução de emissões (European Commission, 2011). Como soluções que visam diminuir o tamanho da frota de veículos (ou ao menos restringir o seu uso) esbarram em fatores políticos e econômicos, os estudos nessa área têm como objetivo encontrar combustíveis menos poluentes, alternativas ao diesel e à gasolina.

O bioetanol é uma fonte quase renovável de energia que pode ser produzida a partir de matéria prima agrícola. É amplamente utilizado no Brasil e nos Estados Unidos, seja puro (conhecido como E100) ou como aditivo da gasolina (conhecido como E20 ou E25, de acordo com a porcentagem adicionada à gasolina, $20 \%$ ou 25\%). Comparado com a gasolina convencional, o etanol é considerado um combustível cuja queima gera menores concentrações de material particulado (PM), óxidos de nitrogênio $\left(\mathrm{NO}_{\mathrm{X}}\right)$, monóxido de carbono $(\mathrm{CO})$ e dióxido de carbono $\left(\mathrm{CO}_{2}\right)$, sendo uma boa opção para reduzir a poluição do ar e o aquecimento global.

Em um experimento controlado na cidade de Fairbanks, no Alasca, por exemplo, Mulawa et al. (1997) coletaram amostras de material particulado de carros a gasolina e as compararam com dados de emissões de carros abastecidos com E10 (gasolina com 10\% de álcool). Os autores constataram que os carros com E10 emitiam menos material particulado e que os níveis desse poluente aumentavam em dias mais frios. Yoon et al. (2009) conduziram uma investigação similar e concluíram que a combustão de etanol e da mistura E85 (85\% etanol e 15\% gasolina) emitia concentrações inferiores de hidrocarbonetos, monóxido de carbono e óxidos de nitrogênio quando comparados com a gasolina sem aditivos sob diversas condições experimentais.

Apesar de diversos trabalhos e do senso comum considerarem o etanol uma alternativa menos poluente à gasolina, quando as emissões de veículos abastecidos com etanol são associadas à concentração ambiente de ozônio $\left(\mathrm{O}_{3}\right)$, os estudos têm apontado para uma direção diferente. Pereira et al. (2004), por exemplo, expuseram câmaras contendo etanol puro e uma mistura de 22-24\% etanol em gasolina ao sol para estudar a formação do ozônio e concluíram que as concentrações máximas 
do poluente eram, em média, $28 \%$ maiores para o álcool do que para a mistura gasolina/etanol. Jacobson (2007) juntou modelos de previsão para a poluição do ar e o clima com inventários de emissões futuras e dados populacionais e epidemiológicos para examinar o efeito da troca da gasolina por E85 na incidência de câncer e casos de mortalidade e hospitalização em Los Angeles, em particular, e nos Estados Unidos, como um todo. O autor concluiu que o risco de câncer era o mesmo com a utilização dos dois combustíveis, mas uma frota futura de veículos rodando com E85 aumentaria a hospitalização por complicações relacionadas à poluição por ozônio.

Utilizando uma mudança real na preferência por gasolina, ocasionada por flutuações de larga escala no preço do etanol, Salvo e Geiger (2014) analisaram a associação entre a proporção de carros bicombustíveis abastecidos com gasolina na cidade de São Paulo com os níveis de ozônio medidos no começo da tarde durante os anos de 2008 a 2011. Os autores concluíram que o uso do etanol em São Paulo está associado a maiores concentrações do poluente. Esse estudo foi ampliado por Salvo et al. (2017), utilizando dessa vez dados de 2008 a 2013 e analisando também o efeito na concentração de partículas ultrafinas. Os resultados apontaram novamente associação entre o maior uso de etanol e aumento na concentração de ozônio, mas queda no número de partículas ultrafinas. Por fim, Salvo e Wang (2017) sumarizaram essa discussão analisando a variação nos níveis de ozônio em quatro períodos de maior penetração do etanol. Eles concluíram que a química atmosférica da cidade de São Paulo é limitada em compostos orgânicos voláteis ${ }^{1}$ e que esses períodos estavam associados a maiores concentrações do poluente.

Neste capítulo, aplicaremos diversas técnicas de modelagem apresentadas nos Capítulos 3 e 4 aos disponibilizados por Salvo et al. (2017), tendo como objetivo entender o mecanismo de formação do ozônio e, principalmente, sua relação com o uso de gasolina/etanol.

\subsection{Entendendo o problema}

Far better an approximate answer

to the right question, which is often vague, than an exact answer to the wrong question,

which can always be made precise. - John Tukey

O primeiro passo de qualquer análise estatística é entender bem o problema a ser resolvido. Embora pareça uma tarefa óbvia, é muito comum nos perdermos durante a modelagem por não termos relacionado com clareza o objetivo do estudo com as informações disponíveis para alcançálo. De maneira geral, essa etapa requer três delineamentos: quais perguntas serão respondidas, qual a dimensão do problema e quais métricas serão utilizadas para avaliar o erro associado às nossas conclusões. Definir esses pontos envolve conhecer a fundo tanto as técnicas estatísticas quanto o fenômeno de interesse

O nosso objetivo neste capítulo é investigar se existe associação entre a concentração de ozônio e a proporção de carros a gasolina rodando na cidade de São Paulo. Assim, qualquer modelo que

\footnotetext{
${ }^{1}$ Isso significa que geração de ozônio é limitada pela quantidade de compostos orgânicos voláteis presentes na troposfera. Esses compostos são um dos principais percursores do ozônio e sua fonte primária é a queima parcial ou evaporação de etanol.
} 
decidirmos usar deve levantar evidências contra ou a favor dessa pergunta. Em segundo plano, também podemos aproveitar para estudar o mecanismo de formação do ozônio, sua variação ao longo do ano e como ele se relaciona com variáveis climáticas.

Dimensionar a análise significa entender a complexidade do problema a ser resolvido. Não é raro termos mais ou menos informação do que precisamos para responder a pergunta de interesse, e então devemos avaliar se não estamos gastando muito esforço para responder perguntas que não são relevantes ou então investigando uma pergunta que não pode ser respondida com os dados disponíveis.

O processo por trás de um fenômeno pode ser muito complexo, sendo que a maioria das vezes não conseguimos nem mesmo identificar todas as variáveis envolvidas no seu mecanismo. A formação do ozônio troposférico certamente é um exemplo disso. É um processo espaço-temporal que depende de reações químicas complicadas e de um grande número de variáveis, a maior parte delas difícil de ser medida com precisão.

Diante desse complicado panorama, devemos ter cuidado para:

1. não escolher um modelo muito complexo para responder uma pergunta que poderia ser respondida por um modelo mais simples;

2. não escolher um modelo muito simples para descrever associações complexas entre as variáveis.

Essa medida de complexidade reflete o balanço entre viés e variância discutido na Seção 4.1. No primeiro caso, poderíamos obter um modelo pouco interpretável ou, no caso de sobreajuste, que não fosse generalizável para além da amostra. Já no segundo, poderíamos obter um modelo insuficiente para respondermos a pergunta de interesse com precisão, podendo levar a conclusões inadequadas ou superficiais.

Dado o objetivo definido anteriormente, queremos descobrir qual é a relação entre a variável resposta e um dos preditores, ou seja, entender melhor o mecanismo escondido dentro da caixapreta apresentada na Figura 3.1. Os dados disponibilizados pelos autores, além de variáveis de calendário e da proporção estimada de carros bicombustíveis abastecidos com gasolina na cidade de São Paulo, contêm informação horária da concentração de ozônio, clima e trânsito. Uma ideia inicial seria propor um modelo para relacionar as observações horárias do ozônio com os preditores. Idealmente, esse modelo deveria controlar a correlação das observações medidas no mesmo dia, o que pode ser feito, por exemplo, usando variáveis indicadoras para hora do dia ou a partir de um modelo misto. No entanto, se examinarmos a proporção estimada de carros a gasolina, verificamos que ela varia, no máximo, de um dia para o outro. Isso significa que, para responder a pergunta do estudo, não precisamos modelar a relação entre as variáveis dentro de cada dia, já que o principal preditor não apresenta essa granularidade.

Uma boa estratégia nesse caso é agregar as observações feitas no mesmo dia, utilizando, por exemplo, a média ou máxima diária. Dessa forma, eliminamos necessidade de modelar a correlação entre as medidas feitas no mesmo dia. Salvo et al. (2017), além de considerarem a média diária, excluíram da análise os meses de junho a setembro, período no qual a concentração de ozônio é menor devido às baixas temperaturas e menor radiação solar. Retirar os meses frios também diminui a complexidade do problema, já que estamos eliminando um forte componente sazonal, que precisaria ser modelado. No entanto, essa escolha restringe a inferência do modelo, que não poderá ser generalizada para a temporada de inverno. Como o maior interesse em estudos de poluição está 
na redução dos índices mais altos, é razoável limitar a conclusão da análise apenas ao período de maiores concentrações.

Outra consequência da exclusão desses meses está na escolha do modelo. Removendo esses dias da amostra, não teremos mais um problema de série temporal usual, já que as medidas não são mais equidistantes no tempo.

Por fim, precisamos definir como medir os erros associados às conclusões dos modelos. Para os modelos de regressão apresentados no Capítulo 3, podemos usar testes de hipóteses para avaliar se o coeficiente referente à proporção de carros abastecidos com gasolina é ou não estatisticamente significativa para explicar a variação da concentração do ozônio. Para modelos não interpretáveis, nos restam os métodos gráficos discutidos na Seção 4.7. Para medir a qualidade do ajuste, podemos utilizar o RMSE e o $R^{2}$ (ver Seção 3.1.7).

As estratégias apresentadas até aqui consideram apenas o conhecimento prévio sobre o fenômeno estudado e as variáveis disponíveis. Podemos continuar buscando informação sobre o fenômeno para melhorarmos nossa intuição sobre o modelo mais adequado a partir de uma análise exploratória.

\subsection{Análise exploratória}

O objetivo desta análise exploratória é investigar o comportamento dos preditores considerados por Salvo et al. (2017) e entender como eles se relacionam com a concentração de ozônio. Por pragmatismo, apresentaremos aqui apenas a análise da estação Parque Dom Pedro II. De uma forma geral, os resultados são os mesmos para as outras 11 estações de monitoramento (ver Seção 2.1). A análise exploratória completa pode ser visualizada nas postagens disponíveis em https://rpollution.com/categories/ozônio.

Na Seção 2.1.1, vimos como a concentração do ozônio se comporta ao longo do dia (Figura 2.2). Como no período da manhã o ozônio ainda está sendo gerado e no final do dia ele já foi quase inteiramente consumido, é razoável analisarmos apenas a média diária no intervalo de pico, entre 12 e 17 horas. Isso significa que vamos relacionar o uso de etanol com o pico diário do ozônio, o que é suficiente para responder à pergunta de interesse.

Mesmo considerando apenas a concentração de ozônio medida entre 12 e 17 horas, as condições climáticas e de tráfego no período da manhã podem ser fatores importantes na formação do poluente. Assim, além das médias dessas variáveis no período da tarde, poderíamos considerar também valores médios pela manhã (entre 8 e 11 horas).

Vamos investigar inicialmente a associação entre a concentração de ozônio e a proporção estimada de carros a gasolina rodando na cidade. Pela Figura 5.1, observamos que existem dois picos de utilização de gasolina durante o período analisado, um no começo de 2010 e outro no começo de 2011. Após o segundo pico, a proporção estimada de carros a gasolina varia pouco, próximo a $50 \%$. Repare que os dois picos acontecem no começo do ano, o que gera um desbalanço deste preditor quando observamos sua distribuição em cada mês (Figura 5.3). Se não controlarmos bem as outras variáveis envolvidas nesse mecanismo, como a concentração de ozônio é naturalmente maior no verão, esse desbalanço pode gerar uma correlação espúria, isto é, a associação encontrada entre as variáveis ser apenas coincidência.

Analisando agora o gráfico de dispersão na Figura 5.2, não encontramos indícios claros de associação entre o ozônio e a proporção estimada de carros a gasolina. Isso significa que, se as 
variáveis estão associadas, essa relação está sendo mascarada pelo efeito dos outros preditores.

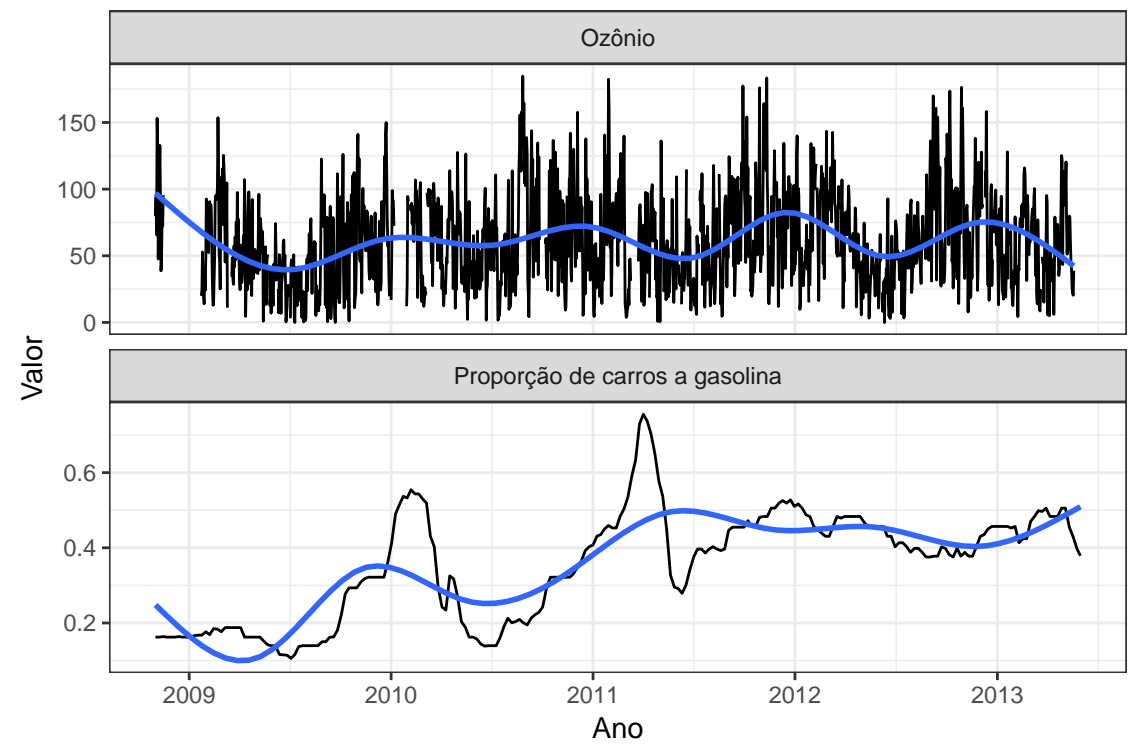

Figura 5.1: Séries da concentração de ozônio diária média e da proporção estimada de carros a gasolina rodando na cidade. As curvas azuis representam as séries suavizadas por splines cúbicos. Dados da estação Dom Pedro II, de 2008 a 2013.

Nas Figuras 5.4 e 5.5, podemos observar a distribuição da temperatura média, pela manhã e pela tarde, para cada mês do ano, e também comparar as séries de cada variável. Repare que a temperatura de manhã é muito mais sensível às estações do ano, enquanto a temperatura à tarde varia mais. Pela Figura 5.6, observamos que a concentração de ozônio parece mais associada com a temperatura pela tarde, o que é razoável devido ao papel da luz solar no mecanismo gerador do poluente.

Repetindo a mesma análise para as outras variáveis climáticas ${ }^{2}$, podemos concluir:

- dias com maior radiação estão associados a maiores níveis de ozônio;

- categorizando a variável precipitação em "Choveu no período" e "Não choveu no período"3, os períodos sem chuva estão associados a maiores concentrações de ozônio;

- umidade alta, principalmente à tarde, está associada com menores concentrações de ozônio;

- a relação entre a velocidade do vento, tanto de manhã quanto à tarde, e a concentração de ozônio não é muito clara;

- e parece haver uma leve associação entre a ocorrência de inversões térmicas e maiores concentrações de ozônio.

Analisando agora o trânsito diário médio na região da estação de monitoramento (Figura 5.7), não parece clara qual a relação com a concentração de ozônio. No entanto, se observamos agora a Figura 5.8, observamos que a concentração diária média de ozônio é, em geral, maior nos fins de semana, enquanto o congestionamento tende a ser menor nesses dias. Como não há motivos para

\footnotetext{
${ }^{2}$ Os gráficos para os outros preditores podem ser encontrados em https://www.rpollution.com/flexdashboards/ozonioclima-sp/dash-ozonio-clima-sp.html.

${ }^{3} \mathrm{~A}$ escolha pela categorização se deve ao alto número de zeros (dias sem chuva) que essa variável possui.
} 


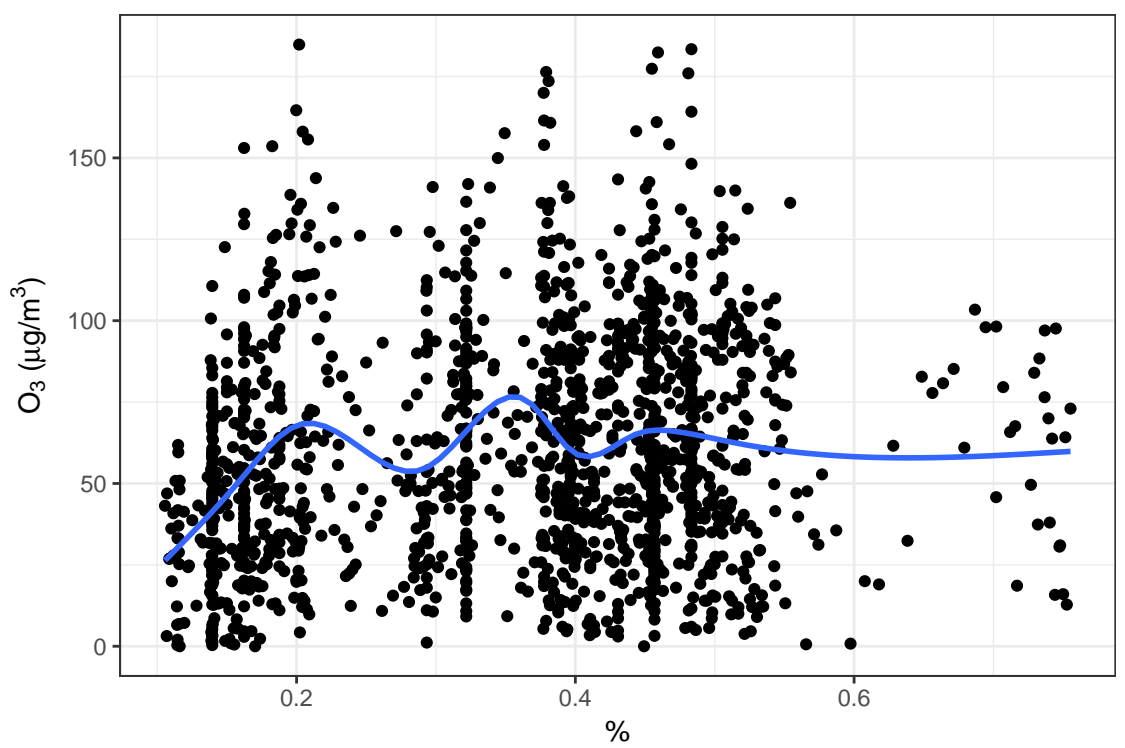

Figura 5.2: Gráfico de dispersão da concentração de ozônio contra a proporção estimada de carros rodando a gasolina na cidade. Dados da estação Dom Pedro II, de 2008 a 2013.

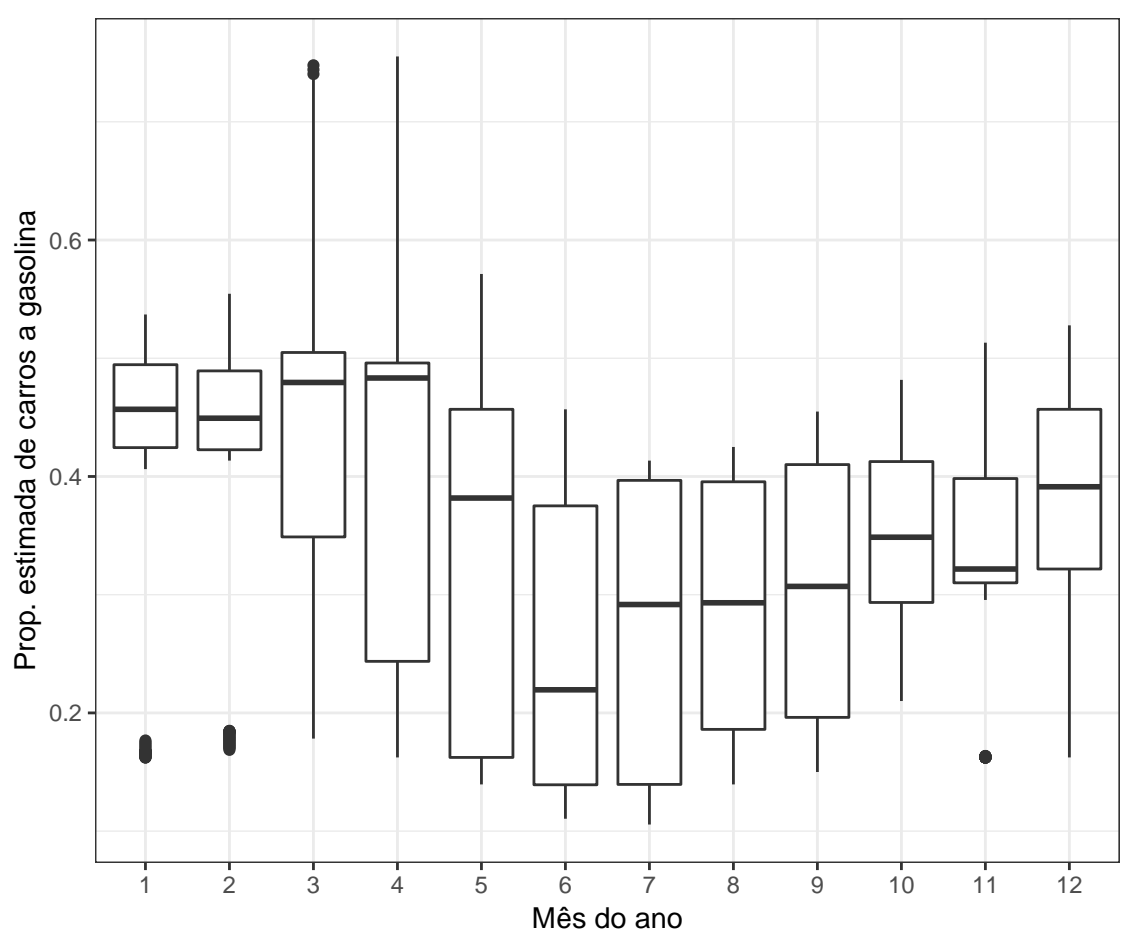

Figura 5.3: Boxplot da proporção estimada de carros a gasolina para cada mês. 


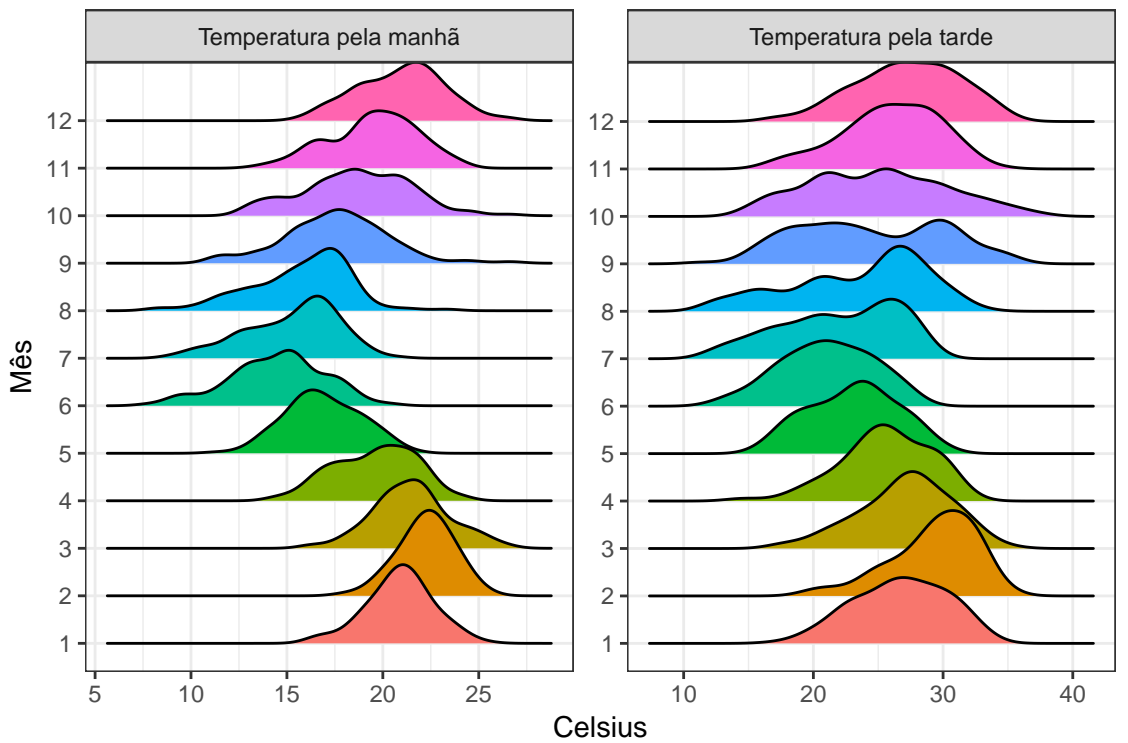

Figura 5.4: Gráficos ridge da temperatura diária média nos períodos da manhã (das 8 às 11 horas) e no período da tarde (12 às 17 horas). Dados da estação Dom Pedro II, de 2008 a 2013.

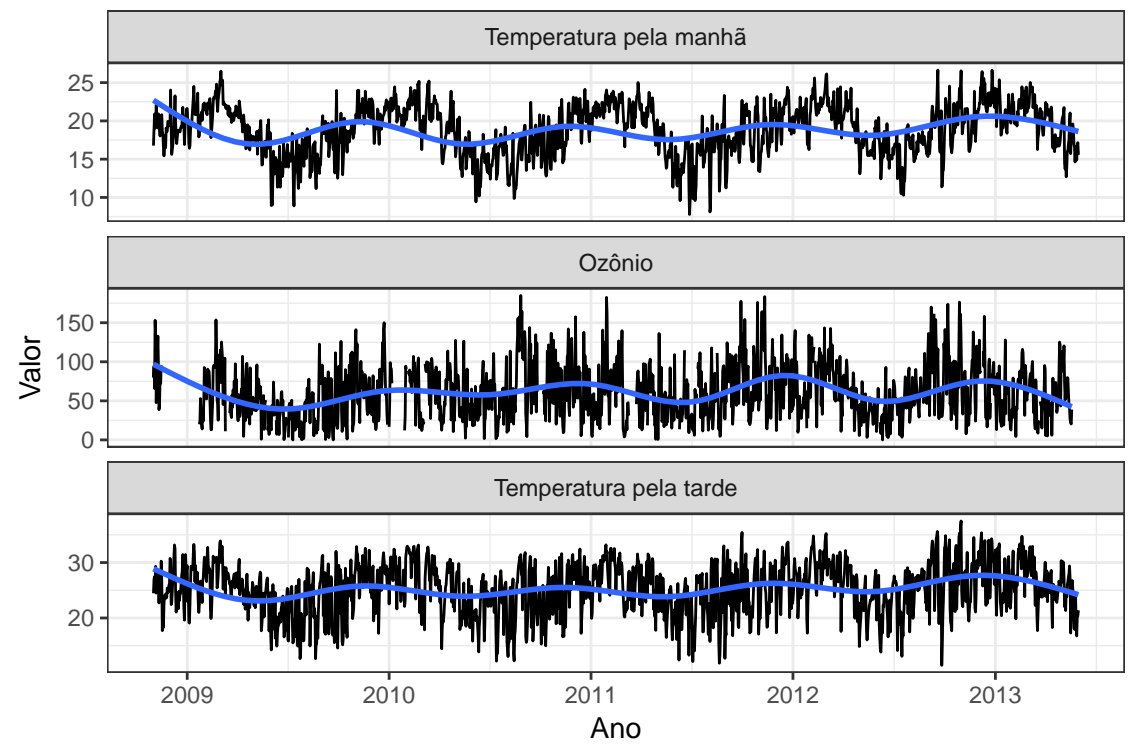

Figura 5.5: Gráficos das séries da concentração de ozônio e da temperatura diária média nos periodos da manhã (das 8 às 11 horas) e no periodo da tarde (12 às 17 horas). Dados da estação Dom Pedro II, de 2008 a 2013. 


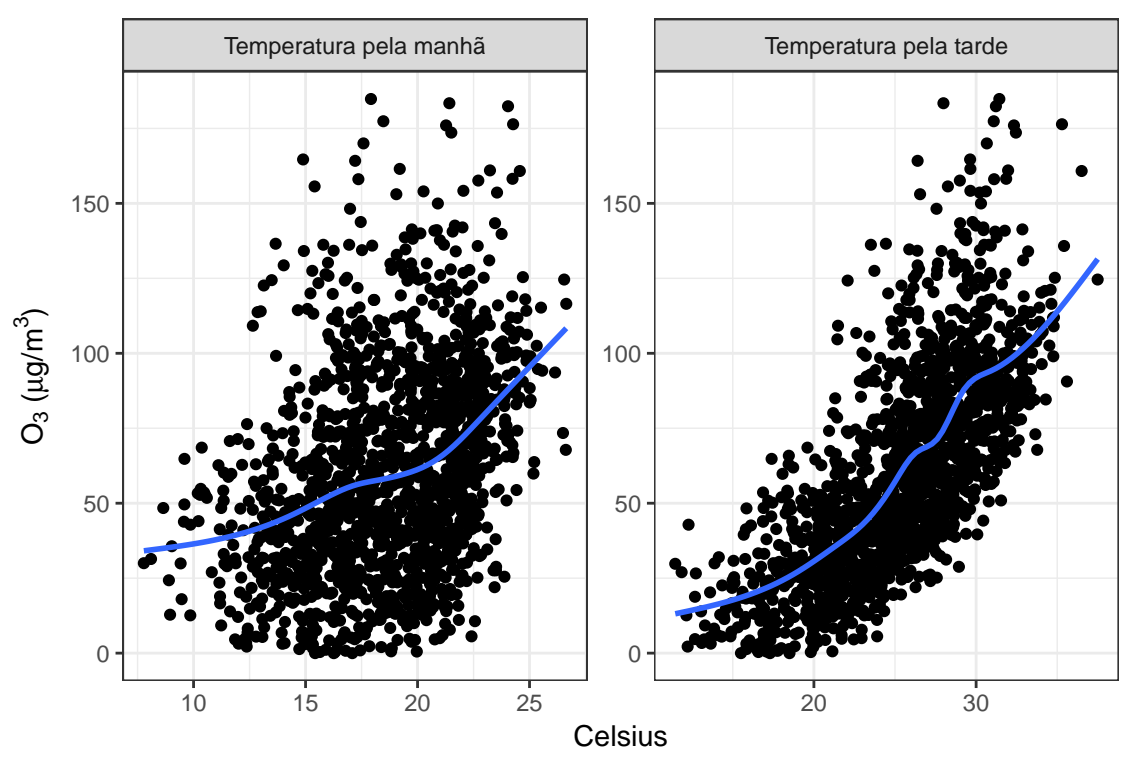

Figura 5.6: Gráficos de dispersão da concentração de ozônio pela temperatura diária média nos períodos da manhã (das 8 às 11 horas) e no periodo da tarde (12 às 17 horas). Dados da estação Dom Pedro II, de 2008 a 2013.

acreditar que as condições climáticas sejam diferentes nos fins de semana, é razoável supor que a concentração de ozônio é maior em dias de pouco tráfego.

Se essa relação for verdadeira, isso implica que, independentemente de qual for a relação entre o uso de etanol e a concentração de ozônio, maiores circulações de veículos tendem a diminuir os níveis do poluente. Para melhor avaliar essa hipótese, vamos estudar a concentração de ozônio em dias com maior proporção estimada de carros abastecidos com álcool e em dias com maior proporção estimada de carros abastecidos com gasolina. Como podemos observar pela Figura 5.9, a concentração de ozônio é maior em dias de menor tráfego independentemente de qual combustível está sendo mais utilizado na cidade.

Nas próximas seções, vamos prosseguir com a análise discutindo o ajuste de diversos modelos aos dados.

\subsection{A análise conduzida por Salvo et al. (2017)}

Antes de discutir as diferentes estratégias que adotamos para investigar a relação entre a concentração de ozônio e o uso de gasolina/etanol, vamos apresentar os resultados da análise feita por Salvo et al. (2017).

Os autores optaram por remover da análise os meses de junho a setembro, optando por uma amostra mais homogênea em relação às condições climáticas. Além disso, eles juntaram as observações de todas as 12 estações de monitoramento, formando uma única amostra em que cada observação representa as medidas diárias médias de uma estação. O modelo final apresentado por Salvo et al. (2017) foi o modelo de regressão linear (3.3), considerando as variáveis apresentadas na Tabela 5.1.

A estimativa reportada para o parâmetro referente à proporção de carros abastecidos com gasolina foi $-16.66 \pm 10.01$ (mais ou menos dois desvios-padrão) ${ }^{4}$, o que indica que o aumento

\footnotetext{
${ }^{4}$ Esse foi o resultado de um dos modelos, no qual foi utilizado mínimos quadrados ordinários para estimação dos
} 


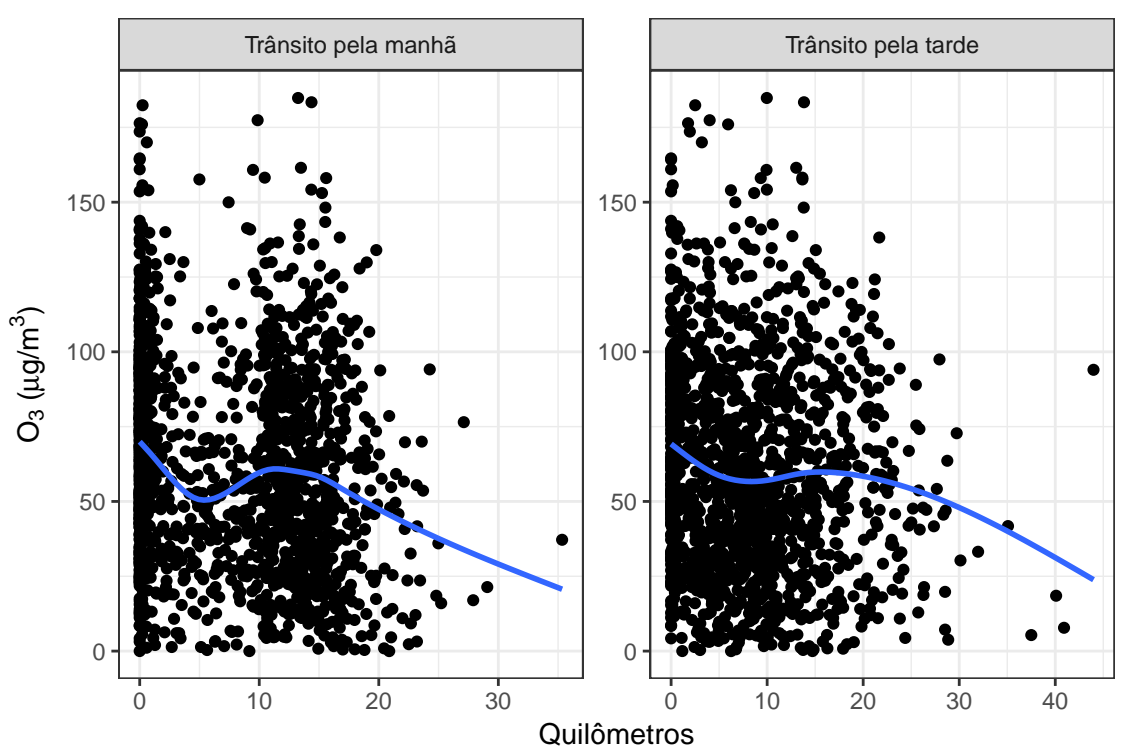

Figura 5.7: Gráficos de dispersão da concentração de ozônio pelo congestionamento diário médio, na região da estação de monitoramento, nos períodos da manhã (das 8 às 11 horas) e no período da tarde (12 às 17 horas). Dados da estação Dom Pedro II, de 2008 a 2013.

(a) Concentração de ozônio

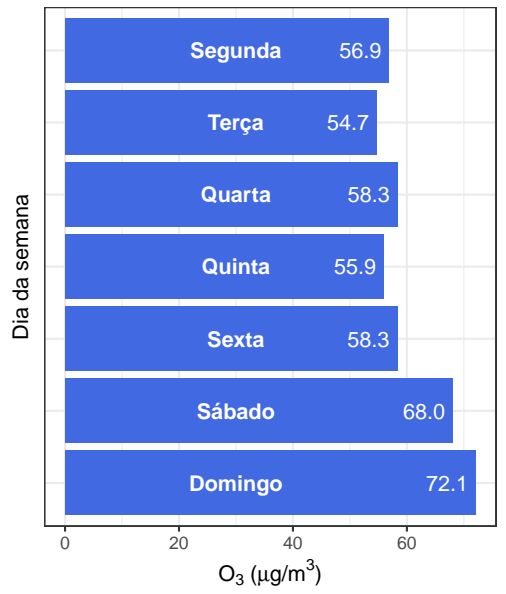

(b) Trânsito

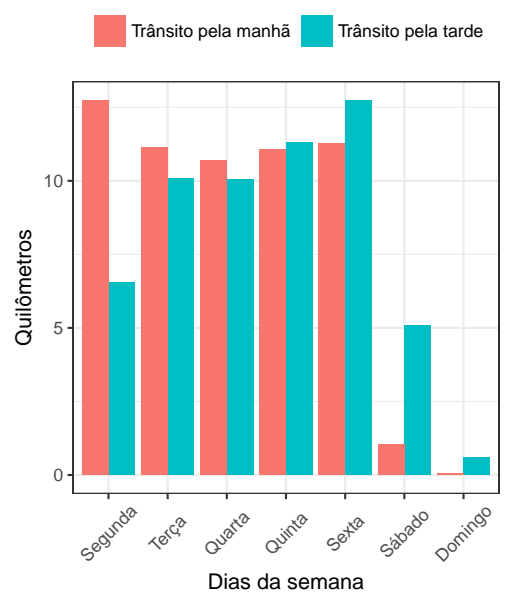

Figura 5.8: Relação entre a concentração de ozônio e o congestionamento na região da estação de monitoramento ao longo da semana. (a) Concentração de ozônio diária média ao longo da semana. (b) Congestionamento diário médio, no período da manhã e da tarde, na região da estação de monitoramento ao longo da semana. Dados da estação Dom Pedro II, de 2008 a 2013. 


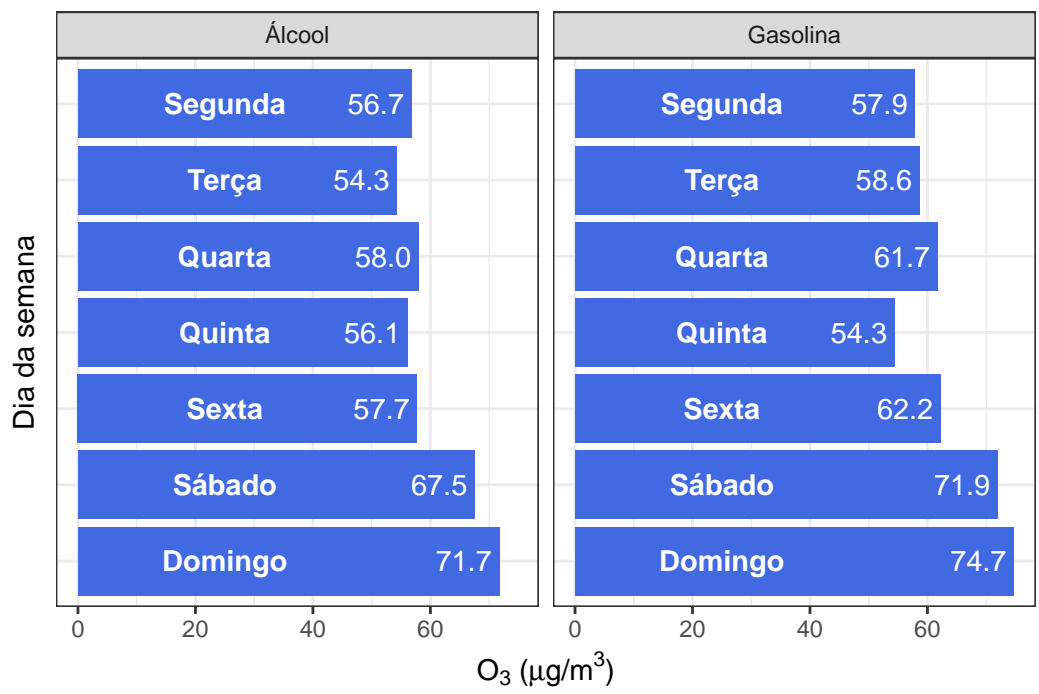

Figura 5.9: Concentração de ozônio diária média ao longo da semana em dias com maior proporção de estimadas de carros abastecidos com álcool e em dias com maior proporção estimada de carros abastecidos com gasolina. Dados da estação Dom Pedro II, de 2008 a 2013.

Tabela 5.1: Preditores considerados pelo modelo para a concentração de ozônio ajustado em Salvo et al. (2017).

\begin{tabular}{|c|c|c|}
\hline Tipo & Variáveis & $\begin{array}{l}\text { Número de } \\
\text { parâmetros }\end{array}$ \\
\hline Etanol & Proporção estimada de carros a gasolina. & 1 \\
\hline Estação & Indicador de estação. & 11 \\
\hline Calendário & $\begin{array}{c}\text { Indicadores de dia da semana, semana do ano, } \\
\text { férias e feriados públicos. }\end{array}$ & 44 \\
\hline Tendência & $\begin{array}{l}\text { Termo de tendência geral e específica para cada } \\
\text { estação. }\end{array}$ & 12 \\
\hline Clima & $\begin{array}{c}\text { Temperatura, radiação, umidade, velocidade do } \\
\text { vento e indicadores de precipitação e de } \\
\text { inversão térmica. }\end{array}$ & 9 \\
\hline Trânsito & $\begin{array}{l}\text { Indicadores de congestionamento na região da } \\
\text { estação de monitoramento, na cidade como um } \\
\text { todo e inauguração de vias importantes. }\end{array}$ & 18 \\
\hline Total & 16 preditores + intercepto & 96 parâmetros* \\
\hline
\end{tabular}

*95 parâmetros dos preditores +1 parâmetro do intercepto.

da proporção estimada de carros a gasolina na cidade está associada com a diminuição da concentração de ozônio. Como medida de qualidade de ajuste, os autores reportaram a proporção da variância da concentração de ozônio explicada pelo modelo $\left(\mathrm{R}^{2}\right)$ : $70.65 \%$.

Adicionalmente, calculamos o erro de teste do modelo, usando validação cruzada (5-fold) e o RMSE como métrica. O valor encontrado foi 19.74. Utilizamos também o valor da estatística do teste t de cada coeficiente como medida de importância dos preditores. Os cinco preditores mais parâmetros e bootstrapping para o cálculo do erro padrão das estimativas. 


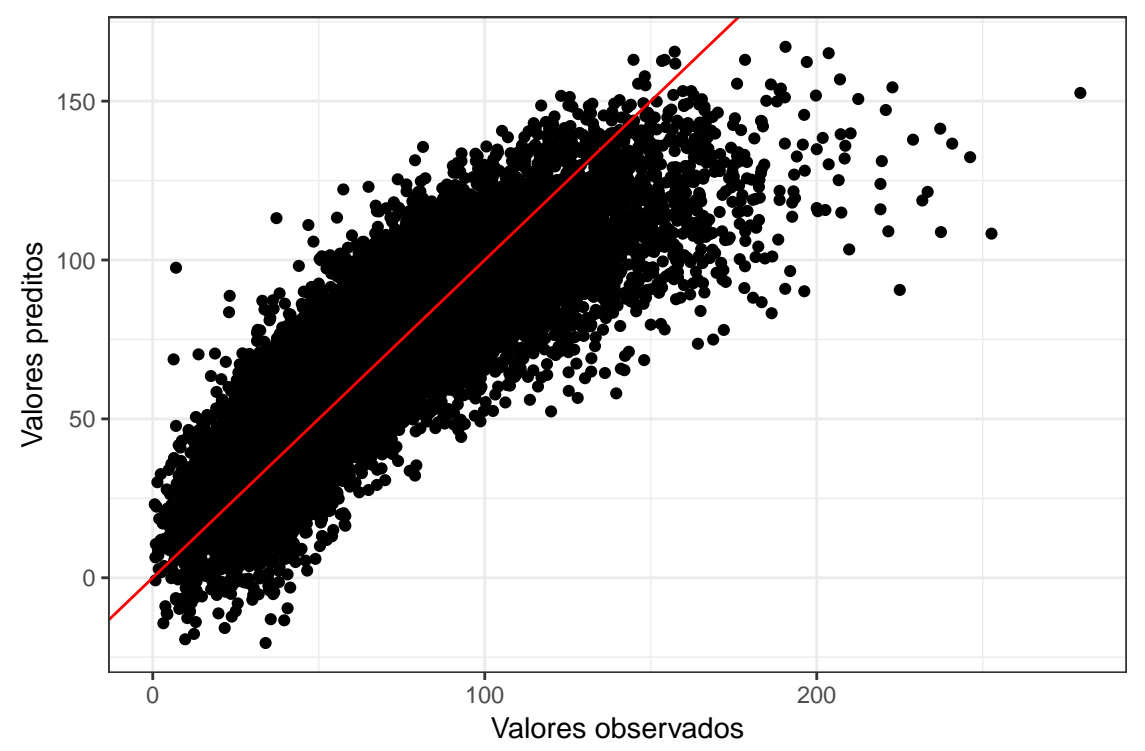

Figura 5.10: Valores da concentração de ozônio preditos pelo modelo de regressão linear ajustado por Salvo et al. (2017) contra os valores observados.

importantes foram: temperatura, velocidade do vento, radiação, umidade e variável indicadora para a estação São Caetano do Sul. A variável correspondente à proporção estimada de carros a gasolina foi considerada apenas a décima quinta mais importante.

Na Figura 5.10, apresentamos o gráfico dos valores preditos pelo modelo contra os valores observados. Os pontos acima da reta vermelha representam as observações superestimadas pelo modelo, isto é, aquelas cujo valor predito foi maior do que o valor observado. Os pontos abaixo da curva representam os valores subestimados. Podemos observar que o modelo subestima valores muito altos da concentração de ozônio, isto é, o modelo não consegue explicar os picos do poluente. Esse comportamento é essencialmente ruim dado o objetivo do estudo, já que gostaríamos de avaliar principalmente os dias nos quais os níveis de ozônio estão altos.

Nas próxima seções, vamos comparar o resultado obtido pelos autores com outras estratégias de análise, visando obter ajustes mais precisos e avaliar se as conclusões encontradas pelos autores sem mantêm. Inicialmente, vamos utilizar as mesmas variáveis para explorar modelos mais flexíveis que o modelo de regressão linear. Em seguida, vamos testar novas estratégias de análise para avaliar a robustez dos resultados.

\subsection{Ajustando outros modelos}

O modelo de regressão linear, embora muito utilizado pela sua simplicidade e interpretabilidade, pode ser muito restritivo, já que faz muitas suposições fortes sobre a relação entre as variáveis. Para avaliar se modelos mais flexíveis são mais adequados para descrever a relação entre a concentração de ozônio e a proporção estimada de carros abastecidos com gasolina, vamos ajustar modelos aditivos generalizados, modelos de regressão segmentada, uma floresta aleatória e um XGBoosting. A variável resposta e os preditores serão os mesmos utilizados por Salvo et al. (2017). As performances serão comparadas a partir do RMSE calculado usando validação cruzada 5-fold. Também discutiremos como interpretar cada modelo e se as interpretações obtidas corroboram ou não as conclusões dos autores. 


\subsubsection{Modelos aditivos generalizados}

Com o objetivo de ajustar um modelo mais flexível em relação a suposição de linearidade, consideraremos primeiramente modelos aditivos generalizados com as distribuições Normal, Gama e Normal Inversa. Embora a distribuição Normal gere resultados com uma interpretação mais intuitiva, as distribuições Gama e Normal Inversa são, em teoria, mais adequadas à natureza da variável resposta, uma medida positiva e assimétrica. Funções não-lineares foram atribuídas a todos os preditores numéricos: proporção estimada de carros abastecidos com gasolina, temperatura, radiação, umidade, velocidade do vento e tendência. Os demais preditores entraram no modelo de forma linear. Splines suavizados foram utilizados na estimação das funções e o grau de suavização foi escolhido automaticamente por meio de validação cruzada. Nos três modelos, a proporção estimada de carros a gasolina foi considerada estatisticamente significante para explicar a concentração de ozônio. A performance de cada modelo está descrita na Tabela 5.2.

Tabela 5.2: Resultados dos modelos aditivos generalizados em comparação com o modelo utilizado por Salvo et al. (2017).

\begin{tabular}{c|c|c|c}
\hline Modelo & RMSE & $\begin{array}{c}\text { \% var. } \\
\text { explicada }\end{array}$ & Variáveis mais importantes \\
\hline Normal & 19.82 & 70.50 & $\begin{array}{c}\text { Temperatura, velocidade do vento, } \\
\text { umidade, radiação e tendência } \\
\text { Temperatura, velocidade do vento, } \\
\text { umidade, radiação e tendência } \\
\text { Temperatura, radiação, umidade, } \\
\text { velocidade do vento e tendência }\end{array}$ \\
\hline $\begin{array}{c}\text { inversa } \\
\text { Salvo et al. } \\
(2017)\end{array}$ & 19.74 & 70.65 & $\begin{array}{c}\text { Temperatura, velocidade do vento, } \\
\text { radiação, umidade e var. ind. } \\
\text { estação São Caetano do Sul }\end{array}$ \\
\hline
\end{tabular}

Os resultados dos modelos Normal e Gama ficaram muito próximos do modelo de regressão linear ajustado pelos autores. Já o modelo Normal Inversa se mostrou inferior, mostrando que essa distribuição (com função de ligação $1 / \mu^{2}$ ) não é adequada aos dados. Observamos que, para esses modelos, a tendência entrou como uma das cinco variáveis mais importantes para explicar a variabilidade da concentração de ozônio, o que não aconteceu para o modelo de regressão linear. Isso provavelmente se deve à maior flexibilidade desses modelos, que capturam a não linearidade desse componente temporal. No modelo com distribuição Normal, a proporção estimada de carros a gasolina foi considerada a décima terceira mais importante e nos modelos Gama e Normal Inversa foi a nona mais importante.

A maneira usual de interpretar os modelos aditivos generalizados é a partir dos gráficos dos preditores contra suas funções estimadas ${ }^{5}$. Na Figura 5.11, apresentamos esse gráfico para o preditor referente à proporção estimada de carros a gasolina utilizando o modelo com distribuição Normal. A partir dele, observamos que

- a função estimada sugere uma relação não linear entre as variáveis;

- para valores extremos, menores que $20 \%$ e maiores que 60\%, um aumento da proporção estimada de carros a gasolina está associada com um aumento na concentração de ozônio;

\footnotetext{
${ }^{5}$ Os preditores que entraram no modelo de forma linear podem ser interpretados de maneira análoga ao modelo de regressão linear.
} 
- para valores intermediários, entre $20 \%$ e $60 \%$, um aumento da proporção estimada de carros a gasolina está associada, de uma forma geral, com uma diminuição da concentração do ozônio;

- mesmo na faixa intermediária, onde a gasolina parece assumir um papel protetor, a curva não é monótona, isto é, ela decresce com diferentes velocidades, sendo crescente ao redor de $50 \%$;

- por esse modelo, o valor da proporção de carros a gasolina que geraria o menor impacto no nível de ozônio seria aproximadamente 58\%;

- como há relativamente poucos dias com proporção estimada de carros a gasolina muito baixa ou muito alta ${ }^{6}$, devemos tomar cuidado ao tirarmos conclusões sobre a relação entre as variáveis nesses intervalos;

- os indícios trazidos por esse gráfico não contradizem os resultados encontrados por Salvo et al. (2017), mas sim os complementam, levantando outras hipóteses para um problema inerentemente complexo.

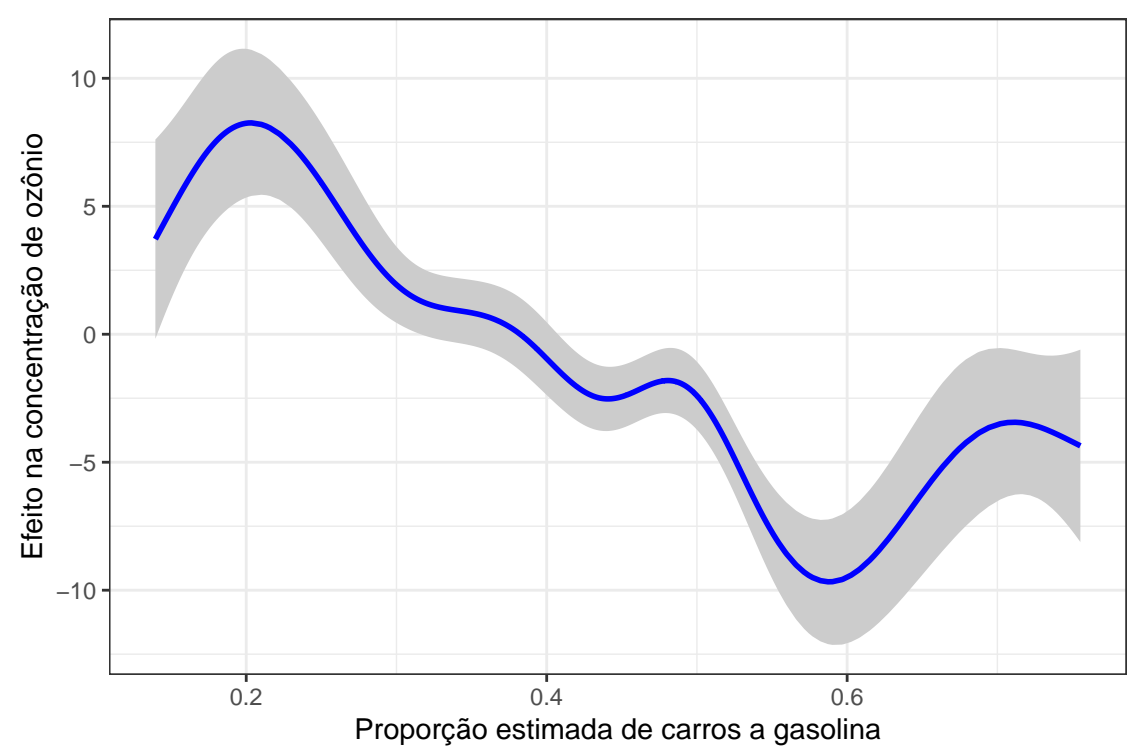

Figura 5.11: Função não-linear estimada pelo modelo aditivo generalizado com distribuição Normal para a proporção estimada de carros rodando a gasolina. A área cinza em volta da curva representa o intervalo de confiança com 2 erros-padrão para cima e para baixo.

A Figura 5.12 apresenta o gráfico dos valores preditos contra os valores observados para o modelo com distribuição Normal (a) e para o modelo com distribuição Gama (b). O modelo com distribuição Normal possui o mesmo problema do modelo de regressão linear: ele subestima valores altos da concentração de ozônio. Já o modelo com distribuição Gama corrige em parte esse comportamento. De maneira geral, ambos os modelos tendem a errar mais conforme o valor da concentração de ozônio aumenta.

Para avaliar a variabilidade das estimativas, criamos 200 amostras de bootstrapping e ajustamos o modelo aditivo generalizado com distribuição Normal (que apresentou o melhor desempenho) para cada uma delas. Na Figura 5.13, apresentamos o resultado para a função estimada da variável referente à proporção estimada de carros a gasolina. As curvas cinzas são as 200 funções estimadas,

\footnotetext{
${ }^{6}$ Como pode ser observado pela amplitude do intervalo de confiança dado pela área cinza em torno da curva.
} 
(a)

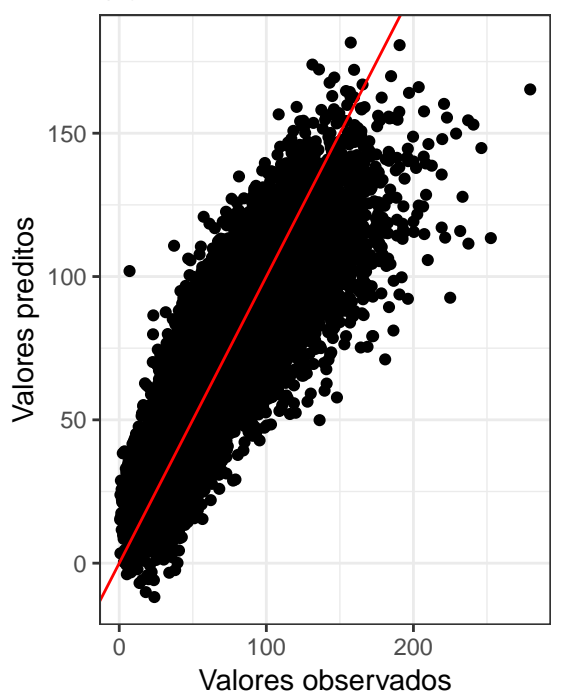

(b)

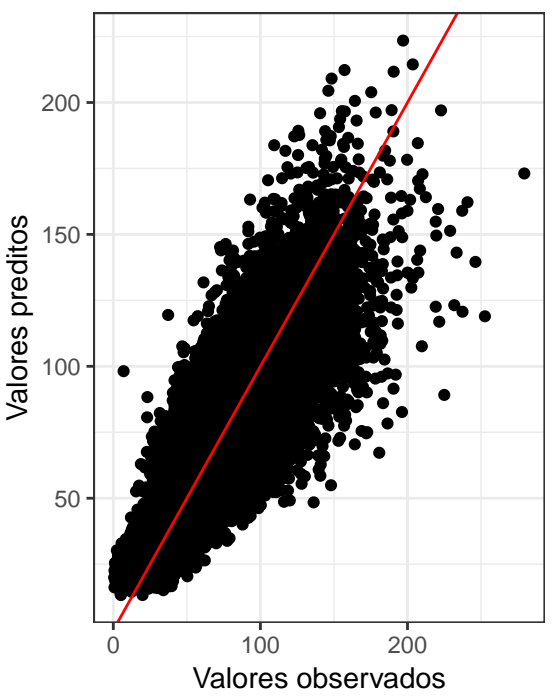

Figura 5.12: Valores da concentração de ozônio preditos pelo modelo com distribuição Normal (a) e pelo modelo com distribuição Gama (b) contra os valores observados.

uma para cada amostra de bootstrapping, e representam a variabilidade da função apresentada na Figura 5.11. A curva azul é a curva suavizada por splines cúbicos. Podemos notar que o modelo é consistente com as interpretações obtidas para a Figura 5.11. Esse gráfico também ressalta a maior variabilidade nos extremos do preditor.

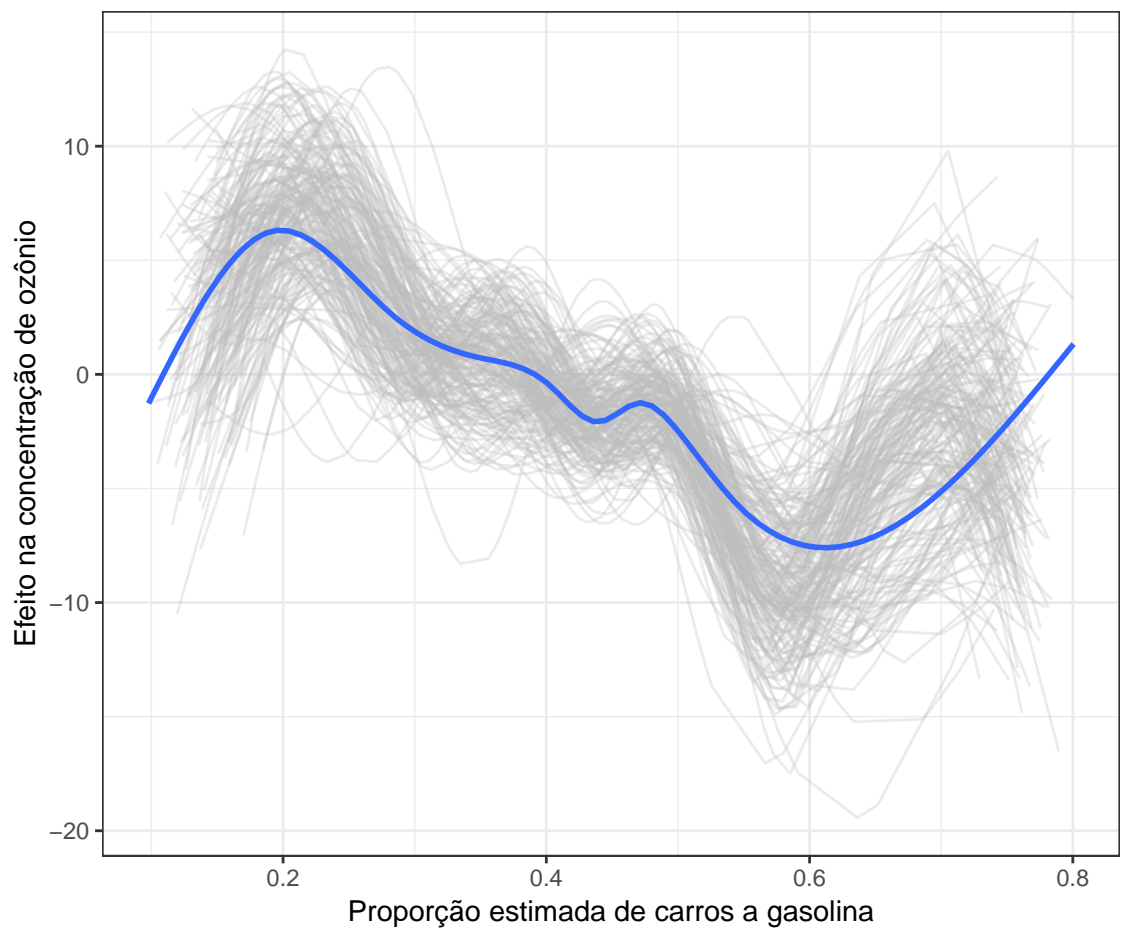

Figura 5.13: Em cinza, as funções estimadas da variável referente à proporção estimada de carros a gasolina para cada uma das 200 amostras de bootstrapping. Em azul, a curva suavizada por splines cúbicos.

Embora o modelo aditivo tenha levantado outras hipóteses sobre a relação entre a concentração de ozônio e a proporção estimada de carros a gasolina, ele não trouxe ganho de precisão se compararmos com o modelo de regressão linear. Vamos então continuar explorando a não linearidade 
começando com um modelo de regressão segmentada, mais simples do que o modelo aditivo, e, em seguida, ajustando uma floresta aleatória, um modelo não-linear mais flexível para tentar aumentar a precisão do ajuste.

\subsubsection{Modelo de regressão segmentada}

Para explorar um modelo não linear mais simples do que o modelo aditivo generalizado, ajustamos o modelo de regressão segmentada discutido na Seção 3.1.5. Com base na Figura 5.11, optamos por segmentar a reta de regressão primeiro em dois pontos, com valores iniciais ${ }^{7}$ por volta de 0.2 e 0.6, e em seguida em três pontos, com valores iniciais por volta de $0.2,0.5$ e 0.6. Esses pontos representam as maiores inflexões da curva estimada no modelo aditivo Normal para a proporção estimada de carros a gasolina. Como o modelo é altamente sensível ao ponto de segmentação inicial, testamos diversas combinações de pontos com valores ao redor desses números. A combinação que obteve o menor RMSE foi $(0.21,0.6)$ para o modelo com dois pontos e $(0.21,0.51,0.59)$ para o modelo com três. Os resultados para estes modelos estão apresentados na Tabela 5.3.

Tabela 5.3: Resultado do modelo de regressão segmentada.

\begin{tabular}{c|c|c|c}
\hline $\begin{array}{c}\text { Pontos de } \\
\text { segmentação } \\
\text { estimados }\end{array}$ & RMSE & $\begin{array}{c}\text { \% var. } \\
\text { explicada }\end{array}$ & Variáveis mais importantes \\
\hline$(0.51,0.58)$ & 19.6 & 70.50 & $\begin{array}{c}\text { Temperatura, vento, radiação, } \\
\text { umidade e var. ind. para a estação } \\
\text { São Caetano do Sul }\end{array}$ \\
$(0.26,0.51,0.58)$ & 19.45 & 71.23 & $\begin{array}{c}\text { Temperatura, vento, radiação, } \\
\text { umidade e var. ind. para a estação } \\
\text { São Caetano do Sul }\end{array}$ \\
\hline
\end{tabular}

Observamos que os modelos apresentam performance ligeiramente melhor do que a dos modelos lineares e aditivos (menor RMSE e maior $\mathrm{R}^{2}$ ). As variáveis mais importantes para explicar a concentração de ozônio continuam as mesmas do modelo de regressão linear. A proporção de carros a gasolina foi considerada estatisticamente significativa (valor-p $<0.001$ ) em ambos os modelos, sendo que a Figura 5.14 apresenta as retas de regressão segmentada estimadas para o efeito desse preditor na variação da concentração de ozônio. Quando comparamos esses gráficos com os gráficos do modelo aditivo generalizado (Figuras 5.11 e 5.13), notamos que ambos os modelos capturam relações não-lineares semelhantes, principalmente a queda acentuada do efeito por volta do valor 0.5 e o aumento próximo ao valor 0.6. A diferença entre o modelo com 2 pontos e o com 3 pontos é que o primeiro não captura o vale existente em torno do 0.28 que o segundo modelo sugere.

Embora as funções não lineares dos modelos de regressão segmentada e do modelo aditivo apresentem algumas diferenças, ambos sugerem que um modelo linear não é o mais adequado para investigar a associação entre a concentração de ozônio e a proporção de carros bicombustíveis abastecidos com na cidade. Ambos os modelos também estimam que a proporção ótima de carros a gasolina para a redução dos níveis de ozônio estaria em torno de 58\%. A seguir, ajustaremos um modelo mais flexível, na tentativa de melhorarmos a precisão das estimativas.

\footnotetext{
${ }^{7}$ Utilizados no processo iterativo de estimação.
} 

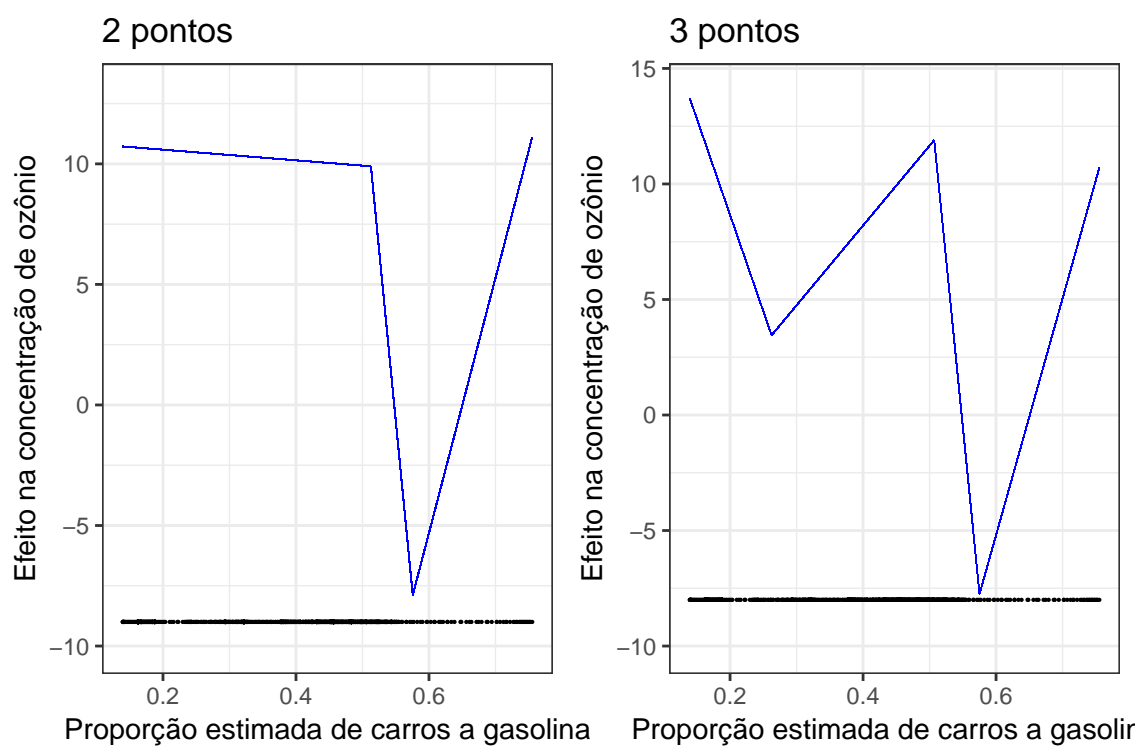

Figura 5.14: Retas de regressão segmentada para a proporção estimada de carros a gasolina. O efeito representa o valor da concentração de ozônio para cada valor da proporção estimada de carros a gasolina se todos os outros preditores tivessem valor igual a 0. Essa medida não tem interpretação prática, mas pode ser utilizada para calcular a variação no ozônio quando variamos a proporção de carros a gasolina.

\subsubsection{Floresta aleatória}

Em busca de resultados mais precisos, ajustamos também uma floresta aleatória aos dados. Os resultados estão resumidos na Tabela 5.4.

Tabela 5.4: Resultado da floresta aleatória aplicado aos dados de Salvo et al. (2017). Os hiperparâmetros referentes ao tamanho minimo de cada nó e o número de preditores sorteados em cada amostra foram definidos por validação cruzada.

\begin{tabular}{c|c|c|c|c}
\hline $\begin{array}{c}\text { Tamanho } \\
\text { mínimo dos } \\
\text { nós }\end{array}$ & $\begin{array}{c}\text { Número de } \\
\text { preditores em } \\
\text { cada amostra }\end{array}$ & RMSE & $\begin{array}{c}\% \text { var. } \\
\text { explicada }\end{array}$ & Variáveis mais importantes \\
\hline 1 & 48 & 14.11 & 85.72 & $\begin{array}{c}\text { Temperatura, umidade, } \\
\text { radiação, vento e tendência }\end{array}$ \\
\hline
\end{tabular}

Observamos que a floresta aleatória apresentou um menor erro de teste (RMSE $=14.11)$ do que o modelo de regressão linear (19.74), além de explicar uma maior porcentagem da variação da concentração de ozônio ( $85.72 \%$ contra $70.65 \%$ do modelo de regressão linear). Os cinco preditores mais importantes foram temperatura, umidade, radiação, vento e tendência, iguais aos encontrados nos modelos aditivos generalizados. A proporção estimada de carros a gasolina foi o sexto preditor mais importante.

A Figura 5.15 apresenta o gráfico dos valores preditos contra os valores observados para a floresta aleatória. Fica nítido, ao compararmos com os outros modelos, a redução da diferença entre os valores preditos e observados. No entanto, ainda observamos que valores altos da concentração de ozônio tendem a ser subestimadas pelo modelo.

Apesar de termos um ajuste mais preciso, a partir desse modelo não conseguimos interpretar diretamente a relação entre a proporção estimada de carros a gasolina e a concentração de ozônio. Não sabemos se esse preditor é estatisticamente significativo e, em caso positivo, em qual direção está associado à resposta. Sem essa interpretação, não conseguimos responder à pergunta de interesse 


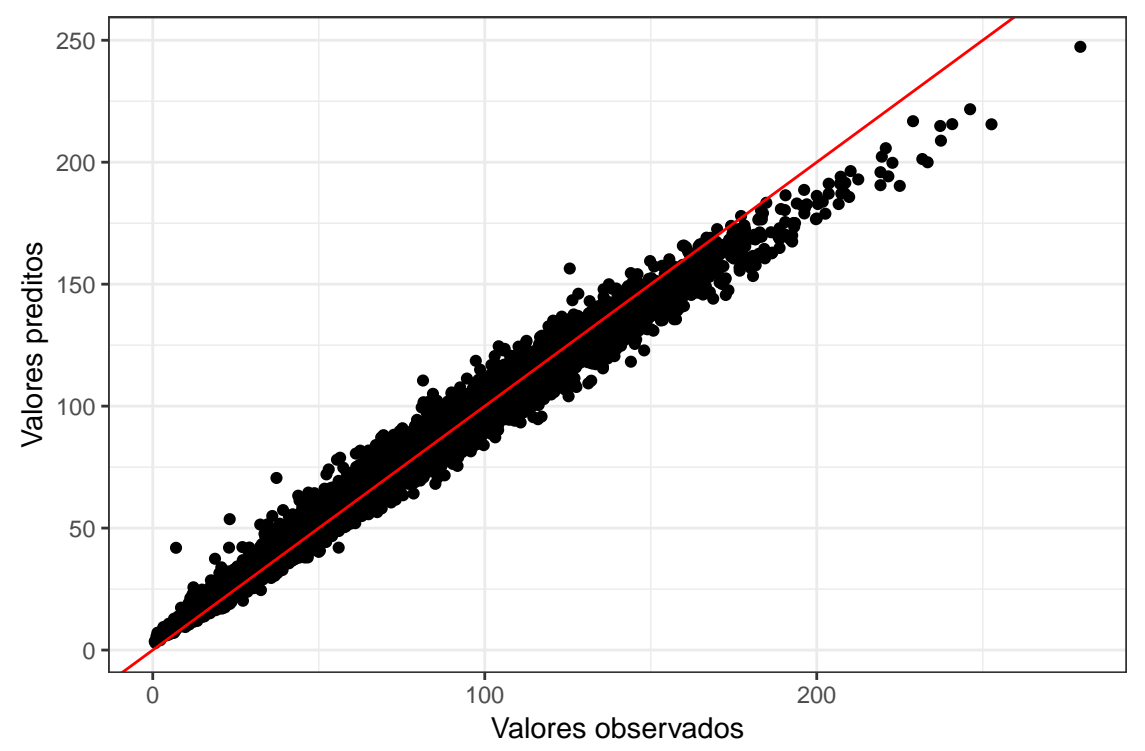

Figura 5.15: Valores da concentração de ozônio preditos pelo a floresta aleatória contra os valores observados.

do estudo.

Para resolver esse problema, vamos utilizar as técnicas gráficas apresentadas na Seção 4.7 para investigar o efeito da proporção estimada de carros a gasolina na concentração de ozônio. Na Figura 5.16, apresentamos os gráficos de dependência parcial (PDP) e de efeitos locais acumulados para esse preditor. Observamos que o efeito é muito parecido com o encontrado no modelo aditivo generalizado. A semelhança entre as curvas dos dois gráficos sugere que a proporção de carros a gasolina não é correlacionada com outros preditores.
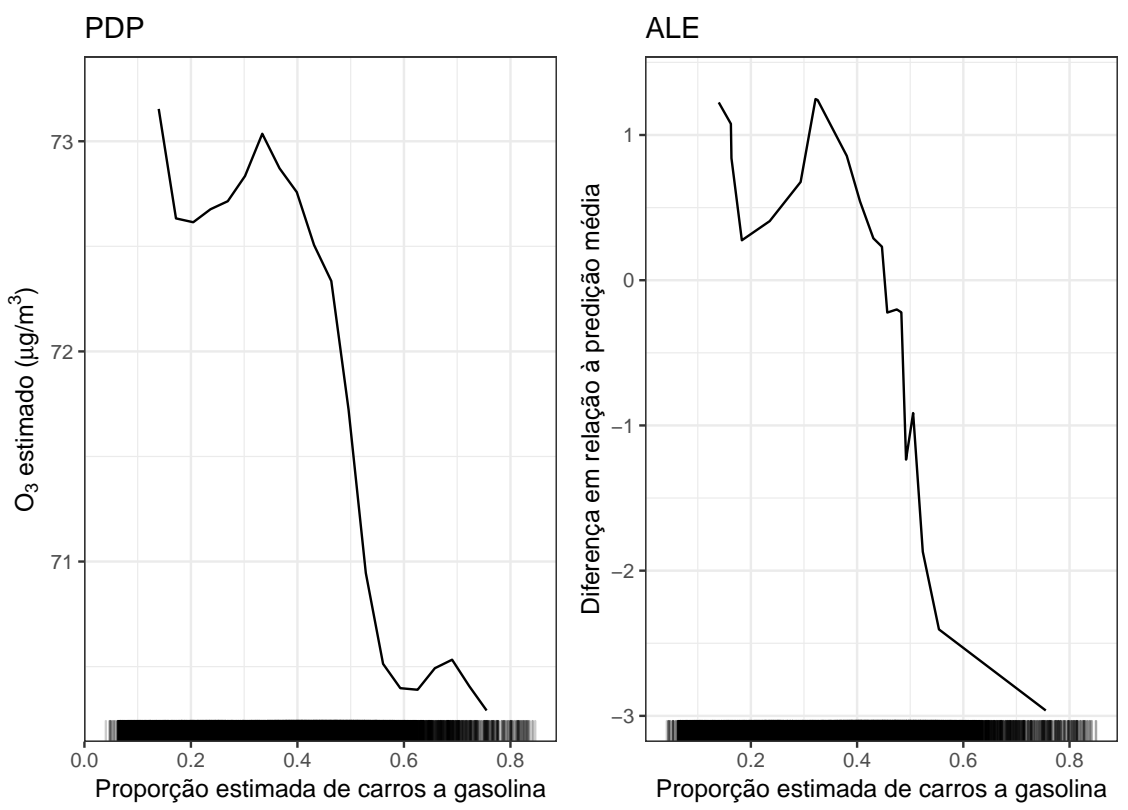

Figura 5.16: Gráficos de dependência parcial (PDP) e de efeitos locais acumulados para a floresta aleatória.

Os resultados encontrados aqui mostraram que a floresta aleatória ratificou as conclusões encontradas pelo modelo aditivo generalizado. Na próxima seção, vamos dar mais um passo na direção da precisão e ajustar um XGboost aos dados. 


\subsection{XGBoost}

Graças a sua acurácia e eficiência computacional, o XGBoost é um dos modelos mais utilizados hoje em dia em tarefas de predição. Com o objetivo de validar os resultados encontrados até então, vamos ajustar esse modelo aos dados e avaliar se, primeiro, realmente obtemos um melhor ajuste e, segundo, se as conclusões apontam na mesma direção que os modelos anteriores.

O desempenho do XGBoost ajustado está apresentado na Tabela 5.5. Podemos observar que, de fato, o ajuste foi mais preciso do que para os modelos de regressão linear, aditivo generalizado e a floresta aleatória.

Tabela 5.5: Performance do modelo XGBoost aplicado aos dados de Salvo et al. (2017) em comparação com os outros modelos ajustados.

\begin{tabular}{|c|c|c|c|}
\hline Modelo & RMSE & $\begin{array}{l}\% \text { var. } \\
\text { explicada }\end{array}$ & Variáveis mais importantes \\
\hline XGBoost & 12.24 & 88.56 & $\begin{array}{l}\text { Temperatura, umidade, radiação, } \\
\text { tendência e vento }\end{array}$ \\
\hline Floresta aleatória & 14.11 & 85.72 & $\begin{array}{c}\text { Temperatura, umidade, radiação, } \\
\text { vento e tendência }\end{array}$ \\
\hline GAM (Normal) & 19.82 & 70.50 & $\begin{array}{l}\text { Temperatura, vento, umidade, } \\
\text { radiação e tendência }\end{array}$ \\
\hline $\begin{array}{l}\text { Salvo et al. } \\
\quad(2017)\end{array}$ & 19.74 & 70.65 & $\begin{array}{l}\text { Temperatura, velocidade do vento, } \\
\text { radiação, umidade e var. ind. } \\
\text { estação São Caetano do Sul }\end{array}$ \\
\hline
\end{tabular}

Agora, assim como fizemos para a floresta aleatória, vamos utilizar os gráficos de dependência parcial (PDP) e de efeitos locais acumulados (ALE) para avaliar o efeito da proporção estimada de carros a gasolina na concentração de ozônio predita pelo modelo. Podemos observar (Figura 5.17) que a proporção de carros a gasolina não parece exercer um efeito claro na concentração de ozônio estimada, variando a depender do valor desse preditor.
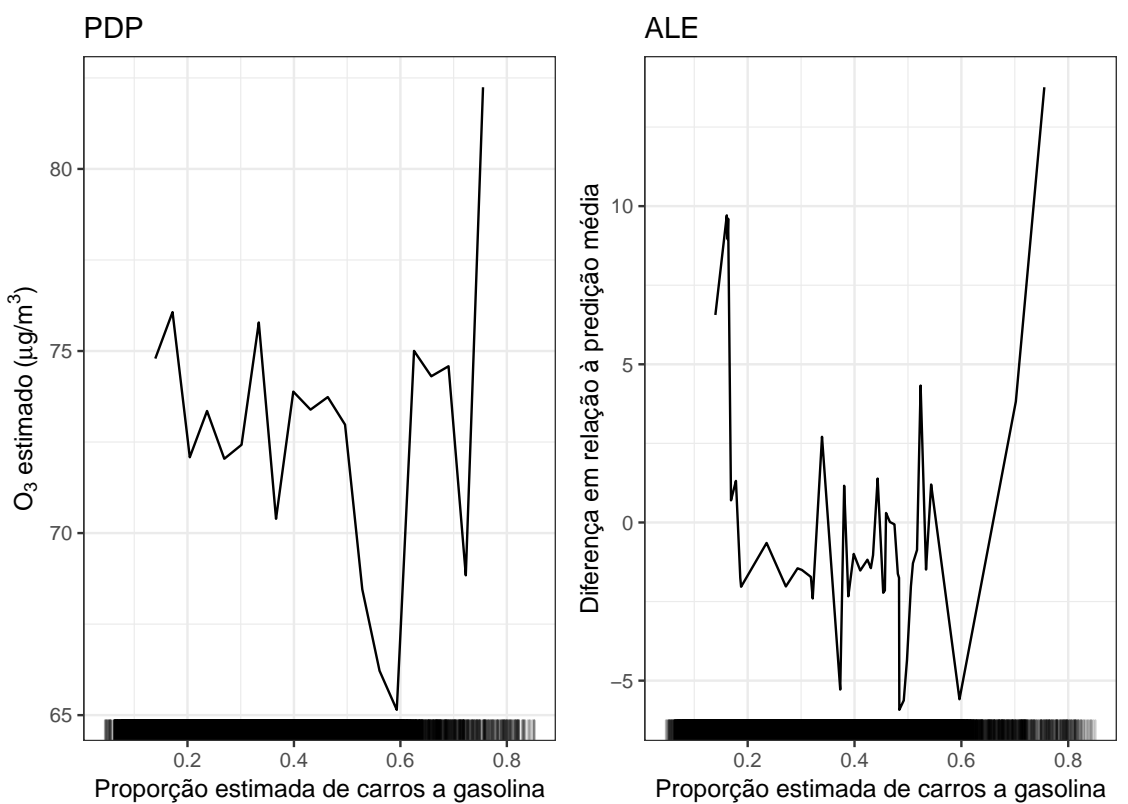

Figura 5.17: Gráficos de dependência parcial (PDP) e de efeitos locais acumulados para a proporção estimada de carros a gasolina do modelo XGBoost. 
Para avaliarmos a qualidade das interpretações feitas pelos gráficos de dependência parcial e de efeitos locais acumulados, apresentamos na Figura 5.18 o ALE para a temperatura, umidade, radiação e velocidade do vento. Podemos observar que a interpretação encontrada é razoável com o conhecimento sobre a geração do ozônio: temperatura e radiação estão positivamente associadas e velocidade do vento e umidade negativamente associadas.
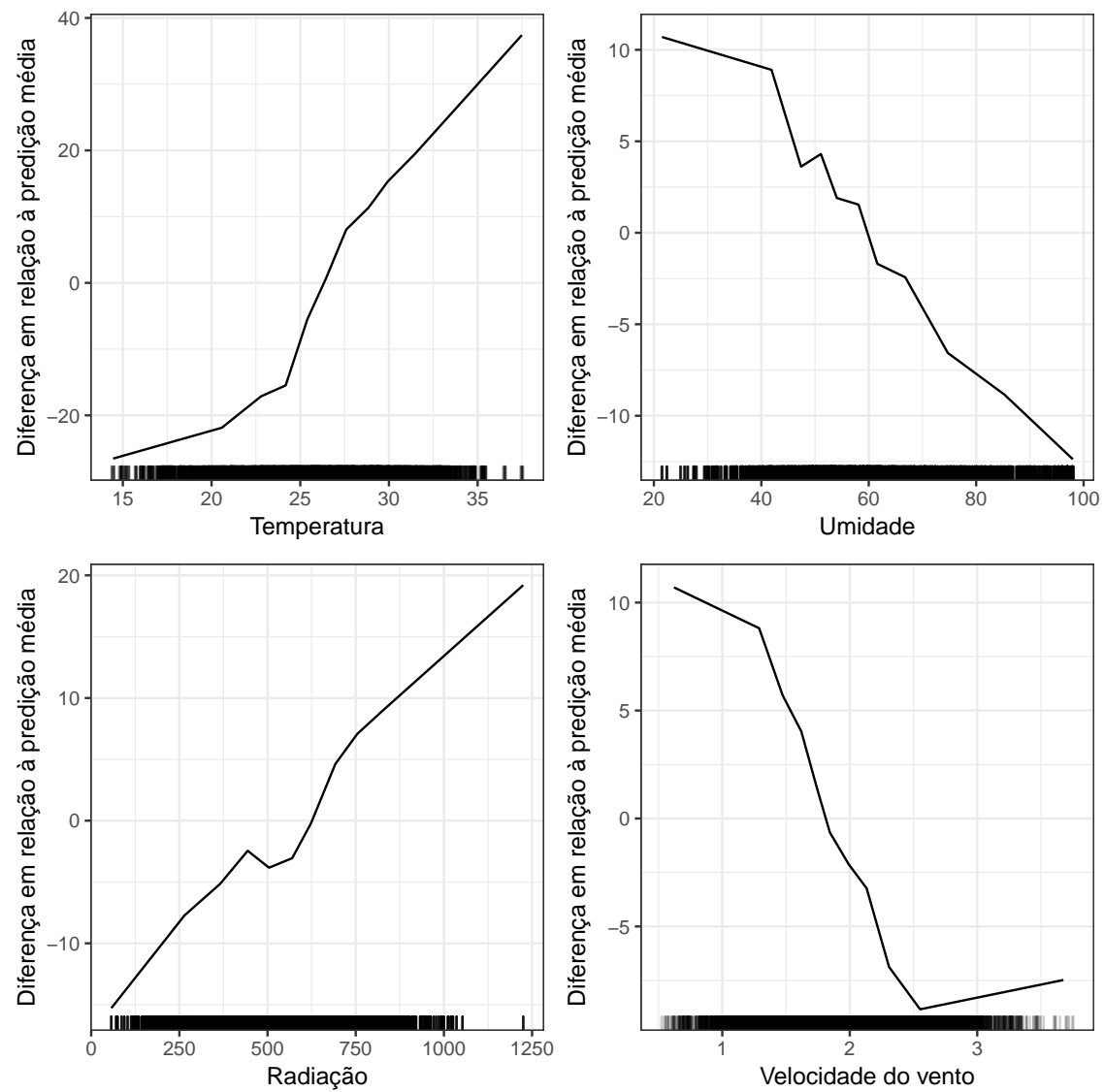

Figura 5.18: Gráficos de efeitos locais acumulados para as variáveis climáticas do modelo XGBoost.

Os resultados desta seção levantaram algumas dúvidas sobre o verdadeiro efeito da proporção estimada de carros a gasolina na concentração de ozônio e também sobre a capacidade dessa variável realmente estar representando o real uso de gasolina/etanol na cidade. Nas próximas seções, utilizaremos novas estratégias de análise para continuar testando a robustez das conclusões obtidas neste estudo.

\subsection{Outras estratégias de análise}

Como forma de avaliar a robustez dos indícios encontrados até então, vamos apresentar nesta seção algumas alternativas para as estratégias de análise adotadas anteriormente.

\subsubsection{Seleção de variáveis}

O modelo de regressão linear ajustado por Salvo et al. (2017) tem 96 parâmetros (Tabela 5.1). Podemos tentar diminuir esse número removendo as variáveis menos importantes do modelo utilizando regularização (Seção 4.4) para encolher os coeficientes dos preditores menos importantes e também fazer seleção de variáveis. 
Com esse objetivo, ajustamos um modelo de regressão linear utilizando o LASSO como técnica de regularização. No entanto, o valor do hiperparâmetro de penalização escolhido por validação cruzada foi igual a 0 , indicando que a estimação sem penalização produz o modelo com melhor relação entre viés e variância.

Também testamos a regressão ridge, para avaliar se apenas encolher os coeficientes na direção do zero diminuiria a variância do modelo, mas novamente o modelo completo foi selecionado como o melhor.

\subsubsection{Transformando a variável resposta}

Vimos na última seção que os modelos ajustados subestimam a concentração de ozônio quando tentamos predizer valores muito altos do poluente. A nossa suspeita é que existe alguma variável importante para explicar os valores desses níveis elevados de ozônio que não foi inserida na análise. No entanto, existem situações em que esse problema de ajuste se deve às restrições impostas pelo modelo.

No caso do modelo de regressão linear, supomos que a associação entre a concentração de ozônio e cada um dos preditores era linear, o que pode não ser razoável, principalmente quando a variável resposta tem distribuição assimétrica (Figura 5.19).

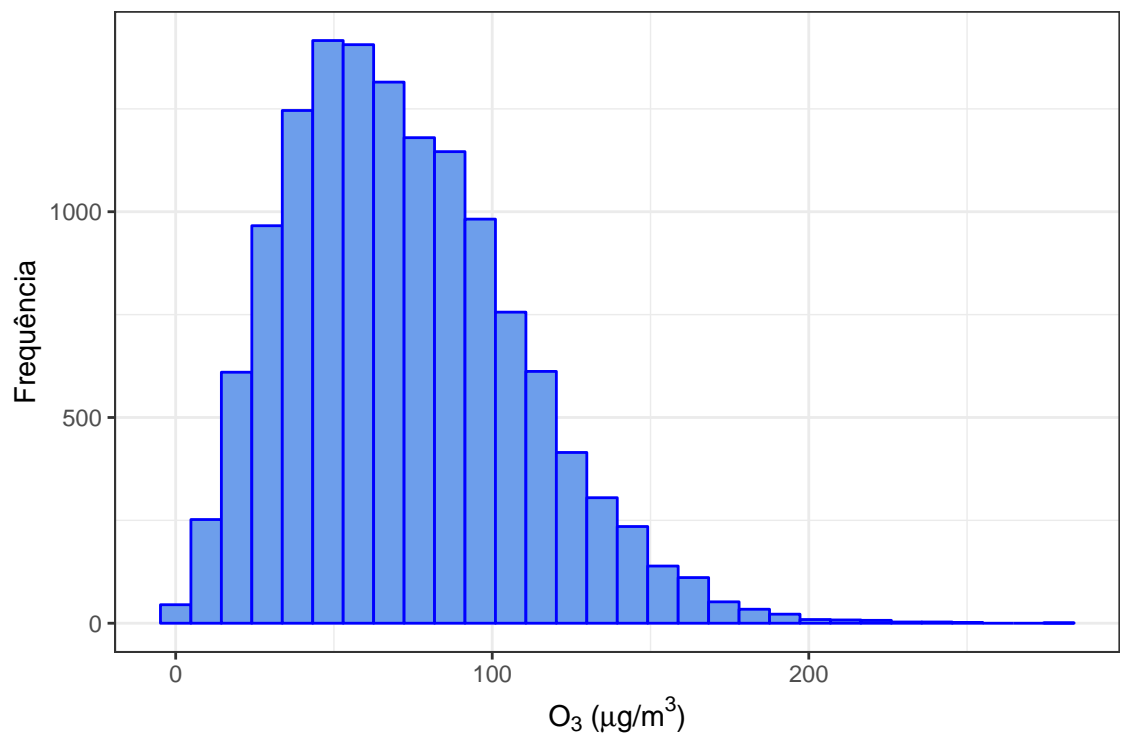

Figura 5.19: Distribuição da concentração de ozônio na amostra considerada por Salvo et al. (2017).

Como tentativa de melhorar o ajuste do modelo ajustado por Salvo et al. (2017), podemos aplicar alguma transformação à concentração de ozônio na tentativa de reduzir a assimetria da variável. Na Tabela 5.6, apresentamos os resultados do modelo de regressão linear ajustado com as transformações $\log$ e Box-Cox (com $\lambda=0.51)$. Com a ajuda da Figura 5.20, observamos que, para o modelo de regressão linear, a transformação logarítmica melhora o ajuste dos valores mais elevados, mas causa um maior viés nos valores pequenos. Já a transformação de Box-Cox melhora o ajuste tanto dos valores baixos quanto dos altos, diminuindo o RMSE do modelo e aumentando a porcentagem da variância explicada. Como a floresta aleatória não faz restrições sobre a distribuição da variável resposta, o ganho encontrado ao transformamos a variável foi muito pequeno.

Embora esses modelos não tragam novas informações sobre o fenômeno sob estudo, seus resul- 
Tabela 5.6: Resultado dos modelos ajustados com a variável resposta transformada.

\begin{tabular}{|c|c|c|c|c|}
\hline Modelo & Transformação & RMSE & $\begin{array}{l}\% \text { var. } \\
\text { explicada }\end{array}$ & Variáveis mais importantes \\
\hline Regressão linear & $\begin{array}{c}\text { Sem } \\
\text { transformação }\end{array}$ & 19.74 & 70.65 & $\begin{array}{l}\text { Temperatura, vento, radiação, } \\
\text { umidade e var. indicadora da } \\
\text { estação São Caetano }\end{array}$ \\
\hline Regressão linear & $\log$ & 21.18 & 71.31 & $\begin{array}{c}\text { Temperatura, radiação, vento, } \\
\text { umidade e var. indicadora da } \\
\text { estação São Caetano }\end{array}$ \\
\hline Regressão linear & Box-Cox & 19.48 & 74.02 & $\begin{array}{l}\text { Temperatura, radiação, vento, } \\
\text { umidade e var. indicadora da } \\
\text { estação São Caetano }\end{array}$ \\
\hline Floresta aleatória & $\begin{array}{l}\text { Sem } \\
\text { transformação }\end{array}$ & 14.11 & 85.72 & $\begin{array}{c}\text { Temperatura, umidade, radiação, } \\
\text { vento e tendência }\end{array}$ \\
\hline Floresta aleatória & Box-Cox & 14.04 & 86.87 & $\begin{array}{c}\text { Temperatura, umidade, radiação, } \\
\text { vento e tendência }\end{array}$ \\
\hline
\end{tabular}

tados são importantes como validação da análise, mostrando que os indícios encontrados até então são robustos em relação a distribuição da variável resposta.
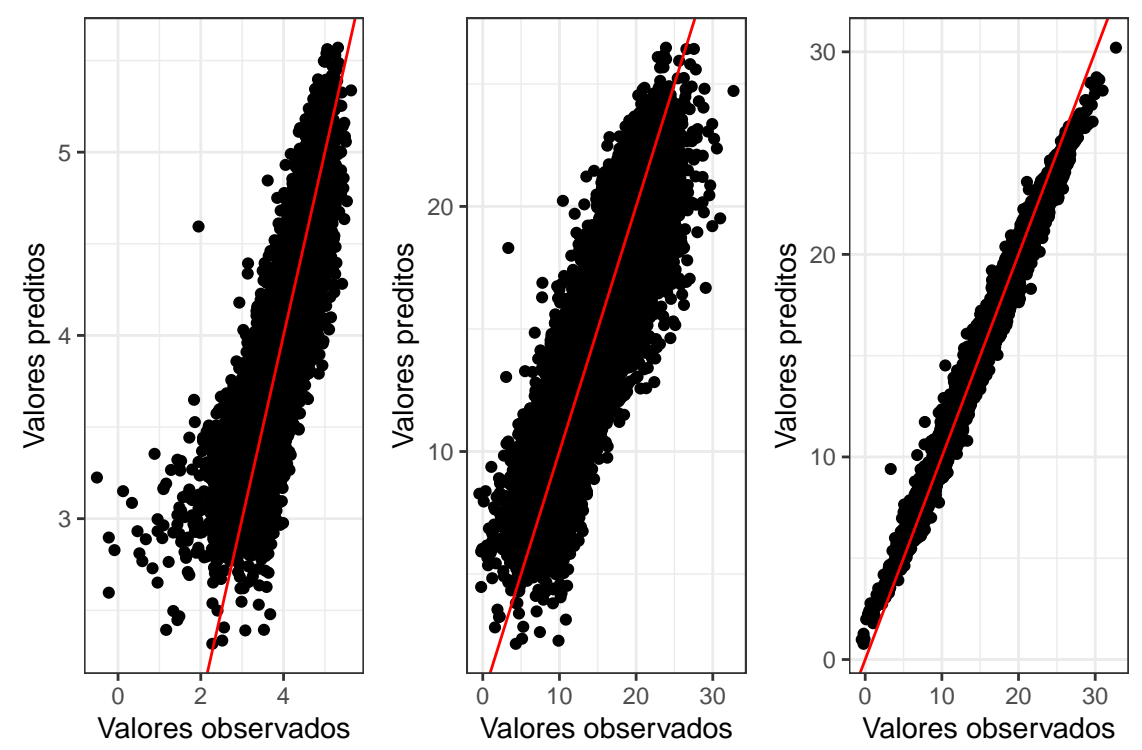

Figura 5.20: Gráficos dos valores da concentração de ozônio preditos pelos modelos contra os valores observados. No painel da esquerda, modelo de regressão linear com transformação log. No painel do meio, modelo de regressão linear com transformação Box-Cox. No painel da direita, floresta aleatória com transformação Box-Cox.

\subsubsection{Modelo para a máxima diária}

Para verificar se os resultados são robustos quanto a maneira escolhida para agregar as observações de um mesmo dia, vamos agora ajustar o modelo de regressão linear e a floresta aleatória utilizando a concentração diária máxima de ozônio como variável resposta.

Na Tabela 5.7, apresentamos os resultados dos ajustes. Observamos uma queda considerável na performance dos modelos em relação aos resultados para a média diária, mostrando que, ou os preditores considerados não explicam muito bem a variabilidade da máxima diária, ou precisamos 
encontrar um modelo mais adequado para essa nova variável.

Tabela 5.7: Resultado dos modelos ajustados com a variável resposta transformada.

\begin{tabular}{|c|c|c|c|}
\hline Modelo & RMSE & $\begin{array}{l}\% \text { var. } \\
\text { explicada }\end{array}$ & Variáveis mais importantes \\
\hline Regressão linear & 28.00 & 61.01 & $\begin{array}{l}\text { Vento, radiação, temperatura e } \\
\text { variáveis indicadoras das estações } \\
\text { Ibirapuera e São Caetano }\end{array}$ \\
\hline Floresta aleatória & 20.45 & 79.86 & $\begin{array}{c}\text { Temperatura, radiação, umidade, } \\
\text { vento e tendência }\end{array}$ \\
\hline
\end{tabular}

Observamos pela Figura 5.21 que os modelos para essa nova variável também subestimam valores altos da máxima diária.
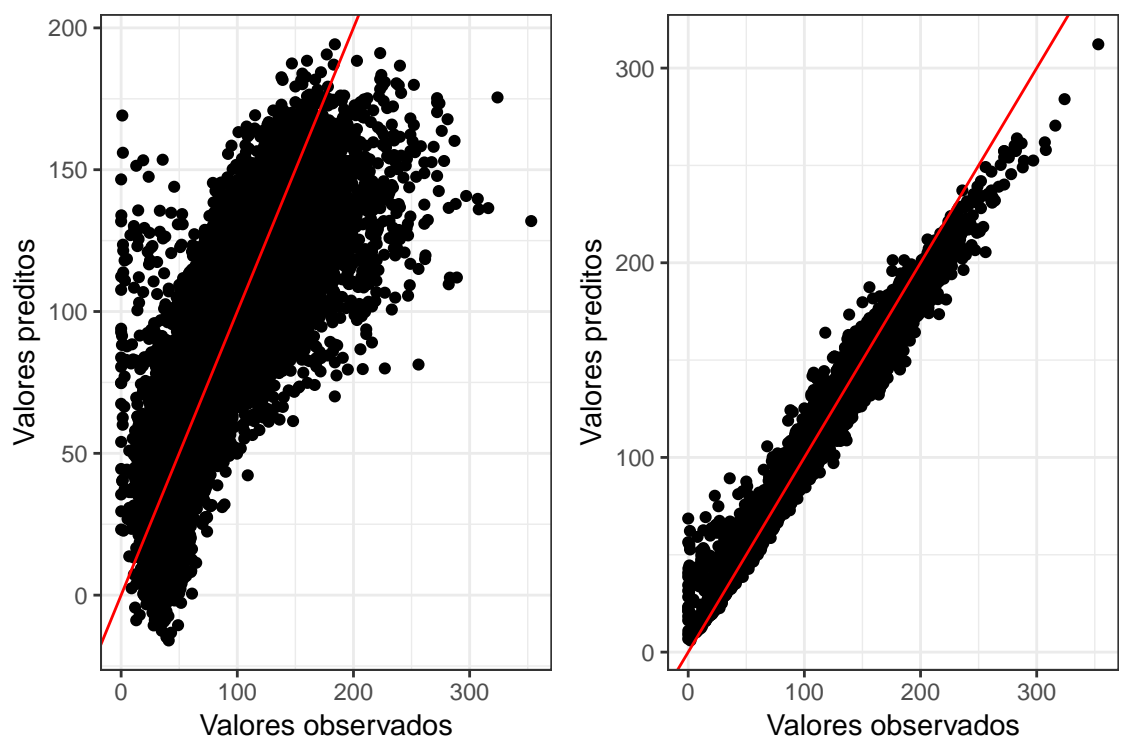

Figura 5.21: Gráficos dos valores da máxima diária da concentração de ozônio preditos pelos modelos contra os valores observados. No painel da esquerda, modelo de regressão linear e, no painel da direita, a floresta aleatória.

Apesar da redução na precisão dos modelos, os resultados obtidos apontam na mesma direção: a proporção estimada de carros a gasolina é estatisticamente significativa para explicar variações na concentração de ozônio. Além disso, de uma maneira geral, o aumento dessa proporção tende a diminuir as concentrações do poluente.

\subsubsection{Ajustando cada estação separadamente}

A estratégia adotada até aqui para tratar as diferentes estações de monitoramento foi juntar as informações de todas elas em uma única amostra, analisando os dados conjuntamente e incluindo variáveis indicadoras para controlar o efeito de cada estação.

O mecanismo gerador do ozônio é altamente dependente da química atmosférica e das condições climáticas do local. Dada a grande área em que as estações estão espalhadas ${ }^{8}$, podemos refazer a

\footnotetext{
${ }^{8}$ São Paulo ocupa uma área de mais de 1500 quilômetros quadrados, estando entre as 10 maiores cidades do mundo.
} 
análise ajustando um modelo para cada uma das estações para avaliar se os resultados encontrados são robustos em relação à posição geográfica de cada estação.

Na Tabela 5.8, apresentamos os resultados do modelo de regressão linear para cada uma das 12 estações medidoras de ozônio. O modelo ajustado foi o mesmo considerado pelos autores, com exceção das variáveis relacionadas à estação de monitoramento. Analisando as estimativas dos coeficientes da proporção de carros a gasolina, observamos que essa variável é positivamente associada com a concentração de ozônio nas estações IPEN e São Caetano do Sul ${ }^{9}$, contrariando a conclusão para as outras estações e para os resultados com a amostra agregada.

Em relação à performance dos modelos, o RMSE para cada estação não difere muito do encontrado para o modelo global. A proporção da variabilidade explicada só está muito abaixo para a estação Parelheiros. De uma forma geral, as variáveis meteorológicas são as mais importantes para explicar a concentração de ozônio, sendo que a temperatura ficou entre as cinco primeiras em todos os modelos.

Essa diferença levanta algumas questões que devem ser estudadas mais profundamente:

- O modelo de regressão linear é o melhor para explicar a associação entre as variáveis?

- Existem variáveis importantes para explicar a concentração de ozônio que não foram incluídas no estudo?

- O efeito da proporção de carros abastecidos a gasolina na concentração de ozônio vai depender da região estudada, mesmo quando analisamos diferentes áreas de uma mesma cidade?

Mesmo não sendo sempre possível responder a todas as perguntas levantadas com os dados disponíveis, levantar dúvidas é importante tanto para ponderar as conclusões do estudo em questão quanto para motivar a realização de novos estudos. Discutiremos melhor os pontos em torno dessas perguntas nos comentários da próxima seção.

\subsection{Comentários}

As análises realizadas neste capítulo indicaram que a associação entre a concentração de ozônio e a proporção estimada de carros a gasolina não é linear. Para valores muito baixos ou muito altos da proporção estimada de carros a gasolina, a relação com a concentração de ozônio não é muito clara. Embora os modelos aditivos e de regressão segmentada indiquem uma associação positiva nesses intervalos, o número relativamente pequeno de dias com proporções muito baixas ou muito altas nos impede de tirar conclusões mais concretas. A não-linearidade sugerida pelos modelos reflete bem a complexidade do fenômeno sob estudo.

Os modelos também apontaram que a direção dessa associação é, em geral, negativa, mas a forma variou consideravelmente a depender do modelo escolhido. Também mostramos que os resultados dependem da estação de monitoramento, indicando a importância da química atmosférica local na formação do ozônio ou a impossibilidade da estimativa da proporção de carros a gasolina representar toda a cidade.

Se a associação negativa entre essas variáveis for verdadeira, ela pode ser explicada pelo mecanismo gerador do ozônio troposférico. Dentre outros fatores, esse processo depende da presença de

\footnotetext{
${ }^{9}$ Para a estação IPEN, o coeficiente é marginalmente significativo.
} 
Tabela 5.8: Resultados dos modelos para cada estação. A estimativa apresentada na segunda coluna se refere ao coeficiente da proporção de carros a gasolina rodando na cidade.

\begin{tabular}{|c|c|c|c|c|}
\hline Estação & $\begin{array}{l}\text { Estimativa } \\
\text { (erro- } \\
\text { padrão) }\end{array}$ & RMSE & $\begin{array}{l}\% \text { var. } \\
\text { explicada }\end{array}$ & Variáveis mais importantes \\
\hline Diadema & $\begin{array}{r}-15.46 \\
(5.01)\end{array}$ & 17.05 & 76.87 & $\begin{array}{l}\text { Vento, temperatura, radiação } \\
\text { variável ind. para a abertura } \\
\text { do anel viário e umidade }\end{array}$ \\
\hline Dom Pedro II & $\begin{array}{r}-18.78 \\
(6.35)\end{array}$ & 18.90 & 69.81 & $\begin{array}{c}\text { Radiação, vento, } \\
\text { temperatura, umidade e } \\
\text { variável ind. para a semana } \\
40\end{array}$ \\
\hline Ibirapuera & $-5.84(6.5)$ & 20.24 & 70.88 & $\begin{array}{c}\text { Temperatura, vento, } \\
\text { radiação, variável ind. para a } \\
\text { abertura do anel viário e } \\
\text { umidade }\end{array}$ \\
\hline IPEN & $12.7(7.2)$ & 22.11 & 66.94 & $\begin{array}{c}\text { Radiação, temperatura, } \\
\text { vento, variável ind. para a } \\
\text { abertura do anel viário e } \\
\text { tendência }\end{array}$ \\
\hline Mauá & $\begin{array}{r}-28.09 \\
(6.17)\end{array}$ & 20.76 & 67.35 & $\begin{array}{l}\text { Temperatura, vento, variável } \\
\text { ind. para a abertura do anel } \\
\text { viário, umidade, radiação }\end{array}$ \\
\hline Moóca & $\begin{array}{l}-60.02 \\
(7.77)\end{array}$ & 21.35 & 63.05 & $\begin{array}{l}\text { Radiação, proporção de } \\
\text { carros a gasolina, vento, } \\
\text { temperatura e umidade }\end{array}$ \\
\hline $\begin{array}{c}\text { Nossa Senhora do } \\
\text { Ó }\end{array}$ & $-32.6(4.53)$ & 17.19 & 74.59 & $\begin{array}{c}\text { Temperatura, radiação, } \\
\text { vento, proporção de carros a } \\
\text { gasolina, variável ind. para a } \\
\text { semana } 45\end{array}$ \\
\hline Parelheiros & $\begin{array}{l}-24.61 \\
(5.57)\end{array}$ & 18.28 & 59.64 & $\begin{array}{l}\text { Vento, variável ind. para } \\
\text { inversão térmica, umidade, } \\
\text { radiação, temperatura }\end{array}$ \\
\hline Pinheiros & $\begin{array}{l}-24.41 \\
(5.78)\end{array}$ & 19.24 & 65.96 & $\begin{array}{l}\text { radiação, variável ind. para a } \\
\text { abertura do anel viário, } \\
\text { vento, umidade, temperatura }\end{array}$ \\
\hline Santana & $\begin{array}{l}-21.91 \\
(5.91)\end{array}$ & 18.31 & 72.70 & $\begin{array}{l}\text { Temperatura, vento, } \\
\text { radiação, umidade, variável } \\
\text { ind. para a semana } 44\end{array}$ \\
\hline Santo André & $-23.1(6.45)$ & 20.20 & 67.52 & $\begin{array}{l}\text { Temperatura, vento, } \\
\text { radiação, umidade, proporção } \\
\text { de carros a gasolina }\end{array}$ \\
\hline $\begin{array}{l}\text { São Caetano do } \\
\text { Sul }\end{array}$ & $38.37(7.53)$ & 21.17 & 70.26 & $\begin{array}{l}\text { Vento, tendência, radiação, } \\
\text { variável ind. para a abertura } \\
\text { do anel viário, temperatura }\end{array}$ \\
\hline
\end{tabular}

$\mathrm{NO}_{2}$, gerado principalmente pela queima de gasolina, e compostos orgânicos voláteis (VOCs), gerado em maior quantidade por veículos a etanol. Como explicado com mais detalhes em Madronich (2014), ambientes limitados em $\mathrm{NO}_{2}$ tendem a gerar mais ozônio quando mais $\mathrm{NO}_{2}$ é lançado na atmosfera e ambientes limitados em VOCs tendem a gerar mais ozônio quando mais VOCs é lançado. 
Os resultados encontrados sugerem que a atmosfera na cidade de São Paulo é, em grande parte, limitada em VOCs e, portanto, a formação de ozônio depende de um maior número de veículos abastecidos com etanol. Além disso, a maior queima de gasolina (e diesel) pela manhã gera mais NO, que reage com o ozônio durante a tarde, diminuindo seus níveis. Por isso, verificamos uma relação, em geral, negativa entre congestionamento e concentração do poluente. Essa relação, no entanto, não parece ser linear, ou seja, ter uma frota inteiramente formada por carros a gasolina não levaria a menores índices de ozônio. Encontramos indícios de uma proporção ótima de carros a gasolina por volta de $60 \%$.

Os resultados contrários encontrados para as estações IPEN e São Caetano do Sul podem indicar que esses locais são limitados em $\mathrm{NO}_{2}$, sendo preciso estudar melhor a química atmosférica nessas regiões.

Na maioria dos modelos, observamos um maior erro para valores altos da concentração de ozônio. Isso indica que, possivelmente, estamos deixando fora da análise alguma variável que explique os picos desse poluente.

Neste tipo de estudo, também é importante considerarmos a relevância prática dos resultados. Usando a estimativa encontrada por Salvo et al. (2017), quando a proporção de carros a gasolina sobe de $30 \%$ para $80 \%$, mantendo todas as outras variáveis constantes, a concentração diária média de ozônio tende a diminuir $8.3 \mu \mathrm{g} / \mathrm{m}^{3}$. Considerando a concentração média de ozônio em toda a amostra, uma redução média de $72.2 \mu \mathrm{g} / \mathrm{m}^{3}$ para $63.9 \mu \mathrm{g} / \mathrm{m}^{3}$ pode não ter relevância para a criação de políticas públicas para a redução de emissões de etanol.

Assim, para avaliar o real impacto da redução do ozônio, podemos estudar o efeito desse poluente no número de casos de doenças e mortes relacionadas com a poluição. Nesse sentido, apresentaremos no próximo capítulo algumas análises associando dados de poluição com dados epidemiológicos. 


\section{Capítulo 6}

\section{Poluição e saúde pública}

Embora o estudo da poluição do ar só tenha passado a ser tratado como ciência no século 20, relatos milenares de problemas ambientais e de saúde pública envolvendo queima de compostos e derretimento de metais foram encontrados em cidades da antiguidade, como Grécia e Roma (Jacobson, 2002). Nos países que formam o Reino Unido, há registros descrevendo as consequências da queima de madeira, carvão e o derretimento de metais ao longo de toda a Idade Média. A criação das máquinas a vapor no século XVII e XVIII e a utilização de combustíveis fósseis iniciada no século XIX pioraram os eventos de poluição do ar nos países industrializados, exigindo a criação de regulamentações e órgãos de controle e monitoramento (Jacobson, 2002).

No capítulo anterior, discutimos estudos que associavam os índices de poluição ao uso de combustíveis. Agora, o foco será o impacto da poluição do ar na saúde pública. A literatura contemporânea sobre o tema é vasta. Schwartz e Dockery (1992), por exemplo, concluíram que a concentração de partículas suspensas no ar estava positivamente associada com a mortalidade no dia seguinte em Steubenville, Ohio. Saldiva et al. (1995) encontraram associação positiva entre a mortalidade diária em idosos (idade maior que 65 anos) e a concentração de PM10 em São Paulo. Os autores concluíram não existir um nível seguro para a concentração do poluente no cenário estudado. Peters et al. (2000) estudaram a chance de intervenções realizadas por desfibriladores cardiovasculares implantados em pacientes com histórico alto de arritmia. A partir dos resultados de um modelo logístico, eles concluíram que havia associação positiva entre o aumento de óxidos de nitrogênio e o número de arritmias que geravam intervenções. Hoek et al. (2002) acompanharam uma coorte de 5000 holandeses entre 55 e 59 anos para investigar a associação entre exposição a material particulado e morte por doenças cardiopulmonares. Os autores concluíram que o risco de morte estava associado com os níveis atmosféricos do poluente e, mais consistentemente, com viver perto de vias de tráfego intenso. Utilizando uma função de impacto na saúde, Fann et al. (2012) estimaram que 80 mil mortes prematuras seriam evitadas se os níveis diários de PM2.5 nos Estados Unidos fossem reduzidos em $5 \mu \mathrm{g} / \mathrm{m}^{3}$ e que, em 2005, os níveis de PM2.5 causaram cerca de 130 mil mortes prematuras em pessoas com mais de 29 anos de idade. Cox (2012), no entanto, em nota ao editor, afirmou que Fann et al. (2012) interpretaram coeficientes do modelo como se eles representassem relações causais entre a concentração de poluentes e o número de mortes. Segundo o autor, a análise realizada por Fann et al. (2012) não garante a causalidade proposta em suas conclusões, que deveriam ser interpretadas apenas como associação estatística.

Neste capítulo, utilizaremos dois problemas como exemplo. Primeiro, vamos expandir a análise do capítulo anterior e investigar se a proporção estimada de carros abastecidos com gasolina está 
associada com a mortalidade na cidade de São Paulo, com foco em crianças e idosos. Em seguida, vamos comparar esses resultados com os de uma análise utilizando a própria concentração de ozônio como preditora da mortalidade.

\subsection{Uso de etanol e mortalidade}

No capítulo anterior, utilizamos os dados disponibilizados por Salvo et al. (2017) para estudar a relação entre a proporção estimada de carros bicombustíveis abastecidos com gasolina na cidade de São Paulo e a concentração troposférica de ozônio. As análises conduzidas tanto pelos autores quanto neste trabalho encontraram indícios de que o aumento do uso de gasolina estaria associado com uma diminuição da concentração de ozônio. Enquanto Salvo et al. (2017) estimaram uma relação linear entre as variáveis, os modelos do capítulo anterior sugeriram que essa associação é não linear, sendo que sua direção e intensidade podem depender do valor da proporção de carros a gasolina na cidade.

Se esse indício for verdadeiro, dado o impacto do ozônio na saúde pública, é razoável pensarmos em políticas públicas para controlar o uso do etanol, visando diminuir os níveis do ozônio. Contudo, Salvo et al. (2017) mostraram também que o aumento da proporção estimada de carros a gasolina está associado com o aumento de partículas finas, enquanto Salvo e Geiger (2014) mostraram que o aumento dessa variável está associado com maiores concentrações de monóxido de carbono e de nitrogênio. Assim, é interessante avaliarmos a associação da proporção estimada de carros a gasolina diretamente na mortalidade, investigando o impacto do uso de etanol na saúde pública independentemente dos poluentes aos quais ele está associado. Além disso, podemos utilizar a concentração de ozônio agora como preditor para explicar a variação da mortalidade e comparar se o uso de etanol e a concentração de ozônio impactam a mortalidade da mesma forma.

Para cumprir esses objetivos, vamos utilizar os dados climáticos e de poluição disponibilizados por Salvo et al. (2017) e dados de mortalidade extraídos do Sistema de Informações de Mortalidade (SIM) do DATASUS, a plataforma de tecnologia da informação do Sistema Único de Saúde. O período avaliado será novamente de 2008 a 2013. Seguindo diversos estudos (Chang et al., 2017; Conceição et al., 2001a; Garrett e Casimiro, 2011; Saldiva et al., 1995; Schwartz e Dockery, 1992), controlaremos as condições climáticas, a tendência e a sazonalidade por meio das seguintes variáveis: temperatura (mínima, média, máxima ou variação diária ${ }^{1}$ ), umidade, dia da semana, mês (ou estação do ano), indicador de dia útil e termo de tendência linear. Para os modelos com a concentração de ozônio como preditor, vamos considerar a concentração média na cidade, calculada nas 12 estações de monitoramento consideradas em Salvo et al. (2017).

Embora a poluição esteja associada com morbidade e mortalidade em geral, alguns grupos merecem atenção especial. Segundo relatório da OMS (WHO, 2004), crianças (até 5 anos) são mais suscetíveis aos efeitos adversos da poluição pois, entre outros fatores, elas respiram uma maior quantidade de ar proporcionalmente ao seu peso do que adultos, costumam praticar mais atividades físicas ao ar livre e possuem sistema imunológico pouco desenvolvido. Idosos compreendem outro grupo de risco, sendo altamente vulneráveis a casos extremos de poluição devido à maior incidência de doenças pré-existentes e sistema imunológico vulnerável. Focaremos a análise nesses dois grupos de maior risco.

\footnotetext{
${ }^{1}$ Temperatura máxima menos a temperatura mínima dentro de um mesmo dia.
} 
A Figura 6.1 apresenta as séries da mortalidade diária para crianças e idosos. Observamos que no período observado há uma leve tendência positiva para as crianças e uma forte tendência positiva para os idosos. Também notamos o comportamento sazonal da série de idosos, com maiores picos acontecendo nos meses de inverno, ao contrário da concentração de ozônio, cujos picos tendem a acontecer no verão.

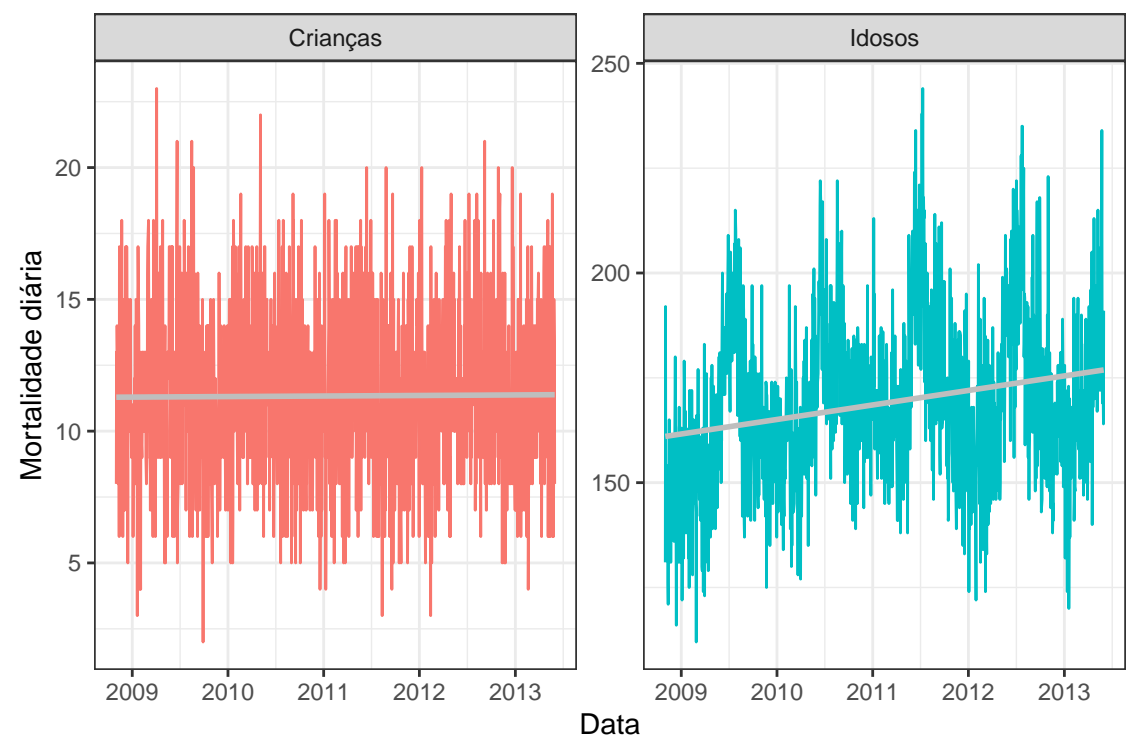

Figura 6.1: Séries da mortalidade diária para crianças e idosos.

A seguir, ajustaremos alguns modelos para avaliar a associação da mortalidade com a proporção estimada de carros a gasolina. Em seguida, ajustaremos modelos utilizando a concentração de ozônio como preditor para compararmos os resultados obtidos.

\subsubsection{Modelos Poisson e floresta aleatória}

Como a mortalidade diária é um dado de contagem, ajustamos inicialmente modelos com distribuição Poisson (ver Seção 3.2.3) para avaliar a relação dessa quantidade com a proporção estimada de carros a gasolina rodando na cidade de São Paulo. Ajustamos um modelo linear generalizado e um modelo aditivo generalizado. Na tentativa de obter resultados mais precisos, ajustamos também uma floresta aleatória, bem como um XGBoost. Como os resultados desse último modelo ficaram muito próximos ao da floresta aleatória, optamos por omiti-los aqui.

A Tabela 6.1 apresenta os resultados dos modelos ajustados para idosos e crianças. Podemos observar que:

- o modelo linear generalizado Poisson indicou relação positiva entre a mortalidade em idosos e a proporção estimada de carros a gasolina, sendo que um aumento de $10 \%$ na proporção de carros a gasolina estaria associado a um aumento de $91 \%$ na mortalidade;

- ao contrário do modelo linear generalizado, o modelo aditivo não encontrou indícios de associação entre a mortalidade em idosos e a proporção estimada de carros a gasolina;

- a floresta aleatória não melhorou muito o ajuste em relação ao modelo aditivo; 
- nenhum dos modelos considerados ficou bem ajustado aos dados de modalidade infantil, indicando que os preditores utilizados não são suficientes para explicar essa variável.

Para avaliar a melhor escolha de preditores, ajustamos modelos com mês ou estação do ano para controlar a sazonalidade e temperatura média, mínima, máxima ou variação de temperatura ao longo do dia para controlar a temperatura. Utilizando o RMSE como métrica de performance, a melhor escolha em todos os modelos foi aquela com os preditores mês e temperatura média.

Tabela 6.1: Resultados do modelo Poisson para mortalidade geral em crianças e idosos.

\begin{tabular}{c|c|c|c|c}
\hline Modelo & Grupo & RMSE & $\begin{array}{c}\text { \% var. } \\
\text { explicada }\end{array}$ & $\begin{array}{c}\text { Relação com a prop. } \\
\text { estimada de carros a } \\
\text { gasolina (valor-p) }\end{array}$ \\
\hline Linear & Idosos & 15.55 & 40.45 & $\begin{array}{c}\text { Positiva }(<0.001) \\
\text { Não há }(0.61)\end{array}$ \\
\hline Aditivo & Idosos & 3.24 & 0.72 & Não há $(0.21)$ \\
& Crianças & 3.24 & 44.40 & Não há $(0.87)$ \\
\hline Floresta & Idosos & 15.08 & 44.52 & - \\
aleatória & Crianças & 3.23 & 0.84 & - \\
\hline
\end{tabular}

Na Figura 6.2, apresentamos o gráfico dos valores preditos contra os valores observados para o modelo linear generalizado. Observamos que os modelos não se ajustam muito bem aos dados, principalmente para a mortalidade infantil.
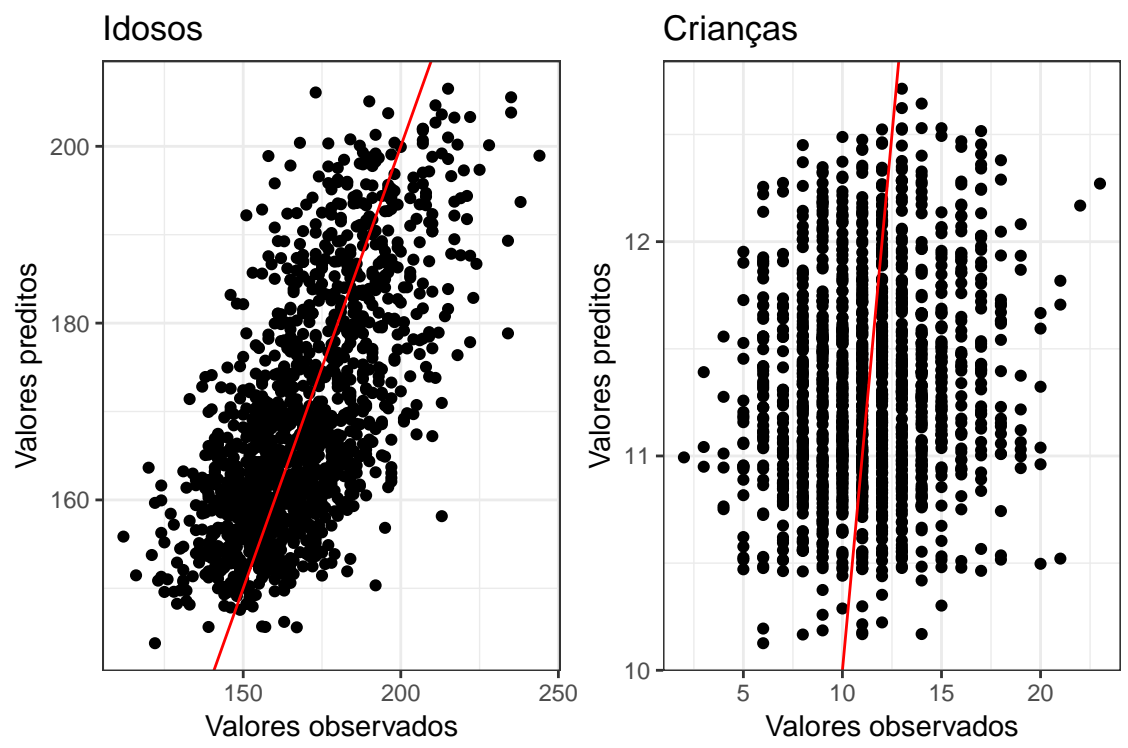

Figura 6.2: Gráfico dos valores preditos versus os valores observados para o modelo linear generalizado com distribuição Poisson para cada um dos grupos.

Observando agora os gráficos das funções não lineares ajustadas para a proporção de carros a gasolina (Figura 6.3), verificamos que de fato os modelos aditivos não indicam associação entre as duas variáveis. Para a mortalidade em idosos, embora o gráfico mostre uma relação negativa, pelo intervalo de confiança (95\%) indicado pela área cinza, notamos que o verdadeiro efeito poderia ser uma reta horizontal.

Na Figura 6.4 apresentamos os gráficos de dependência parcial e de efeitos acumulados construídos considerando a floresta aleatória para a mortalidade em idosos e a proporção estimada de 

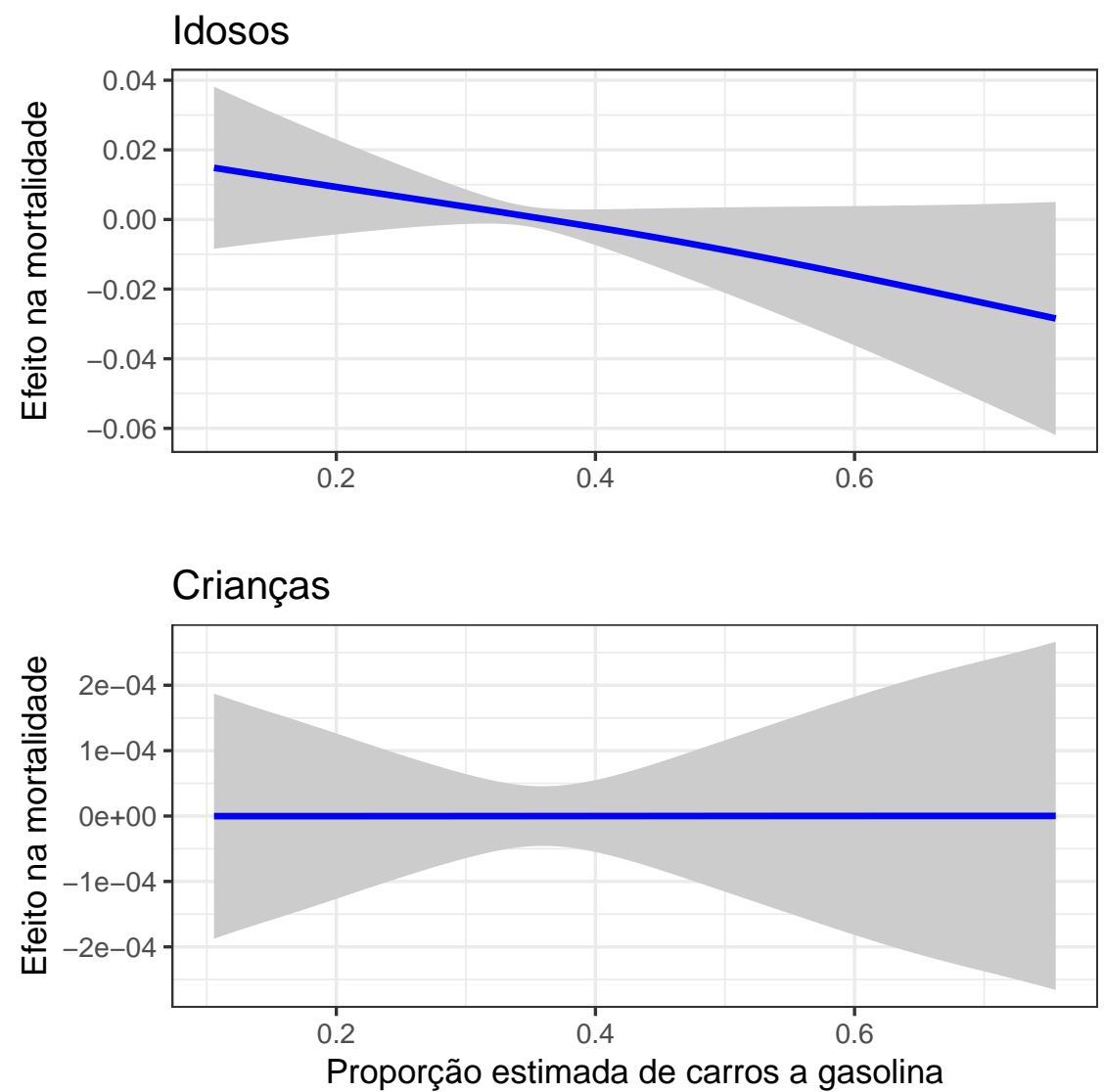

Figura 6.3: Funções estimadas para a proporção estimada de carros a gasolina pelo modelo aditivo Poisson para cada grupo.

carros a gasolina. Os gráficos sugerem que a associação deste preditor na mortalidade é, em geral, negativa: quanto maior a proporção de carros a gasolina, menor a mortalidade. A forma da relação no entanto é estranha, apresentando um pico entre 0.4 e 0.5 , o que é difícil de explicar na prática.
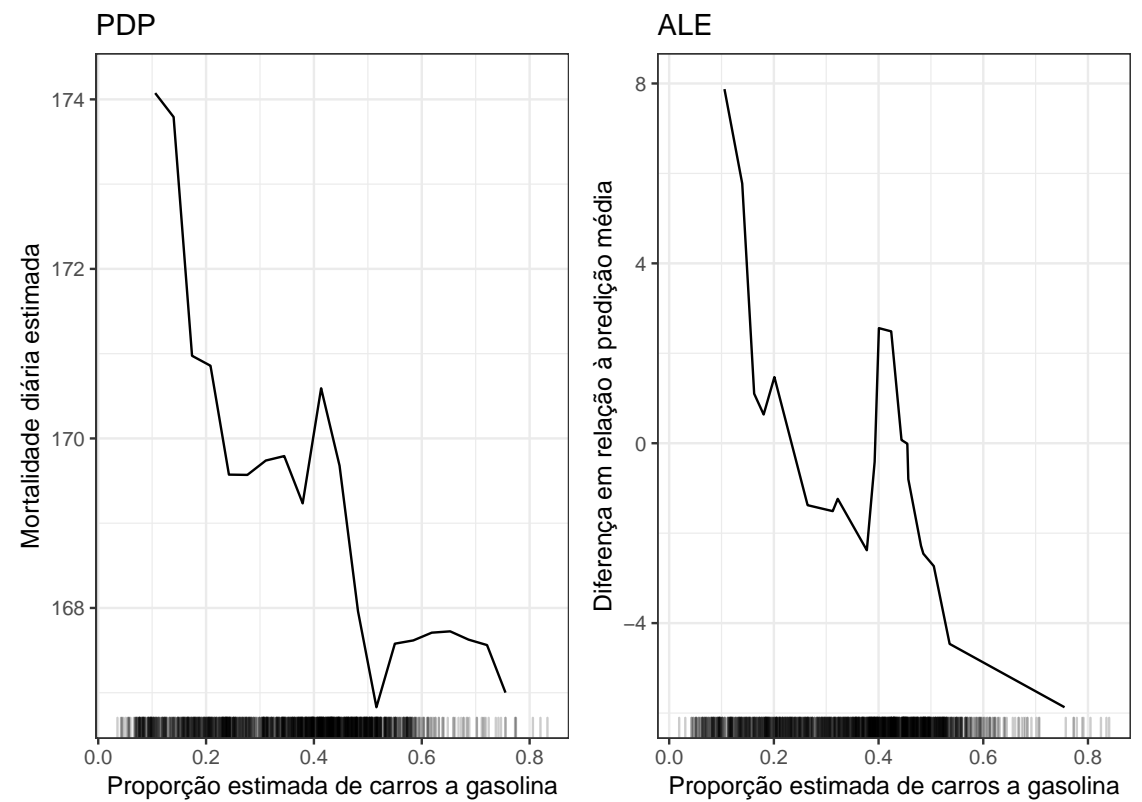

Figura 6.4: Gráficos de dependência parcial (PDP) e de efeitos acumulados (ALE) da floresta aleatória para a variável proporção estimada de carros a gasolina. 
Como cada modelo apontou uma conclusão diferente, precisamos continuar investigando a relação entre essas variáveis na tentativa de encontrar resultados mais robustos. A seguir, vamos avaliar se a associação entre mortalidade e proporção de carros a gasolina pode estar defasada no tempo.

\subsubsection{Floresta aleatória para a série defasada}

Como o uso de combustível e a mortalidade são ambos processos temporais, é razoável avaliarmos se o efeito da proporção estimada de carros a gasolina na mortalidade pode estar defasado no tempo, isto é, se o valor deste preditor em um determinado dia está associado com o número de mortes no futuro. Focaremos a análise aqui apenas no grupo de idosos, pois os modelos considerados para mortalidade infantil, assim como na seção anterior, não se ajustaram aos dados.

Para isso, inicialmente, construímos o gráfico da função de correlação cruzada com defasagem até 30 dias (Figura 6.5), mas não observamos indícios de correlação entre essas variáveis. Para investigar mais a fundo, ajustamos a floresta aleatória considerada na seção anterior com a proporção estimada de carros a gasolina defasada até 21 dias. Os resultados dos 10 melhores modelos, segundo o RMSE, estão apresentados na Tabela 6.2. Observamos uma leve redução do erro do modelo em comparação o ajuste sem defasagem (RMSE igual a 15.08), porém não há consistência na ordem das melhores defasagens.

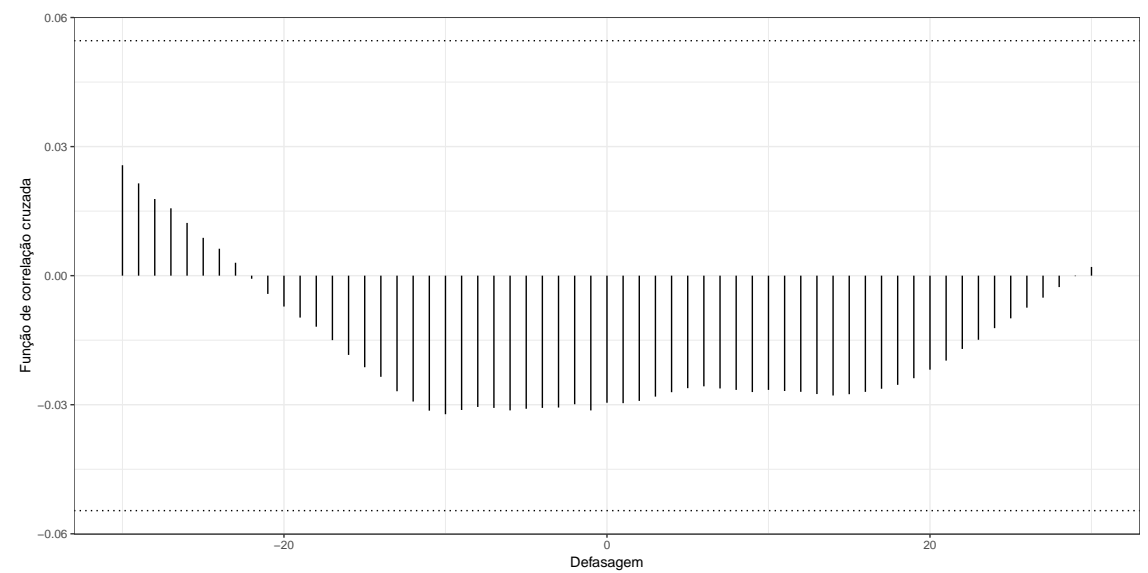

Figura 6.5: Gráfico de correção cruzada da mortalidade diária para idosos contra a proporção estimada de carros a gasolina.

O gráfico de dependência parcial e de efeitos locais acumulados para o modelo com proporção estimada de carros a gasolina defasada em 10 dias (Figura 6.6) indica também uma relação negativa entre as variáveis, um pouco mais suave do que a encontrada na seção anterior.

Observamos até aqui que cada modelo levou a uma conclusão diferente sobre o efeito da proporção estimada de carros a gasolina na mortalidade geral, com os resultados dessa seção corroborando a indicação de que o aumento do número de carros à gasolina estaria associado a um número menor de mortes. A seguir, vamos analisar a relação entre o uso de gasolina/etanol com as concentrações de ozônio e óxidos de nitrogênio. Em seguida, avaliaremos o efeito desses poluentes diretamente na mortalidade. O objetivo será, a partir dessas análises, tentar entender melhor como a mortalidade pode estar associada com a proporção de carros a gasolina. 
Tabela 6.2: Resultados do modelo da floresta aleatória com proporção estimada de carros a gasolina defasada no tempo. Os valores estão ordenados do menor ao maior RMSE.

\begin{tabular}{c|c|c|c}
\hline Grupo & Defasagem & RMSE & \% var. explicada \\
\hline \multirow{7}{*}{ Idosos } & 10 & 14.74 & $46.31 \%$ \\
& 6 & 14.78 & $46.49 \%$ \\
& 5 & 14.81 & $46.22 \%$ \\
& 7 & 14.81 & $46.24 \%$ \\
& 26 & 14.82 & $45.68 \%$ \\
& 8 & 14.82 & $46.33 \%$ \\
& 17 & 14.82 & $46.15 \%$ \\
& 9 & 14.83 & $45.95 \%$ \\
& 19 & 14.83 & $45.95 \%$ \\
\hline
\end{tabular}
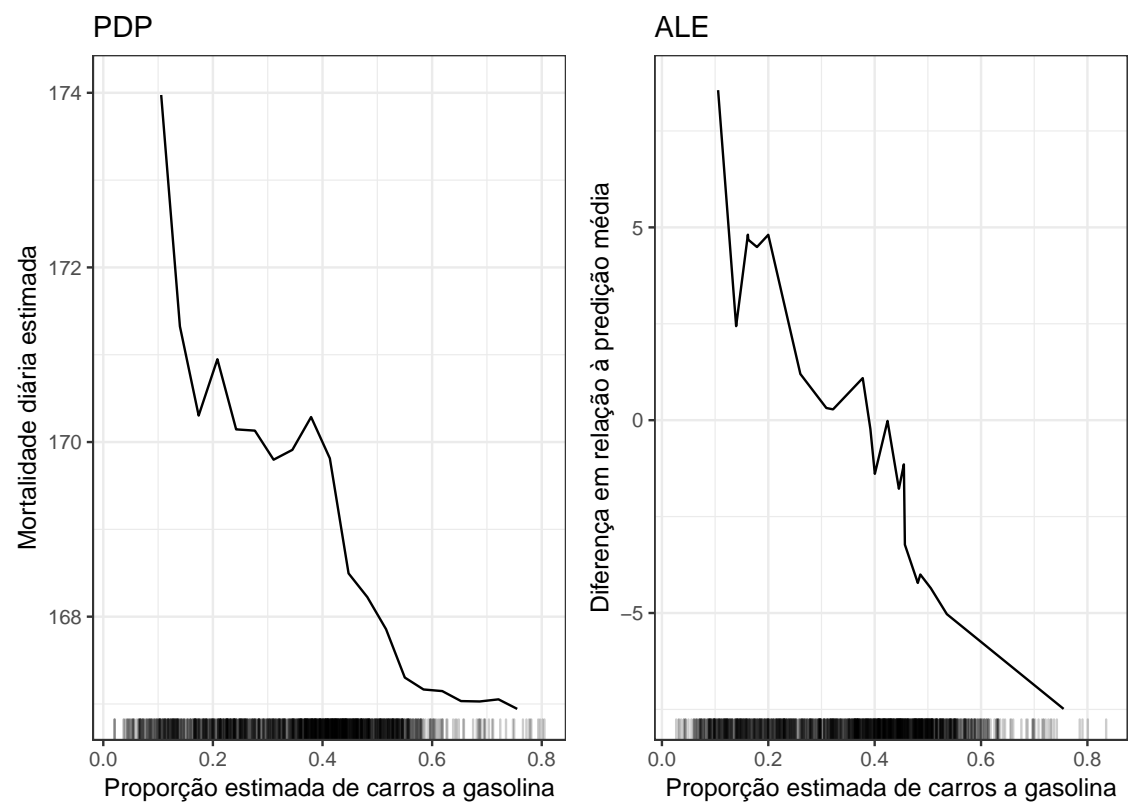

Figura 6.6: Gráficos de dependência parcial (PDP) e de efeitos acumulados (ALE) da floresta aleatória para a variável proporção estimada de carros a gasolina defasada em 3 dias.

\subsection{Uso de etanol e a relação entre ozônio e $\mathrm{NO}_{\mathrm{X}}$}

Na próxima seção, vamos analisar o efeito do ozônio e dos óxidos de nitrogênio $\left(\mathrm{NO}_{\mathrm{X}}\right)$ diretamente na mortalidade. Antes disso, como estratégia para verificar se a proporção de carros a gasolina rodando na cidade é uma boa medida para representar a relação entre as concentrações de $\mathrm{O}_{3}$ e $\mathrm{NO}_{\mathrm{X}}$, vamos criar uma nova variável dada pela razão

$$
\frac{\text { concentração de } \mathrm{NO}_{\mathrm{x}}}{\text { concentração de } \mathrm{O}_{3}}
$$

e ajustar os modelos de regressão linear e floresta aleatória para investigar a associação desse índice com a proporção de carros a gasolina, usando como variáveis de controle as mesmas consideradas pelos modelos da Seção 5.5.

Na Figura 6.7 apresentamos as séries desse índice para as 7 estações na Região Metropolitana de São Paulo que monitoram a concentração de ambos os poluentes e na Tabela 6.3 algumas medidas 
descritivas. Observamos que o índice varia em geral entre 0 e 1 , com alguns valores aberrantes, dias em que a média diária do $\mathrm{NO}_{\mathrm{x}} / \mathrm{O}_{3}$ (das 5 h às 11 h) estava muito alta e/ou a concentração de $\mathrm{O}_{3}$ estava muito baixa.

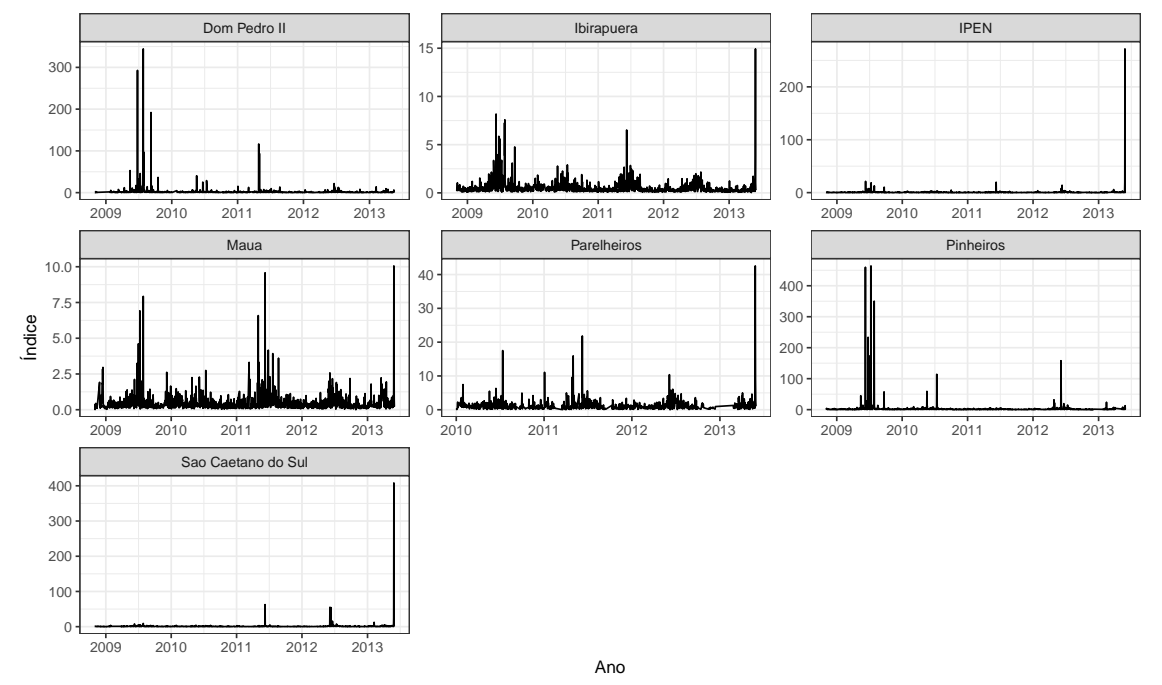

Figura 6.7: Séries do indice $\mathrm{NO}_{\mathrm{x}} / \mathrm{O}_{3}$ de 2008 a 2013 para as 7 estações na Região Metropolitana de São Paulo que monitoram a concentração de ambos os poluentes.

Tabela 6.3: Resultados dos modelos ajustados para o indice $\mathrm{NO}_{\mathrm{x}} / \mathrm{O}_{3}$.

\begin{tabular}{c|c|c|c|c|c|c|c}
\hline Estação & Média & DP & Min & Q1 & Q2 & Q3 & Max \\
\hline Dom Pedro II & 2.48 & 13.85 & 0.03 & 0.53 & 0.9 & 1.68 & 344.3 \\
Ibirapuera & 0.51 & 0.7 & 0.024 & 0.21 & 0.34 & 0.57 & 14.93 \\
IPEN & 0.8 & 7.06 & 0.0087 & 0.18 & 0.34 & 0.64 & 271.79 \\
Mauá & 0.47 & 0.65 & 0.005 & 0.18 & 0.31 & 0.52 & 10.06 \\
Parelheiros & 1.29 & 2.01 & 0.029 & 0.45 & 0.87 & 1.54 & 42.56 \\
Pinheiros & 3.12 & 21.2 & 0.011 & 0.55 & 1.02 & 1.91 & 464.08 \\
São Caetano do & 1.24 & 10.7 & 0.01 & 0.34 & 0.58 & 0.98 & 408.21 \\
Sul & & & & & & & \\
\hline
\end{tabular}

$\mathrm{Na}$ Tabela 6.4 apresentamos os resultados dos modelos ajustados para o índice $\mathrm{NO}_{\mathrm{x}} / \mathrm{O}_{3} . \mathrm{O}$ modelo de regressão linear aponta uma relação positiva entre o índice e a proporção estimada de carros a gasolina, de tal forma que o aumento de $1 \%$ na proporção estaria associado a um aumento médio de 0.3 no índice, fixando todas as outras variáveis. Já a floresta aleatória, que se ajustou melhor aos dados do que o modelo de regressão linear, indicou uma relação em forma de "u"entre as variáveis (Figura 6.8), sendo que a relação é negativa para valores pequenos da proporção estimada de carros a gasolina, é inexistente para valores intermediários e é positiva partir de $40 \%$.

Tabela 6.4: Resultados dos modelos ajustados para o indice $\mathrm{NO}_{\mathrm{x}} / \mathrm{O}_{3}$.

\begin{tabular}{c|c|c|c}
\hline Modelo & RMSE & $\begin{array}{c}\text { \% var. } \\
\text { explicada }\end{array}$ & $\begin{array}{c}\text { Relação com o índice } \\
\text { (valor-p) }\end{array}$ \\
\hline Regressão linear & 0.64 & 55.52 & Positiva $(<0.001)$ \\
Floresta aleatória & 0.57 & 65.04 & Forma de "u" \\
\hline
\end{tabular}

Esses resultados sugerem que a associação entre a proporção de carros a gasolina e a relação $\mathrm{NO}_{\mathrm{X}} / \mathrm{O}_{3}$ não é muito clara, assim como observado nos modelos do Capítulo 5 para a concentração de 

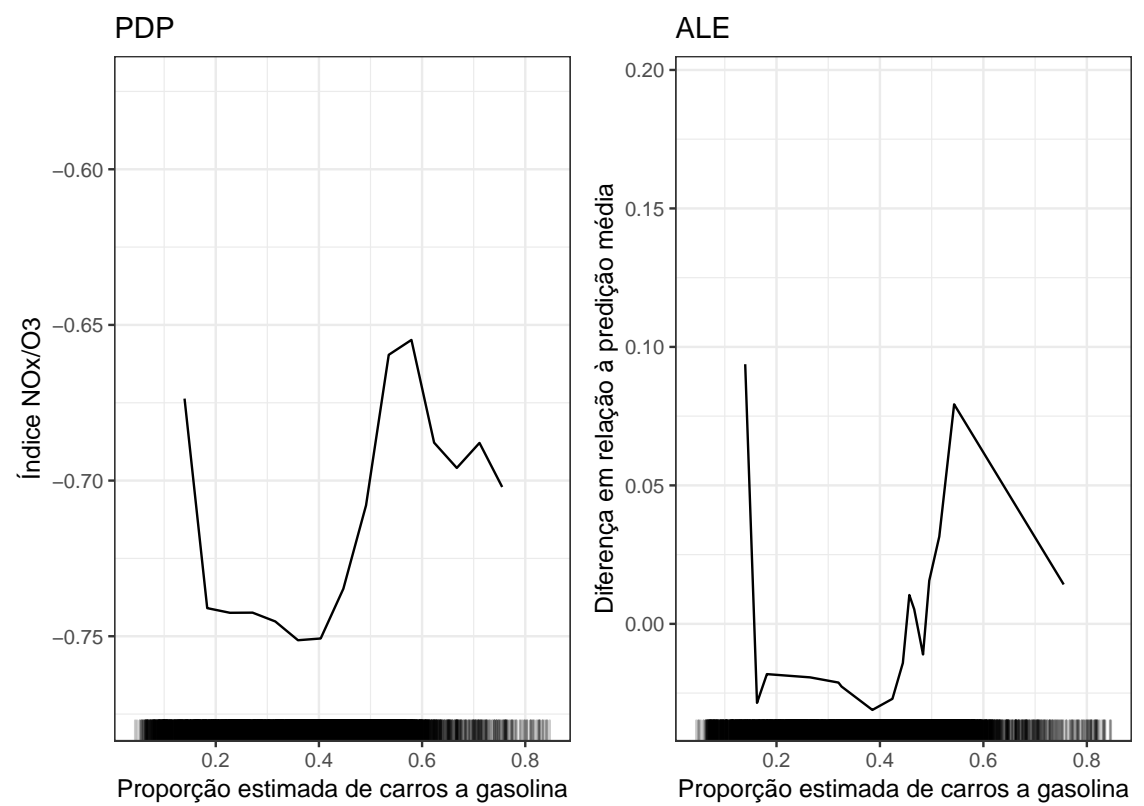

Figura 6.8: Gráficos de dependência parcial (PDP) e de efeitos acumulados (ALE) da floresta aleatória para o indice $\mathrm{NO}_{\mathrm{x}} / \mathrm{O}_{3}$.

ozônio. Na próxima seção, vamos investigar a relação desses poluentes diretamente na mortalidade.

\subsection{Concentração de $\mathrm{O}_{3}$ e $\mathrm{NO}_{\mathrm{x}}$ e mortalidade}

Nesta seção, apresentaremos os resultados dos modelos ajustados para a mortalidade diária utilizando a concentração de $\mathrm{O}_{3}$ e $\mathrm{NO}_{\mathrm{x}}$ diretamente como preditores. O objetivo é comparar esses resultados com aqueles obtidos nas seções anteriores para avaliar se a proporção estimada de carros a gasolina estaria representando bem o efeito desses poluentes na mortalidade.

Os modelos ajustados aqui consideraram como controle os seguintes preditores: temperatura, umidade, tendência, mês do ano, dia da semana e variável indicadora de dia útil. As concentrações de ozônio e óxidos de nitrogênio utilizadas foram as médias diárias para toda a cidade, calculadas a partir das medidas das 6 estações dentre as 12 consideradas por Salvo et al. (2017) que mediam ambos os poluentes.

A Tabela 6.5 apresenta os resultados dos modelos ajustados. Observamos que nenhum modelo indicou associação entre mortalidade em idosos ou crianças e concentração de ozônio. Por outro lado, todos indicaram relação positiva entre a concentração de $\mathrm{NO}_{\mathrm{x}}$ e mortalidade em idosos. Entre os três modelos considerados, o que obteve melhor ajuste foi o modelo aditivo. Pelas Figuras 6.9 e 6.10 , observamos que tanto o modelo aditivo quanto a floresta aleatória sugerem formas semelhantes para o efeito do $\mathrm{NO}_{\mathrm{x}}$ na mortalidade em idosos.

Os resultados encontrados indicam que a mortalidade em idosos aumenta com a concentração de $\mathrm{NO}_{\mathrm{X}}$. Se a proporção estimada de carros a gasolina fosse uma boa representante da relação entre ozônio e óxidos de nitrogênio, esperaríamos que a mortalidade em idosos aumentasse também com o número de carros a gasolina. No entanto, embora os modelos da seção anterior sugerirem que esse preditor explique a variabilidade do balanço $\mathrm{NO}_{\mathrm{x}} / \mathrm{O}_{3}$, nossa análise anterior encontrou uma associação negativa entre a proporção estimada de carros a gasolina e a mortalidade em idosos.

Mais uma vez, assim como no capítulo anterior, a falta de robustez nos resultados pode apontar 
Tabela 6.5: Resultados dos modelos ajustados para a mortalidade diária utilizando a concentração de ozônio como preditor.

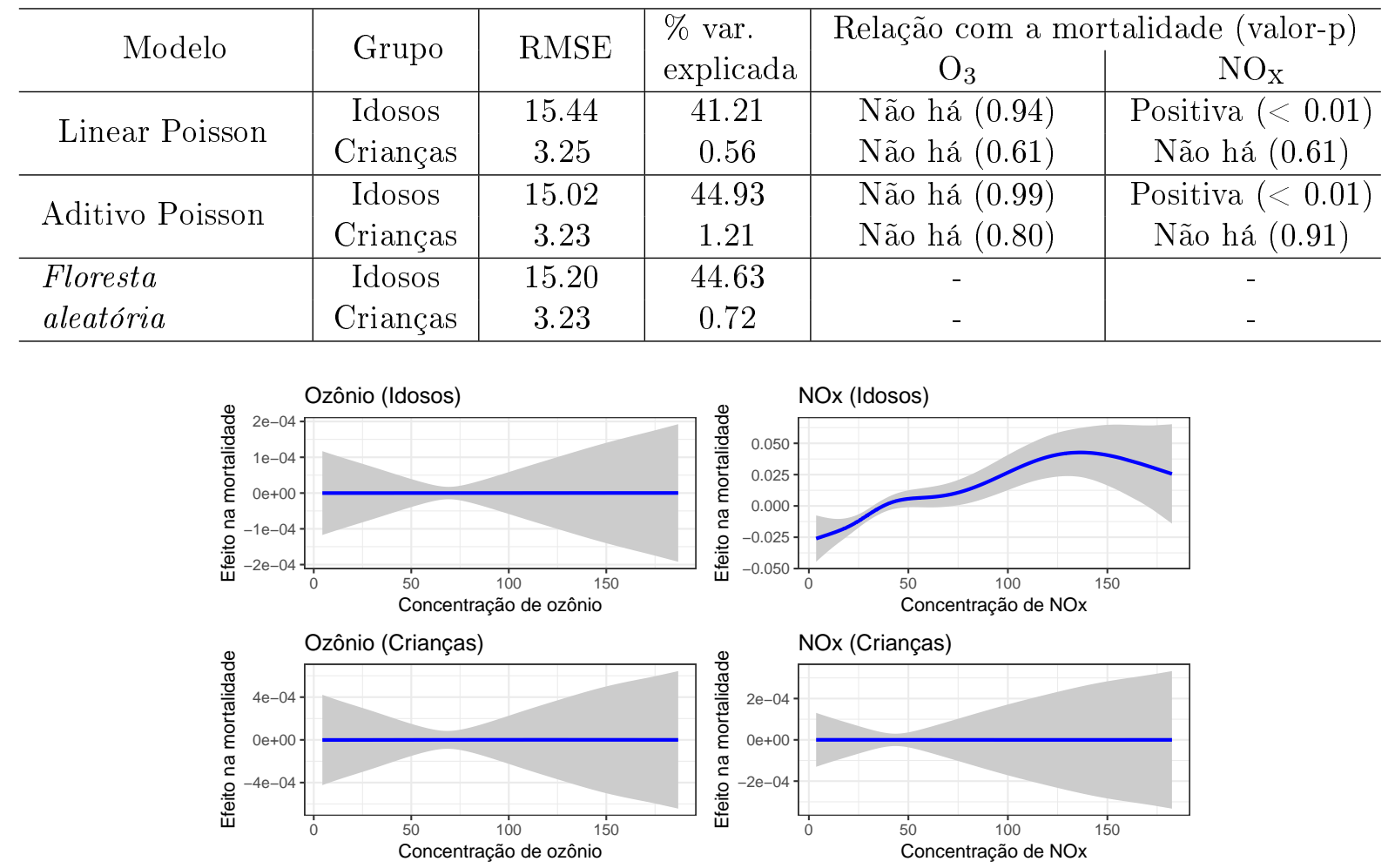

Figura 6.9: Gráfico da função não linear estimada pelos modelos aditivos generalizados para as concentrações de ozônio e de óxidos de nitrogênio.

para diversas direções: ausência de preditores importantes, erros de medida ou problemas com as suposições por trás da proporção estimada de carros a gasolina ou até mesmo a impossibilidade dos modelos considerados explicarem um fenômeno inerentemente complexo.

Para finalizar, ajustamos também uma floresta aleatória com os valores de $\mathrm{O}_{3}$ e $\mathrm{NO}_{\mathbf{x}}$ defasados em até 30 dias. Dentre as defasagens com menores RMSE, destacamos a de 1 dia, com RMSE igual a 14.90 e proporção da variabilidade explicada igual a 45.98\%. Pela Figura 6.11, vemos que o modelo sugere relação positiva tanto entre a concentração de $\mathrm{O}_{3}$ quanto a de $\mathrm{NO}_{\mathrm{x}}$ com a mortalidade em idosos.

Na próxima seção, encerraremos a investigação desse capítulo reajustando os modelos considerados até aqui agora para a mortalidade por doenças respiratórias e cardiovasculares.

\subsection{Efeito na mortalidade por doenças cardio pulmonares}

Na literatura, diversos trabalhos apontam associação entre mortalidade por doenças cardio pulmonares e exposição à poluição do ar (Conceição et al. (2001a); Garrett e Casimiro (2011); Peters et al. (2000); Polezer et al. (2018); Pope et al. (2002), entre outros). Podemos avaliar então se os resultados obtidos nas últimas seções para a mortalidade geral se mantêm quando filtramos a base apenas para essas causas específicas.

Para filtrar a base de mortalidade, utilizamos a décima versão do CID (Classificação Internacional de Doenças). Os códigos considerados foram: 

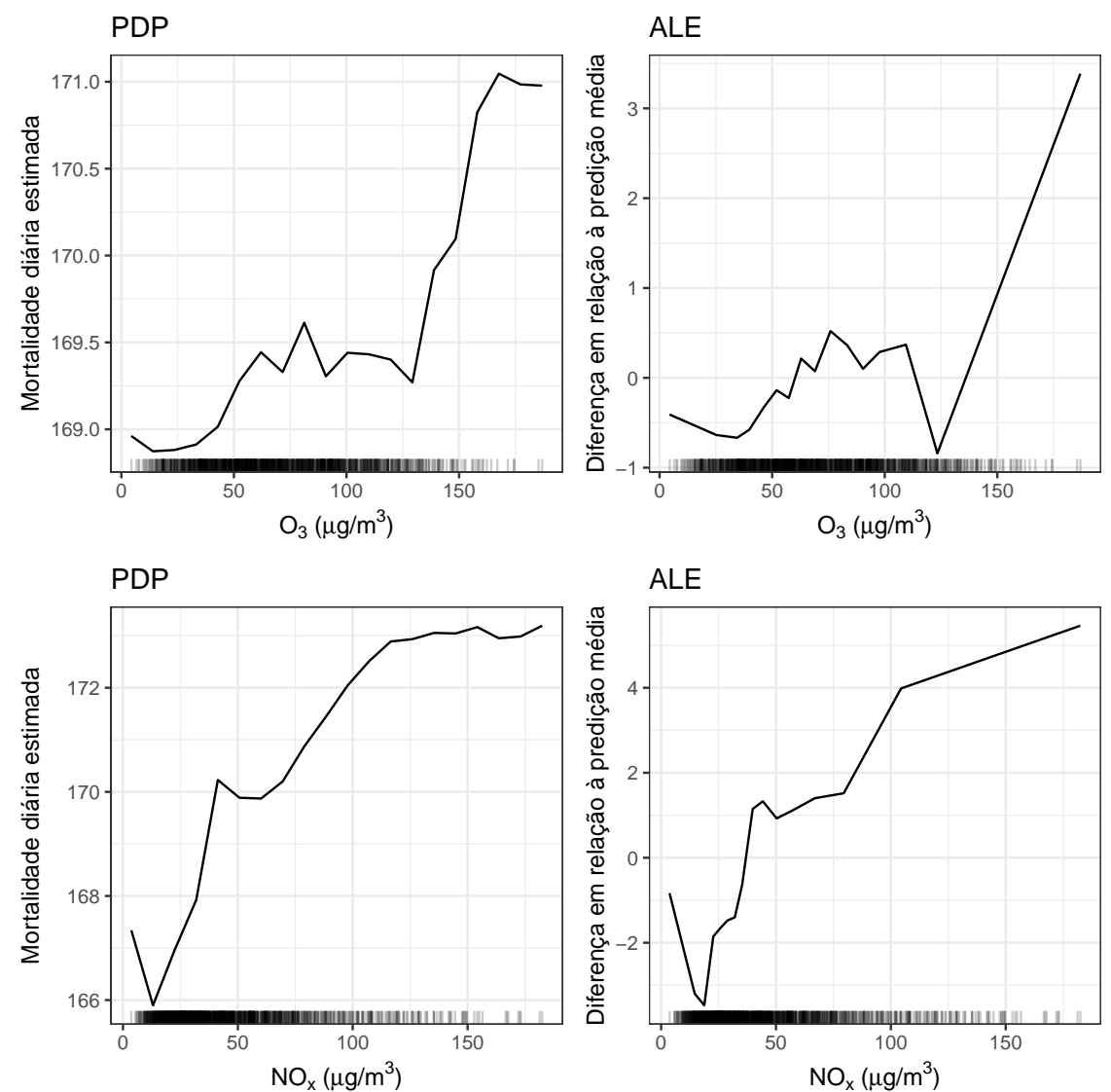

Figura 6.10: Gráficos de dependência parcial (PDP) e de efeitos acumulados (ALE) da floresta aleatória (idosos) para as concentrações de ozônio e de óxidos de nitrogênio.

- C34.9 - câncer de pulmão;

- I00 a I99 - doenças do aparelho circulatório;

- J00 a J99 - doenças do aparelho respiratório.

Os modelos considerados foram os mesmos da seção anterior: modelo Poisson linear e aditivo e floresta aleatória. Apresentaremos aqui os resultados apenas para o grupo de idosos, pois mais uma vez os modelos não se ajustaram bem aos dados de mortalidade infantil.

Os resultados dos modelos ajustados estão apresentados na Tabela 6.6. Verificamos que os resultados dos três modelos estão de acordo com aqueles encontrados para a mortalidade geral: relação positiva com o $\mathrm{NO}_{\mathrm{x}}$ e inexistência de associação com o ozônio. As Figuras 6.12 e 6.13 nos ajudam a interpretar o efeito do $\mathrm{NO}_{\mathrm{X}}$ na mortalidade por doenças cardio pulmonares.

Tabela 6.6: Resultados dos modelos ajustados para a mortalidade diária utilizando a concentração de ozônio como preditor.

\begin{tabular}{c|c|c|c|c}
\hline \multirow{2}{*}{ Modelo } & \multirow{2}{*}{ RMSE } & \% var. & \multicolumn{3}{|c}{ Relação com a mortalidade (valor-p) } \\
& & explicada & $\mathrm{O}_{3}$ & NO $_{\mathbf{x}}$ \\
\hline Linear Poisson & 11.42 & 39.32 & Não há $(0.37)$ & Positiva $(<0.01)$ \\
Aditivo Poisson & 11.13 & 42.79 & Não há $(0.22)$ & Positiva $(<0.01)$ \\
Floresta aleatória & 11.27 & 41.30 & - & - \\
\hline
\end{tabular}



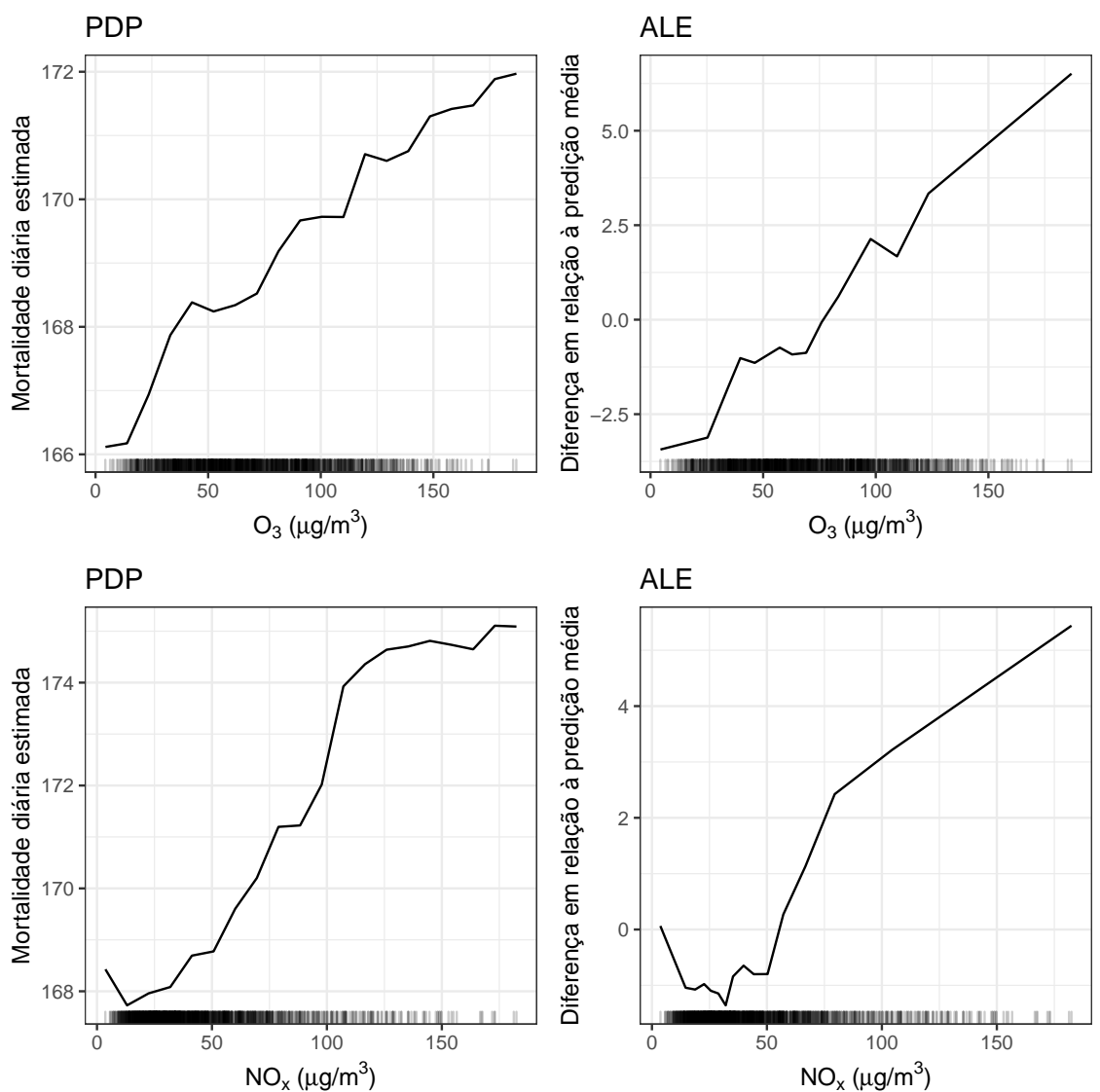

Figura 6.11: Gráficos de dependência parcial (PDP) e de efeitos acumulados (ALE) da floresta aleatória (idosos) para as concentrações de ozônio e de óxidos de nitrogênio defasadas em 1 dia.
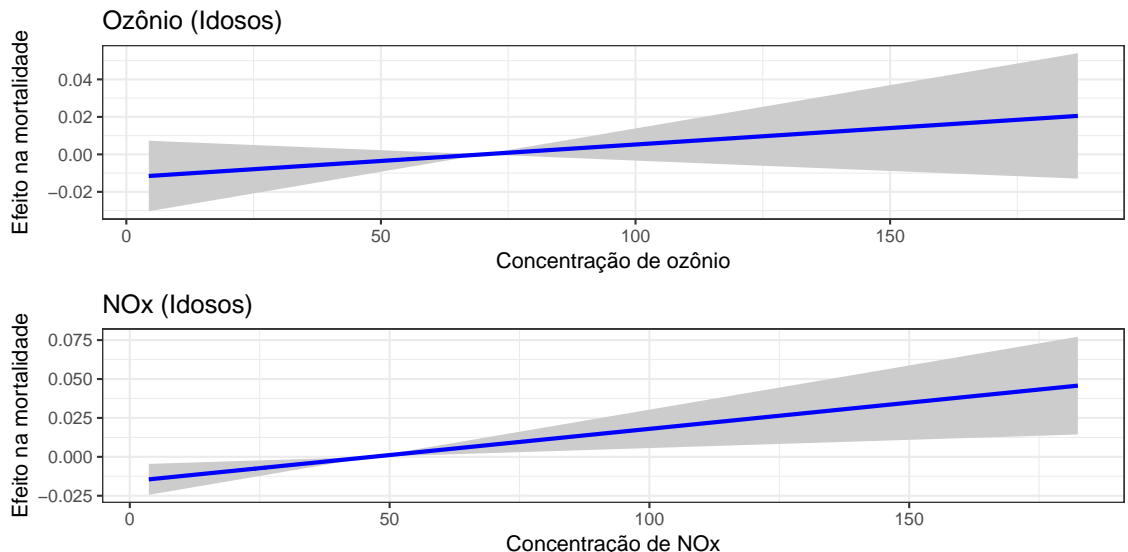

Figura 6.12: Gráfico da função não linear estimada pelo modelo aditivo generalizado para as concentrações de ozônio e de óxidos de nitrogênio considerando a base de mortalidade filtrada para doenças cardio pulmonares.

Ajustamos também uma floresta aleatória com os valores de $\mathrm{O}_{3}$ e $\mathrm{NO}_{\mathrm{x}}$ defasados em até 30 dias. O modelo com defasagem de 1 dia ficou entre aqueles com menor RSME (11.17) e maior proporção da variabilidade explicada (42.40\%.). Pela Figura 6.11, assim como para a mortalidade geral, vemos que o modelo sugere relação positiva tanto do $\mathrm{O}_{3}$ quanto do $\mathrm{NO}_{\mathrm{x}}$ com a mortalidade em idosos.

Os resultados encontrados para a mortalidade geral são robustos quando filtramos a base apenas para mortes por doenças cardio pulmonares. Eles sugerem que a poluição por $\mathrm{NO}_{\mathrm{x}}$ é mais sensível para a saúde pública do que a poluição por $\mathrm{O}_{3}$. Muitas outras estratégias poderiam ser adotadas para 

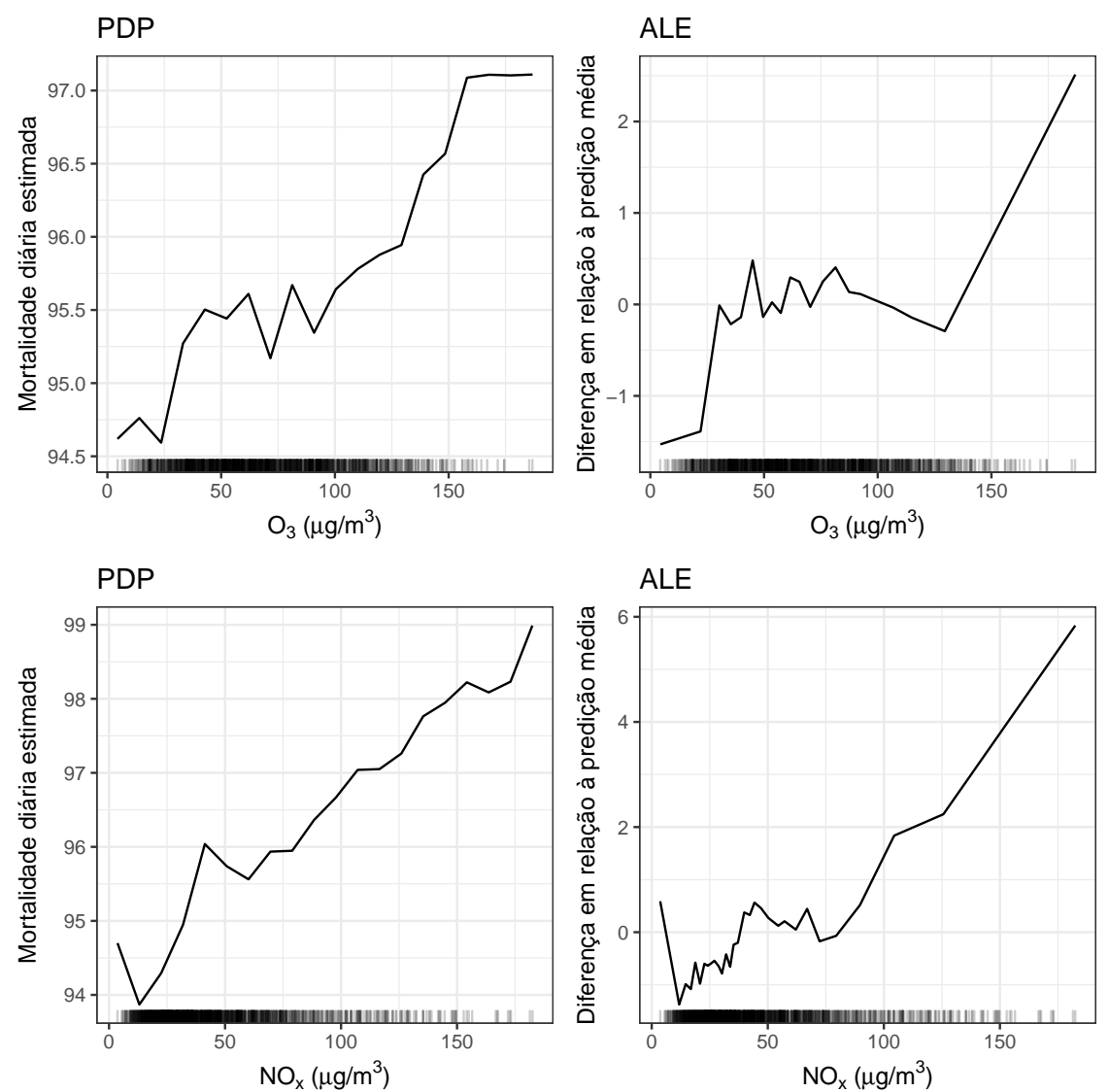

Figura 6.13: Gráficos de dependência parcial (PDP) e de efeitos acumulados (ALE) da floresta aleatória (idosos) para as concentrações de ozônio e de óxidos de nitrogênio, considerando a base de mortalidade filtrada para doenças cardio pulmonares.

continuar investigando a relação da poluição do ar com a mortalidade. Poderíamos, por exemplo, levar em consideração a distribuição espacial tanto das mortes quanto dos poluentes. Também poderíamos focar em morte por doenças mais específicas, cuja associação com o nível de poluição deseja-se estudar, ou considerar outros poluentes, como material particulado, monóxido de carbono ou dióxido de enxofre. Ao longos das análises, nós mostramos o quanto é complexo estudar os fenômenos que envolvem poluição atmosférica, e que dificilmente vamos encontrar respostas simples para as perguntas que os rodeiam. Cabe a nós pesquisadores identificar os principais indícios que os dados nos fornecem e motivar novos estudos e experimentos para continuar aprofundando o nosso conhecimento sobre o meio em que vivemos. 

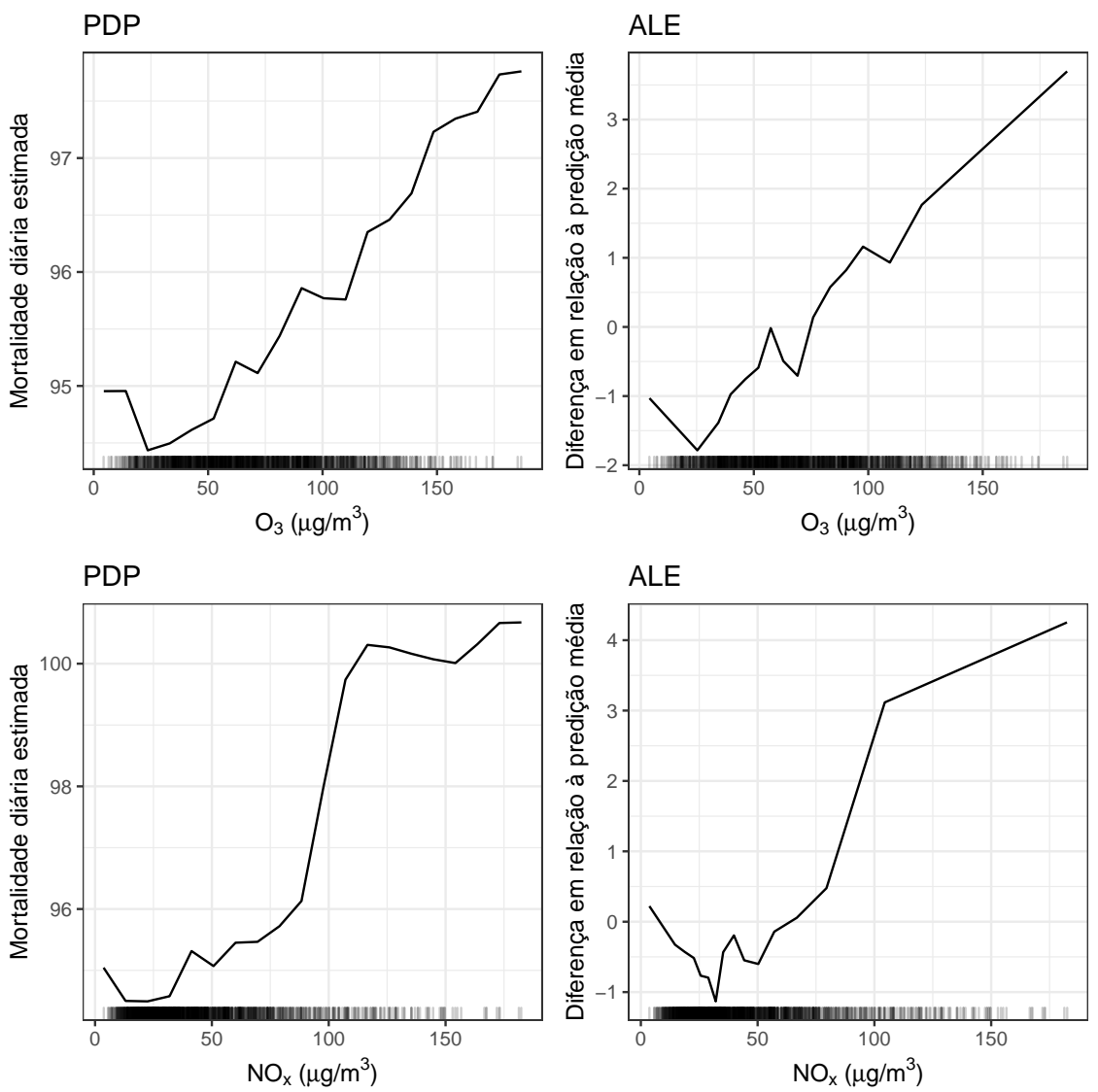

Figura 6.14: Gráficos de dependência parcial (PDP) e de efeitos acumulados (ALE) da floresta aleatória (idosos) para as concentrações de ozônio e de óxidos de nitrogênio defasadas em 1 dia, considerando a base de mortalidade filtrada para doenças cardio pulmonares.. 


\title{
Capítulo 7
}

\section{Obtendo dados de poluição}

\author{
The fact that data science exists as a field \\ is a colossal failure of statistics. \\ To me, what I do is what statistics is all about. \\ It is gaining insight from data using modelling and visualization. \\ Data munging and manipulation is hard \\ and statistics has just said that's not our domain. \\ - Hadley Wickham
}

Duas etapas cruciais da análise de dados são a coleta e a estruturação dos dados. Na maioria dos estudos, a obtenção de dados requer a realização de experimentos, medições ou aplicação de questionários. Não é raro encontrarmos trabalhos comprometidos por falhas na coleta, seja por ausência de variáveis importantes, por má especificação da população alvo, por falta de aleatorização ou questionários mal construídos. Na Estatística, as áreas de Amostragem, Planejamento de Experimentos e Teoria da Resposta ao Item dão atenção especial à coleta de dados, criando delineamentos amostrais com base nos objetivos do estudo.

A estruturação dos dados consiste na transferência dos registros obtidos na coleta para uma base de dados retangular ${ }^{1}$. Para diminuir o tempo e esforço gastos nessa etapa, que muitas vezes chega a ser a parte mais demorada da análise estatística, é essencial estar claro como a base deve estar estruturada para a análise e dispor de ferramentas que auxiliem a execução dessa tarefa. Na linguagem R, os pacotes janitor, tidyr e dplyr são especializados respectivamente em limpeza, manipulação e transformação de dados.

Em estudos de poluição do ar, a coleta de dados é realizada principalmente por experimentos laboratoriais ou por meio de instrumentos de medição colocados em vias de grande movimento, túneis, parques, próximos a fábricas e outros locais de interesse. Também é comum a instalação de estações de monitoramento automático que medem diversos parâmetros periodicamente. Essas estações geralmente são controladas por órgãos ambientais, que disponibilizam os dados gratuitamente $^{2}$ pela internet ${ }^{3}$.

\footnotetext{
${ }^{1}$ Em que cada linha representa uma observação (unidade amostral) e cada coluna representa uma variável.

${ }^{2}$ No Brasil. Em outros países, pode ser necessário pagar para a obtenção dos dados.

${ }^{3}$ Alguns portais, como o do Instituo Nacional de Meteriologia (INMET), requerem uma solicitação informando os dados desejados. Após o pedido ser processado, os dados são enviados por e-mail ou, quando o volume é muito grande, são postados em uma mídia física para o endereço do solicitante.
} 
A obtenção de dados da internet, no entanto, nem sempre é uma tarefa simples, em especial quando o volume de informação que precisamos transferir é muito grande e o acesso a eles não foi construído da melhor maneira. Além disso, raramente a base se encontra formatada para análise, sendo preciso passar também por uma etapa de estruturação.

Com o aumento da disponibilização de dados na internet ao lado da dificuldade de acesso e estruturação, uma abordagem de coleta de dados conhecida raspagem de dados web (web scraping) vem se tornando cada vez mais popular. Seu objetivo é criar rotinas computacionais para baixar dados de páginas e sistemas na internet de forma automática e estruturada. Embora essas rotinas exijam conhecimento de programação web, elas podem ser realizadas no mesmo ambiente da análise de dados quando utilizamos linguagens como o $\mathrm{R}$ ou o Python.

Neste capítulo, discutiremos os conceitos básicos de web scraping e apresentaremos alguns portais para se obter dados meteorológicos e de poluição do ar, tanto no Brasil quanto em outros lugares do mundo.

\subsection{Raspagem de dados web}

A raspagem de dados web é a tarefa de se extrair dados da internet de forma automatizada. Hoje em dia é muito comum termos acesso rápido e fácil a qualquer conjunto de informações pela web, mas raramente esses dados estão estruturados e em uma forma de fácil obtenção pelo usuário.

Fazer web scraping é necessário quando os dados são disponibilizados publicamente, mas o acesso manual a eles é exaustivo ou impraticável, por exemplo, quando queremos baixar uma série de 30 anos de concentração de um poluente, mas os dados são disponibilizados mês a mês, com cada arquivo em uma página diferente. Quando os dados não são públicos, a construção dos algoritmos de raspagem deve levar em conta os termos de uso da página, pois algumas não permitem a extração dos dados ou o acesso via algoritmo. Também é recomendável sempre verificar se o órgão ou a empresa já não possui uma API (Application Programming Interface), isto é, um sistema criado para facilitar o acesso de terceiros aos dados.

O fluxo do web scraping, como podemos observar no diagrama a seguir (Figura 7.1), é composto por seis etapas: identificar, navegar, replicar, parsear, validar e iterar.

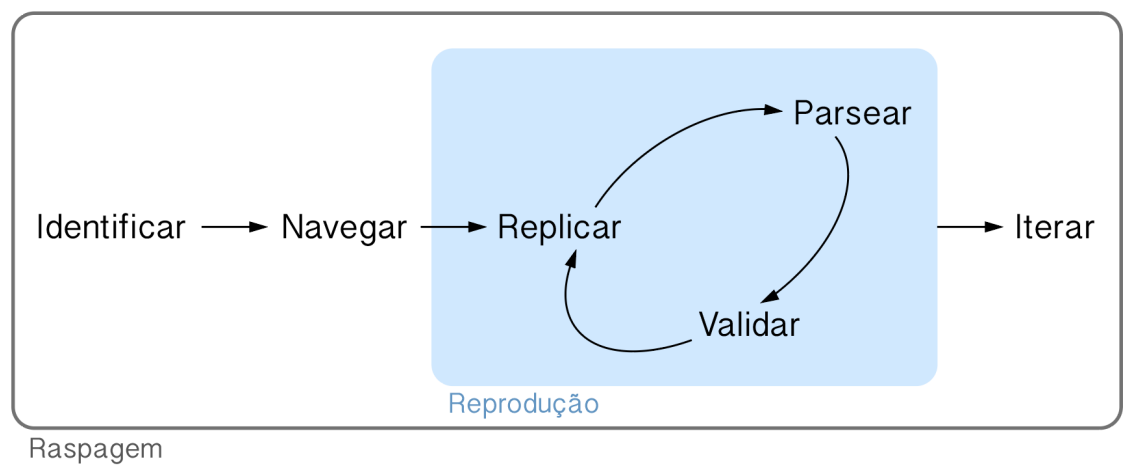

Figura 7.1: O fluxo do web scraping.

A seguir, descreveremos de forma geral cada uma dessas etapas. 


\section{Identificar}

No primeiro passo do fluxo, precisamos identificar a informação que vamos coletar, isto é, entender bem qual é a estrutura das páginas que queremos raspar e traçar um plano para extrair tudo que precisamos.

Se, por exemplo, estamos interessados em uma tabela que aparece no corpo de diversas páginas web, precisamos listar todas as páginas que devem ser acessadas (definir o conjunto de endereços eletrônicos que serão acessados) e avaliar se essa tabela sempre aparece com o mesmo formato.

\section{Navegar}

O objetivo desta etapa é descobrir qual e que tipo de requisição é feita para o servidor que hospeda o site gerar os dados que queremos extrair.

Esta etapa exige algum conhecimento de programação web, pois consiste em usar ferramentas de desenvolvedor do navegador para encontrar a fonte dos dados a partir das chamadas HTTP ou dos resultados das funções JavaScript.

\section{Replicar}

Se tivéssemos que fazer várias requisições HTTP para chegar até a informação que queremos, seria nesta etapa que tentaríamos replicar essas chamadas. Aqui, é necessário compreender absolutamente tudo que a página está fazendo para trazer o conteúdo até você, como a existência de parâmetros, cookies, tokens etc.

No R, é possível fazer requisições GET e POST a partir das funções GET () e POST () do pacote httr.

\section{Parsear}

O anglicismo parsear vem do verbo to parse, que quer dizer algo como analisar ou estudar, mas que, no contexto do web scraping, significa extrair os dados desejados de um arquivo HTML. Esta etapa é essencialmente dependente da estrutura de dados que está sendo baixada e de como ela foi disponibilizada na página.

\section{Validar}

Se tudo ocorreu bem, validar os resultados será uma tarefa simples. Precisamos apenas reproduzir o procedimento descrito até agora para algumas outras páginas de modo a verificar se estamos de fato extraindo corretamente tudo o que queremos.

Caso encontremos algo de errado precisamos voltar ao terceiro passo, tentar replicar corretamente o comportamento do site e parsear os dados certos nas páginas.

\section{Iterar}

O último passo consiste em colocar o scraper em produção. Aqui, ele já deve estar funcionando corretamente para todos os casos desejados e estar pronto para extrair todos os dados que precisamos. 


\subsection{Dados no Brasil}

Dados de poluição do ar no Brasil geralmente são disponibilizados pelas Órgãos Estaduais de Meio Ambiente, sendo que o acesso a esses dados, em geral, pode ser feito direta ou indiretamente no portal de cada órgão. Dos 27 estados brasileiros, apenas 9 monitoram a qualidade do ar: Bahia, Espírito Santo, Minas Gerais, São Paulo, Rio de Janeiro, Rio Grande do Sul, Paraná, Goiás e Distrito Federal.

Uma solução integrada para acessar esses dados foi desenvolvida pelo Instituo de Energia e Meio Ambiente (IEMA), que compilou os dados de monitoramento dos órgãos ambientais de todo o país em uma plataforma unificada e acessível. A Plataforma de Qualidade do Ar, em sua primeira versão, compilou os valores anuais da concentração de poluentes atmosféricos, criando uma base de dados entre os anos de 2000 e 2014 de todos os estados que disponibilizam tais informações. Com o objetivo de explorar em mais detalhes os poluentes monitorados, a plataforma passou a incorporar dados horários e diários a partir de 2015.

Na Figura 7.2, apresentamos um mapa das estações de monitoramento disponíveis na plataforma do IEMA. Fica clara a falta de dados sobre as regiões Norte e Nordeste do país.

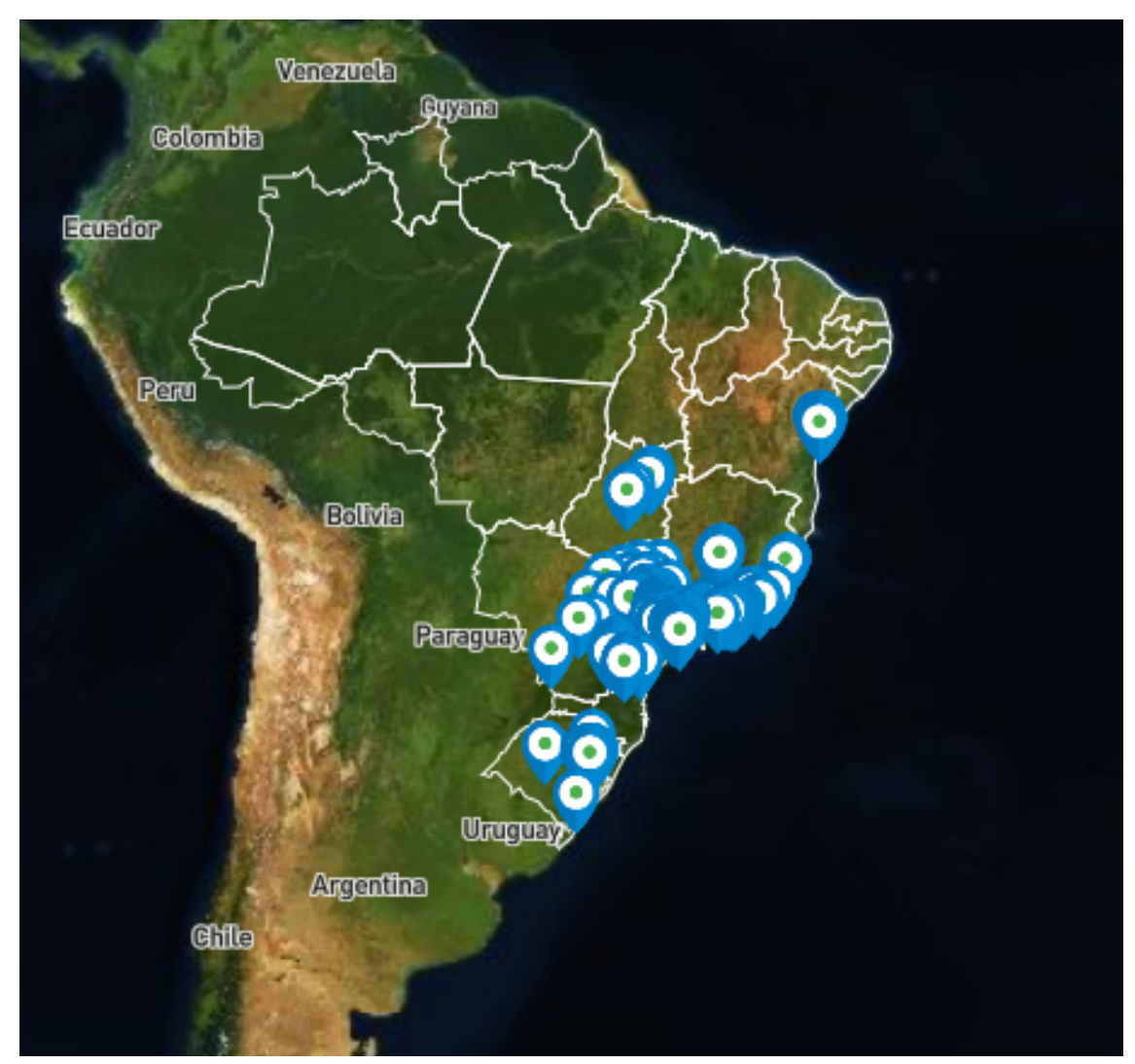

Figura 7.2: Mapa de estações de monitoramento disponíveis na Plataforma de Qualidade do Ar do Instituto de Energia e Meio Ambiente.

Para o estado de São Paulo, a CETESB (Companhia Ambiental do Estado de São Paulo) oferece um sistema de consulta de medidas em tempo real e de relatórios diários, mensais e anuais. O sistema, chamado Qualar, também permite a exportação de diversas séries históricas de poluentes e parâmetros meteorológicos, além de informações sobre as estações de monitoramento.

Para facilitar o acesso aos dados, já que o sistema possui restrições estruturais (como baixar dados de vários poluentes ou estações de uma única vez) e também pode se tornar lento quando 
precisamos acessar séries muito longas, nós desenvolvemos o pacote koffing, na linguagem R. $\mathrm{O}$ processo se resume ao uso da função scraper_cetesb (), que tem, entre outros argumentos, o parâmetro a ser baixado, a estação medidora e o login e senha de acesso ao Qualar. Dada uma lista de parâmetros e estações, a função pode ser utilizada dentro de um laço para baixar os dados de diversas estações e poluentes automaticamente. Para instalar o pacote, basta rodar o seguinte comando devtools: :install_github ("atmoschem/koffing") .

Dados de emissão podem ser obtidos no portal do Sistema de Estimativas de Emissões e Remoções de Gases de Efeito Estufa (SEEG), que produz estimativas anuais das emissões de gases de efeito estufa (GEE) no Brasil e documentos analíticos sobre a evolução das emissões. O SEEG avalia os cinco setores que são fontes de emissões - Agropecuária, Energia, Mudanças de Uso da Terra, Processos Industriais e Resíduos. Os dados constituem uma série que cobre o período de 1970 até 2017, exceto para o setor de Mudança de Uso da Terra que tem a série de 1990 a 2017. São considerados todos os gases de efeito estufa contidos no inventário nacional como $\mathrm{CO}_{2}, \mathrm{CH}_{4}$, $\mathrm{N}_{2} \mathrm{O}$ e os HFC.

A maioria dos órgãos de monitoramento ambiental também disponibiliza dados climáticos, como temperatura, radiação solar, umidade, velocidade e direção do vento e precipitação. Bases mais consolidadas podem ser encontradas no portal do Instituto Nacional de Meteorologia (INMET).

A seguir, apresentaremos os principais portais com acesso a dados internacionais de clima e poluição.

\subsection{Dados em outros países}

Lançado em março de 2000, o programa MOPPIT (Measurements Of Pollution In The Troposphere) lançado pela NASA tem como objetivo medir o monóxido de carbono troposférico em escala global. Os dados podem ser baixados diretamente do seguinte site: https://search.earthdata.nasa. gov $/$.

A NASA também possui outros canais de visualização e disponibilização de dados, como o portal Atmospheric Science Data Center, para dados atmosféricos, e o ambiente Giovanni, para parâmetros geofísicos.

O portal suíço AirVisual disponibiliza visualizações, métricas e previsões para dados de material particulado e meteorológicos em mais de 10000 pontos de monitoramento espalhadas em todo o mundo (Figura 7.3).

Nos EUA, a Agência de Proteção Ambiental (EPA) é o órgão federal que regulamenta e monitora os níveis de poluição da terra, água e ar com o objetivo de proteger a saúde humana e o meio ambiente. Em conjunto com outras agências ambientais, a EPA criou o Airnow, uma plataforma de monitoramento da qualidade do ar com informações horárias de ozônio e material particulado para todos os estados americanos, totalizando mais de 400 cidades.

Na Europa, a Agência Europeia de Meio Ambiente (EEA) é a responsável por implementar as diretivas da União Europeia com respeito ao controle de emissões e à qualidade do ar. A agência mantem um portal de monitoramento horário de ozônio, material particulado, dióxido de nitrogênio, dióxido de enxofre e monóxido de carbono para diversas cidades em toda a Europa. Os dados do portal podem ser baixados na página de Air Quality e-Reporting. 


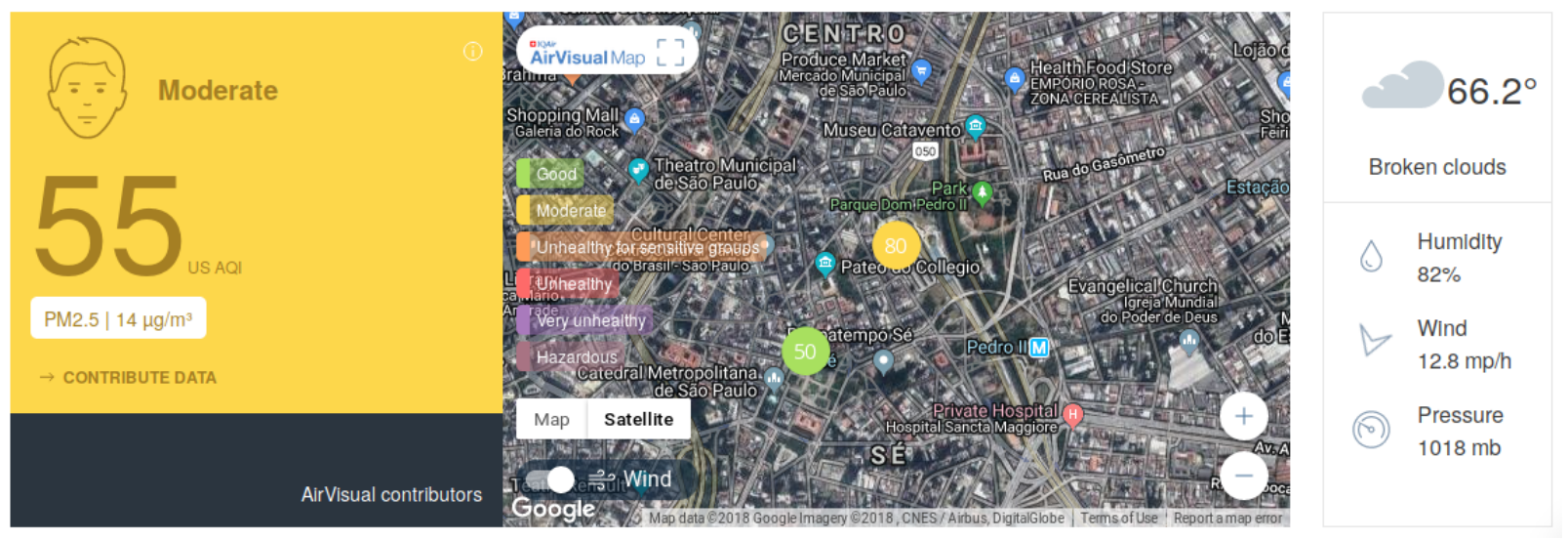

Figura 7.3: Exemplo de visualização do portal AirVisual para a estação Parque Dom Pedro II, em São Paulo. 


\section{Capítulo 8}

\section{Discussão}

Durante a última década, novas tecnologias vêm mudando bastante a forma como estatísticos encaram a análise de dados. A utilização de computadores, instrumentos de medição cada vez mais sofisticados e a internet geram um volume de informação cada vez maior, abrindo novas possibilidades em áreas que historicamente sofriam com a escassez de dados. As preocupações que antes giravam em torno de encontrar o modelo mais adequado para os dados e derivar resultados assintóticos para a construção de intervalos de confiança e testes de hipóteses, foram em certo grau substituídas pelo desenvolvimento de algoritmos que melhor capturam os padrões escondidos nos dados e que possam ser generalizados para além da amostra. Além disso, a necessidade de extrair dados da internet, manipular bases gigantescas e comunicar resultados de forma atraente passaram a frequentar o radar do estatístico.

Essa nova forma de se fazer Estatística chamada Ciência de Dados incorporou diversas ideias interessantes à análise de dados, mas o seu principal requisito é um que sempre fez parte da formação dos estatísticos: a análise crítica. Entender o fenômeno de interesse, o objetivo do estudo, as restrições de cada técnica e ser capaz de avaliar criticamente os resultados é essencial independentemente da abordagem de análise que estamos seguindo.

O aspecto multidisciplinar faz os estudos de poluição do ar um exemplo claro disso. Os principais desafios nessa área envolvem a modelagem de fenômenos naturalmente complexos, e a utilização de modelos muito simples para representá-los pode levar a conclusões superficiais e, por consequência, a criação políticas públicas insuficientes.

Neste trabalho, mostramos que os resultados encontrados por Salvo e Geiger (2014) e Salvo et al. (2017) sobre a associação entre a concentração de ozônio e a proporção de carros bicombustíveis abastecidos com gasolina na cidade de São Paulo podem levar a algumas conclusões equivocadas. O modelo de regressão linear utilizado não captura a relação não linear que modelos mais flexíveis sugeriram existir entre as variáveis. Embora as análises realizadas apontarem que, de fato, o aumento do uso de etanol estar associado com maiores médias diárias de ozônio, entender a forma dessa relação é importante para uma maior compreensão do mecanismo gerador do ozônio e para a criação de estratégias de redução de emissões.

A ausência de padrão no efeito da proporção estimada de carros a gasolina indicada pelo $X G$ Boost, o modelo que resultou no melhor ajuste, levanta dúvidas sobre a possibilidade de encontrar um modelo simples e interpretável para explicar a associação desse preditor com a concentração de ozônio e também nos faz questionar qual precisão essa medida representa o uso de etanol em cada região da cidade. Apesar de Salvo e Huse (2013) terem realizado um trabalho cuidadoso para 
estimar essa quantidade, algumas das suposições feitas são muito fortes, e podem estar gerando bastante ruído quando utilizamos essas estimativas para explicar a concentração de ozônio.

Primeiro, estamos supondo que a proporção de carros a gasolina é a mesma para toda a cidade, o que pode ser falso principalmente para uma metrópole com as dimensões e as desigualdades sociais de São Paulo. Também assumimos que o efeito dessa variável é o mesmo em todas as regiões, o que pode não ser verdade como mostramos ao ajustar um modelo para cada estação de monitoramento. Por fim, não são consideradas medidas de evaporação do etanol nos instantes de abastecimento, o que seria um preditor importante pois é uma das principais fontes de compostos voláteis orgânicos, um dos elementos responsáveis pela formação do ozônio troposférico.

Além disso, também expandimos a análise realizada por Salvo et al. (2017) investigando o efeito da proporção estimada de carros a gasolina e da concentração de ozônio na mortalidade geral em crianças e idosos. Os modelos ajustados não indicaram uma relação clara entre as variáveis. Ao considerarmos a concentração de ozônio e de óxidos de nitrogênio como variáveis explicativas, em vez da proporção de carros a gasolina, encontramos associações positivas entre esses preditores e a mortalidade, principalmente quando defasamos as concentrações em um dia. Essa relação também foi observado quando filtramos a mortalidade apenas para doenças cardio pulmonares.

Os resultados nas duas análises mostraram, sobretudo, a dificuldade de se analisar dados de poluição do ar, as diversas estratégias existentes para abordar cada problema e o quanto devemos ser cuidadosos ao interpretar os resultados. Em problemas tão complexos, dificilmente vamos conseguir respostas simples, sendo preferível, em alguns casos, levantar mais hipóteses do que tentar chegar em respostas definitivas.

Esta tese buscou ser uma ponte entre a Estatística e as outras disciplinas que compõem o estudo da poluição do ar. O compartilhamento de conhecimento de forma acessível é essencial para que haja colaboração entre pesquisadores e para que os trabalhos caminhem na direção certa. Este esforço continuará, pois há muitos tópicos que não foram abordados aqui, como estudos de previsão, estratégias de imputação de dados ou o uso de modelos de redes neurais. Além disso, novas técnicas e modelos vêm surgindo todos os dias, demandando que a construção dessa ponte seja um processo contínuo, e não parado no tempo.

Ao passo que a ciência cria novas tecnologias, a tecnologia também muda o jeito como fazemos ciência. A Estatística não é diferente. 


\section{Referências}

Achen(2005) Christopher H. Achen. Let's put garbage-can regressions and garbage-can probits where they belong. Conflict Management and Peace Science, 2: 327-339. Citado na pág. 37

Barros et al.(2009) Michelli Barros, Gilberto A. Paula e Victor Leiva. An $\mathrm{r}$ implementation for generalized Birnbaum-Saunders distributions. Computational Statistics and Data Analysis, 53 (4): 1511-1528. Citado na pág. 44

Beer et al.(2011) Tom Beer, John Carras, David Worth, Nick Coplin, Peter K. Campbell, Bin Jalaludin, Dennys Angove, Merched Azzi, Steve Brown, Ian Campbell, Martin Cope, Owen Farrell, Ian Galbally, Stephen Haiser, Brendan Halliburton, Robert Hynes, David Jacyna, Melita Keywood, Steven Lavrencic, Sarah Lawson, Sunhee Lee, Imants Liepa, James McGregor, Peter Nancarrow, Michael Patterson, Jennifer Powell, Anne Tibbett, Jason Ward, Stephen White, David Williams e Rosemary Wood. The health impacts of ethanol blend petrol. Energies, (4): 352-367. Citado na pág. 2

Belusic et al.(2015) Andreina Belusic, Ivana Herceg-Bulic e Zvjezdana Bencetic Klaic. Using a generalized additive model to quantify the influence of local meteorology on air quality in zagreb. Geofizika, 32: 48-78. Citado na pág. 34, 45

Bollerslev(1986) Tim Bollerslev. Generalized autoregressive conditional heteroscedasticity. $J$. Econ., 31: 307-327. Citado na pág. 54

Box e Jenkins(1970) George E. P. Box e Gwilym M. Jenkins. Time series analysis: forecasting and control. Holden-Day, San Francisco. Citado na pág. 48

Breiman(2001) Leo Breiman. Statistical modeling: The two cultures. Statistical Science, 16(3): 199-231. Citado na pág. 29, 30

Breiman e Friedman(1985) Leo Breiman e Jerome H. Friedman. Estimating optimal transformations for multiple regression and correlations (with discussion). Journal of the American Statistical Association, 80(391): 580-619. Citado na pág. 46

Buhr et al.(1992) M. P. Buhr, M. Trainer, D. D. Parrish, R. E. Sievers e F. C. Fehsenfeld. Assessment of pollutant emission inventories by principal component analysis of ambient air measurements. Geophysical Research Letters, 19(10): 1009-1012. doi: 10.1029/92GL01020. Citado na pág. 51

Bussab e Morettin(2013) W. O. Bussab e P. A. Morettin. Estatística Básica. Editora Saraiva, São Paulo. Citado na pág. 5

Cameron e Miller(2015) Adrian C. Cameron e Douglas L. Miller. A practitioner's guide to cluster-robust inference. J. Human Resources, 50(2): 317-372. Citado na pág. 35

Carslaw et al.(2007) David C. Carslaw, Sean D. Beevers e James E. Tate. Modelling and assessing trends in traffic-related emissions using a generalised additive modelling approach. Atmospheric Environment, 41: 5289-5299. Citado na pág. 2 
Casella e Berger(2001) George Casella e Roger L. Berger. Statistical Inference. Duxbury Press; 2nd edition. Citado na pág. 32, 41

Chang et al.(2017) Shih Ying Chang, William Vizuete, Marc Serre, Lakshmi Pradeepa Vennam, Mohammad Omary, Vlad Isakov, Michael Breen e Saravanan Arunachalam. Finely resolved onroad PM2.5 and estimated premature mortality in central North Carolina. Risk Analysis. doi: 10.1111/risa.12775. URL http://dx.doi.org/10.1111/risa.12775. Citado na pág. 106

Chavent et al.(2009) Marie Chavent, Hervé Guegan, Vanessa Kuentz, Brigitte Patouille e Jérôme Saracco. PCA and PMF based methodology for air pollution sources identification and apportionment. 20: 928-942. URL https://hal.archives-ouvertes.fr/hal-00332015/file/Env-2009-preprint. pdf. Citado na pág. 51

Child(2006) D Child. The Essentials of Factor Analysis. Bloomsbury Academic Press, $3^{\mathrm{a}}$ edição. Citado na pág. 51

Chuang et al.(2011) Ya-Hsiu Chuang, Sati Mazumdar, Taeyoung Park, Gong Tang, Vincent. C. Arena e Mark J. Nicolich. Generalized linear mixed models in time series studies of air pollution. Atmospheric Pollution Research, 2(4): 428 - 435. URL http://www.sciencedirect.com/science/ article/pii/S1309104215304694. Citado na pág. 53

Conceição et al.(2001a) Gleice M. S. Conceição, Simone G. E. K. Miraglia, Humberto S. Kishi, Paulo H. N. Saldiva e Julio M. Singer. Air pollution and child mortality: a time-series study in São Paulo, Brazil. Environmental Health Perspectives, 109(3): 347-350. Citado na pág. 2, 106, 114

Conceição et al.(2001b) Gleice M. S. Conceição, Paulo H. N. Saldiva e Julio M. Singer. Modelos MLG e MAG para análise da associação entre poluição atmosférica e marcadores de morbimortalidade: uma introdução baseada em dados da cidade de São Paulo. Revista Brasileira de Epidemiologia, 4(3): 206-219. Citado na pág. 2, 42, 44

Cortina-Januchs et al.(2015) Maria Guadalupe Cortina-Januchs, Joel Quintanilla-Dominguez, Antonio Vega-Corona e Diego Andina. Development of a model for forecasting of pm10 concentrations in salamanca, mexico. Atmospheric Pollution Research, 6(4):626-634. ISSN 1309-1042. doi: https://doi.org/10.5094/APR.2015.071. URL http://www.sciencedirect.com/science/article/pii/ S1309104215301951. Citado na pág. 3

Coull et al.(2001) Brent Coull, Joel Schwartz e Matt Wand. Respiratory health and air pollution: additivemixed model analyses. Biostatistics, 2(3): 337-349. Citado na pág. 53

$\operatorname{Cox}(\mathbf{2 0 1 2})$ L. A. Cox. Miscommunicating risk, uncertainty, and causation: Fine particulate air pollution and mortality risk as an example. Risk Analysis, 32(5). Citado na pág. 105

Demidenko(2013) Eugene Demidenko. Mixed models: theory and applications with $R$. Wiley, New York. Citado na pág. 36

Dobson(1990) Annette J. Dobson. An introduction to generalized linear models. Chapman and Hall, New York. Citado na pág. 42

Dordonnat et al.(2008) V. Dordonnat, S. J. Koopman, M. Ooms, A. Dessertaine e J. Collet. An hourly periodic state space model for modelling french national electricity load. International Institute of Forecasters, 24: 566-587. Citado na pág. 55

Eckner(2018) Andreas Eckner. A framework for the analysis of unevenly spaced time series data. Journal of the American Statistical Association. URL http://eckner.com/papers/unevenly_ spaced_time_series_analysis.pdf. Citado na pág. 7 
Elangasinghe et al.(2014) Madhavi Anushka Elangasinghe, Naresh Singhal, Kim N. Dirks e Jennifer A. Salmond. Development of an ANN-based air pollution forecasting system with explicit knowledge through sensitivity analysis. Atmospheric Pollution Research, 5(4): 696 - 708. ISSN 1309-1042. URL http://www.sciencedirect.com/science/article/pii/S1309104215302786. Citado na pág. 3

Engle(1982) Robert F. Engle. Autoregressive conditional heteroscedasticity with estimates of the variance of united kingdom inflation. Econometrica, 50: 987-1007. Citado na pág. 54

European Commission(1999) European Commission. EU focus on clean air. Office for Official Publications of the European Communities. Citado na pág. 1

European Commission(2011) European Commission. Climate action. https://ec.europa.eu/ clima/policies/strategies/2050_en, 2011. [Online; acessado 15-03-2017]. Citado na pág. 79

Everitt e Hothorn(2011) Brian Everitt e Torsten Hothorn. An Introduction to Applied Multivariate Analysis with $R$. Use R! Springer-Verlag New York. Citado na pág. 53

Fann et al.(2012) Neal Fann, A. D. Lamson, S. C. Anenberg, K Wesson, D. Risley e B. J. Hubbel. Estimating the national public health burden associated with exposure to ambient PM2.5 and ozone. Risk Analysis, 32: 81-95. Citado na pág. 105

Feng et al.(2015) Xiao Feng, Qi Li, Yajie Zhu, Junxiong Hou, Lingyan Jin e Jingjie Wang. Artificial neural networks forecasting of pm2.5 pollution using air mass trajectory based geographic model and wavelet transformation. Atmospheric Environment, 107: 118 - 128. doi: https://doi.org/10.1016/j.atmosenv.2015.02.030. URL http://www.sciencedirect.com/science/ article/pii/S1352231015001491. Citado na pág. 3

Fisher(1918) Ronald Fisher. The correlation between relatives on the supposition of Mendelian inheritance. Transactions of the Royal Society of Edinburgh, 652(2): 399-433. Citado na pág. 53

Galecki e Burzykowski(2013) Andrzej Galecki e Tomasz Burzykowski. Linear Mixed-Effects Models Using R. Springer. Citado na pág. 53

Garrett e Casimiro(2011) Pedro Garrett e Elsa Casimiro. Short-term effect of fine particulate matter (pm2.5) and ozone on daily mortality in Lisbon, Portugal. Environ Sci Pollut Res, 18: 1585-1582. Citado na pág. 106, 114

Goodfellow et al.(2016) Ian Goodfellow, Yoshua Bengio e Aaron Courville. Deep Learning. MIT Press. http://www.deeplearningbook.org. Citado na pág. 30

Gower(1971) C. John Gower. A general coefficient of similarity and some of its properties. Biometrics. Citado na pág. 73

Hastie e Tibshirani(1990) Trevor Hastie e Robert Tibshirani. Generalized additive models. London:Chapman \& Hall. Citado na pág. 3, 45, 46, 67

Hastie et al.(2008) Trevor Hastie, Robert Tibshirani e Jerome Friedman. The Elements of Statistical Learning. Springer Series in Statistics. Springer. Citado na pág. 3, 5, 29, 30, 31, 32, 39, 45, $46,47,48,67,69$

Hoek et al.(2002) Gerard Hoek, Bert Brunekreef, Sandra Goldbohm, Paul Fischer e Piet A van den Brandt. Association between mortality and indicators of traffic-related air pollution in the netherlands: a cohort study. The Lancet, 360: 1203:1209. Citado na pág. 105

Jacobson(2002) Mark Z. Jacobson. Atmospheric Pollution History, Science, and Regulation. Cambridge. Citado na pág. 105 
Jacobson(2007) Mark Z. Jacobson. Effects of ethanol (E85) versus gasoline vehicles on cancer and mortality in the United States. Environmental Science $\mathscr{G}$ Technology, 41(11): 4150-4157. Citado na pág. 80

James et al.(2013) Gareth James, Daniela Witten, Trevor Hastie e Robert Tibshirani. An Introduction to Statistical Learning. Springer Series in Statistics. Springer, New York. Citado na pág. 5, $31,32,34,38,39,47,48,61,63,64,65,67$

Jasarevic et al.(2014) Tarik Jasarevic, Glenn Thomas e Nada Osseiran. 7 million premature deaths annually linked to air pollution. http://www.who.int/mediacentre/news/releases/2014/ air-pollution/en/, 2014. [Online; acessado 13-03-2017]. Citado na pág. 1

Javanmard e Montanari(2014) Adel Javanmard e Andrea Montanari. Hypothesis testing in high-dimensional regression under the gaussian random design model: Asymptotic theory. arXiv:1301.4240v3 [stat.ME]. Citado na pág. 67

Jolliffe(2002) I. T. Jolliffe. Principal Component Analysis. Springer Series in Statistics. Springer, $2^{\text {a }}$ edição. Citado na pág. 51

Kalman(1960) R. E. Kalman. A new approach to linear filtering and prediction problems. Trans. ASME J. of Basic Eng., (82): 35-45. Citado na pág. 55

Kalman e Bucy(1961) R. E. Kalman e R. S. Bucy. New results in filtering and prediction problems. Trans. ASME J. of Basic Eng., (83): 95-108. Citado na pág. 55

Katsouyanni et al.(1996) K. Katsouyanni, J. Schwartz, C. Spix, G. Touloumi, D. Zmirou, A. Zanobetti, B. Wojtyniak, J. M. Vonk, A. Tobias, A. Pönkä, S. Medina, L. Bachárová e H. R. Anderson. Short term effects of air pollution on health: a european approach using epidemiologic time series data: the aphea protocol. Journal of Epidemiology \&3 Community Health, 50(Suppl 1): S12-S18. ISSN 0143-005X. doi: 10.1136/jech.50.Suppl_1.S12. URL http://jech.bmj.com/content/50/Suppl_1/S12. Citado na pág. 2

Kiefer e Wolfowitz(1952) J. Kiefer e J. Wolfowitz. Stochastic estimation of the maximum of a regression function. Ann. Math. Statista, 23: 462-466. Citado na pág. 70

Kloog et al.(2012) Itai Kloog, Francesco Nordio, Brent A. Coull e Joel Schwartz. Incorporating local land use regression and satellite aerosol optical depth in a hybrid model of spatiotemporal PM2.5 exposures in the mid-atlantic states. American Chemical Society, 46: 11913-11921. Citado na pág. 2, 53

Kumar e Ridder(2010) Ujjwal Kumar e Koen De Ridder. GARCH modelling in association with FFT-ARIMA to forecast ozone episodes. Atmospheric Environment, 44(34): 4252 - 4265. ISSN 1352-2310. doi: https://doi.org/10.1016/j.atmosenv.2010.06.055. URL http://www.sciencedirect. com/science/article/pii/S1352231010005340. Citado na pág. 55

Leiva(2015) Victor Leiva. The Birnbaum-Saunders distribution. Academic Press; 1 edition. Citado na pág. 44

Leiva et al.(2008) Victor Leiva, Michelli Barros, Gilberto A. Paula. e Antonio Sanhueza. Generalized birnbaum-saunders distribution applied to air pollutant concentration. Environmetrics, 19: 235-249. Citado na pág. 44

Liao et al.(1999) Duanping Liao, John Creason, Card Shy, Ron Williams, Randall Watfs e Roy Zweidinger. Daily variation of particulate air pollution and poor cardiac autonomic control in the elderly. Environ Health Perspect, 107(7): 521-525. Citado na pág. 53 
Lin et al.(1999) C. A. Lin, M. A. Martins, S. C. Farhat, C. A. Pope, G. M. Conceição, V. M. Anastácio, M. Hatanaka, W. C. Andrade, W. R. Hamaue, G. M. Bohm e P. H. Saldiva. Air pollution and respiratory illness of children in São Paulo, Brazil. Paediatric and Perinatal Epidemiology, 13(4): 475-488. ISSN 1365-3016. doi: 10.1046/j.1365-3016.1999.00210.x. URL http://dx.doi.org/10.1046/j.1365-3016.1999.00210.x. Citado na pág. 2

Lockhart et al.(2014) Richard Lockhart, Jonathan Taylor, Ryan J. Tibshirani e Robert Tibshirani. A significance test for the lasso. Annals of Statistics, (2). Citado na pág. 67

Madronich(2014) Sacha Madronich. Ethanol and ozone. Nature Geoscience: news \&s views, 7: 395-397. Citado na pág. 102

Magalhães e Lima(2013) Marcos Magalhães e Antonio Carlos Pedroso Lima. Noçôes de Probabilidade e Estatística. Edusp. Citado na pág. 5

McCulloch e Searle(2001) Charles E. McCulloch e Shayle R. Searle. Generalized, linear, and mixed models. Wiley, New York. Citado na pág. 36

Morettin e Toloi(2004) Pedro A. Morettin e Clelia M. C. Toloi. Análise de Series Temporais. ABE - Projeto Fisher e Editora Edgard Blucher, São Paulo. Citado na pág. 16, 49, 50, 54

Muggeo(2003) Vito Muggeo. Estimating regression models with unknown break-points. Statistics in Medicine, 22: 3055-3071. Citado na pág. 38

Mulawa et al.(1997) Patricia A. Mulawa, Steven H. Cadle, Kenneth Knapp, Roy Zweidinger, Richard Snow, Randy Lucas e Joseph Goldbach. Effect of ambient temperature and E10 fuel on primary exhaust particulate matter emissions from light-duty vehicles. American Chemical Society: Environ. Sci. Technol., 31 (5): 1302-1307. Citado na pág. 79

Nelder e Wedderburn(1972) John A. Nelder e R. William M. Wedderburn. Generalized linear models. Stat Soc A, 135: 370-384. Citado na pág. 3, 41, 65

Nicholson(2001) W. Keith Nicholson. Elementary Linear Algebra. McGraw-Hill Ryerson, $2^{\mathrm{a}}$ edição. Citado na pág. 52

Paula(2013) Gilberto A. Paula. Modelos de Regressão com apoio computacional. São Paulo. URL https://www.ime.usp.br/ giapaula/texto_2013.pdf. Citado na pág. 36, 42, 43

Pereira et al.(2004) Pedro Afonso Pereira, Leilane Maria B. Santos, Eliane Teixeira Sousa e Jailson B. de Andrade. Alcohol- and gasohol-fuels: a comparative chamber study of photochemical ozone formation. Journal of the Brazilian Chemical Society, 15(5): 646-651. Citado na pág. 79

Peters et al.(2000) Annette Peters, Emerson Liu, Richard L. Verrier, Joel Schwartz, Diane R. Gold, Murray Mittleman, Jeff Baliff, J. Annie Oh, George Allen, Kevin Monahan e Douglas W. Dockery. Air pollution and incidence of cardiac arrhythmia. Lippincott Williams \& Wilkins, 11 (1): 11-17. Citado na pág. 105, 114

Polezer et al.(2018) Gabriela Polezer, Yara S. Tadano, Hugo V. Siqueira, Ana F.L. Godoi, Carlos I. Yamamoto, Paulo A. de Ándre, Theotonio Pauliquevis, Maria de Fátima Andrade, Andrea Oliveira, Paulo H.N. Saldiva, Philip E. Taylor e Ricardo H.M. Godoi. Assessing the impact of pm2.5 on respiratory disease using artificial neural networks. Environmental Pollution, 235: 394 - 403. ISSN 0269-7491. doi: https://doi.org/10.1016/j.envpol.2017.12.111. URL http://www.sciencedirect.com/science/article/pii/S0269749117337107. Citado na pág. 4, 114

Pope et al.(2002) C. Arden Pope, Richard T. Burnett, Michael J. Thun, Eugenia E. Calle, Daniel Krewski, Kazuhiko Ito e George D. Thurston. Lung cancer, cardiopulmonary mortality, and long-term exposure to fine particulate air pollution. American Medical Association, 287(9): 1132 - 1141. Citado na pág. 114 
R Core Team(2016) R Core Team. R: A Language and Environment for Statistical Computing. R Foundation for Statistical Computing, Vienna, Austria, 2016. URL https://www.R-project.org/. Citado na pág. 5

Ribeiro et al.(2016) Marco Tulio Ribeiro, Sameer Singh e Carlos Guestrin. "Why should I trust you?" Explaining the predictions of any classifier. arXiv:1602.04938v3 [cs.LG]. Citado na pág. 73

Saldiva et al.(1994) P. Saldiva, A. Lichtenfels, P. Paiva, I. Barone, M. Martins, E. Massad, J. Pereira, V. Xavier, J. Singer e G. Bohm. Association between air pollution and mortality due to respiratory diseases in children in São Paulo, Brazil: a preliminary report. Environmental Research, 65(2): 218 - 225. ISSN 0013-9351. doi: http://dx.doi.org/10.1006/enrs.1994.1033. URL http://www.sciencedirect.com/science/article/pii/S0013935184710334. Citado na pág. 2

Saldiva et al.(1995) Paulo H. N. Saldiva, C. Arden Pope, Joel Schwartz, Douglas W. Dockery, Ana Julia Lichtenfels, Joao Marcos Salge, Ivana Barone e Gyorgy Miklos Bohm. Air pollution and mortality in elderly people: a time-series study in São Paulo, Brazil. Archives of Environmental Health: An International Journal, 50: 159-163. Citado na pág. 2, 31, 44, 105, 106

Salvo e Geiger(2014) Alberto Salvo e Franz M. Geiger. Reduction in local ozone levels in urban São Paulo due to a shift from ethanol to gasoline use. Nature Geoscience, 7: 450-458. Citado na pág. xiv, $2,3,8,18,19,35,40,55,63,80,106,125$

Salvo e Huse(2013) Alberto Salvo e Cristian Huse. Build it, but will they come? Evidence from consumer choice between gasoline and sugarcane ethanol. Journal of Environmental Economics and Management, (66): 251-279. Citado na pág. 125

Salvo e Wang(2017) Alberto Salvo e Yi Wang. Ethanol-blended gasoline policy and ozone pollution in São Paulo. Journal of the Association of Environmental and Resource Economists, 4(3). Citado na pág. 80

Salvo et al.(2017) Alberto Salvo, Joel Brito, Paulo Artaxo e Franz M. Geiger. Reduced ultrafine particle levels in São Paulo's atmosphere during shifts from gasoline to ethanol use. Nature Communications, 8: 1-14. Citado na pág. v, vii, x, xvi, xix, 2, 3, 8, 9, 31, 35, 63, 80, 81, 82, 86, 88, $89,90,91,94,96,97,98,103,106,113,125,126$

Schwartz et al.(1996) J. Schwartz, D. W. Dockery e L. M. Neas. Is daily mortality associated specifically with fine particles? J Air Waste Manag Assoc, 10(46): 927-939. Citado na pág.

Schwartz(1994) Joel Schwartz. Nonparametric smoothing in the analysis of air pollution and respiratory illness. Statistical Society of Canada, 22(4): 471-487. Citado na pág. 2

Schwartz(1996) Joel Schwartz. Air pollution and hospital admissions for respiratory disease. Epidemiology, 1(7): 20-28. Citado na pág. 2

Schwartz e Dockery(1992) Joel Schwartz e Douglas Dockery. Particulate air pollution and daily mortality in Steubenville, Ohio. American Journal of Epidemiology, 135(1): 12-25. Citado na pág. $2,44,105,106$

Sen et al.(2009) Pranab Kumar Sen, Julio da Mota Singer e Antonio Carlos Pedroso de Lima. From Finite Sample to Asymptotic Methods in Statistics. Cambridge: Cambridge University Press, $1^{\mathrm{a}}$ edição. Citado na pág. 31

Shumway e Stoffer(2006) Robert H. Shumway e David S. Stoffer. Time Series Analysis and Its Applications (with $R$ examples). Springer Texts in Statistics. Springer, New York, $2^{\mathrm{a}}$ edição. Citado na pág. $16,34,48,49,50,54$ 
Singer et al.(2018) Julio Singer, Juvêncio Nobre e Francisco Marcelo Rocha. Análise de Dados Longitudinais (versão parcial preliminar). http://www.ime.usp.br/ jmsinger/Textos, São Paulo. Citado na pág. 39, 53

Stingone et al.(2017) Jeanette A. Stingone, Om P.Pandey, Luz Claudio e Gaurav Pandey. Using machine learning to identify air pollution exposure profiles associated with early cognitive skills among u.s. children. Environmental Pollution, 230: 230-240. Citado na pág. 4

Tecer(2009) Lokman Hakan Tecer. A factor analysis study: Air pollution, meteorology, and hospital admissions for respiratory diseases. Toxicological \&3 Environmental Chemistry, 91(7): 13991411. doi: $10.1080 / 02772240902732316$. Citado na pág. 51

Thurston e Spengler(1985) George D. Thurston e John D. Spengler. A quantitative assessment of source contributions to inhalable particulate matter pollution in metropolitan boston. Atmospheric Environment (1967), 19(1): 9 - 25. ISSN 0004-6981. Citado na pág. 51

WHO(2004) World Health Organization WHO. Health aspects of air pollution. Relatório Técnico E83080. Citado na pág. 106

Wickham(2010) Hadley Wickham. A layered grammar of graphics. Journal of Computational and Graphical Statistics, 19(1): 3-28. Citado na pág. 8

Wickham e Grolemund(2017) Hadley Wickham e Garrett Grolemund. $R$ for Data Science. O’Reilly, $1^{\text {a }}$ edição. Citado na pág. xiii, $4,5,7$

Wilkinson(2005) Leland Wilkinson. The Grammar of Graphics. Statistics and Computing. Springer. 2nd edition. Citado na pág. 8

Williams(1987) Alistair D. Williams. Generalized linear model diagnostic using the deviance and single case deletion. Applied Statistics, 36: 181-191. Citado na pág. 43

Wood(2006) Simon N. Wood. Generalized Additive Models: An Introduction with R. Chapman \& Hall/CRC Texts in Statistical Science. Chapman and Hall/CRC, $1^{\text {a }}$ edição. Citado na pág. 43

Yoon et al.(2009) S. Yoon, S. Ha, H. Roh e C. Lee. Effect of bioethanol as an alternative fuel on the emissions reduction characteristics and combustion stability in a spark ignition engine. Proceedings of the Institution of Mechanical Engineers, Part D: Journal of Automobile Engineering, 223: 941-951. Citado na pág. 79

Zannetti(1990) P. Zannetti. Air pollution modelling: theories, computational methods and available software. Springer Science+Business Media, LLC, New York. Citado na pág. 1, 55 